\title{
AN EMPIRICAL STUDY OF THE USEFULNESS \\ OF ACCOUNTING RATIOS TO DESCRIBE \\ LEVELS OF INSOLVENCY RISK
}

by

MERVYN GEORGE LINCOLN

Submitted in fulfilment of the requirements for the degree of Doctor of Philosophy in the Graduate School of Business Administration, University of Melbourne 
Abstract

This study aims to add a new dimension to research in Australia on the use of accounting ratios to predict corporate failure. Previous studies have used the statistical technique of discriminant analysis to derive models for predicting whether a firm will or will not fail. This study will use the same statistical technique but with three differences:

(a) The ratios to be used in the discriminant analysis are selected by a method which ensures that no arbitrary limit is placed on their number.

(b) Because the significance of accounting ratios can vary from industry to industry, four industries are separately analysed: manufacturing, retail, property, and finance.

(c) The statistical probabilities yielded by the analysis are used to measure a firm's current level of insolvency risk.

The extra dimension is added by interpreting the characteristic patterns of insolvency risk which emerge: an analysis of the factors causing the differences in these patterns throws new light on the causes, symptoms, and remedies of financial distress. 
ACKNOWLEDGEMENT

I am indebted to my supervisor at the University of Melbourne, Professor F.K. Wright (Department of Accounting) for his constructive criticism, which has improved the thesis, and for his encouragement, which has motivated me more than he realizes. He read the drafts not only carefully, but also expeditiously, and I appreciate the latter almost as much as the former.

\section{COMPLETION DATE}

Since the final typing of the thesis commenced in september 1982, it has not been possible for me to incorporate any relevant article, book or other references received after this date.

\section{DECLARATION}

I hereby declare that the whole thesis, unless specifically indicated to the contrary in the text, is my own original work. 
Contents

Abstract

Acknowledgement

List of Tables

vi

List of Figures

$\mathrm{x}$

Chapter 1 : Aim and Methodology 1

Chapter 2 : Discriminant Analysis 14

Chapter 3 : Selection of Firms for Research and Analysis

Chapter 4 : Selection of Financial Variables and Standardization of Accounting Data

Chapter 5 : Analysis of Ratio Means

Chapter 6 : Derivation of Best Discriminant Functions

Chapter 7 : Developing an Index of Risk

Chapter 8 : Patterns of Insolvency Risk

Chapter 9 : Analysis of Ratios in Best

Functions

Chapter 10 : Actions to Reduce the Level of Insolvency Risk

Chapter 11 : Conclusion

References

Appendix A : Sample Failed Firms by Industry; year founded, year listed, year of failure, age at failure and highest-asset figure during the three years before failure

Appendix B : Matched Failed and Nonfailed Companies, by Industry and Years

Appendix C : Ratio Means for Failed (F) and Nonfailed (NF) Groups 
Appendix D : Combination $1 \mathrm{~A}$ and Combination $2 \mathrm{~A}$

Appendix E : Classification Accuracy of the Best Functions Derived from Ratios in Combinations $1 \mathrm{~A}$ and $2 \mathrm{~A}$ : Year-byYear Figures

Appendix F : Measures of Skewness

Appendix G : Combination $1 \mathrm{~B}$

Appendix $\mathrm{H}$ : Combination $1 \mathrm{C}$

Appendix I : Combination ID

Appendix J : Highest Classification Accuracy of Functions Derived from Combinations IA, IB, IC and ID: Year-by-Year Figures

Appendix K : The Quadratic Equation for the Manufacturing and Retail Industry

Appendix L : A Summary of Failure Prediction Models

Appendix M : The Probability of Being Classified in the Failed Group for 14 Firms by 6 Discriminant Functions: Manufacturing and Retail

Appendix N : Patterns of Insolvency Risk for 13 Firms from Each of 6 Discriminant Functions: Manufacturing and Retail

Appendix 0 : The Probability of Being Classified in the Failed Group for 10 Firms by 6 Discriminant Functions: Property and Finance

Appendix P : Patterns of Insolvency Risk for 10 Firms from Each of 6 Discriminant Functions: Property and Finance

Appendix Q : 1. Property Function with Highest Classification Accuracy: (a) Graph of Relationship between $\mathrm{z}$-score and Level of Insolvency Risk, (b) Index of Insolvency Risk

2. Property Function with Highest Classification Accuracy one Year Before Failure: (c) Graph of Relationship between $z$-score and Level of Insolvency Risk, (d) Index of Insolvency Risk 
Appendix R : Graphs of Insolvency Risk

Appendix S : Z-Scores, Levels of Insolvency Risk, Weighted and Unweighted Ratios, for Selected Failed and Nonfailed Firms

Appendix $\mathrm{T}$ : A Re-evaluation of the "Acid Test Ratio" QAQL

Glossary of Variables 
1. Average Age of Failed Public Companies by Industry: 1969-78

2. Size of Business Failures

3. Frequency Distribution by Industry of Fiscal Year of Failure

4. Estimate of Prior Probability of Failure by Industry for the Period 1969-1978

5. Number of Failed and Nonfailed Companies Chosen for Analysis

6. Manufacturing Firms: Composition of Assets One Year Before Failure

7. Manufacturing Firms: Proportion of Total Funds Obtained from Long-Term Liabilities

8. Manufacturing Firms: Proportion of Total. Funds obtained from Bank overdraft

9. Retail Firms: Relationship Between QAQL and BOTF

10. Comparison of Number of Ratios in Combinations 1 and $1 \mathrm{~A}, 2$ and $2 \mathrm{~A}$

11. Classification Accuracy of the Best Functions for each Industry Derived from Ratios in Combinations $\mathrm{IA}$ and $2 \mathrm{~A}$

12. Number of Ratios in Manufacturing Industry whose Distributions were Approximately Symmetrical and Normal

13. Average Annual Percentage of Ratios which Approximate a Symmetrical Distribution

14. Average Annual Percentage of Combination $1 \mathrm{~A}$ Ratios for Nonfailed Firms which

Approximate a Symmetrical Distribution Before and After Adjustment for Extreme Values 
15. Highest Classification Accuracy of Functions Derived from:

(a) Combination 1 A ratios (i.e., all ratios) and unadjusted data;

(b) Combination lA ratios (i.e., all ratios) and adjusted data;

(c) Combination $1 \mathrm{~B}$ ratios (i.e., ratios approximately symmetrical) and adjusteà data

16. Highest Classification Accuracy of Functions Derived from:

(a) Combination $1 \mathrm{~A}$ ratios (i.e., all ratios) and unadjusted data;

(b) Combination $1 \mathrm{~A}$ ratios (i.e., all ratios) and aajjusted data;

(c) Combination $1 \mathrm{~B}$ ratios (i.e., ratios approximately symetrical) and adjusted data;

(d) Combination $1 \mathrm{C}$ ratios (i.e., ratios with correlation coefficients of less than 0.75 ) and adjusted or unadjusted data;

(e) Combination ID ratios (i.e., ratios approximately symmetrical and with correlation coefficients of less than $0.75)$ and adjusted data

17. Manufacturing and Retail: The Years From Which the Functions with the Highest Classification Accuracy were Derived

18. Manufacturing and Retail: Correlation Matrix of Ratios in Selected Function

19. Manufacturing and Retail: Relative Contribution Tests and Ranks of Ratios in the Chosen Function

20. Manufacturing and Retail: Classification Accuracy of Chosen Function

21. Manufacturing and Retail: Comparison of Classification Accuracy:

(a) The Best Year 1 Function;

(b) The Chosen (Year 4) Function

22. Manufacturing and Retail: Direct and Stepwise Ratio Selection Methods

23. Manufacturing and Retail: Comparative Classification Accuracy: Lineax and Quadratic Classification Rules 
24. Manufacturing and Retail: Comparative

Classification Accuracy: 7-Variable and 10-Variable Functions

25. Manufacturing and Retail: Comparison of Group Means :

(a) Logarithm of Tangible Assets;

(b) Stability of Earnings

26. Manufacturing and Retail: Model Efficiency Comparison Tests

27. Average Classification Accuracy of Models Derived by Researchers

28. Property and Finance: Classification Accuracy of Chosen Function

29. Property and Finance: Comparative

Classification Accuracy: Linear and Quadratic Classification Rules

30. Property and Finance: Comparison of Group Means:

(a) Logarithm of Tangible Assets;

(b) Stability of Earnings

31. Property and Finance: Comparative Classification Accuracy: 2-Variable and 4-Variable Functions

32. Property and Finance: Model Efficiency Comparison Tests

33. Property: Highest Classification Accuracy

34. Property: Model Efficiency Comparison Tests

35. Property: Highest Classification Accuracy:

(a) Year 1 Function;

(b) Year 2 Function

36. Finance: Classification Accuracy of Chosen Function using Two Cutoff Scores:

(a) -0.21 ;

(b) 0.00

37. Scorecard for the A-Score: Argenti

38. Manufacturing and Retail: The Range of the Probability of a Firm being Classified in the Failed Group as Measured from Six Discriminant Functions 
39. Manufacturing and Retail: Distribution of Rankings from 1 (Lowest $P(F)$ ) to 6 (Highest $P(F)$ ) of Chosen Function

40. Property and Finance: The Range of the Probability of a Firm being Classified in the Failed Group as measured from Six Discriminant Functions

41. Property and Finance: Distribution of Rankings from 1 (Lowest $P(F)$ ) to 6 (Highest $P(F)$ ) of Chosen Function

42. Manufacturing and Retail: Index of Insolvency Risk

43. Property and Finance: Index of Insolvency Risk

44. Analysis of Insolvency Risk - Simpson-Pope Holdings Ltd.

45. Total Assets of Failed Firms

46. Total Assets of Twenty-six Surviving Firms During the Period they Reduced their Level of Insolvency Risk

47. Number of Failed Firms which Changed Chief Executives up to Five Years Before Failure

48. Change in Liabilities of Failed Firms from Five Years Before Failure

49. Change in Ordinary Capital of Failed Firms from Five Years Before Failure 
1. Distributions of Discriminant Z-Scores

2. Financial Streams of Typical Accounting

Items in the Profit Statement and

Balance sheet for a Public Company

3. Flow Chart 1: Assets, Liabilities, Working Capital and Shareholders' Funds Streams

4. Flow Chart 2: Cash Flow, Profit, Assets, Liabilities, Working Capital, and Shareholders' Funds Streams

5. Flow Chart 3: Cash Flow, Profit, Assets, Liabilities, Working Capital and Shareholders" Funds Streams

6. Flow Chart 4: Paths and Ratios for Combination 1 and Combination 2

7. PITTAI: Comparison of Mean Values: Manufacturing Industry

8. CFBTL: Comparison of Mean Values: Retail and Finance Industries

9. Patterns of $P(F)$ for A.G. Healing Traced from Each of Six Discriminant Functions

10. Graph of Relationship Between Z-Scores and Insolvency Risk for Manufacturing and Retail Firms

11. Graph of Relationship Between z-Scores and Insolvency Risk for Property and Finance Firms

12. Graph of Insolvency Risk of Simpson-Pope Holdings Ltd.

13. Pattern of Insolvency Risk: 12206

14. Pattern of Insolvency Risk: 2208

15. Pattern of Insolvency Risk: $3 \quad 210$

16. Pattern of Insolvency Risk: 4 211

17. Pattern of Insolvency Risk: $5 \quad 214$ 
18. Pattern of Insolvency Risk: 6

19. Pattern of Insolvency Risk: 7

20. Pattern of Insolvency Risk: 8

21. Pattern of Insolvency Risk: 9

22. Pattern of Insolvency Risk: 10

23. Pattern of Insolvency Risk: 11 
Chapter 1

Aim and Methodology

Justification for this Study

In recent years, there have been several studies using the statistical technique of discriminant analysis to develop a combination of accounting ratios which would predict corporate failure. However, further work may be done on finding the best combination for the purpose.

The only published works in Australia are by Castagna and Matolcsy (1977, 1981), Altman and Izan (1982); their approach is similar to that used overseas in that they developed a classification model composed of accounting ratios. The usefulness of such models can be increased by (a) a wider selection of ratios, (b) a concentration on individual industries, and (c) more precise gradations in the estimates of insolvency risk. Instead of aiming for the basic prediction that a firm will or will not fail, it would be helpful to develop a means of measuring the estimated level of insolvency risk and to analyse the causes of changes in the levels.

The development of a more precise model would provide management with earlier warning signals of a deterioration in financial standing, and would yield more prompt information on the actions necessary to reduce the level of risk. To the extent that this would minimize the incidence of corporate failure, it would have financial, social and 
economic benefits. The hope of producing these benefits is the implicit justification for all such studies.

Deakin (1972) explicitly justifies his research into company failure in America by the need to help avoid the high financial and social costs of bankruptcy. In Australia the situation is becoming increasingly like that of America because, with the trend towards fewer and larger firms, a growing number of people are dependent on the financial security of any one business entity. Foster (1978) also offers and supports a number of reasons for the importance of predicting failure: these include usefulness for public policy, and protection for investors, lenders and auditors.

While classical economists such as Schumpeter (1939) argue that corporate failure may have some advantages for an economy, because failure eliminates the inefficient and poorly-managed firms and thus avoids prolonged misuse of resources, it is obviously more efficient to correct the misuse of resources without allowing the firm to fail.

Since the prevention of corporate failure confers these financial, social and economic benefits, a mechanism to forestall failure is worth constructing. 


\section{Objective}

This study aims to add a new dimension to the research in Australia on the use of accounting ratios to estimate insolvency risk. The objective is to develop models from accounting variables ${ }^{1}$ to measure levels of insolvency risk for firms in different industries, and to explain the factors which cause variations in these levels.

To achieve its objective, the study will attempt to construct a model which produces from the information in a firm's financial statements one figure which represents the financial standing of the firm. For greater ease of interpretation, this figure will be converted to a measure of insolvency risk, in the form of an index ranging from 0 to 1 . The trends in these computed risk measurements will be analysed to assist in the development of a theory of corporate financial distress: its causes, symptoms, and remedies.

\section{Related Studies}

In other countries there has been an increase in published studies attempting to predict bankruptcy. The

1. The word 'variable' is used because as well as ratios, the logarithm of tangible assets is to be considered. 
studies have adopted three approaches: the qualitative, the quantitative, and a combination of these two methods.

\section{Qualitative Approach - Symptoms}

Those supporting the qualitative approach believe that a list of symptoms can be compiled to serve as a warning system of business collapse: if a company manifests any of the critical symptoms contained in the list, then it could fail. The methodology is to tell the story of some business failures and endeavour to draw some lessons from them. For instance, Ross and Kami (1973) looked at several firms which had failed, and compiled "ten commandments" to avoid business failure; they then attempted to substantiate these by illustrating how each commandment had been broken by some firms which failed.

In his research into corporate collapse, Argenti (1976) was critical of the qualitative method. He concluded that, if all the lists which have been published were combined, the resulting list would contain at least fifty symptoms. Since low-risk companies could exhibit some of the high-risk symptoms, however, such a list would be of limited value.

It seems that the use of the qualitative approach in assessing insolvency risk would require individual symptoms to be weighted by their degree of importance; this is because a firm could display some symptoms and not others - 
accordingly, without any weighting of symptoms, it would not know its level of risk. Because of the subjectiveness involved in both selecting and weignting qualitative items, this research does not intend to pursue tine qualitative course.

Quantitative Approach - Ratios

Those who follow the quantitative path rely on the use of accounting ratios to measure the insolvency risk of firms. For more than eighty years, business analyst's have been calculating ratios from financial statements to determine the financial status of any given commercial enterprise. Horrigan (1968) traced the origin of financial ratios back to the 1890's when the practice arose of comparing the current assets of a business with its current liabilities. Since tnen, the number of ratios used in financial analysis has increased: a recent study (Taffler and iisshaw, 1977) of the accounting reports of failed and surviving companies was based on eighty ratios.

Those researching the predictive power of accounting ratios have used both the univariate and multivariate methods of analysis.

Univariate ratio analysis. The univariate approacin calculates individual ratios which are compared with various benchmarks for risk assessment. These benchmarks 
include previous figures for the same firm, and the average for firms engaged in similar activities. A study by Beaver (1966) represents, according to Horrigan (1968), a landmark in univariate ratio analysis for predictive purposes. Using advanced statistical techniques in comparing the ratios of failed and nonfailed companies, Beaver found that some ratios predicted better than others up to five years before failure. He cited the cash flow to total debt ratio as the best single indicator of financial instability. Later studies (Bazley, 1976; Strebel and Andrews, 1977) confirmed the predictive power of this ratio, and established guidelines for its use by analysts. Prior to Beaver's study, writers on accounting ratios had emphasized profits rather than cash flow. His investigation proved the utility of financial ratios involving cash flow, and this ratio group is now more popular among analysts.

One difficulty with the univariate approach is that different ratios can imply different predictions for the same firm. Since individual ratios can point in different directions, and each can signify varying degrees of insolvency risk, their use to signal impending problems has some potential for confusion. For instance, a firm may have a profitability ratio which would indicate impending bankruptcy, but a liquidity ratio which indicates that it is safe. 
Multivariate ratio analysis. The use of multivariate approaches to financial statement analysis has long been seen as a means of overcoming the possibility of ambiguity in univariate ratio analysis. The multivariate approach combines and weights several key ratios to obtain a score which is given a risk rating from a table relating scores to levels of risk.

The first study employing multivariate ratio analysis was by Alexander Wall $(1928,1936)$. He developed a linear discriminant function using seven ratios. This was criticized, however, on the grounds that both the ratios and their weights had been chosen subjectively. Recent research by Tamari $(1964,1978)$ on developing an index of risk from subjectively determined ratios and weights has defended Wall's method. Tamari tested his own index of risk, comprising six weighted ratios, on a sample of failed and nonfailed firms. He concluded that it was a valid analytical tool, although it was "not the result of valid statistical analysis" (Tamari, 1978, p.194).

Altman (1968) was the first to use an advanced multivariate analysis technique, known as discriminant analysis, for research into financial distress. He collected a paired sample of failed and nonfailed companies, and selected a set of financial ratios based on their popularity in the literature of ratio analysis. From these, the application of mathematical discriminant 
analysis yielded a linear function of ratios which made the best distinction between the two company groups. A score for each company was calculated, then compared with a cutoff score, and the companies allocated to the failed or nonfailed group. The predicted group membership was compared with the actual group membership to measure the accuracy of the classification.

Since these first steps were taken by Altman, discriminant analysis has gained popularity among multivariate analysts in exploring the use of accounting information to predict company Eailures. A summary and an evaluation of the United States studies have been recorded by both Foster (1978) and Lev (1974). There has been similar research in France, United Kingdom, Canada, West Germany, Japan, Netherlands and Brazil: a partial list of these works is in Altman, Baidya and Ribeiro-Dias (1979).

There are, however, a number of methodological problems in the application of discriminant analysis in finance. These are summarized by Eisenbeis (1977) who draws attention to the need for users of the technique to recognize its pitfalls. Despite debate on the best way to resolve its statistical problems, discriminant analysis remains the most widely accepted and the most robust of the statistical techniques available for the development of models assessing corporate risk. 


\section{Qualitative and Quantitative - Symptoms and Ratios}

Users of this approach have developed a scorecard consisting of financial and nonfinancial variables to measure insolvency risk. For instance, Argenti (1977) combined some symptoms and ratios to arrive at a discriminant index which he called an "A-score". Such an approach will not be utilized in this study, however, because much of the scoring is subjective and depends largely on personal judgement. The objective of this study is not just "results", but a greater understanding of the factors which contribute to different levels of insolvency risk; the introduction of subjective biases and perceptions from a mixed methodology could hamper the achievement of that objective.

\section{Research Methodology}

Because in univariate analysis the order of importance of the ratios is not clear, and therefore the predictive value of each is not evident, this study will apply discriminant analysis. As in other studies concerned with the prediction of financial distress, the predictor will be applied to two categories of companies: failed and nonfailed. The term 'failure' has been defined in a variety of ways in the literature. Castagna and Matolcsy (1981), surveying the major empirical studies of company failure, identified seven different definitions which had been employed, thus highlighting one of the 
difficulties of generalizing from past research. For the present study, failure will be considered to have occurred when a receiver or a liquidator is appointed under the provisions of the Companies Act. However, for the finance industry, "failed firms" will include those which were unable to raise additional funds and were taken over as part of a rescue operation: this can be referred to as a forced merger. This expanded definition will not apply to other industries because of the difficulty in deciding whether, in cases where a merger has taken place, it was as a rescue operation or owing to circumstances other than impending failure.

In predicting whether a firm will fail, researchers have selected a collection of discriminating ratios that measure characteristics on which failed and nonfailed firms are expected to differ. Ideally the ratios which are selected for inclusion in the analysis should be those identified as important by a theoretical framework. In practice this has been prevented by the absence of a well-defined theory of corporate distress. This has caused researchers to use varying approaches to ratio selection, the most common approach being to review the literature and compile a list of ratios found to be significant indicators of corporate problems. One of the limitations of this earlier work was that researchers arbitrarily narrowed the field of ratios for potential inclusion in a model, so that some quite important ratios 
could have been omitted.

The approach adopted to ratio selection in this investigation will be different, as ratios selected will not be restricted to those found useful in previous studies. This study will develop a framework for inclusion of all accounting ratios which can be calculated from a firm's annual accounts. The usefulness of the model will then reflect the usefulness of financial statements, since all items comprising those statements will have been combined to produce the final list of accounting ratios.

A weakness inherent in accounting information is the diversity in reporting standards. For instance, the performance of risk prediction models may be affected by differences in accounting technique, not only across companies but also for individual companies over time. To try to overcome the problem of variation in reporting, this study will attempt to standardize financial statements before calculating accounting ratios.

Because the significance of accounting ratios can vary from industry to industry, this research will analyse four industries: manufacturing, retail, property, and finance.

Following resolution of the statistical issues in discriminant analysis, discriminant functions will be 
produced. Most previous research has attempted to predict, from these functions, whether a firm will simply fail or not fail. This study will attempt to be more precise by making use of a statistic generated by discriminant analysis and which has not been used by previous financial investigators: the probability of group membership. ${ }^{2}$ These probabilities will be used to develop an index of risk where a point on the scale will represent the probability at a particular time that the firm is classified as failing: this probability will be referred to as the firm's level of insolvency risk. Classifications of probable failure will, therefore, be represented by index values ranging from 0.5 to 1 , whilst classifications of probable survival will be represented by index values in the range 0 to $0.499 .^{3}$ As the values move upwards the insolvency risk increases.

A measure of a firm's insolvency risk is provided by the functional relationship between the discriminant score and an index of risk. The index of risk will be computed from the statistical relationship between a score and the

2. Ohlson (1980) also attempted to develop probabilistic estimates of failure. He preferred logit analysis, suggesting that discriminant analysis could give poor approximations unless certain statistical assumptions are satisfied. This study aims to test if the probabilities from discriminant analysis can be regarded as reliable: Altman and Izan (1982, p.22) suggested that this probability is a useful statistic.

3. A firm is in the failure zone - 0.5 to 1 - when the model recognizes it as having the financial characteristics of companies which have failed. A firm is in the nonfailure zone - 0 to 0.499 - when the model identifies it has having the qualities of surviving companies. 
likelihood of that score's being in the failed group. The trend of a firm's score, and the corresponding risk figure, will be traced over five years, and this will provide information on the patterns of insolvency risk which were followed by failed and nonfailed firms.

The research will conclude by examining to what extent changes in the values of the ratios in a function affect the firm's score and its level of insolvency risk. This examination will contribute to an understanding of the circumstances, as evidenced in financial statements, which lead to instability. The information on financial events which cause a change in insolvency risk will acquaint management with the actions necessary to prevent, or to reverse, an adverse trend in a firm's risk rating. 
Discriminant analysis is a statistical technique used to classify and/or make predictions in problems where the dependent variable appears in qualitative form, e.g., male or female, bankrupt or nonbankrupt. Its first use was taxonomic (Fisher, 1936). In taxonomic work, discriminant analysis is the ultimate criterion: it represents the best way of classifying observations into one of several defined groupings - known as a priori groups - dependent upon the observation's individual characteristics. The classification results cannot be upset by subsequent events. In predictive work, however, discriminant analysis only yields a provisional classification which can ultimately be verified or refuted.

The use of discriminant analysis in financial issues was pioneered by Durand (1941), who used it for predicting the credit worthiness of used car loan applicants. Since Durand, there have been various studies in finance which employed this method for both taxonomic and predictive purposes $^{1}$. Those concerned with classification have used different dependent variables for classifying firms: Walter (1956) was interested in the classification of

1. Altman (1968, p.591) provides a review of the use of discriminant analysis in financial contexts. 
price-earnings ratios, and smith (1965) sought classification into standard investment categories.

The technique was first used for predicting business failure by Altman (1968). Fe derived a function which was used to classify firms into one of two groups - failed and surviving - and checked the accuracy of the classification by comparing the prediction with the actual status of the firm. Since this first use by Altman, discriminant analysis has gained popularity for the development of explanatory and predictive models of financial insecurity because of the inherent Iimitations of univariate analysis ${ }^{2}$.

The increasing employment of discriminant analysis has been accompanied by critical examination of the adequacy of the technique for bankruptcy studies ${ }^{3}$. The problem areas examined include: the violation of the assumption that the variables are normally distributed, the appropriate form of the discriminant function (linear or quadratic), the method of selecting the variables for inclusion in the function, the assessment of its classification accuracy, and the interpretation of individual

2. Foster (1978, ch. 14) outlined these limitations.

3. Joy and Tollefson (1975) were critical of aspects of Altman's (1968) application of discriminant analysis. Altman and Eisenbeis (1978) answered the criticisms. This prompted replies from Joy and Tollefson (1978) and scott (1978). Eisenbeis (1977) summarized the methodological and statistical problems of the technique. 
variables in the function. This attention given to discriminant analysis has led to a better understanding of the method. Recent progress in the above areas was a reason given by Altman, Haldeman and Narayanan (1977) for constructing a new formula to predict business failure.

Despite some methodological problems in the application of discriminant analysis, it does not appear that statistical method has come up with a more acceptable technique for classifying firms into a priori groups. The aim of tinis chapter is to investigate the problems which can arise when using the technique, and their impact on this study.

\section{A Description of the Use of Discriminant Analysis in This study}

The data input for discriminant analysis in this research will be the financial statements of two groups of companies - failed and nonfailed - and a list of variables which can be obtained from items in the financial statements. The task of discriminant analysis will be to search for that combination of variables which best depicts the difference between the financial characteristics of failed and nonfailed companies. This combination will be referred to as a discriminant function, 
which can be in either linear or quadratic form ${ }^{4}$. The efficiency of the discriminant function in distinguishing between failed and nonfailed companies is tested by computing the discriminant score - referred to as $\mathrm{Z}$-score - for each company, and examining the extent of overlap in the distribution of $\mathrm{Z}$-scores for the failed group with the distribution of $\mathrm{Z}$-scores for the nonfailed group. If the overlap in the distribution is small, the discriminant function separates the groups clearly. If the overlap is large, the function is a poor discriminator between the groups. The distributions of discriminant Z-scores in Figure 1 illustrate this concept.

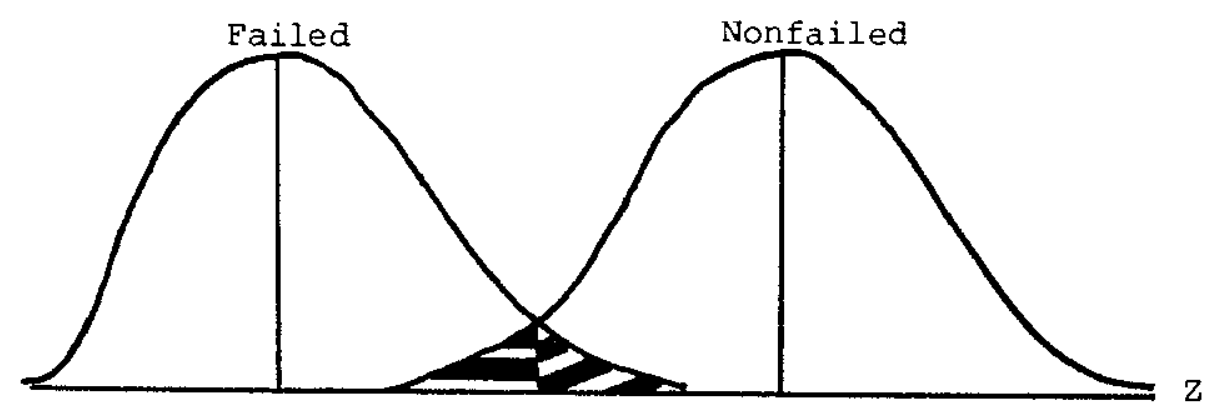

Discriminant Function

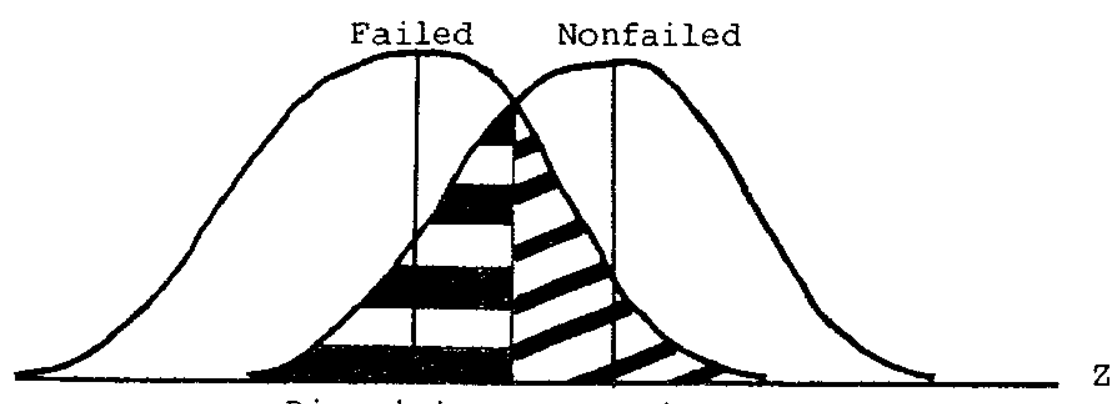

Discriminant Function

Figure 1. Distribution of Discriminant Z-Scores

4. For example, linear discriminant functions are of the form $\mathrm{z}=\mathrm{C}+\mathrm{k}_{1} \mathrm{v}_{1}+\mathrm{k}_{2} \mathrm{v}_{2}+\mathrm{k}_{3} \mathrm{v}_{3}+\mathrm{k}_{4} \mathrm{v}_{4}+\ldots \mathrm{k}_{n} \mathrm{v}_{\mathrm{n}}$ when $Z$ is the score of the discriminant function, $C$ is a constant, the $k^{\prime} s$ are the weighting coefficients, and the $v^{\prime}$ 's are the values of the ratios used in the analysis. 
The top diagram represents a function that is a relatively good discriminator between failed and nonfailed companies, whereas the lower diagram shows a function that is a relatively poor discriminator. The shaded areas represent the probabilities of misclassifying failed and nonfailed companies whose scores are in the area of overlap. These probabilities will be used in this study to develop an index of risk.

\section{Assumptions of Discriminant Analysis}

The statistical theory of discriminant analysis for deriving both a linear and a quadratic discriminant function assumes that the discriminating ratios have a multivariate normal distribution. An additional assumption for a linear function is that the group dispersion matrices are equal across all groups, i.e., that the ratios do not have a significantly different spread about their means. Since it does not require this equality of group dispersion, the quadratic function is statistically more correct than the linear where there is inequality of group dispersion. The issue that has emerged in the literature on the application of discriminant analysis is the effect of violations of these assumptions upon the classification accuracy of the discriminant function. This literature will now be briefly reviewed.

The distribution of the ratios. We consider first the assumption common to both forms of discriminant 
analysis, that the distribution of the ratios is multivariate normal. This assumption is necessary because the calculation of the optimum combination of ratios is based upon the statistical F-test of significance, which in turn is based on an assumption of normality.

Eisenbeis (1977, p.375) suggests the violation of the normality assumption may bias the tests of statistical significance and estimated error rates. Accepting his criticism, what really matters, however, is not whether bias will result, but rather how much bias will result from how much departure from normality. Other authors have found the effect of the departure from normality to be of no great importance. For instance, discriminant analysis has been recently described (Nie, Hadlai, Hull, Jenkins, Steinbrenner \& Brent, 1975, p.435) as robust, and the conclusion was drawn that therefore the normality assumption need not be strictly adhered to. The judgement that discriminant analysis is robust is supported by other writers (Hair, Anderson, Tatnam \& Grablowsky, 1979, p.187; Harris, 1975, p.233), who suggest that discriminant analysis is not very sensitive to violation of the normality assumption unless the violations are extreme; however these authors do not define what they mean by "extreme". In listing the methodological problems of discriminant analysis, Castagna and Matolcsy (1981, p.25) exclude the normality assumption, while Eisenbeis (1977, pp. 895-896) himself does not put it in his "severe" group of problems. The tactic which most researchers who use 
discriminant analysis have adopted is to proceed as if the departure from the normality assumption is of no great importance.

In this study an attempt will be made to test the significance of the normality assumption. Two techniques for reducing the departure from normality will be explored: the standard log transformation of ratios, and the deletion of extreme ratio values. The aim is to compare the classification accuracy of functions derived from adjusted data with functions derived from the original data. This test will provide an indication of the robustness of discriminant analysis.

Equality of group dispersion. The discriminant function can be expressed in either linear or quadratic form. Linear functions assume an equality of dispersion of the discriminating ratios; where there is inequality of group dispersion - the ratio values having a significantly different spread about their means - the quadratic function is statistically more appropriate.

Before adopting a linear discriminant function a test of equality of group dispersion should be undertaken. Many researchers, however, have omitted this test to see whether the hypothesis of equality of group dispersion should be rejected, and proceeded with the linear structure because of the apparent robustness of discriminant analysis. For instance Nie et al. (1975, p.435) and 
Hair et al. (1979, p.87) have commented that the assumption of the equality of dispersion need not be strictly adhered to.

In those bankruptcy studies in which the hypothesis of equality of group dispersion has been tested it has invariably had to be rejected. This rejection suggests that although the linear function is still useful in practice it could be less accurate in correctly classifying firms than the quadratic. A test of this limitation of the linear function is to derive a quadratic function - which does not logically require equality of dispersion - and compare its classification accuracy with that of the linear model.

Whenever Altman et al. (1977,p.38) analysed results using both the linear and quadratic functions, they found a clear superiority of the linear framework in accurately predicting failed and nonfailed companies. Castagna and Matolcsy (1981,p.28) did not, however, produce such a conclusive result: they sometimes found that the quadratic function classified more accurately than the linear function. According to Eisenbeis and Avery $(1972, \mathrm{p} .38)$, when there is inequality of dispersion and the groups are widely separated with little overlap, the form of the classification rule - linear or quadratic - is not very significant. Marks and Dunn (1974) demonstrated that it is difficult to generalize on the appropriate classification rule solely on the basis of whether the 
hypothesis of equality of group dispersion is accepted or rejected.

The difficulty of deciding on the appropriate classification rule when there is unequal group dispersion suggests the desirability of deriving both a linear and quadratic function. The choice can then be made for that classification rule which best discriminates between failed and nonfailed companies.

This study will compare the predictive accuracy of linear and quadratic equations when there is unequal group dispersion. This will provide another test of the robustness of a linear discriminant function when an assumption is violated.

\section{Application of Discriminant Analysis}

The application of discriminant analysis can be divided into three major stages: derivation, validation, and interpretation. The derivation stage involves specification of the function which best separates the two groups. The validation stage consists of developing a classification matrix to further evaluate the predictive accuracy of the discriminant function. This matrix shows the number of firms which have been both correctly and incorrectly assigned to their group: the percentage correctly classified for each group is then shown, as is the overall percentage of firms correctly classified. The 
interpretation stage includes determining which of the ratios contribute the most to discriminating between the failed and the surviving companies.

The rest of this chapter will be concerned with the methodological or statistical problems in each of the stages which could have an influence on the practical usefulness of the result.

Stage one: derivation. Discriminant analysis provides two computational methods of selecting ratios for inclusion in the function: the direct method and the stepwise method.

The direct method introduces all ratios concurrently, and the discriminant function is created from the entire ratio set. This approach ignores the relative discriminating power of any one of the ratios.

The alternative, the stepwise method, involves introducing the ratios into the discriminant function one at a time on the basis of their discriminating power. The stepwise approach begins by choosing the single best discriminating ratio. This ratio is then paired with each of the other ratios one at a time, and a second ratio is chosen. The second ratio is the one which is best able to improve the discriminating power of the function in combination with the first ratio. The third and subsequent ratios are selected in a similar manner. As additional ratios are included, some previously selected 
ratios may be removed if the information they contain about group differences is available in some combination of the other included ratios. Eventually, either all ratios will have been included in the function or some will have been excluded as not contributing significantly toward further discrimination.

The stepwise method will be useful for this study where a relatively large number of ratios will be considered for inclusion in the function. By sequential selection of the next best ratio at each step, ratios which are not useful in discriminating between failed and nonfailed groups will be eliminated, so that the function will be based on a subset of the ratios.

Hair et al. (1979, p.96) comment that the reduced set of ratios typically is almost as good as, and sometimes better than, the complete set of ratios. However, Eisenbeis (1977, pp.885-886) recommends that "if classification accuracy is a primary goal" the results from the direct method should be compared with those from the stepwise method. This is because the stepwise method may give inferior classification results. Castagna and Matolcsy (1981, p.28) employed the stepwise procedure on their ten-ratio set to determine the best ratio subset. They found that the optimal subset consisted of five ratios but that this model did not perform as well as the model based on the ten-ratio set in the overall classification of failed 
and surviving companies.

The approach taken in this research will be to derive discriminant functions using both the direct method and the stepwise method. The classification results of the best function derived from the direct process will be compared with that produced from the stepwise process. The function with the higher classification accuracy will be chosen for subsequent analysis.

Stage two: validation. After the discriminant function has been computed its level of significance is assessed. If the statistical test indicates that the function discriminates significantly, then it is customary to develop classification matrices to provide a more accurate assessment of the discriminating power of the function. Before constructing classification matrices an optimum cutoff score is determined.

1. Cutoff score determination. The cutoff score is the criterion against which each firm's discriminant score is judged to determine into which group the firm should be classified. The cutoff score is influenced by four factors: the group centroids, the relative size of the groups, the a priori group probabilities, and costs of misclassification.

(a) Group centroids and the relative size of the groups. By averaging the $z$-scores for all the firms 
within both the failed group and the nonfailed group, discriminant analysis arrives at the mean of the Z-scores for each group. The group mean is referred to as a centroid and in this study, which involves two groups, there are two centroids. The centroids indicate the most typical location of an individual firm from a particular group, and a comparison of the group centroids tells how far apart the failed and nonfailed groups are along the scale of 2 -scores.

In this study, since the groups are not of equal size, a weighted average of the group centroids will provide the provisional cutoff score $\left(\mathrm{z}_{\mathrm{Cu}}\right)$. The calculation of $\mathrm{z}_{\mathrm{Cu}}$ is a straightforward, noncontroversial mathematical procedure: the formula may be found in Hair et al. (1979, p.98) .

(b) The a priori group probabilities and costs of misclassification. The implicit assumption underlying $\mathrm{Z}_{\mathrm{Cu}}$ is that the expected costs of misclassification are the same in either direction. However, if the expected costs of misclassification are not equal then $Z_{\mathrm{Cu}}$ shifts towards the group with the higher expected cost of misclassification. For instance, if the expected cost of misclassifying a failed company is nigher, then $\mathrm{z}_{\mathrm{cu}}$ moves towards the nonfailed group centroid; in the opposite circumstances it shifts to the side of the failed group centroid. The formula for the adjustment is as follows: $z_{c}=z_{c u} \pm \ln \frac{q_{1} c_{1}}{q_{2} c_{2}}$ where $z_{C}=$ optimum cutoff score; $z_{C u}=$ 
provisional cutoff score value after allowing for unequal group sizes; $q_{1}, q_{2}=$ prior probability of failure $\left(q_{1}\right)$ and nonfailure $\left(q_{2}\right) ; C_{1}, C_{2}=$ costs of Type $I$ exror $\left(C_{1}\right)$ and Type II error $\left(C_{2}\right)^{5}$. If $\frac{q_{1} C_{1}}{q_{2} C_{2}}=1$ then there is no adjustment to the cutoff score determined by the centroids and sample sizes since $\ln 1=0$.

The difficulty with rnaking the adjustments for prior probabilities and error costs, however, is that their values depend upon user criteria. For instance, prior probabilities will depend on the period of time a user is interested in the company; e.g., on the basis of a given set of facts about a company, a long-term lender would assign a higher probability of failure than a short-term lender. Similarly, a lender secured by a mortgage debenture would be expected to lose less in a failed company than an unsecured creditor, who in turn would lose less than a shareholder. For these reasons most researchers have not adjusted the cutoff score for prior probabilities and error costs. The expectation is that in most instances, in fact, $\frac{q_{1} C_{1}}{q_{2} C_{2}}$ will equal one. This is in accordance with practical experience: the proportion of companies that fail is low, and the financial loss in doing business with a company which fails is greater than the loss from not doing business with a

5. Type I error is misclassifying a failed company: predicting it will not fail but it does fail. Type II error is misclassifying a nonfailed company: predicting it will fail but it does not fail. 
company which does not fail.

Joy and Tollefson (1975, pp.723-725) and Eisenbeis (1977, p.889) were critical, however, of the lack of research into the effects on model efficiency of different levels of prior probabilities and error costs. Acknowledging the potential bias in ignoring prior probabilities and error costs, Altman et al. (1977, pp.43-46) compared the impact of unequal priors and unequal costs on the efficiency of their model (the ZETA model) with the impact they would have on the efficiency of alternative strategies. The objective was to show that, under most (if not all) plausible circumstances, the unadjusted ZETA model would outperform two naive strategies.

The measure of efficiency was expected cost (EC). The formula used for calculating the expected cost of ZETA $-E C_{Z}$. was as follows:

$$
E C_{2}=q_{1}\left(M_{12} / N_{1}\right) C_{1}+q_{2}\left(M_{21} / N_{2}\right) C_{2}
$$

where $M_{12}, M_{21}=$ observed Type $I$ and Type II errors respectively, and $\mathrm{N}_{1}, \mathrm{~N}_{2}=$ number of firms in the failed $\left(\mathrm{N}_{1}\right)$ and nonfailed $\left(\mathrm{N}_{2}\right)$ groups.

The two strategies used for comparison with the ZETA model were: 
(i) A strategy based on the assumption that all firms are classified as nonfailed: for example a lender would accept all loan applications. The calculation of its expected cost - $E C_{\max }$ - would be: $\mathrm{EC}_{\max }=\mathrm{q}_{1} \mathrm{C}_{1}$

(ii) A strategy based on the assumption that observed error rates would equal prior probabilities. This is referred to as a proportional chance strategy and its expected cost - EC prop - would be:

$$
E C_{\text {prop }}=q_{1}\left(q_{2}\right) C_{1}+q_{2}\left(q_{1}\right) C_{2}
$$

If $\mathrm{EC}_{\max }$ and $\mathrm{EC}_{\text {prop }}>\mathrm{EC}_{\mathrm{Z}}$ this indicates the extent to which the naive strategies are less efficient than the ZETA model.

The ZETA model researchers investigated the actual failure rate of firms, and the net loan loss experience of a sample of American banks. The comparison analysis consisted of the researched set of prior probabilities and error costs, and several other sets within the likely limits of each parameter. They found in all instances the ZETA model had a lower expected cost than the two naive models.

In this study, the assessment of classification accuracy for selecting the best models will be on the assumption that the prior probabilities and error costs cancel out. Model efficiency tests will then be performed along the lines proposed by Altman et al. (1977). 
If the derived functions are more efficient than the alternative strategies - $\mathrm{EC}_{\max }$ and $\mathrm{EC}_{\text {prop }}$ - they will be useful for further analysis.

2. Constructing classification matrices. In this study, discriminant functions will be derived for each of five successive years. The classification accuracy of each function will then be calculated for each of the five years. A function would correctly identify the status of all firms only in the special case where all failed companies have been in failure zone consistently for the five years before failure, but nonfailed companies did not enter failure zone during those five years. This special case, however, would be most unlikely to arise. For instance, a nonfailed company could have a level of insolvency risk which puts it in the failure zone, but corrective action by management has subsequently reduced its insolvency risk and this has returned the enterprise to the nonfailure zone. Alternatively, unforeseen events, not reflected in financial statements because of their suddenness, could change the insolvency risk of a business previously in the nonfailure zone, and cause it to fail.

Because it cannot be presumed that a firm will be in the one zone for a period of five years, this examination (unlike other studies) will not refer to misclassification as the "error rate" of a model. A misclassification need not be due to a failure of the model to forecast the 
ultimate financial status of a company. A firm, which has been correctly assigned to a particular zone by the model, may have been taken out of that zone by subsequent events. The term used here will be "misclassification", meaning the percentage of cases which during all, or part, of the five year period exhibited financial characteristics other than those appropriate to the firm's final classification.

The model selected for further investigation in this research will be that which, over a five year period, has the fewest failed companies in the nonfailed zone and nonfailed companies in the failed zone. If this model proves more efficient than naive strategies, using various values of prior probabilities and misclassification costs, it will form the basis for measuring insolvency risk and explaining the factors causing change in financial stability.

There are three commonly adopted methods - often referred to as validation techniques - for measuring the ability of a model to identify the group to which a firm belongs in a given year: original-sample, holdout-sample, and Lachenbruch test.

In the original-sample test, misclassification rates are estimated from the same data as were used to determine the function. This validation method gives an estimate of how well the function describes the data from which it 
was computed. An evaluation of this method by Lachenbruch and Mickey (1968) concluded that there could be undue upward bias in the estimates from small samples. However, Altman et al. (1977, p.38) found only slight upward bias.

The holdout-sample method attempts to overcome the bias of the original-sample method by splitting the sample, one part being used to derive the function, and the other part used to estimate the adequacy of the function. Because this estimate is calculated from different data, the holdout method indicates how well the function recognizes group membership. A limitation of the holdout method is that it requires a larger sample size than the other methods, which do not require the sample to be split. In business failure studies, the limited sample size of failed companies could prevent the use of this method.

The Lachenbruch test, as explained by its founder (Lachenbruch, 1967) holds out one observation at a time and classifies each held-out observation by means of a discriminant function based on all the other observations. The procedure is repeated until all observations are classified. Eisenbeis (1977, p.895) believes the Lachenbruch method gives almost unbiased estimates and overcomes the small-sample limitation of the holdout method. Scott (1978, p.202) goes further and claims that the Lachenbruch method is clearly superior to the split-sample validation approach. 
For testing the classification accuracy of the function for years other than the year from which the function was derived, the holdout-validation test is used. The holdout method is much more satisfactory when working with separate discriminant functions for successive years: one year's function can be tested on other years' data and the sample is not required to be split. For this reason the holdout method is more commonly used in this context.

In this research the sample sizes would be too small for sample splitting. For the year from which the function is computed, the original-sample and the Lachenbruch validation techniques will be applied. This test will indicate the extent of upward bias in the original sample approaches. In testing the function against data from other years, the holdout method will be used on the complete sample.

Stage three: interpretation. Discriminant functions are capable of being used in two different ways: (a) to simply assign firms to the appropriate category, and (b) to determine the relative importance of the individual ratios which affect the probability of failure. The attitude which one takes to intercorrelation of ratios is dependent on which of the above two uses one has in mind. For the first purpose - classification accuracy intercorrelation does no harm, and may even help the discriminating power of a ratio set; however for the second purpose - interpretation of discriminant weights 
assigned to ratios - intercorrelation can present serious problems.

A certain degree of correlation among the ratios of any firm can be expected: many ratios have a common denominator or numerator, some financial statement items tend to move in the same direction as certain others, and the numerical difference between functionally independent variables may be very slight. A study by Horrigan (1965, p.560) concluded that both short-term and long-term solvency ratios were highly correlated groups ${ }^{6}$. Foster's analysis (1978, p.42) confirmed this picture.

Most researchers concerned with the classification of failed and surviving firms have chosen to ignore correlation among the ratios. One researcher who refused to ignore correlation was Edmister (1972, pp.1482-1484). Because he believed that successful forecasts require independence of ratios, he used a procedure to limit intercorrelation: he arbitrarily decided that a variable should not be permitted to enter the function if its simple correlation-coefficient with a variable already in the function is greater than 0.31 . This substantially reduced the number of variables free to enter the function, and gave rise to a degree of independence of the predictor

6. Horrigan bases his descriptions on the range in which the coefficient of correlation lies, viz.: $0.25-0.49$ "moderate" correlation; 0.50 - 0.74 "high" correlation; 0.75 - 1.00 "extremely high" correlation. 
variables. Although his prime concern was classification accuracy, Edmister unfortunately did not compare the results based on his subset of ratios with that based on all ratios.

Research indicates that where the primary concern is for interpretation of the discriminant function's variables and their coefficients, multicollinearity could present a problem; there is the potential for the coefficients to be misleading. In market research, studies concerned with the interpretation of variables (Gilbert, 1968; Moore, 1973; Dillon \& Goldstein, 1978) reported that linear discriminant functions whose variables had low to moderate correlations were more useful for explanation purposes than those functions whose variables were highly correlated. Hair et al. (1979, p.118) suggest that multicollinearity can sometimes cause the variable coefficients to be unreliable, and mislead interpretation of the relative importance of variables.

This study is concerned with the impact of correlation on interpretation. In order to reduce the difficulties which may arise in assessing the respective contributions of two or more highly correlated variables, it is proposed to omit one of each pair, provided that this omission has no significant effect on classification accuracy. This reduced list of ratios will be compiled by including only one of a pair of ratios whose correlation exceeds 0.75 . In making the choice for retention, preference will be 
given to that ratio with the higher "F" statistic produced from an "F" test on the individual discriminating ability of the variables.

The impact of correlation will be tested by comparing the classification accuracy of a function derived from a list of all ratios with that derived from the above subset list of ratios. If there is little difference in the classification accuracy of the two functions, that derived from the subset will be used for further analysis. If the classification accuracy of the function derived from the list of all ratios is significantly better, then caution will be necessary in interpreting the relative importance of each of the ratios.

\section{Summary}

This chapter has explored the main issues that have emerged in the literature on discriminant analysis. This exploration suggests the need to test the impact on classification accuracy of violating the assumptions that the ratios are multivariate normal and have equality of dispersion. There is also the issue of the effect on classification accuracy of some ratios having an extremely high level of correlation.

This study will attempt to resolve these issues by deriving discriminant functions both from all the ratios and from the following subsets: ratios with a correlation 
less than 0.75 , ratios transformed to reduce degree of skewness, ratios which are approximately normal and with a correlation less than 0.75. In this process the other issues raised in this chapter will also be tested: these include the stepwise and direct ratio selection methods, linear and quadratic slassification rules, Lachenbruch and original-sample validation techniques, and model efficiency tests. 
Selection of Firms for Research and Analysis

The first studies on the efficiency of ratios in predicting business difficulties were made in the early 1930's. Smith and Winakor $(1930,1935)$ initiated this development with their analysis of a sample of firms which had experienced financial distress during the period 1923-1931. Their study, which looked at the trends in individual ratios of failed companies, was deficient in that it lacked a contrasting control group of successful firms.

Two other studies concerning the predictive power of ratios were also carried out in the 1930's, and control groups were used in these (Fitzpatrick, 1932; Ramser \& Foster, 1931). Subsequent studies have followed their lead and relied on the use of a control group of nonfailed companies to analyse the characteristics of the ratios of failed companies. The approach to firm selection has been to collect a sample of firms which have failed over a period of time. The same number of surviving companies is then selected at random. The next step is to pair the failed and surviving firms, and obtain the financial statements of a pair for the same time period, usually for the last five years of the failed firm's existence. This process of matching a failed firm with a surviving firm is referred to as the 
paired-sample technique.

The data input for this research will come from the financial statements of both failed and nonfailed firms. However, unlike most previous studies this one will examine more nonfailed firms than failed firms ${ }^{1}$. Therefore, the term "paired-sample technique" - which refers to pairing a failed and nonfailed firm on a one-to-one basis - will not be used here. The term used will be "matched-sample technique", meaning that a failed firm can be compared with more than one surviving firm. The selection of the firms for matching requires consideration of the availability of data, differences in the financial characteristics of industries, size of samples and matching criteria - size of firms, age of firms and industry classification. This chapter reviews the decisions taken on these issues by previous researchers in selecting firms for research and analysis, and outlines the method of selection chosen in this research.

\section{Availability of Data}

Business firms can be divided into two broad categories: publicly and privately owned. Researchers have found that the probability of failure of public companies is not as high as it is among smaller private firms. Beaver (1966, p.72), suggested that for this reason the

1. Two other studies that had more nonfailed than failed firms were Deakin (1977) and Ohlson (1980). The reasons for having more nonfailed than failed firms are outlined on pp. 44-45. 
population of smaller firms would be the more relevant population upon which to test the predictive ability of ratios. However, it is a reason which cannot be accepted. The fact that public companies have a lower average probability of failure means that investors would be prepared to take greater risks with a public company than with a private company; consequently, improvement of the estimation of failure probabilities could be just as important in either case.

Most research on the ability of accounting ratios to distinguish between failed and nonfailed firms has been concerned with public companies. A major reason for this has been that financial information on public firms has been more readily available. A notable exception was a study of small firms by Edmister (1972) in co-operation with the United States Small Business Administration. To overcome the problem of availability of data, researchers such as Wilcox (1973), have suggested using the data on medium sized private businesses which is available to banks. In a study of private companies, using bank data, Hoeven (1979) attempted to use multivariate analysis of ratios for the purpose of determining the risk of loans to businesses. However, he found that much of the financial information available to banks was unusable because of the wide variation in reporting standards; hence his results were very limited. 
firms suffers from the fact that the accounting statements are more often presented to minimize the tax payable than in accordance with generally accepted accounting principles. There is no organization that standardizes these statements to make feasible a comparison between those of failed and nonfailed firms.

On the other hand, the provisions of the Companies Act, the public reporting standards of the accounting organizations, and the requirements of the stock exchanges ensure the availability of adequate financial information on public companies.

The difficulty in obtaining reliable financial information on private firms means that this study will confine itself to public companies. Whether the findings will possess any relevance to smaller firms can only be answered by testing on them the discriminant functions derived from the study of public companies. There is no published study on the application to private firms of ratios which have been found to have predictive power for public companies.

\section{Differences in the Financial Characteristics of Industries}

An early study on ratios (Bliss, 1923) suggested that industry factors must be incorporated in any complete ratio analysis. Littleton (1926) compared the working capital ratio of firms in different industries, and concluded that the same numerical value of the ratio implied 
a different level of short term financial stability in various activities. A recent Australian study (Bird and McHugh, 1977) found evidence to support the hypothesis that the mean values of some accounting ratios vary from industry to industry. The means of ratios for the sample of firms - classified by industry - used in this study are shown in Appendix C. An inspection of these confirms that some accounting ratios differ systematically between the manufacturing, retail, property and finance industries. For instance, the proportion of funds borrowed by manufacturing and retail companies is considerably less than that borrowed by property and finance firms. This then causes differences between industries in some other ratios involving total liabilities: for example, the manufacturing and retail firms have higher profit (after interest and tax) to total liabilities ratios than property and finance firms. Because of the slower rate of turnover of stock, and a higher proportion of credit sales, manufacturing firms have a higher mean working capital ratio than retail firms. This difference in the means of accounting ratios between industries supports the practice of financial analysts in considering these differences when interpreting ratios.

Since univariate ratio analysis is improved by allowing for differences between industries, it might be expected that a similar effect would occur in multivariate ratio analysis: a multiratio model derived from a sample 
comprising several industries with different financial characteristics would not be expected to classify firms as accurately as separate models each based on a single industry. This hypothesis will be tested in this present study. Since the study covers four different industries, a test will be carried out which compares the performance of three single-industry models with the performance of models based on two-industry samples and a combined model based on all four ${ }^{2}$. Single-industry models will be derived, and because there is more similarity in their financial structure, the manufacturing and retail industries will be combined, as will the property and finance industries. The classification accuracy of the best model from each industry group will then be compared, to test the hypothesis that single-inaustry models will classify more accurately than combined-industry models.

Because ratios vary between industries, most researchers, when comparing the ratios of failed and existing firms, have chosen specific business sectors ${ }^{3}$. However, Wilcox (1973) and Altman et al. (1977) combined retailers and manufacturers, arguing that, since their

2. Because there are only four failed finance firms (see p.54), one cannot legitimately use discriminant analysis to develop a single-industry model for the finance industry: hence only three-single industry models will be constructed.

3. For instance, Altman (1973) on railroads, Sinkey on commercial banks, Korobow and stuhr (1975) on commercial banks, Altman and Lorris (1976) on brokers/ dealers, Altman (1977) on savings and loan associations, and several on manufacturing companies including Altman (1968), Deakin (1972) and Edmister (1972). 
financial characteristics were similar, their ratios could be directly compared. On the other hand, an Australian study (Castagna \& Matolcsy, 1981) combined firms in the manufacturing, retailing, land development, building and accommodation industries. Although no justification was explicitly given for combining these apparently diverse industries, the implicit justification seemed to be the desire for a maximum sample size of failed companies and for a single model to cover all industries. Altman and Izan (1982), appreciating the usefulness of a model for all industries, attempted to. overcome the problem of industry differences by adopting an "industry relative approach": this involved adjusting a firm's "raw ratio" by dividing it by the appropriate industry median.

Size of Samples.

In this study, as in most other such studies, a limiting factor is the number of failed companies for which data can be obtained. This in turn limits the number of subsamples which can be constructed, and hence the number of separate industry models that can be developed.

This study - for the period 1969 to 1978 - compiled the population of failed companies for each of the four industries: in total there were 41 failed companies made up of 13 manufacturing, 9 retail, 15 property and 4 
finance firms.

However the number of nonfailed companies for which data is available is very much larger; this suggests that there might be advantages in departing from "pairing", and matching more than one nonfailed company to each failed one. The advantage of a larger number of nonfailed firms is that it lowers the sample error. This point was raised by Lev $(1974$, p.150). He concluded: "There seems to be no practical or statistical reason why the control group could not be much larger than the failed sample. The main advantage of a large control group will be the decrease in sampling errors of the estimates of the solvent firm's economic characteristics and hence an improvement in the precision of measurements." Lev was supported by Joy and Tollefson (1975, pp.725-726), who argued that in bankruptcy studies the sample size of the more likely group should not be limited by the sample size of the less likely group. In his study Ohlson (1980, p.110) found sample size to be important: he utilized 2058 nonfailed firms compared to 105 failed.

In this failure study, the failed firms which are tested are the whole population of bankrupt companies. If the sample of nonfailed enterprises were the same size, that would represent less than five per cent of the population of surviving companies ${ }^{4}$. To try, therefore, to limit the sample error, unequal sample-sizes were used in this

4. See Table 4 on p. 59. 
investigation: a larger proportion of existing companies were included in the sample by matching, where possible, more than one nonfailed firm to a failed firm. The matched firms are listed in Appendix B. The number of nonfailed firms selected were: 39 manufacturing, 19 retail, 20 property, and 12 finance; a total of 90 surviving firms, or approximately 11 per cent of that population, were matched to the 41 failed companies ${ }^{5}$.

In the application of discriminant analysis most statistical tests are based on an assumption of normality in the data distribution: it would be expected that the larger the number of cases in a homogeneous sample, the more the likelihood of this assumption being met. There is no accepted standard, however, of what constitutes a minimum sample size to satisfy the assumption of normality: there appears to be no criterion other than informed judgement. In using discriminant analysis this judgement is influenced by the fact that previous researchers have described the technique as robust, and considered that the assumption of normality need not be strongly adhered to. Accordingly, this study will derive models from a range of sample sizes: the minimum sample size will be based on single-industry data - excluding the finance industry and the maximum sample size on combined-industry data ${ }^{6}$.

5. See pp.61-62 for an explanation of the process of selecting surviving companies.

6. It has been judged that the number of failed finance firms - four - is too few to derive a model from finance-industry data. 
While single-industry data could be expected to be more homogeneous, combined-industry data may provide a model with a higher level of statistical certainty. The criterion for the selection of the model(s) for subsequent analysis will be classification accuracy.

\section{Matching-sample Criteria}

Studies have relied on the use of a control group of nonfailed companies to investigate the ability of accounting ratios to distinguish between failed and nonfailed firms. The approaches adopted in selecting the nonfailed firms have ranged from a random selection from the population of nonfailed firms to a random selection from firms of similar age, size and industry characteristics. The reasoning behind the approach adopted in this study will now be outlined.

If a characteristic of the firm - in this case, age, size or industry - has no effect on the probability of failure, and is not associated with any other variable that has such an effect, it does not matter whether the characteristic is used as a matching criterion or not: using it as a matching criterion will neither help nor impair the analysis. However, if the characteristic either has a direct effect on the probability of failure, or is associated (either positively or negatively) with a variable that has such an effect, then the question whether to use the characteristic as a matching criterion 
becomes important: there arises a fundamental conflict with any such potential matching criterion and this conflict will now be illustrated.

The object of matching is to reduce the random sampling error, and thus make the statistical tests more sensitive. However, there is a fundamental conflict because tine matching process negates any discriminatory power that the matching characteristic (age, size or industry) may have.

The question to be resolved, in deciding whether to. match by age, size, or industry, is whether there is a variable for the characteristic which could potentially capture riuch or all of its effect, anci thus possibly improve the explanatory power of the function. If there is, the variable should be made available for inclusion in the function, and the characteristic it represents should not be used as a matching criterion. To do otherwise would mean that one would never know whether it has any discriminatory power or not, which is not very satisfactory. If, however, the effect of a characteristic is complex and unlikely to be captured by variables, there is a case for using that characteristic as a matching criterion in order to improve the statistical efficiency of the analysis.

The matching criteria: (a) size of firm, (b) age of firm, (c) industry of firm, will now be considered. The aim will be to suggest a variable (if any) which captures 
the effect of a criterion: then the firms will not be matched by the criterion. Where no such variable exists matching will be by the criterion.

Size of firms. The impact that the characteristic size would have on discriminatory power would be negated by matching by size. However, there is the belief that size could have discriminating power, while size can be measured. Altman et al. (1977, p.31) tested the discriminatory power of asset size by including the logarithm of tangible assets as a variable. The objective of the logarithmic trans-. formation was to help normalize the distribution of the variable. Asset size was retained in their seven-ratio discriminant function because it was found to improve the function's discriminating power significantly. Ohlson (1980, pp.122-123) also found size to be an important predictor.

Since there is a variable to capture the size effect, size will be omitted from the matching criteria: the variable to capture the size effect, logarithm of tangible assets, will be added to the list of variables.

Age of firms. Because of the possibility that age could have some discriminatory power, and there is a ratio which will capture most of any age effect, age will be omitted from the matching criteria. The ratio considered is retained profits to total assets ${ }^{7}$. The age of a firm

7. This ratio, to measure the age of a firm, was first considered by Altman (1968, p.595). 
is implicitly considered in this ratio: a relatively young firm will probably show a low level of retained profits to total assets because it has not had time to build up its cumulative profits, while an older firm could be expected to have built up a higher level of funding from retained profits.

Industry classification. It is recognized that industry characteristics do exist but it does not seem these can be quantified and hence, captured by variables. Any effect of the industry variable on the discriminant. function is so complex that it cannot be adequately captured just by building the variable into the discriminant function. Accordingly firms will be matched by industry manufacturing, retail, property and finance - and separate industry functions will be constructed for each industry. The function will then only be applied to the industry from which it was derived. That is the surest (if not the only) way of capturing industry effects.

The main issues involved in compiling financial data for research and analysis have been outlined. The remainder of the chapter details the process chosen for selection of Australian failed and nonfailed companies.

\section{Time Period for Selection of Failed Companies}

The conclusions from a study using analysis of time series are usually intended for application to the 
prediction of future events; the only data available are, of course, from the past, and the further one goes into the past the less relevant the data become for prediction of the future. Because one can obtain statistical reliability only by going into the past, there is inevitably the dilemma between statistical precision and relevance: one can improve statistical precision by extending one's analysis further into the past, but only at the expense of reduced relevance to the future. This is a universal problem and not just one peculiar to this study.

In this study the question examined is whether the trade-off between statistical significance and relevance is a uniform one, or whether there is a point of time at which relevance to the future drops off sharply. If such a point can be found, the choice of an optimum cutoff date for data inclusion becomes less subjective than if the trade-off is more uniform over a period of time. This study suggests that 1969 was a point at which the Australian economic environment changed sharply enough to warrant using that data as a cutoff point for the start of time series analysis: it began a period characterized by a significant increase in both the rate of inflation and the size of business failures.

The higher rate of inflation in the 1970's made business more hazardous and survival less likely. The 1969 to 1978 period saw an increase in the size of 
business failures. For instance, before 1969 the largest company to collapse was Reid Murray Acceptance with total assets of $\$ 40,000,000$. In the 1970's, however, four companies failed with assets in excess of $\$ 100,000,000^{8}$.

The annual increase in the cost of living index rose from 4 per cent in 1969-1970, to a peak of 15.2 per cent in 1973-1974; the average annual increase was 9.8 per cent over the 1969-1978 period ${ }^{9}$. This high rate of inflation made it hard for firms to finance the increased cost of their operations. Studies by Sheehan \& Rose . (1975) and Mathews (1975) on the impact of inflation on business made particular reference to the difficulty of meeting the increased replacement cost of trading stock and fixed assets. Business management responded by adopting more stringent policies to optimize the funds employed in assets, and by raising profit margins. The financial position of many firms was weakened, however, by their increasing reliance on short-term debt finance; this was caused both by the difficulty in obtaining longterm debt and by the slump in share prices making equity funding more difficult.

This brief review of the financial environment during 1969 to 1978 suggests that the pre-1969 period is less

8. They were Associated Securities Ltd. $(\$ 283,000,000)$, Cambridge Credit Ltd. $(\$ 174,000,000)$, Gollin Holdings Ltd. $(\$ 143,000,000)$, and Mineral Securities Ltd. $(\$ 126,000,000)$.

9. Source - Australian Bureau of Statistics - Consumer Price Index - Quarterly Reports. 
likely to be useful for deriving a model for application in the foreseeable future.

\section{Selection of Failed Companies}

This study has defined "failure" both as the appointment of a receiver or liquidator under the provisions of the Companies Act, and as a forced merger ${ }^{10}$. The two sources used in finding the public companies which had had a receiver or a liquidator appointed during 1969 to 1978 were: the names of delisted companies published by . the Sydney Stock Exchange, and Jobson's Year Books from 1968 to 1978. The stock exchange publication gave the reasons for delisting, which included "the appointment of a liquidator", and "at the request of a receiver". A shortcoming of the stock exchange list, however, was that the appointment of a receiver is not necessarily followed by delisting of the company, so that a company which had "failed", according to our definition, need not appear on the list of delisted companies. As a cross-check, therefore, Jobson's Business Digests were searched for companies which had had receivers or liquidators appointed. By this dual approach all companies which conformed to the first part of the definition of failure were identified.

A review of the failed mining companies showed that they were mainly in the exploration stage, with no mining

10. See p.10 for definition of forced merger. 
income of note. Their survival had depended upon finding and developing a profitable mine before their shareholders' funds were exhausted; the financial statements of these firms indicated that this had not happened and so they had failed. This was in contrast to surviving mining companies which had either discovered an incomeproducing mine, or had some shareholders' funds left to continue exploration. Because univariate ratio analysis of non-income-producing mining firms was not very useful it only indicated the rate at which funds were spent on exploration - it was decided to exclude mining firms from this study.

The list of failed companies was further reduced by eliminating those which had less than three years' financial data prior to failure. It was felt that less than three years' data would be insufficient to assess the trend in a firm's insolvency-risk profile.

The list now consisted of 13 manufacturing, 9 retail, 15 property, and 2 finance companies. Two finance companies, which were subject to a forced merger, were then added to the Iist: Finance Corporation of Australia Ltd., and IAC Holdings Ltd. Both companies, because of losses on property loans, were unable to meet debenture-trustdeed requirements to raise additional funds from the public. To avert their being placed in receivership, they were taken over and the new owners invested additional 
capital in the firms; it was only these rescue operations that prevented the appointment of a receiver or liquidator ${ }^{11}$.

The failed firms selected for research and analysis are listed in Appendix A. The firms are classified by industry; data on year founded, year listed, date of failure, age at failure date, and highest total assets during the three years before failure, have been tabulated.

\section{Characteristics of Failed Firms}

Age. Table 1 lists the average age, within each industry group, of companies which failed between 1969 and 1978: age is defined as the period from when a firm was founded to when it failed.

The average age of failed public companies suggests that age is not a barrier to failure: most failed firms became established in their business and traded for many years before collapsing. There is a significant difference between the age of failure for small firms and public companies. For instance, Williams (1975) found that 87.4 per cent of Australian small business failures

11. The Reserve Bank instructed the parent company of Finance Corporation of Australia Ltd., Bank of Adelaide, to merge with another Australian bank because of the inability of the Bank of Adelaide to finance its ailing subsidiary. One of the world's biggest banks, Citicorp Ltd., was forced by commercial necessity to merge the operations of its financially distressed subsidiary, IAC Holdings Ltd., with its world-wide business. 
from 1960 to 1963 and 1970 to 1973 occurred in businesses less than ten years old ${ }^{12}$; by contrast, only 9.8 per cent of the failed public companies in this study were less than ten years old.

Table 1

Average Age of Failed Public Companies by Industry

$$
1969-78
$$

\begin{tabular}{lc} 
Industry & $\begin{array}{c}\text { Average Age } \\
\text { (yrs.) }\end{array}$ \\
\hline Manufacturing & 48 \\
Retail & 43 \\
Property & 17 \\
Finance & 31
\end{tabular}

Source: Appendix A

12. Smal1 business was defined as employing less than one hundred people. 
Size. The data in Table 2 highlights the fact that failure is not confined to small public companies.

Table 2

Size of Business Failures

\begin{tabular}{ccc} 
Size & Number & Percentage \\
\hline Under \$IM & 2 & 4.8 \\
$\$ 1 M-\$ 5 M$ & 13 & 31.7 \\
$\$ 5 M-\$ 10 M$ & 9 & 22.0 \\
$\$ 10 M-\$ 50 M$ & 10 & 24.4 \\
$\$ 50 M-\$ 100 M$ & 2 & 4.8 \\
Over $\$ 100 M$ & 5 & $\underline{12.3}$ \\
& $\underline{41}$ & $\underline{100.0}$
\end{tabular}

Source: Appendix A

Timing of failure. Table 3 is a frequency distribution of the fiscal year of failure. 
Table 3

Frequency Distribution by Industry of Fiscal Year of failure

No. of Failed Firms Year of Manufacturing Retail Property Finance
Failure

\begin{tabular}{|c|c|c|c|}
\hline 1969 & 2 & 1 & - \\
\hline 1970 & - & 1 & - \\
\hline 1971 & 4 & - & - \\
\hline 1972 & 1 & 3 & - \\
\hline 1973 & - & - & - \\
\hline 1974 & 1 & - & 3 \\
\hline 1975 & 2 & 3 & 3 \\
\hline 1976 & 2 & 1 & 3 \\
\hline 1977 & 1 & - & 5 \\
\hline 1978 & - & - & 1 \\
\hline & 13 & 9 & 15 \\
\hline
\end{tabular}

Source: Appendix A

The failures of manufacturing and retail companies are more evenly distributed over the ten-year period than those of property and finance firms. The fact that manufacturing and retail firms display a fairly constant rate of failure over time suggests that their financial position is influenced less by swings in the business cycle than by other factors. The clustering of failures in property and 
finance companies was expected, because their higher level of borrowing makes them more vulnerable to financial distress when the business cycle turns down.

Company failure rates classified by industry. The formula for calculating the cutoff score, to classify firms into the failed or nonfailed groups, includes the prior probability of failure 13 . An estimate of the probability of a firm's failing during the period 1969 to 1978 was computed by comparing the number of listed companies in 1969 with the number of those companies which subsequently failed. The results, by industry, appear in Table 4.

Table 4

Estimate of Prior Probability of Failure by Industry for the Period $1969-1978$

\begin{tabular}{lccc} 
Industry & $\begin{array}{l}\text { No.of Listed } \\
\text { Industrial Coys. } \\
\text { at } 30.6 .69\end{array}$ & No.Failed & Failure \\
\hline $\begin{array}{l}\text { Manufacturing } \\
\text { Retail }\end{array}$ & 410 & 13 & 3.2 \\
Property & 125 & 15 & 7.2 \\
Finance & 80 & 4 & 18.8 \\
Sub Total & 55 & 41 & 7.3 \\
Other & 670 & - & 6.1 \\
& 180 & -11 & -
\end{tabular}

Source: Jobson's Year Book and Appendix A

13. See pp.26-28 for the formula (including $\mathrm{Z}_{\mathrm{C}}$ ) and its description. 
The estimates indicate variability of the failure rate from industry to industry. The information in this table will be referred to later in this study (see pp. in relation to the possibility of users adjusting the cutoff score of the derived model.

\section{Sources of Financial Information}

The financial statements of the failed and nonfailed companies were obtained from two sources: the sydney stock Exchange Statistical Service (Statex) and company annual reports. The statex service aims to produce comparable data: comparable from one company to the next, comparable in the same company from one year to the next. This service is helpful for a study which compares the financial ratios of one company with the ratios of other companies. The annual reports of the sampled companies were collected because of the additional information contained in them. For instance, footnotes to accounts and qualified auditors' reports could provide useful data for this investigation.

For failed companies, financial statements were obtained for the five years preceding failure. The first year prior to failure is defined as the financial year represented by the financial statements immediately before the date of failure. Since failures occurred from 1969 to 1978 inclusive, the first year before failure includes financial statements for the ten-year period 1968 to 1977 , while the fifth year includes the period 1964 through to 1973. 


\section{Sample of Surviving Companies}

As previously mentioned, to reduce sample error the number of nonfailed companies included in the sample was larger than the number of failed firms. A requirement for the sample frame of surviving companies was that each should have had a life of eight years. This was to exclude the first three years of its existence because the first years of companies are often not typical in the scale and nature of operations. The years chosen, by excluding the unrepresentative early years of young companies, were expected to be more reliable for research purposes.

The sample of nonfailed companies was randomly selected, within the same industry groupings as the failed firms, from Jobson's 1978 Year Book. The matchings of the failed and surviving companies are listed in Appendix B, which also shows the years before failure for which financial statements were obtained.

The sample sizes of the failed and nonfailed companies, by industry, are summarized in Table 5. 
Table 5

Number of Failed and Nonfailed Companies

Chosen for Analysis

\begin{tabular}{lcccc} 
Industry & $\begin{array}{l}\text { Size of Failed } \\
\text { Sample }\end{array}$ & $\begin{array}{l}\text { Size of } \\
\text { Nonfailed } \\
\text { Sample }\end{array}$ & $\begin{array}{l}\text { Total } \\
\text { Size }\end{array}$ & $\begin{array}{l}\text { Estimated } \\
\text { Percentage } \\
\text { of all Firms }\end{array}$ \\
\hline $\begin{array}{l}\text { Manufacturing } \\
\text { Retail }\end{array}$ & 13 & 39 & 52 & 13 \\
Property & 9 & 19 & 28 & 22 \\
Finance & 15 & 20 & 35 & 44 \\
& 4 & 12 & 16 & 29 \\
& - & - & -131 & -
\end{tabular}

Source: Appendix $B$ and Table 4

During the $1970^{\prime} \mathrm{s}$ the number of listed public companies was reduced following significant takeover and merger activity. Because of this, the number of firms still operating in 1978 was much fewer than in 1969. The number of surviving firms in the retail and property industries was markedly reduced and those included in the control group for this study represent most of the firms still operating exclusively in these industries. It is for this reason that the matching of firms in the retail and property industries could not be on a basis of three nonfailed to one failed as applied to the manufacturing and finance industries. 
Summary

This chapter has outlined the steps taken in the selection of firms for further research and analysis. The matching-sample technique has been selected: following analysis of the disputed issues, a method was chosen for its application. The annual financial statements, covering a five-year period for each of the 131 companies, represent a large data base for investigating the ratios of collapsed and surviving companies. The next chapter will deal with the selection of variables to be calculated from these financial statements. 


\section{Chapter 4}

Selection of Financial Variables and Standardization of Accounting Data

The data input required for the application of discriminant analysis includes a list of variables, and financial figures from which the variables can be calculated. This chapter examines both the criteria for identifying the variables to be analysed, and the adjustments needed to standardize the accounting information to ensure that variables are comparable within and between firms.

\section{Selection of Financial Variables}

If there were an established theory of corporate financial distress, the variables to be included in any test of that theory would be specified by the functional form of the theory. In the absence of any widely accepted theory, however, the selection of variables has to be based on individual judgement, and various approaches have been adopted by different researchers.

Beaver (1966, p.78) laid the foundation for further research when he selected thirty ratios, each meeting at least one of three criteria: the ratio had appeared frequently in the literature, it had performed well in one of the previous studies, or the ratio could be defined in terms of a cash-flow concept. 
In his first study Altman (1968, p.594) chose twentytwo ratios "... on the basis of their (1) popularity in the literature, (2) potential relevancy to the study, and a few 'new ratios' initiated in this paper." There was no indication given, however, of the criteria used in deciding if a ratio was potentially relevant to the study. The new ratios were: Retained earnings/Total Assets and Market value of equity/Book value of total debt; both these ratios were included in his best discriminant function.

In a later study Altman et al. (1977, p.32) had twenty-seven variables. These comprised: "A number of financial ratios and other measures ... found to be helpful in providing statistical evidence of impending failures ... and in addition ... several 'new' measures that were thought to be potentially helpful as well." These new variables were: size (assessed by the logarithm of gross tangible assets), earnings variability (defined as the standard error of estimate around a ten year trend in earnings before interest and tax to total assets), and the proportion of total assets which are leased. In addition, to smooth out possible severe temporary fluctuations in the sharemarket valuation of a company, they measured the market value of equity by a five-year average of the total market value; this differed from Altman's (1968) study where the market value of equity was based on a firm's share price at balance date. 
involving Altman (1968, 1977), three were included in his 1977 best function: Retained earnings/Total assets, Log. of gross tangible assets, and Earnings variability. The ratio in the 1968 function, Market value of equity/Book value of total debt, was replaced in the 1977 model by Market value of equity/Total capital, total capital being defined as the sum of the book value of total debt and the market value of equity. In both models, the discriminatory power of the ratio involving the market value of equity was found superior to the same ratio which defined equity at its book value.

Quite a different approach was adopted by Blum (1974). who ignored both popularity in the literature and significance in previous research. His framework for the selection of variables was to describe the business firm as a reservoir of financial resources and to define its probability of failure in terms of the expected flow of those resources. This description is referred to as the liquidasset-flow model of a firm, with three common denominators: liquidity, profitabizity, and variability. He suggested that one would expect failure to be more likely

1. the smaller the reservoir of financial resources,

2. the smaller the inflow of financial resources from operations in both the short and long run,

3. the larger the claims on financial resources by creditors, 
4. the greater the outflow of financial resources required by the operation of the business, and

5. the more highly variable the earnings and claims against resources, represented by outflows to maintain current operations and by obligations to creditors.

Blum used twelve variables derived from his three common denominators:

\section{Liguidity:}

A. Short-run liquidity

Flow: 1. 'Quick flow' ratio'

Position: 2. Net quick inventory

B. Long-run liquidity

Flow: 3. Cash flow/total liabilities

Position: 4. Net worth at fair market value/total liabilities

5. Net worth at book value/ total liabilities

2. Profitability:

6. Rate of return to common shareholders who invest for a minimum of 3 years

3. Variability:

7. Standard deviation of net income over a period

8. Trend breaks for net income ${ }^{2}$

9. Slope for net income 10 - 12. Standard deviation, trend breaks and slope of the ratio, net quick assets/ inventory

1. The 'quick flow' ratio was defined as: Cash and Notes Receivable and Market Securities and (Annual Sales divided by 12) divided by (Cost of Goods Sold Depreciation Expense and Selling and Administrative Expense and Interest) divided by 12 .

2. A trend break is defined as any performance by a variable less favourable in one year than in the preceding year, such as a decline in income from $\$ 10,000$ to $\$ 1,000$ from year 4 to year 3 before failure. 
Lev (1971, pp.102-111) researched the usefulness of the balance sheet decomposition measure (BSDM) in assessing the financial risk of firms ${ }^{3}$. He expected that since the measure indicates the relative stability of the components in a balance sheet, failing firms - which usually experience substantial change in the relationship of items comprising the assets and equities groups - will have on the average larger measures than the solvent firms. His results confirmed this expectation, and he suggested that one should look at the change in classification accuracy resulting from the addition of BSDM to determine whether that addition improved performance.

\section{Variable Selection Procedure Used by This Study}

This review of the approach to variable selection adopted by previous researchers suggests that there are two sources of financial information from which data can be obtained: annual financial statements and sharemarket prices. This study will not select variables which incorporate share prices, on the grounds that, whatever

3. The BSDM is defined as:

$$
\text { BSDM }_{n}=\sum_{i=1}^{2} \sum_{j=1}^{2} q_{i j} \log \frac{q_{i j}}{p_{i j}}
$$

where $\mathrm{q}_{11}=$ current assets in year $n$ divided by $2\left(\mathrm{TA}_{n}^{*}\right)$; $\mathrm{q}_{12}=$ current liabilities in year $\mathrm{n}$ divided by $2\left(\mathrm{TA}_{\mathrm{n}}\right)$; $\mathrm{q}_{21}=$ long-term assets in year $\mathrm{n}$ divided by $2\left(\mathrm{TA}_{n}\right)$; $\mathrm{q}_{22}=$ long-term liabilities and equity in year $\mathrm{n}$ divided by $2\left(T A_{n}\right)$; and $p_{11}, p_{21}, p_{12}$ and $p_{22}$ correspond to similax subscripted $\mathrm{q}^{\prime} \mathrm{s}$, but relate to year $\mathrm{n}-1$. (*TA $=$ Total Assets). 
they might contribute to classificatory power, they are unable to contribute to explanation. At least some of the factors that influence a Eirm's share price will also be reflected in variables which appear in a firm's financial statements. To the extent that this is so, the analysis would be confused; it would be impossible to determine how much of the share-price fluctuation was due to variables already being considered from financial statements, and how much was caused by other factors.

In selecting the variables from a firm's financial. statements, this study aims to ensure that no arbitrary limit is placed on the number that could be used. Only in this way could one feel confident that one was working towards the optimum model.

There were five steps involved in compiling the variables for consideration. These were:

1. Financial streams were developed from typical accounting items in the profit statement and balance sheet of a public company.

2. The financial streams were linked into a flow chart consisting of their accounting items.

3. Paths of accounting items were traced from the flow chart.

4. A combination of ratios was obtained from the accounting items in a path. A selection was 
then made of those combinations which would be used for subsequent discriminant analysis.

5. Variables were added to the selected combinations to take into account both firm size and variability in balance sheet items and income flows.

These five steps are now considered in detail.

The development of financial streams. From the annual accounts of public companies six streams of financial information were defined: profit, cash flow, assets, liabilities, shareholders' funds, and working capital. These streams are detailed in Figure 2 .

Flow chart of financial streams. The accounting items in the financial streams were next linked to form a flow chart. The constraint adopted in linking items was that they must be mathematically independent. For instance, in the asset stream, current assets (CA) plus fixed assets (FAI) equals total assets (TAI), and the ratios CA/TAI and FAI/TAI are functionally related because their total equals one; thus if one ratio is defined explicitly the other is defined implicitly. If $C A$ and FAI were linked to TAI on the same paths the ratios of that path would not be independent. Without independence of ratios, there is a risk that a ratio might be chosen for inclusion in the model because of its functional relationship to another ratio, and not because of its ability to discriminate 
(1) Profit Stream

Profit Available ordinary Shareholders PO

+ Preference Dividend

$=$ Net Profit

$\stackrel{+P D}{=N \mathrm{~N}}$

+ Minority Interests Share of Profit

= Net Operating Profit

$\stackrel{+\mathrm{MIP}}{=\mathrm{NOP}}$

+ Tax

= Net Operating Profit Before Tax

$\frac{+\mathrm{TAX}}{=\mathrm{PBT}}$

+ Interest

= Net Operating Profit Before Interest and Tax

+ INT

(2) Cash Flow Stream

Net operating Profit

NOP

+ Depreciation and Long Service Leave

= Cash Flow

$\stackrel{+D L S}{=C F}$

$+\operatorname{Tax}$

= Cash Flow Before Tax

+TAX

$\overline{=\mathrm{CFBT}}$

(3) Asset Stream

Quick Assets

$\mathrm{QA}$

+ Stock

= Current Assets

+ STOCK

+ Fixed Assets

$=C A$

= Total Assets

+ FAI

(4) Liabilities Stream

Quick Liabilities

+ Bank Overdraft

= Current Liabilities

+ Deferred Liabilities

= Total Liabilities

QL

$+\mathrm{BO}$

$+\mathrm{DL}$

(5) Shareholders' Funds Stream

Ordinary Capital o $O C$

+ Retained Profits

= Ordinary Capital + Retained Profits

$+\mathrm{RP}$

+ Other Reserves

= Ordinary Shareholders' Funds

$+\mathrm{OTH}$

+ Preference Shares

= Shareholders' Funds

$=$ SFO

+ Minority Interests

= Shareholders' Funds + Minority Interests

$+\mathrm{PS}$

$\overline{=S E I}$

$+\mathrm{MI}$

$\overline{=S F I M}$

(6) Working Capital Stream

Current Assets

- Current Liabilities

= Working Capital

$\mathrm{CA}$

$\frac{-C L}{=W C}$

Figure 2. Financial Streams of Typical Accounting Items in the Profit Statement and Balance sheet for a Public Company. 
between failed and nonfailed companies.

Using asset, liabilities, working capital and shareholders' funds streams, flow chart 1 was formed (see Figure 3).

On this chart, various paths can be traced: they might commence at working capital (WC), quick assets (QA) or stock (STOCK), then move to current assets (CA), subsequently take the total assets (TAI) or fixed assets (FAI) route, and finally follow the liabilities or shareholders' funds stream. By way of illustration, two examples of paths are given, one being traced in red, the other in blue. The path beginning at QA, passing through TAI, and pursuing the liabilities course is depicted in red. The financial items on this path are QA, CA, TAI, $T L, C L$, and $Q L$. The ratios in this combination would be:

$\frac{\mathrm{QA}}{\mathrm{CA}}, \frac{\mathrm{QA}}{\mathrm{TAI}} \frac{\mathrm{QA}}{\mathrm{TL}}, \frac{\mathrm{QA}}{\mathrm{CL}}, \frac{\mathrm{QA}}{\mathrm{QL}}, \frac{\mathrm{CA}}{\mathrm{TAI}} \frac{\mathrm{CA}}{\mathrm{TL}}, \frac{\mathrm{CA}}{\mathrm{CL}}, \frac{\mathrm{CA}}{\mathrm{QL}}, \frac{\mathrm{TAI}}{\mathrm{TL}}, \frac{\mathrm{TAI}}{\mathrm{CL}}, \frac{\mathrm{TAI}}{\mathrm{QL}}, \frac{\mathrm{TL}}{\mathrm{CL}}, \frac{\mathrm{TL}}{\mathrm{QL}}, \frac{\mathrm{CL}}{\mathrm{QL}}$ All the ratios are functionally independent ${ }^{4}$.

There are many other balance-sheet-ratio combinations possible: all start at WC, $Q A$, or STOCK and conclude at the end of a line. Another combination is shown in blue. Seven

4. It should be noted, however, that if some of the potential components are absent (zero valued), two or more of the functionally independent ratios could turn out to be numerically identical. The implications of this fact will be discussed shortly. 


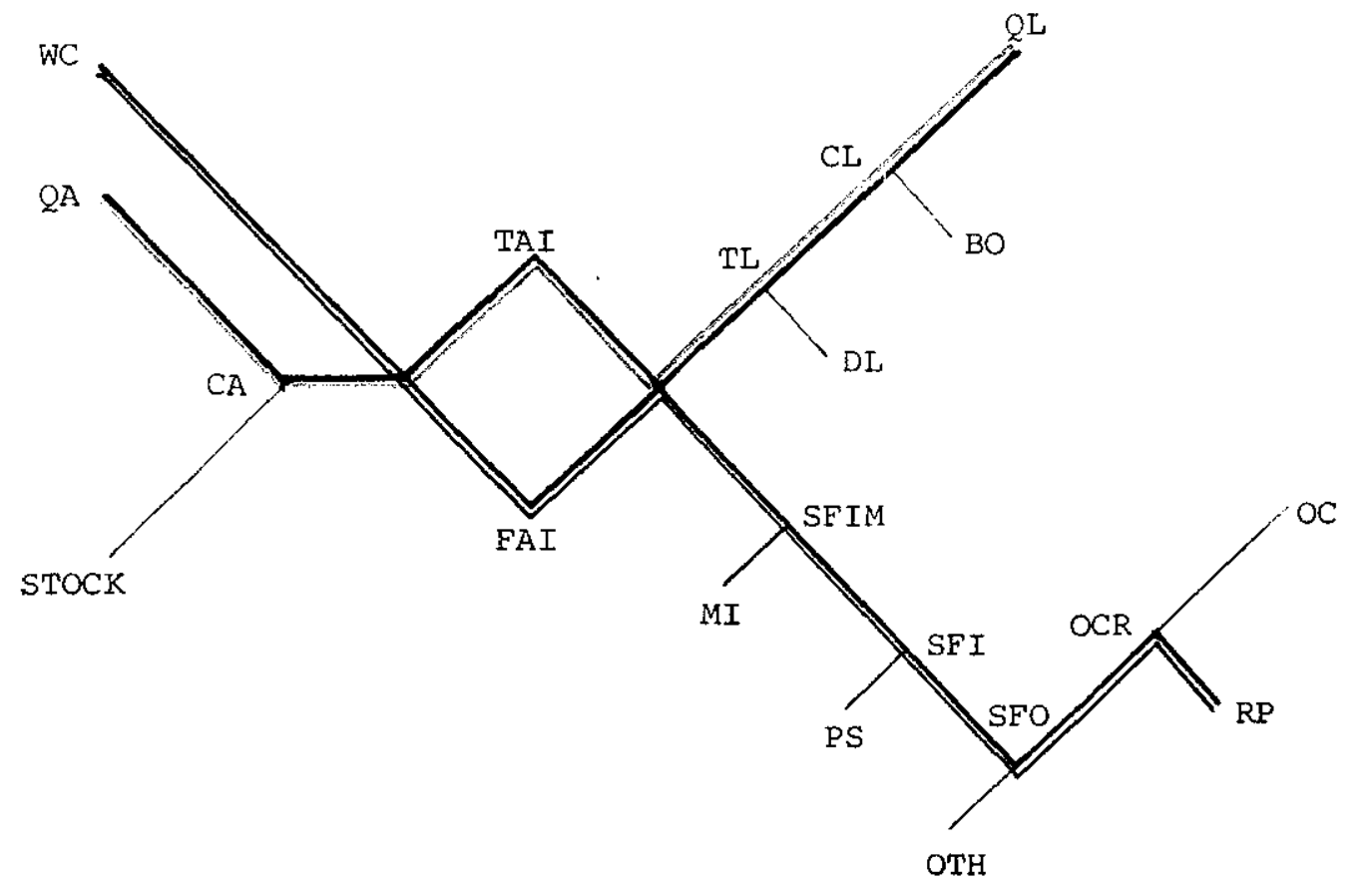

Figure 3. Flow chart 1 : assets, liabilities, working capital and shareholders' funds streams.

WC (working capital)

QA (quick assets)

STOCK (stock)

CA (current assets)

TAI (total assets)

FAI (fixed assets)

TL (total liabilities)

DL (deferred liabilities)

CL (current liabilities)

QL (quick liabilities)

BO (bank overdraft)

SFIM (shareholders' funds including minority interests)

\section{GLOSSARY}

MI (minority interests)

SFI (shareholders' funds excluding minority interests)

PS (preference shares)

SFO (ordinary shareholders' funds)

OCR (ordinary capital and retained profits)

OTH (reserves in shareholders' funds)

oc (ordinary capital)

RP (retained profits) 
items comprise this path: working capital (WC), fixed assets (FAI), shareholders' funds including minority interests (SFIM), shareholders' funds excluding minority interests (SFI), ordinary shareholders' funds (SFO), ordinary capital and retained profits (OCR), and retained profits (RP). Twenty-one independent ratios may be derived from this path. Forty-eight such paths can be traced on flow chart 1 , each giving rise to a number of ratios.

In the next stage, the flow chart is augmented by . including the items from the profit and cash-flow streams: the resulting flow chart 2 is shown in Figure 4 . Once again, a typical path has been traced in red: the number of functionally independent ratios in this path is seventyeight. More than one hundred such paths may be traced on flow chart 2 , each giving rise to a number of ratios.

However, a number of items in the cash flow, profit, and shareholders' funds streams can, in some cases, have the same numerical value for one firm. For instance, in the profit stream of a loss company which did not pay tax, and had no preference shares or minority interests, the following items would all have the same value: net operating profit before tax (PBT), net operating profit after tax (NOP), net operating profit after tax and minority interests (NP), and net operating profit after tax, minority interests, and preference dividends (PO). Because there was no tax payable, the two items in the cash 


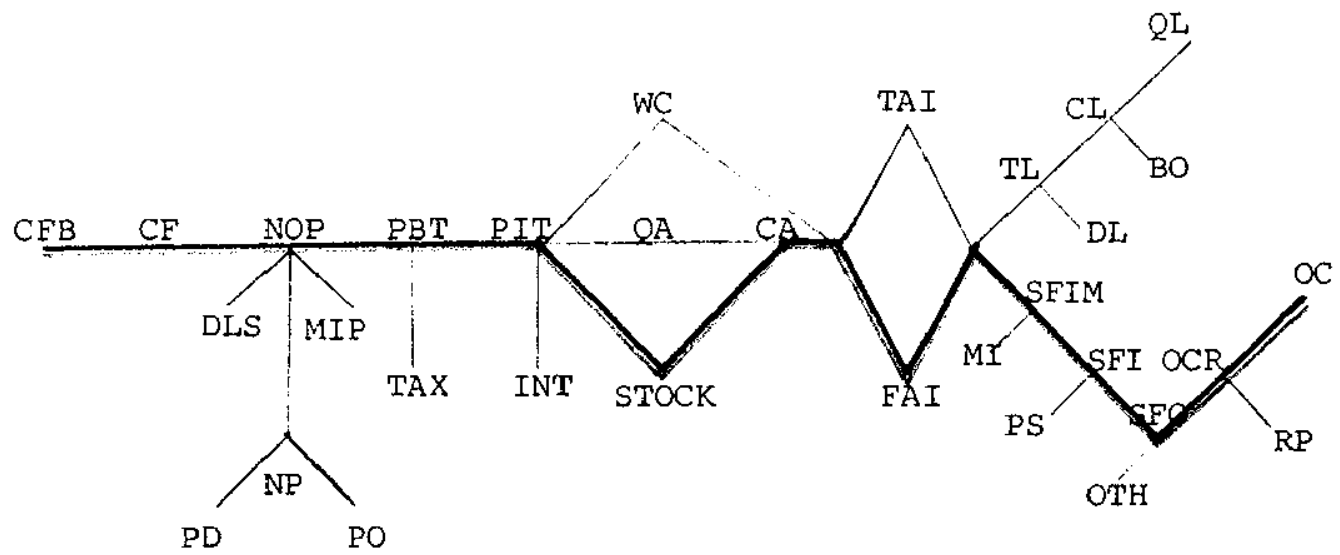

Figure 4. Flow chart 2 : cash flow, profit, assets, liabilities, working capital, and shareholders' funds streams.

\section{GLOSSARY}

\begin{tabular}{|c|c|}
\hline $\mathrm{CFB}$ & (cash flow before tax) \\
\hline $\mathrm{CF}$ & (cash flow after tax) \\
\hline NOP & $\begin{array}{l}\text { (net operating profit } \\
\text { after tax) }\end{array}$ \\
\hline DLS & (non cash charges) \\
\hline $\mathrm{PD}$ & (preference dividend) \\
\hline PO & $\begin{array}{l}\text { (net operating profit } \\
\text { after tax, minority } \\
\text { interests and preference } \\
\text { dividends) }\end{array}$ \\
\hline MIP & $\begin{array}{l}\text { (minority interests share } \\
\text { of profit) }\end{array}$ \\
\hline $\mathrm{NP}$ & $\begin{array}{l}\text { (net operating profit after } \\
\text { tax and minority interests) }\end{array}$ \\
\hline $\mathrm{PBT}$ & $\begin{array}{l}\text { (net operating profit before } \\
\operatorname{tax})\end{array}$ \\
\hline TAX & (tax payable) \\
\hline $\mathrm{PIT}$ & $\begin{array}{l}\text { (net operating profit before } \\
\text { interest and tax) }\end{array}$ \\
\hline $\mathrm{INT}$ & (interest) \\
\hline WC & (working capital) \\
\hline$Q A$ & (quick assets) \\
\hline STOCK & (stock) \\
\hline $\mathrm{CA}$ & (current assets) \\
\hline
\end{tabular}

TAI (total assets)

FAI (fixed assets)

TI (total liabilities)

DL (deferred liabilities)

cr, (current liabilities)

QL (quick liabilities)

BO (bank overdraft)

SFIM (shareholders' funds including minority interests)

MI (minority interests)

SFI (shareholders' funds excluding minority interests)

SFO (ordinary shareholders' funds)

OCR (ordinary capital + retained profits)

OTH (reserves in shareholders' funds)

OC (ordinary capital)

$\mathrm{RP}$ (retained profits) 
flow stream would also be equal: cash flow before tax (CFB) and cash flow after tax (CF). Where either a profitable firm, or a business incurring a loss, did not have minority interests or pre:erence shares, a similar situation - of items having the same numerical value - would exist in the shareholders' funds stream: shareholders' funds including minority interests and preference shares (SFIM) would equal shareholders' funds including preference shares (SFI) and ordinary shareholders' funds (SFO). Where two ratios may be identical in value, the usefulness of including them separately in a discriminant analysis may be severely impaired if such numerical identities arise with any frequency. Accordingly it was decided to make a choice between those items in each fund's stream which could be of equal value for a firm. These choices will now be discussed in detail.

Since the cash flow provides an indication of a firm's capacity to meet commitments, and since a tax commitment is included among the liabilities of profitmaking companies, cash flow before tax (CFB) was preferred to cash flow after tax (CF). To use CF would involve an inconsistency when it is related to quick liabilities ( $Q L$ ), current liabilities (CL) or total Iiabilities (TL). This is because tax would have been deducted from $C F$ but retained in $Q L, C L$ or $T L$. 
numerical value, net operating profit after tax (NOP) was selected. The composition of firm ownership varied from ordinary shareholders only to ordinary, preference and minority shareholders. Because of this inconsistency in ownership and claims to assets, NOP had the advantage, for inter-firm comparison, of representing the return to all shareholders and the return on total assets.

The cash flow and profit streams now consisted of only three items: cash flow before $\operatorname{tax}(\mathrm{CFB})$, net operating profit after tax (NOP), and profit before interest and tax (PIT). These were not combined to form ratios, because in loss companies all could be negative; the calculated ratios would be positive, as would the same ratios for profitable companies. The combining of these three items into ratios would, therefore, not serve any purpose in explaining the financial characteristics of failed and nonfailed companies.

Because the profit and cash flow figures being used are taken before deductions for minority interests and preference dividends, the appropriate variable in the shareholders' funds stream is shareholders' funds before these deductions (SFIM) .

Flow chart 2 was now amended and a new flow chart 3 became the basis of arriving at combinations of ratios (see Figure 5). It will be noted that OTH (reserves in shareholders' funds) has been added to RP (retained profits). This follows an expanded definition of RP (see p.88) and the omission of asset revaluation reserve from the balance sheet (see p. 86). 


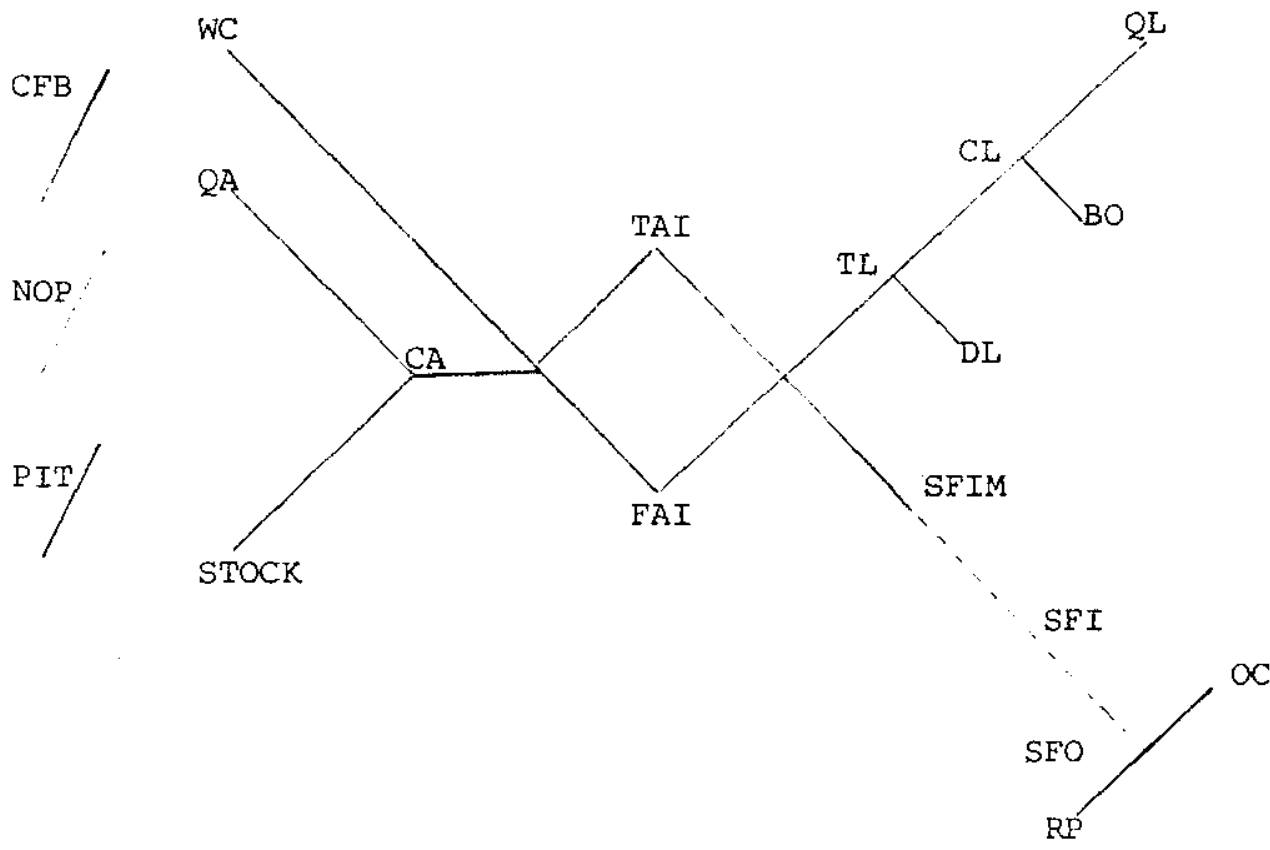

Figure 5. Flow chart 3 : cash flow, profit, assets, liabilities, working capital and shareholders' funds streams.

\section{GLOSSARY}

\begin{tabular}{|c|c|}
\hline CFB & (cash flow be for \\
\hline NOP & $\begin{array}{l}\text { (net operating p } \\
\text { after tax) }\end{array}$ \\
\hline PIT & $\begin{array}{l}\text { (net operating pr } \\
\text { before interest } \\
\text { tax) }\end{array}$ \\
\hline WC & (working capital) \\
\hline$Q A$ & (quick assets) \\
\hline STOCK & (stock) \\
\hline $\mathrm{CA}$ & (current assets) \\
\hline TAI & (total assets) \\
\hline FAI & (fixed assets) \\
\hline
\end{tabular}

\begin{tabular}{|c|c|}
\hline DL & (deferred liabilities) \\
\hline$C L$ & (current liabilities) \\
\hline QL & (quick liabilities) \\
\hline $\mathrm{BO}$ & (bank overdraft) \\
\hline OC & (ordinary capital) \\
\hline $\mathrm{RP}$ & (retained profits) \\
\hline SFIM & $\begin{array}{l}\text { (shareholders' funds } \\
\text { including those of } \\
\text { minority interests and } \\
\text { preference shareholders) }\end{array}$ \\
\hline SEI & $\begin{array}{l}\text { (shareholders' funds excluding } \\
\text { minority interests) }\end{array}$ \\
\hline SFO & (ordinary shareholders' funds) \\
\hline
\end{tabular}


Selection of paths of financial items. In deciding the combinations of items for the application of discriminant analysis it was noticed that there were three sectors of paths which were duplicated. In these instances a decision was required on which route to follow: quick assets (QA) or stock (STOCK), total assets (TAI) or fixed assets (FAI), and liabilities or shareholders' funds.

The QA path was chosen instead of the STOCK path because it is a better measure of liquidity. For instance, QA specifies the funds that will be converted into cash. $\overline{Q L}$ fairly quickly (QA) to pay bills which have to be met almost immediately (QL); the alternative $\frac{\mathrm{STOCK}}{\mathrm{QL}}$ is less relevant to the ability of a business to meet its shortterm commitments.

The TAI path was preferred to the FAI path because of the more complete information in ratios using total assets rather than fixed assets. For example, $\frac{T L}{\mathrm{TAI}}$ indicates the proportion of total funds financed by debt; $\frac{T L}{F A I}$ would not be as comprehensive, describing only the relationship of debt to a long term use of funds, fixed assets.

The third choice was between the liabilities path and the shareholders' funds path. There was no need for both, since total liabilities (TL) plus shareholders' funds (SFIM) equals total assets (TAI). The lizbilities path was selected because of the value of information concerning the composition of debt, in particular the relaticin between 
short-term and long-term debt.

It had previously been decided that since the firms were not being matched by age, the ratio retained profits (RP) to total assets (TAI), would be included to see if there was any predictive value in the age variable (see p.49). Since there was no mathematical conflict between RP and the assets and liabilities streams, it was, in fact, related to all the chosen balance sheet items.

Combination of ratios. Figure 6 shows the result of the selection process described in the preceding section: there are now only two flow charts, giving rise to two sets of ratios. Combination 1 consisting of thirty-nine ratios, and combination 2 comprising thirty ratios, will both be used to derive models. The classification accuracy of the models will then be compared and that combination which is found to have the higher accuracy will be used for further analysis.

Additional variables. To measure the impact on classificatory power of both size, and variability in the structure of the balance sheet and level of profits, additional variables were then included in that combination with the higher classification accuracy. 


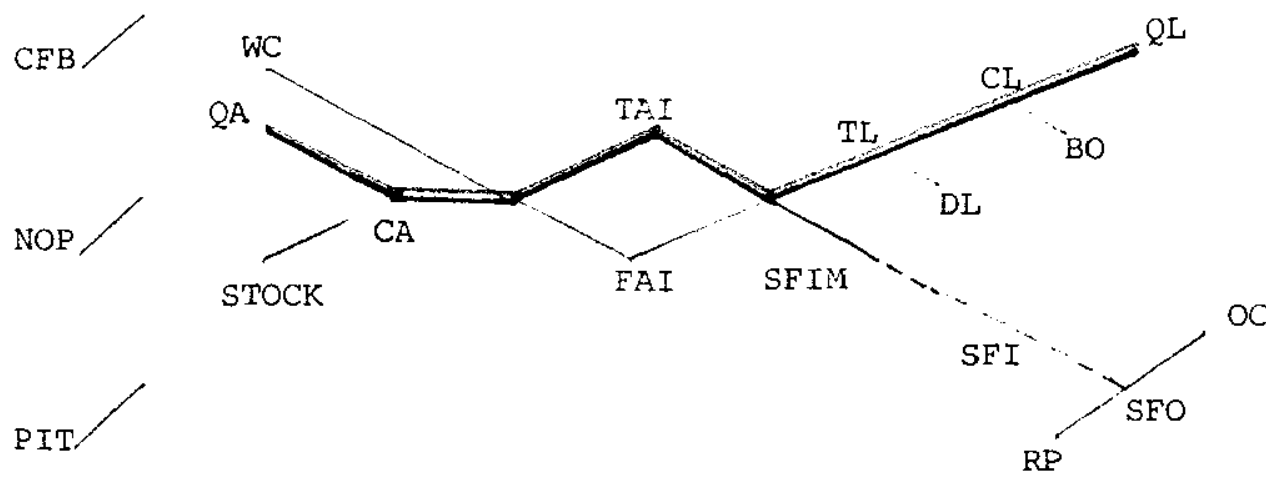

RATIOS

$\frac{C F B}{Q A}, \frac{C F B}{C A}, \frac{C F B}{T A I}, \frac{C F B}{T L}, \frac{C F B}{C L}, \frac{C F B}{Q L}, \frac{N C Z}{C A}, \frac{N O P}{C A}, \frac{N O P}{T A I}, \frac{N O P}{T L}, \frac{N O P}{C L}, \frac{N O P}{Q L}$,

$\frac{P I T}{Q A}, \frac{P I T}{C A}, \frac{P I T}{T A I} ; \frac{P I T}{T L}, \frac{P I T}{C L}, \frac{P I T}{Q L}, \frac{Q A}{C A}, \frac{Q A}{T A I}, \frac{Q A}{T L}, \frac{Q A}{C L}, \frac{Q A}{Q L}, \frac{C A}{T A I}, \frac{C A}{T L}$,

$\frac{C A}{C L}, \frac{C A}{Q L}, \frac{T A I}{T L}, \frac{T A I}{C L}, \frac{T A I}{Q L}, \frac{T L}{C L}, \frac{T L}{Q L}, \frac{C I}{C I}, \frac{Q A}{R P}, \frac{C A}{R P}, \frac{T A I}{R P}, \frac{T L}{R P}, \frac{C L}{R P}, \frac{Q L}{R P}$

\section{COMBINATION 2}

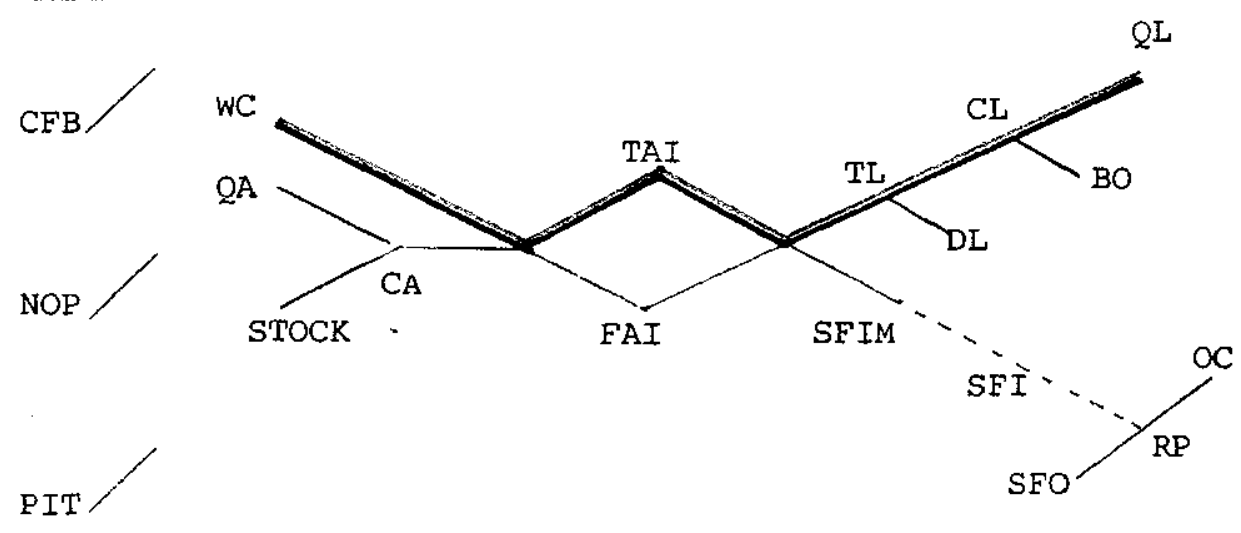

RATIOS

$\frac{C F B}{W C}, \frac{C F B}{T A I}, \frac{C F B}{T L}, \frac{C F B}{C L}, \frac{C F B}{Q L}, \frac{N O P}{W C}, \frac{\text { VOP }}{T F I} \frac{\text { NOP }}{T I} \frac{\text { NOP }}{C L}, \frac{N O P}{Q I}, \frac{P I T}{W C} \frac{\text { PIT }}{\text { TAI }}$

$\frac{\mathrm{PIT}}{\mathrm{TL}}, \frac{\mathrm{PIT}}{\mathrm{CL}}, \frac{\mathrm{PIT}}{\mathrm{QL}}, \frac{\mathrm{WC}}{\mathrm{TAI}}, \frac{\mathrm{WC}}{\mathrm{TL}}, \frac{\mathrm{WC}}{\mathrm{CL}}, \frac{\mathrm{WC}}{\mathrm{QL}}, \frac{\mathrm{TAI}}{\mathrm{TL}}, \frac{\mathrm{TAI}}{\mathrm{CL}}, \frac{\mathrm{TAI}}{\mathrm{QL}}, \frac{\mathrm{TL}}{\mathrm{CL}}, \frac{\mathrm{TL}}{\mathrm{QL}}, \frac{\mathrm{CL}}{\mathrm{QL}}$

$\frac{\mathrm{RP}}{\mathrm{WC}}, \frac{\mathrm{RP}}{\mathrm{TAI}}, \frac{\mathrm{RP}}{\mathrm{TL}}, \frac{\mathrm{RP}}{\mathrm{CI}}, \frac{\mathrm{RP}}{\mathrm{QL}}$

Figure 6. Flow chart 4: patrs 3 d ratios for combination 1 and combination 2 . 
The size of a firm is measured by its total funds employed, defined here as TAI. The logarithm of TAI will be used to help normalize the distribution of this variable.

The structural change in a balance sheet between two consecutive years will be measured by the single statistic, balance sheet decomposition measure (BSDM). A balance sheet is classified into four basic categories: current assets, current liabilities, fixed assets and deferred liabilities plus shareholders' funds; a BSDM is the change in the relationship of the four categories over a twelvemonth period. By comparing decomposition values between failed and nonfailed firms any important structural changes in the balance sheets of the two groups can be identified.

In measuring variability of profit (or stability of earnings) Blum (1974, p.16) used the absolute figure for net profit; this is in contrast to Altman et al. (1977, p.34) who related earnings before interest and tax (PIT) to total assets (TAI). This study will follow Altman's lead because an earnings figure is more useful for interpretation when related to the funds employed in earning that profit. Also PIT neutralizes any variation in earnings caused by factors largely outside the firm's control - changes in both interest and tax rates - and this results in more consistent data for comparison purposes. The variability measure used here will be the standard error of estimate around a six-year trend: for 
instance, for year five before failure, the standard deviation will be calculated for years five to ten, and then for eacin year closer to failure, the last year will be dropped off. By comparing the standard deviations from six-year trends in PITTAI, any important differences in the variability of profit return on investment can be identified for the failed and nonfailed groups.

In summary, besides the variables listed in Figure 6 , three additional ones will be available for inclusion in discriminant functions: $\log$ TAI, BSDM, and standard error of estimate of PITTAI.

\section{Standardizing Financial Statements}

The object of standardizing financial statements is to produce comparable data. The treatment of an accounting item can vary from firm to firm; in addition, during the period covered by this study there had been some changes in accounting standards. Allowance was made for these factors in bringing the accounting information to a consistent basis over the 1964 to 1978 time-span. This involved both the reported profits and balance sheet items.

\section{Adjustments to Profit Measurement}

The net operating profit for each firm was obtained from the sydney stock exchange statistical service (Statex). This service aims to present data in standardized form, so 
as to facilitate comparisons between companies. In particular, statex explains that it frequently adjusts the reported profits of companies ${ }^{5}$. These adjustments mainly ir.volve items which are of a nonoperating nature, or apply to other years, or concern an accounting treatment not widely accepted. The operating profit figure of a company published by statex is accepted for this study. However, further amendments to the statex figure are made in cases where firms prepare their accounts on the principles of equity accounting or tax effect accounting.

Equity accounting became an accepted principle towards the end of the period covered by this investigation. If a company owned from twenty per cent to just below fifty per centof another firm, it could include in its profit the appropriate proportion of the associated company's profit. Before equity accounting, only the dividend received from the associate company had been included in the profit of the investing company. To obtain comparable profit figures, the accounts of companies using equity accounting were adjusted: profit was reduced by the amount of the unrealized profit, as were the balance sheet items, investment in associated companies, and equity profit reserve in shareholders' funds.

5. The adjustments listed on page 1.31 of the 1979 Stock Exchange Financial and Profitability study were: profits/ losses on sale of fixed assets, amortization of intangible assets, utilization of prior years' tax losses, prior period adjustments, provisions for fluctuations and contingencies, non-recurring abnormal items, provision for unexpired risks, and non-standard treatment of depreciation. 
Tax effect accounting was added to Australian accounting standards in 1975. Companies which practise this form of accounting can reduce a current trading loss by taking into account a future tax benefit resulting from the loss. For comparative purposes, this study made adjustments to the accounts of all such companies by reversing the tax effect accounting entry. The consequence of this amendment was to reduce the profit figure (or increase the loss), and to decrease the two balance sheet items, retained profits in the shareholders' funds and future tax benefit in the assets.

\section{Adjustments to Balance Sheet Items}

Besides the adjustments outlined above for tax effect accounting and equity accounting, the standardization of balance sheet items required some further adjustments. These are now considered under the heading of: goodwill, asset revaluation reserve, investments, preference shares, provision for long-service leave and retained profits.

Goodwill. Some firms showed goodwill as an intangible asset, and others as a deduction from equity. The argument for the latter classification is the difficulty of assigning an economic value to goodwill; the total asset figure after removing goodwill is, therefore, a more appropriate figure for ratio analysis. The above argument was accepted for this study and the approach taken was to treat goodwill as a deduction from equity. Other intangible 
assets were similarly treated.

Asset revaluation reserve. There is no standard practice regarding revaluation of assets; for example, companies may suddenly revalue as a defence against takeover. To meet the objective of obtaining comparable data, asset revaluation reserve was deducted from fixed assets and eliminated from shareholders' funds. It was realized that this could hinder comparability in two instances: where firms had a bonus issue of shares from their asset revaluation reserve, and where a revalued asset was sold. During the period. of the study few firms had bonus share issues; where this did occur the value of the issue was added back to asset revaluation reserve, and the new figure deducted from fixed assets and shareholders' funds. However, adjustments were not made where a revalued asset was sold, because of the difficulty in obtaining the revaluation component in its book value. Due to the fact that not all firms had revalued assets and those that did chose different years, it was decided to omit the asset revaluation from the balance sheet - despite possible anomalies described above in comparing firms which had revalued their assets.

Investments. The issue is whether investments in companies listed on prescribed stock exchanges should be classified as a current asset or a fixed asset . The basis

6. Investments could not be shown separately because many companies did not have investments and, therefore, sample size constraints required this item to be included with either current assets or fixed assets. 
of classification of investments which seems most appropriate is that of intention. An examination of the five balance sheets for each firm showed little change in the book value of the investment item "shares in listed public companies." This indicates that the intention of management was to hold the shares for the long term. In this study such investments will, therefore, be classified as fixed assets. Although market value at the balance date is given as a footnote, this study will value investments at cost price: this is consistent with the basis of valuation of other assets. Other investment items - shares in unlisted companies, and loans with a maturity date longer than one year from balance date - will also be recorded as fixed assets.

Preference shares. It could be argued that in a study on financial risk preference shares should be classified as a liability and preference share dividends as an interest expense. This is because preference shares carry a fixed rate of dividend and redeemable preference shares are repayable on a fixed date.

It was decided, however, not to adjust the standard classification of preference shares and their dividends: preference shareholders, unlike lenders, cannot place a firm in receivership if the preference dividend is passed; they are therefore not a source of financial risk. 
Provision for long-service leave. Firms had different practices for classifying the provision for long-service leave: some classified it as a current liability, others as a deferred liability, whilst others again allocated a part to each liability category. In theory long-service leave should be apportioned between the liability categories, the amount payable within twelve months being classified as "current" and the remainder as "deferred". Where there was no apportionment the lack of information meant that any apportionment adopted here would be arbitrary. For consistency it was decided to adopt what . seemed to be the policy of most firms: classify provision for long-service leave as a current liability.

Retained profits. In Figure 5, the definition of retained profits covers all appropriations of profit. The item includes, therefore, all components of shareholders' funds such as general reserve, stock fluctuation reserve, plant replacement reserve, and the balance of unappropriated profits.

\section{Limitations of Financial Statements}

A limitation of the financial data used in this investigation, compared with that available for overseas research, was the lack of information on sales figures and lease commitments.

Before 1971, most Australian companies did not report 
sales figures, but from that year on they have been required to do so. Because the financial statements used in this study commence from 1964 and many firms did not publish sales figures until 1971, the limited sales information was not used; the number of failed companies with disclosed sales was below the accepted minimum for discriminant analysis. Any Euture models using accounting information from 1971 onwards will benefit from the availability of ratios relating to sales after that date.

Altman et a1. (1977, p.33) made adjustments to annual reports by capitalizing leases. They regarded this as their most important amendment, made possible by the mandatory footnotes in financial statements. In Australia, companies are not required to reveal in accounts the extent of their lease commitments. This is unfortunate because leasing has become an increasingly important source of finance for business. It is essentially a form of debt finance, and analysis of the financial stability of firms suffers because of the lack of information on this offbalance sheet source of finance.

\section{Summa ry}

This chapter has outlined both the method of selecting the variables for inclusion in discriminant analysis, and the adjustments made to financial statements to obtain consistency in the comparison of variables. The objective of variable selection has been to obtain a comprehensive 
list which ensures that the best possible model can be constructed. The objective of standardizing financial statements is to minimize anomalies which could damage the comparability of variables between companies.

The remainder of this study analyses and interprets the statistical information which was the output from the running of computer programs on the calculated financial variables. A foldout glossary of the financial variables is on p.356 and may be kept open for reference. 


\section{Analysis of Ratio Means}

This chapter analyses the group means of ratios, and has two aims:

1. To establish whether ratio means are uniformly higher or lower for the failed group of firms than for the surviving group over the five years before failure.

Discriminant analysis chooses that function which best describes the data from which it was derived. However, suppose the selected function includes a ratio whose group means overlap during the five years. Then the classification accuracy of this function would be adversely affected for those years in which tine relationship of the group means was different from that for the year from which the function was derived. Therefore, there would be doubt if the best function to describe the whole five year period had in fact been achieved. Furthermore the interpretation of a function would be confusing where there was an overlap in group means. Accordingly where there is any overlap in the group means of a ratio during the five years, consideration will be given to excluaing that ratio from combination 1 and/or combination 2 . 
2. To gain a better understanding of the financial characteristics of failed and nonfailed firms. This will be useful both in contributing towards a theory of financial distress, and in interpretation of the results from subsequent aiscriminant analysis.

The ratio means are detailed in Appendix $\mathrm{C}$ : they are listed by the single-industry, two-industry, and four-industry samples of firms. For the purpose of this analysis the ratios are divided into the following categories: cash flow/profit to assets, cash flow/profit to. liabilities, short-term assets to long-term assets, liabilities to assets or assets to liabilities, retained profits to assets and liabilities, working capital to assets, working capital to liabilities and cash flow/ profit to working capital. These categories comprise a total of 47 ratios.

\section{Cash Flow/Profits to Assets (9 ratios)}

It was expected that nonfailed firms would earn a higher return on investment and generate a stronger cash flow from their operations. The expectation was confirmed for manufacturing, retail, and finance companies five years before failure, but for only six of the ratios for property firms: three of their ratios had means overlapping in year five (CFBCA, PITQA, PITCA).

A typical pattern of a ratio in this category - 
PITTAI - is illustrated for the manufacturing industry in Figure 7: this shows a distinct separation of means five years before failure, with the gap widening as the date of collapse approaches.

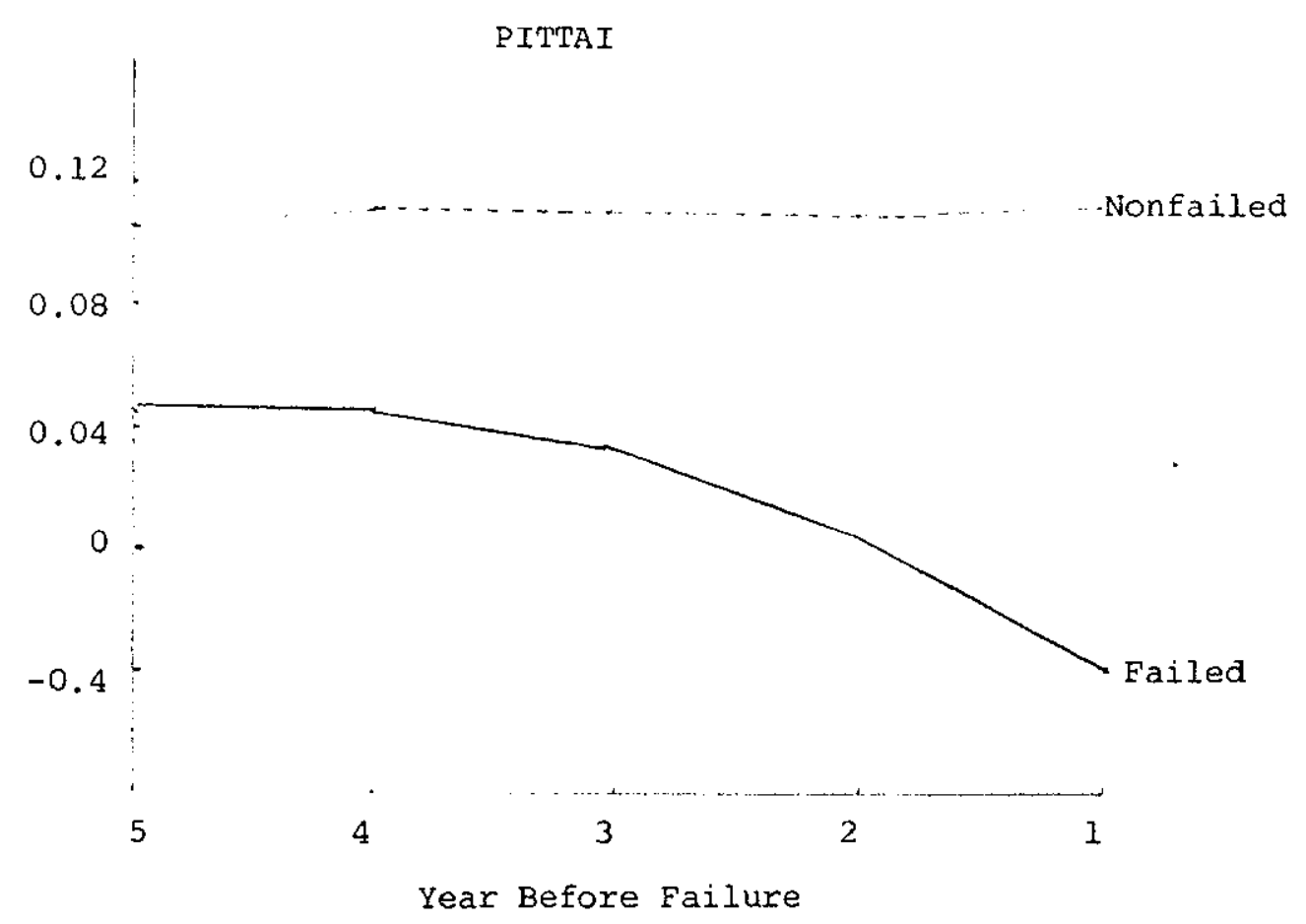

Figure 7. Comparison of Mean Values: Manufacturing Industry.

There were two possible reasons for the continued decline of this ratio, and other ratios in this group, for failed companies: (a) declining profits and cash flow, (b) increasing total assets. In spite of declining profits, 25 failed firms increased their business investment in each of the last five years, while the remaining 16 only marginally reduced their asset base two years before failure: this indicates that management was eitner unable, or reluctant, to sell off unprofitable assets as a course of action to prevent failure. 
Cash Flow/Profit to Liabilities $(9$ ratios)

It was presumed that nonfailed firms would have a higher coverage of debt from the profits and cash flow generated by normal trading operations. This presumption was confirmed for manufacturing, retail and finance firms for the five years, but only for the first two years by property firms. In years 3 and 5 , these ratios were higher for the failed property firms. An examination of the histograms of their ratio values indicated that this erratic trend was caused by an extreme value: for instance, one failed firm completely restructured its finances three years before failure, reducing its debt to a figure less than cash flow; the deletion of this ratio would have prevented the overlap of ratios in year 3. Similarly in year 5, there was a failed company with a low level of borrowing relative to its cash flow. Where there is an obvious distortion in the means because of such an extreme value, the procedure adopted will be to delete the figure from the derivation stage of discriminant analysis but bring it back into the data at the classification stage.

The pattern of this ratio group was for the gap to widen between the means of failed and surviving firms as the date of failure approached. Figure 8 illustrates the cash flow to total liabilities ratio for the retail and finance industries. 
CFBTL

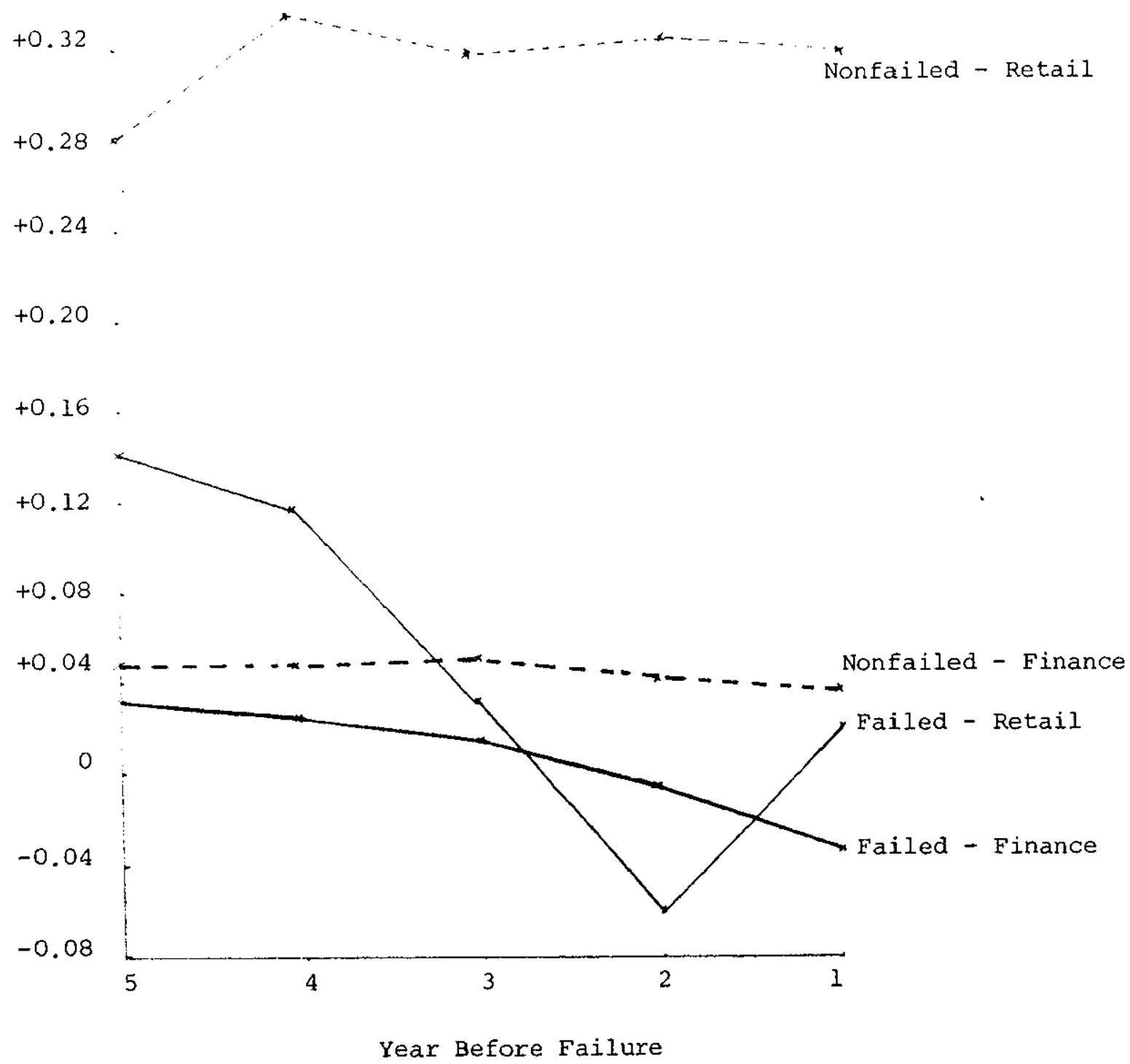

Figure 8: Comparison of Mean Values: Retail and Finance Industries. 
The overlap of the means for the failed retail firms and nonfailed finance firms suggests that, because of the lack of homogeneity in the data between the two industries, there would be a loss of discriminating power when the industries are combined.

Of the 41 failed firms, the total liabilities of 28 companies increased right up to the last balance date before failure: 12 had only a slight decline in total debt one year before failure, and 1 reduced its debt three years before, but then quickly increased it. It seems . that lenders to the failed firms were either unaware of the financial plight of these firms, or hoped the availability of more funds would solve their problems.

\section{Short-term Assets to Long-term Assets (3 ratios)}

The expectation was that failed companies would experience financial difficulties because of the strain on liquidity caused by an excessive build up of stock and debtors; therefore, their ratios would be higher than those of the surviving companies.

For manufacturing companies the expectation was confirmed for current assets to total assets (CATAI) but not for quick assets to total assets (QATAI) or quick assets to current assets (QACA). 
The asset structure of failed and nonfailed manufacturing firms is illustrated in Table 6 .

Table 6

Manufacturing Firms

Composition of Assets: One Year Before Failure

\begin{tabular}{lcc} 
Assets & $\begin{array}{c}\text { Failed } \\
\frac{8}{8}\end{array}$ & $\begin{array}{c}\text { Nonfailed } \\
\frac{8}{8}\end{array}$ \\
\hline Fixed & 31.2 & 37.9 \\
Current & 68.8 & 62.1 \\
Stock & 42.1 & 35.1 \\
Quick Assets & 26.7 & 27.0
\end{tabular}

Source: Appendix C

The above analysis of the composition of assets indicates that, compared to nonfailed firms, failed manufacturing firms had a higher proportion of funds in stock, but a smaller investment in quick assets (debtors). Therefore, it could be concluded that the problem of manufacturing companies in this ratio group is a build up of stock accompanied by a falling away of orders: production could be running ahead of sales in anticipation of forthcoming orders and to keep plant operating. Conversely, nonfailed companies have a lower stock and a higher investment in quick assets, because products are being more readily sold. This conclusion would be modified to the extent to which failed firms have a lower investment 
in fixed assets, owing to (a) older equipment with a lower written-down value, or (b) leased equipment which is not shown as a fixed asset. An examination of financial statements showed that provision for depreciation as a percentage of the cost of plant, was approximately the same for both groups: this suggested that there was little difference between the average ages of the plant of both groups. Comparative information on leasing was not available. If it is assumed that failed companies did not have more leased assets, then the above conclusion need not be modified.

The prediction of a larger investment in short-term assets was confirmed for firms in the retail industry: this indicates that failed retail firms have a combination of a higher investment in stock and debtors relative to their total investment. There was, however, one other factor that caused current assets to total assets (CATAI) to have a higher mean value for failed firms: the amount of retail premises leased. For instance, one failed retail firm had a much higher CATAI ratio than others: an inspection of its accounts indicated a relatively small fixed-asset base because it had few freehold properties, which would lead one to infer that most of its retail premises were leased. This points to the added benefit of this ratio for the retail industry: it can compensate for the lack of direct information on the extent of property leasing as this form of debt finance is implicit in the CATAI ratio. 
During the period of the early 1970's, finance firms invested more funds in land and less in consumer credit. However, failed firms became more neavily involved in land transactions: for instance, three years before failure they had 74 per cent of funds invested in Iand while their matched-surviving firms had only 57 per cent. Consequently, failed firms had a lower QATAI; their problem was overinvestment in stock which could not be readily sold when the property market collapsed.

The activities of property firms ranged from being chiefly investors in income-producing property to being principally concerned with selling property at a profit. The ratio CATAI was lower for the failed group, indicating that on the average their balance sheets showed a higher investment in fixed assets. This was surprising, because it would have been expected that the failed firms were more involved in speculative land transactions, and hence had a lower average investment in fixed assets. It may be that the balance sheets, in fact, did not reflect the actual situations. But, in any case an inspection of the histograms of the three ratios showed that there was considerable overlap in the ratios for the two groups; therefore it would not be expected that these three ratios would be very useful in discriminating between failed and nonfailed firms. 
The expectation was that failed companies would have relied more heavily on debt finance to fund their operations: a higher proportion of their total funds would be liabilities.

Failed manufacturing firms used more debt to finance their operations than nonfailed firms. There was, however, little difference between the groups in the proportion of long-term debt to total funds (see Table 7).

\section{Table 7}

Manufacturing Firms

Proportion of Total Funds obtained from Long-Term Liabilities

\begin{tabular}{lccccc} 
& Yr.1 & Yr.2 & Yr.3 & Yr.4 & Yr.5 \\
\hline Fail & .088 & .105 & .096 & .113 & .109 \\
Nonfail & .113 & .115 & .105 & .110 & .105
\end{tabular}

Source: Appendix C

Failed manufacturing companies placed greater reliance on short-term debt, particularly bank overdraft as indicated in Table 8 . 
Table 8

Manufacturing Firms

Proportion of Total Funds Obtained from

Bank Overàraft

\begin{tabular}{lccccc} 
& Yr.1 & Yr.2 & Yr.3 & Yr.4 & Yr.5 \\
\hline Fail & .221 & .214 & .183 & .167 & .156 \\
Nonfail & .065 & .074 & .072 & .062 & .076
\end{tabular}

Source: Appendix C

Banks consistently provided a higher proportion of funds, seemingly on a permanent basis, to finance the heavier investment in stock of failing manufacturing firms. This indicates that banks are a major reason why failing firms stay in business as long as they do; the banks, of course, have the protection of a tangible security behind the overdraft.

Failed retail firms use more debt to finance theix operations than their nonfailed counterparts. However, the relationship between current assets and short-term liabilities is erratic; for instance the working capital ratio (CACL) is higher for failed firms for Years 3, 4 and 5. This suggests that this ratio will not be a very good predictor of business failure. The "acid test" ratio (QAQL) indicates the relationship between cash and debtors (QA) and creaitors $(Q L)$. The firm with the higher $Q A Q L$ has been traditionally regarded as the more 
financially sound. However, in this study $Q A Q L$ is higher for the failed than for the nonfailed retail companies. To seek an explanation of this fact, Table 9 was constructed, showing for both failed and nonfailed retail firms, the relationship between QAQL and the proportion of total funds obtained from bank overdraft $(\mathrm{BOTF})^{l}$.

Table 9

Retail Firms Relationship Between QAQL and BOTF

\begin{tabular}{ccccc} 
& \multicolumn{2}{c}{ Failed Firms } & & \multicolumn{2}{c}{ Nonfailed Firms } \\
\cline { 5 - 6 } $\begin{array}{c}\text { Yr. before } \\
\text { failure }\end{array}$ & QAQL & BOTF & QAQL & BOTF \\
\hline 1 & 0.674 & 0.158 & 0.562 & 0.040 \\
2 & 0.635 & 0.139 & 0.572 & 0.036 \\
3 & 0.733 & 0.147 & 0.596 & 0.041 \\
4 & 0.693 & 0.142 & 0.597 & 0.039 \\
5 & 0.775 & 0.134 & 0.657 & 0.050
\end{tabular}

The table indicates that the higher QAQL for failed firms was associated with a higher BOTF. This exposes a limitation of the traditional interpretation of QAQL. The table shows that a high QAQL can be due to a high proportion of funds being obtained from bank overdraft, which, in turn, is evidence of a high degree of financial risk because failing firms have a higher level of overdraft. Considerable care is therefore needed in analysing bank overdraft (BO). 
QAQL. If this ratio were included in the best discriminant function it would be because of the greater level of bank overdraft made available to failing retail firms.

Because of the difference previously noted in the asset structures of property firms the ratios CATL and QATL had a wide range of values within both groups of firms. If one extreme ratio value is omitted, TLTAI was nigher for the failed group for the entire five years. This inaicates that the failed firms had exposed themselves to greater risk by using more aebt finance.

Failed finance companies relied more on debt finance for all five years, and their working capital and quickasset ratios were distinctly lower. The failed companies were characterized by a higher proportion of both shortterm borrowings and long-term assets, a situation carrying a higher level of financial risk.

Short-term Liabilities to Longer-term Liabilities ( 3 ratios)

It would be generally expected that failed firms have been placed in a dangerous financial position because of a heavier reliance on short-term debt: therefore, they will have higher ratios in this group than surviving firms.

This expectation was confirmed for CLTL for the manufacturing and retail firms; it was not proved, however, for QLCL because of the greater use of bank overdraft by 
these failed firms. Surviving firms received more of their short-term funds from trade creditors than did failed firms: this suggests that "those in the industry know first" about a firm's financial problems, while banks are unknowing or else shelter behind their security screen.

For property firms no clear pattern emerged in the proportion of total debt coming from short-term sources. This was to be expected because of the wide variation in their asset structures and hence length of borrowings. For instance, those firms with funds employed mainly in fixed assets would have more long-term borrowings than those with funds mainly employed in current assets. Therefore, this category of ratios, because of their overlapping between groups, would be of little use for discriminating purposes.

Similarly for finance firms, no clear pattern seemed to emerge in the three ratios. It would appear that total liabilities, rather than composition of liabilities, will be the more useful for both property and finance firms.

\section{Retained Profits to Assets and Liabilities (6 ratios)}

It was expected that nonfailed firms, because of a higher return on funds, and perhaps a more conservative dividend policy, would have more retainea profits funding investment in operating assets and so providing a better coverage of liabilities. 
The expectation that this set of ratios would be higher in value for nonfailed firms was confirmed for all industries. There was a clear indication, us to five years before failure, that retained profits contributea more to funaing the operations of nonfailed firms than of failed firms. In the manufacturing industry, for instance, the difference in RPTAI between the two groups widened from 11.2 per cent in Year 5 to 32.7 per cent at the last balance date before failure.

Cash Flow/Profit/Retained Profits to Working Capital $(4$ ratios)

It was difficult to establish a prediction of the behaviour of ratios in this group. Not surprisingly, none of this group of ratios was found to discriminate between failed and surviving firms. Because of repeated overlap during the five years, it would be expected that these ratios in the working capital stream - combination 2 ratios - would have less predictive power than most other ratios.

Working Capital to Asseis/Liabilities (4 ratios)

Surviving firms would be expected to have higher working capital to assets/liabilities ratios. The prediction was confirmed in all five years before failure for manufacturing and finance businesses. For retail firms, however, the picture was not clear, with considerable 
overlap in the ratios: this is because, as found earlier, the working capital ratio was not necessarily lower for the failed firms. A similar situation existed for the property firms.

This examination of this set of ratios, and the previous set which also involves working capital, suggests that the combination containing them - combination 2 - may have less usefulness in this study than the other combination of ratios - combination 1 .

\section{Amended Combinations of Ratios}

The optimum function for assessing and explaining financial risk would be that which consists of accounting ratios whose means are uniformly higher or lower for the failed group than for the surviving group. It was resolved, therefore, to amend combinations 1 and 2 by deleting those ratios which had overlapping group means. An inspection of the histograms of ratios, however, revealed that the overlap of some means could be caused by an extreme ratio value. Where the overlap was created by an extreme value, the ratio was not excluded. The amended combinations for each industry, referred to as $1 \mathrm{~A}$ and $2 \mathrm{~A}$, are detailea in Appendix D.

Table 10 shows that the number of ratios left in the combinations for further analysis is still considerable. 
This indicates that a high proportion of the ratios were uniformly higher or lower for the failed group, relative to the nonfailed group, for the five-year period prior to failure.

\section{Table 10}

Comparison of ivumber of Ratios in Combinations

1 and $1 \mathrm{~A}, 2$ and $2 \mathrm{~A}$

\begin{tabular}{lcccc} 
& & \multicolumn{3}{c}{$\begin{array}{c}\text { Number of ratios for } \\
\text { each }\end{array}$} \\
\multicolumn{1}{c}{ Industry Group } & 1 & $1 \mathrm{~A}$ & 2 & $2 \mathrm{~A}$ \\
\hline Manufacturing & 39 & 37 & 30 & 26 \\
Retail & 39 & 35 & 30 & 24 \\
Property & 39 & 35 & 30 & 23 \\
Manufacturing/Retail & 39 & 34 & 30 & 26 \\
Property/Finance & 39 & 35 & 30 & 24 \\
$\begin{array}{l}\text { Manufacturing/Retail/ } \\
\quad \text { Property/Finance }\end{array}$ & 39 & 35 & 30 & 25
\end{tabular}

Source: Figure 6 and Appendix D

Comparative Classification Accuracy of Combinations $1 \mathrm{~A}$ and $2 \mathrm{~A}$

The classification accuracy of discriminant functions derived from the two alternative combinations was compared to show if further discriminant analysis of the ratios in combination $2 \mathrm{~A}$ would be worthwhile: this was because 
the above univariate analysis of ratios involving working capital indicated that there was a considerable overlap of group means, so that many ratios in combination $2 \mathrm{~A}$ would be poor discriminators of a firm's financial status.

A linear function was derived from each year's data for the six industry categories, and its classification accuracy averaged over the five years: this meant that there were five discriminant functions for six industry classes in each of the two combinations of ratios. The classification accuracy of the best from each set of five functions is shown in Table 11; their year-by-year classification accuracy is listed in Appendix E.

\section{Table 11}

Classification Accuracy of the Best Functions for Each Industry Derived from Ratios in Combinations $1 \mathrm{~A}$ and $2 \mathrm{~A}^{2}$ Classification Accuracy

$$
\text { Single-Industry Two-Industry Four-Industry }
$$

Data Data Data

\begin{tabular}{lcccccc}
\multicolumn{1}{c}{ Industrý } & IA & $2 \mathrm{~A}$ & IA & $2 \mathrm{~A}$ & $1 \mathrm{~A}$ & $2 \mathrm{~A}$ \\
\hline Manufacturing & 90.5 & 89.8 & 87.7 & 87.2 & 86.9 & 85.9 \\
Retail & 94.8 & 88.8 & 91.2 & 89.8 & 90.8 & 85.2 \\
Property & 79.7 & 77.6 & 79.7 & 79.5 & 73.6 & 71.1 \\
Finance & - & - & 73.4 & 65.6 & 65.0 & 60.0
\end{tabular}

2. Classification accuracy was based on: (a) linear discriminant functions, (b) the stepwise selection process, (c) original-sample and hold-out sample validation techniques, (d) equal priors. 
In all instances, combination $1 \mathrm{~A}$ yielded the function with the highest classification accuracy, but the difference was only slight. An examination of the ratios in the functions from combination $2 \mathrm{~A}$ showed that in some instances none of the ratios containing working capital (WC) entered the function: the only ratio to be included with any consistency was working capital to total assets (WCTAI). Because this preliminary analysis indicated that the combination 2 ratios were slightly inferior to combination 1 ratios, it was decided that further analysis in this study would be confined to the latter: combination 2 ratios would now be discarded.

\section{Conclusions}

From the analysis carried out in this section the following conclusions, which will form the basis of hypotheses for further testing, can be drawn.

1. The separation of means indicates that firms could be in failure zone from five years before failure: the hypothesis is that failure is not a sudden event but failed firms have different basic financial profiles to nonfailed firms.

2. The separation of the means five years before failure with increasing width of separation up to failure suggests that if a model can be developed which preaicts with a high degree of accuracy in Year 5, then it could 
hold accuracy to the year of failure. A year 1 model may contain ratios which predict very well one year before failure - because of the maximum separation of means but their predictive power could decline in other years as the separation of group means becomes less pronounced. Therefore, the hypothesis is that models derived from Year 1 data will predict less accurately over a five year period than models derived from other years.

3. Table 11 provides some evidence to support the expectation that, because of the lack of homogeneity in the data, there would be a decline in classification accuracy when industries are combined. 


\section{Chapter 6}

\section{Derivation of Best Discriminant Functions}

The aim of this chapter is to derive the best discriminant function for each of the four industries: manufacturing, retail, property and finance. The tasks involved in deriving these functions will be:

1. Testing the impact of violating the assumption that the ratios are distributed normally. The classification accuracy of the best functions previously derived from combination $1 \mathrm{~A}$ (see Table 11) will be compared with those derived from (a) data transformed to reduce the level of skewness in ratio distributions, and (b) ratios whose departure from symmetry is not significant at tine 1 per cent level.

2. Assessing the effect of high correlation among the ratios. Functions will be derived from ratios with correlation coefficients of less tinan 0.75 and their classification accuracy compared with that of the previously derived functions.

3. Selecting the best function for each industry, "best" being judged in terms of classification accuracy and the absence of ambiguity in indicating the factors affecting financial risk. An attempt will then be made 
to improve the classificatory power of these best functions by including three additional variables in each function: logarithm of tangible assets, balance sheet decomposition measure and stability of earnings.

4. Measuring the dispersion of the discriminating ratios in the best functions. Where there is inequality of dispersion a quadratic function will be produced and its classification accuracy compared with the linear function. This will determine whether the linear or quadratic format is the more appropriate.

5. Finding the extent of any upward bias in the original-sample method of measuring classification accuracy by comparing its result with that using the Lachenbruch validation technique. If there is significant upward bias, then the classification accuracy from the Lachenbruch technique will be used in subsequent analysis.

6. Establishing if the best functions perform better than chance. This will be done by comparing the efficiency of the best functions with alternative strategies, and will determine if these functions are useful in explaining the characteristics of failed and existing companies. 
Test of Normality Assumption

This section is concerned with the effect on classification accuracy when the level of skewness in ratio distributions is reduced. There nave been a number of studies on the distribution of ratios. Deakin (1976) considered 11 ratios in each of 19 fiscal years for 114 manufacturing companies; he found that the only ratio which was not significantly different from normal was total debt to total assets ${ }^{1}$. Foster (1978, p.129), Beaver (1966, p.95) and Horrigan (1965, p.559) also provided evidence that normality cannot be assumed but did not quote any results of significance tests of departure from normality.

Horrigan (1965, p.560) and Beaver (1966, p.95) suggested that transforming the data (e.g. logarithm and square root) may make ratios approximately normal. Beaver found however, that the distributions of his transformed variables were almost as badly skewed as the original ones.

1. Deakin excluded retailers, wholesalers, financial institutions, and other non-manufacturing companies on the grounds that the major differences in the nature of their operations would tend to bias the results in favour of rejection of normality assumption. The Il ratios were current assets/sales, quick assets/sales, working capital/sales, current ratio, quick assets/ current liabilities, current assets/total assets, quick assets/total assets, working capital/total assets, cash flow/total debt, net income/total assets, and total debts/total assets. 
An Australian study found less departure from normality than the above American studies. Bird and McHugh (1977, p.25) examined the distribution of ratios in the electrical equipment, accommodation, and food industries; they concluded that, within an industry, current assets to current liabilities, borrowings to total assets, and profits to total assets, approximated a normal distribution, but quick assets to quick liabilities and current assets to total assets were often substantially skewed. It cannot be presumed, however, that for the firms in this study, the results would be the same as theirs for two reasons: this research combines industries for ratio analysis, and there are two groups of firms - failed and nonfailed.

A conclusion from these studies is that it is important to investigate the distribution of the ratios rather than basing analysis on the traditional assumption that they are normally distributed.

There are two statistics for determining the degree to which a distribution of cases approximates a normal curve: skewness and kurtosis. Skewness measures deviation of the distribution from symmetry and kurtosis measures the relative steepness or flatness of the curve. If both statistics depart significantly from zero, one would infer that the aistribution is unlikely to be normal. It is possible for a distribution to be symmetrical but 
not normal because of its having a distinct peak (or flatness).

The skewness and kurtosis figures for the failed and surviving groups were calculated from the ratios in combination IA for each industry. An examination of these figures showed that although there was a close relationship between the two statistics for the failed group, in that those ratios with a low skewness also had a low kurtosis, this did not necessarily apply to the nonfailed group: this latter group was characterized by many of the ratios with a low skewness having a significant peak in their distributions. By way of illustration, Table 12 shows the number of ratios for both groups in the manufacturing industry whose distributions were approximately symmetrical at the $I$ per cent level of significance and were also approximately normal, i.e., their kurtosis measures were also insignificant.

The ratio distributions were both symmetrical and normal for a higher proportion of the failed group than of the nonfailed group. The fact that many of the ratio distributions for nonfailed firms were symmetrical but not normal, because of a fairly tight cluster about the median, was not unexpected. There are widely accepted values for ratios, established as desirable by external 
analysts, and it would be assumed that management of firms would react to the importance of achieving these values. The nonfailed firms were more consistent in achieving these values: hence the tighter cluster of their ratio values.

Table 12

Number of Ratios in Manufacturing Industry whose Distributions were Approximately Symmetrical and Normal Yr. before Failed Group Nonfailed Group failure Symmetrical Normal symmetrical Normal

$\begin{array}{lllll}1 & 31 & 30 & 16 & 8 \\ 2 & 33 & 30 & 16 & 7 \\ 3 & 24 & 24 & 24 & 9 \\ 4 & 15 & 13 & 26 & 12 \\ 5 & 25 & 23 & 18 & 11\end{array}$

Because only a small number of the ratios for surviving firms were normally distributed, it would be unsatisfactory to compare the classification accuracy of functions derived from all ratios with that of functions derived only from ratios whose distributions were normal. Instead the comparison would be made between all ratio distributions and those ratio distributions which were approximately symmetrical. Most of the symmetrical distributions for the failed group would be approximately normal, although only about half those for the nonfailed 
group would be. This reduction in the level of skewness of ratio distributions will still, however, provide some test of the robustness of discriminant analysis when dealing with non-normal data.

The skewness figures for the failed and surviving groups, calculated from the ratios in combination IA for each group, are catalogued in Appendix F. The ratios which have a significant departure from symmetry at the 1 per cent level are marked by an asterisk ${ }^{2}$.

Table 13 shows the percentage of ratios which approximate a symmetrical distribution for failed and nonfailed firms, by ratio clusters and industry. The following conclusions can be arawn from this table and Appendix F.

1. The ratios of collapsed companies were more symmetrical in five of the industry categories - the exception was the retail industry.

2. The manufacturing and retail firms had most ratios approximating symmetry.

3. The ratios expressing balance sheet structure had the highest level of symmetry, while those relating to retained profits had the lowest.

2. The tables used for this assessment were: Biometrica Tables for Statisticians, Pearson \& Hartley, (Cambridge University Press). 


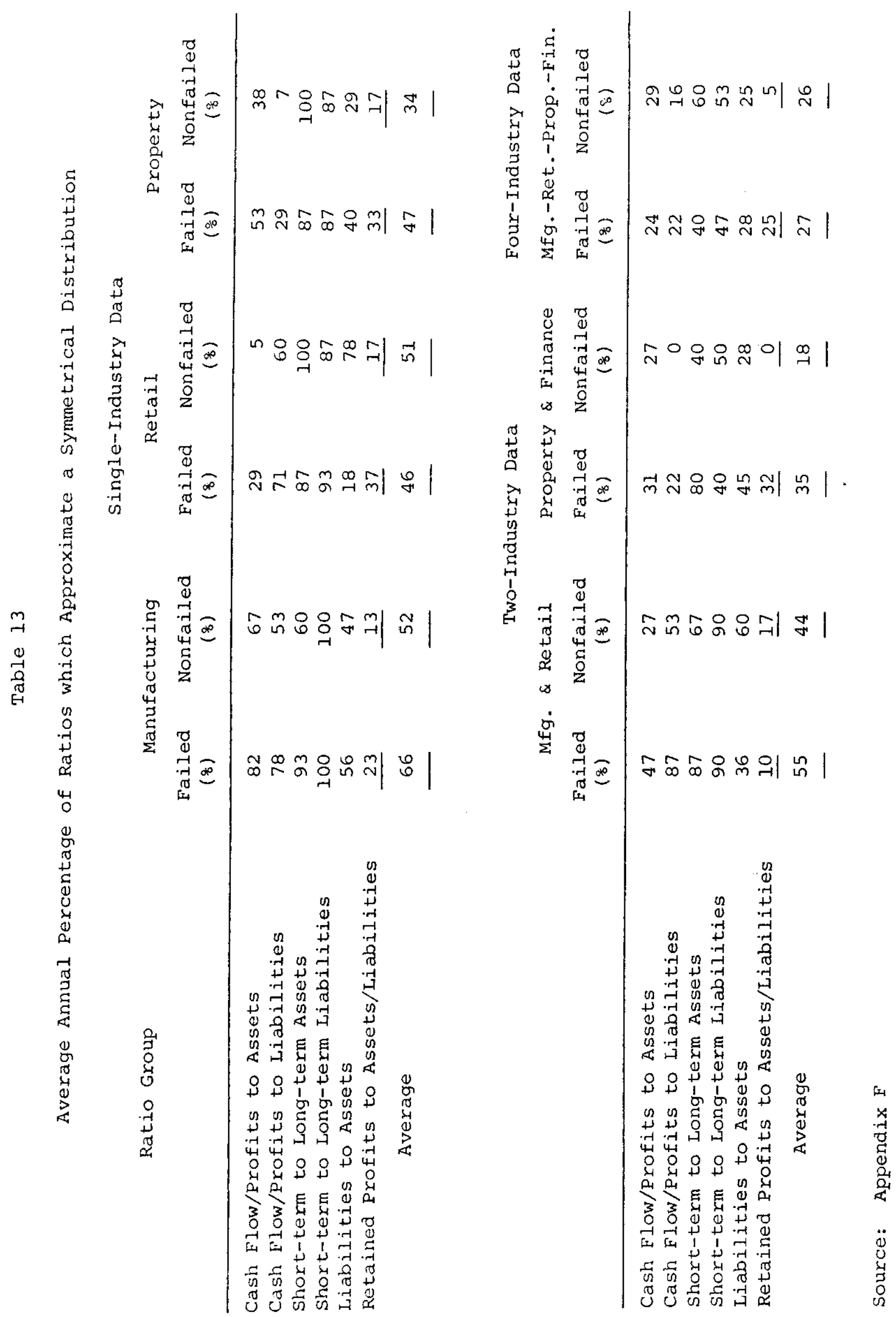


4. There were few ratios consistently symmetrical over the five-year period.

Logarithmic transformation of ratios. An examination of how far a logarithmic transformation of ratios reduces skewness was carried out in the manufacturing and retail category. In order to have all the ratios positive, ten was added to them: the sum was then expressed as a logarithm. The measure of skewness was calculated for each of the transformed ratios: these skewness figures are listed in Appendix $F$, and those with a significant departure from symmetry at the 1 per cent level are marked by an asterisk. The distribution of the logarithmically-transformed ratios was more negatively skewed than that of the original ratios, with only a slight improvement in the number of ratios which approximated symmetry: the percentage of symmetrically-distributed ratios for failed firms increased from 55 per cent to 57 per cent and for nonfailed firms from 44 per cent to 46 per cent. It was decided that this marginal improvement was not sufficient to test the robustness of discriminant analysis ${ }^{3}$.

Deletion of extreme ratio values. Another method of attempting to improve symmetry is the deletion of extreme values for a ratio. Histograms of ratios were examined

3. The conclusion that the transformed ratios are almost as badly skewed as the original was a similar finding to Beaver's - see p. 113. 
for evidence that a significant departure from symmetry was caused by an extreme value. This examination showed that several ratios for nonfailed companias were significantly skewed because one or two ratio values were clearly separated from the others. These extreme values were traced back to the companies, and the accounting items were deleted from the financial data of those firms ${ }^{4}$. The skewness of the ratios was then recalculated for each industry: these are listed in Appendix F.

The comparison of the percentage of combination $1 \mathrm{~A}$. ratios approximately symmetrical before adjustment for extreme values with the number after deleting extreme values is tabulated in Table 14. This indicates an increase in the number of ratios approximately symmetrical for surviving firms in all groups except the fourindustry group. An examination of the histograms of ratios for failed firms showed that extreme values did not pose the same problem: the only adjustments made were to a property company in Year 3 and another in Year 5 both had a low level of borrowings which caused distortion in the skewness measures of ratios containing liabilities. Because of the increase in the number of ratios approximately symmetrical after deleting extreme values, it was decided to use this adjusted-data set to see if

4. The deletion of the underlying financial data was the better way of getting rid of an outlier ratio: if the ratio itself was deleted then it would not be available for inclusion in the function, and it would not be known whether it aiscriminated well between the remaining firms in both groups. 
classification accuracy would be improved when more ratios approximate symmetry in their distributions. Accordingly two additional sets of linear aiscriminant functions were derived from these adjusted data: (a) one set based on all the ratios in combination $1 \mathrm{~A}$ being available for inclusion in the function, and (b) another set based on availability of only those ratios in combination $1 \mathrm{~A}$ which approximate symmetry. For the purpose of deriving set (i), a list was compiled of ratios which were symmetrically distributed in the one year for both failed and nonfailed companies this list is titled Combination $I B$ and is shown in Appendix G.

Table 14

Average Annual Percentage of Combination lA Ratios for Nonfailed Firms which Approximate a Symetrical Distribution Before and After Adjustment for Extreme Values

Industry Industry

\section{Before Adjustment for Extreme values 웅}

44

18 26

\section{After Adjustment for Extreme Values \\ $\%$}

Manufacturing

Retail

Property 
Table 15 shows the highest classification accuracy of functions derived from: (a) combination $1 \mathrm{~A}$ ratios and unadjusted data, (b) combination $1 A$ ratios and adjusted data, and (c) combination 18 ratios and adjusted data.

Although the comparative tests were limited in that (a) even with the adjusted data there were still many ratios significantly skewed, and (b) the symmetrically distributed ratios were limitea in number, the close relationship in the classification accuracy of the alternative functions in Table 15 supports the robustness of discriminant analysis: the assumption of normality need not be strictly adhered to.

\section{Correlation}

Another task is to test the impact on the classification accuracy of discriminant functions of deleting highly correlated ratios from the analysis ${ }^{5}$. Matrices were constructed to show the correlation coefficients of ratios for any given year. These indicated a hign degree of correlation among the cash flow/profits/retainad profits to assets/liabilities ratios. Combinations IA and 13 were amended by omitting one of the ratios where there was a correlation coefficient > 0.75 ; the ratio

5. See pp. 33-36 for a discussion on the need for this test. 


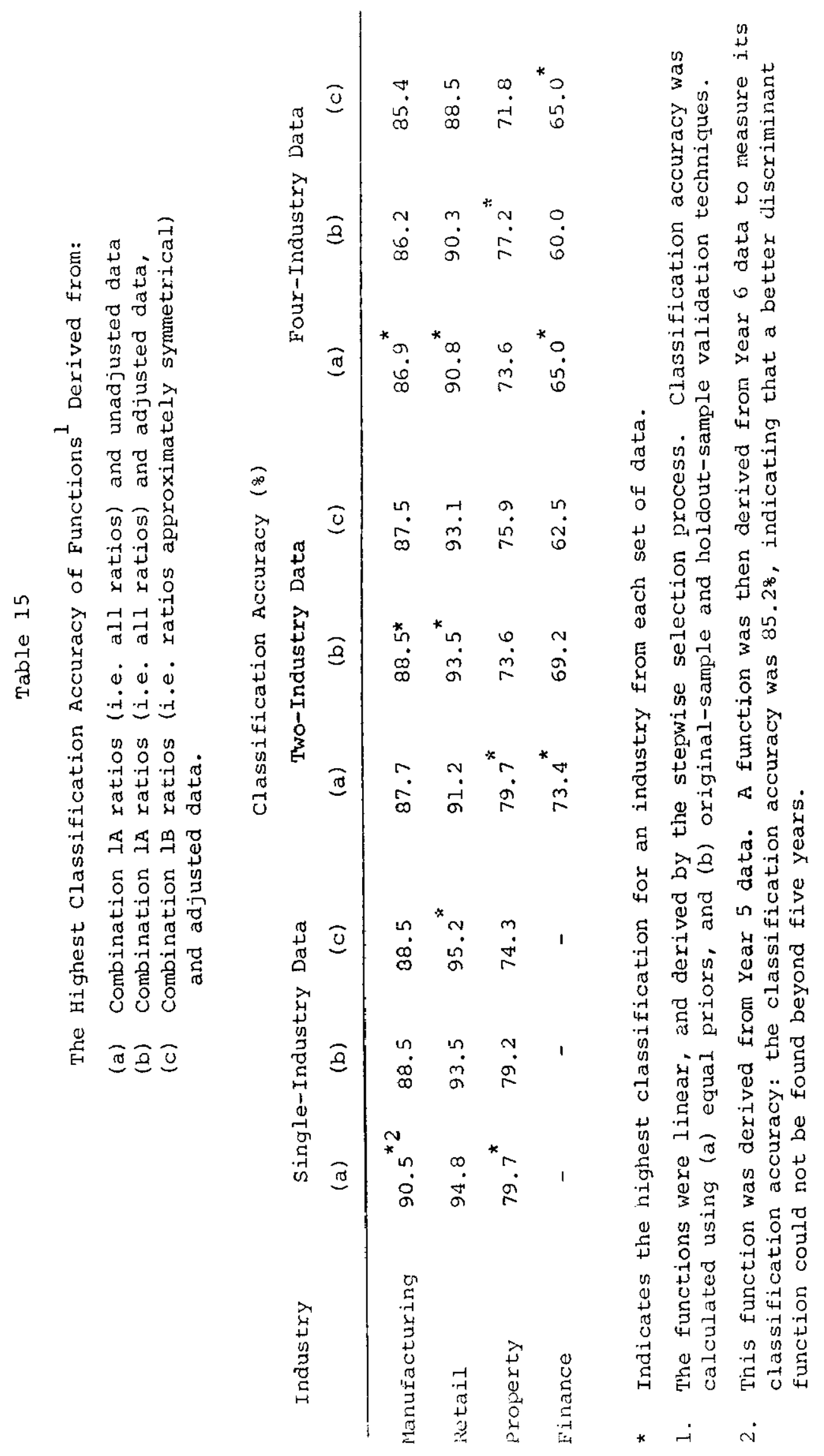


which had the lowest $F$ value for the separation of means was the one deleted ${ }^{6}$. The new ratio combinations $1 \mathrm{c}$ and ID are detailed in Appendices $H$ and $I$. The predictive accuracy of the functions derived from the ratios in these two combinations was then compared with those functions produced from ratios in combinations $1 \mathrm{~A}$ and $1 \mathrm{~B}$ : the highest classification accuracy from each combination is listed in Table 16, and the year-by-year classification accuracy of each function is detailed in Appendix J.

For the manufacturing, retail and property industries, the combinations consisting of ratios with correlation coefficients of less than 0.75 (columns 'd' and 'e') had a classification accuracy approximating that of the ratios with an extremely high level of correlation. This finding confirms the expectation that there will be no significant loss of classification accuracy by choosing those functions whose variables have a low level of correlation.

\section{Years of Highest Classification Accuracy}

Following the analysis of ratio means in chapter 5 it was hypothesized that models derived from Year 1 data will predict less accurately over a five-year period than models derived from other years (see p.110). To test this

\footnotetext{
6. This does not guarantee that the better variable has been chosen because the optimum discriminant function depends upon the interaction of variables. However, since a choice has to be made this seems a reasonable approach.
} 


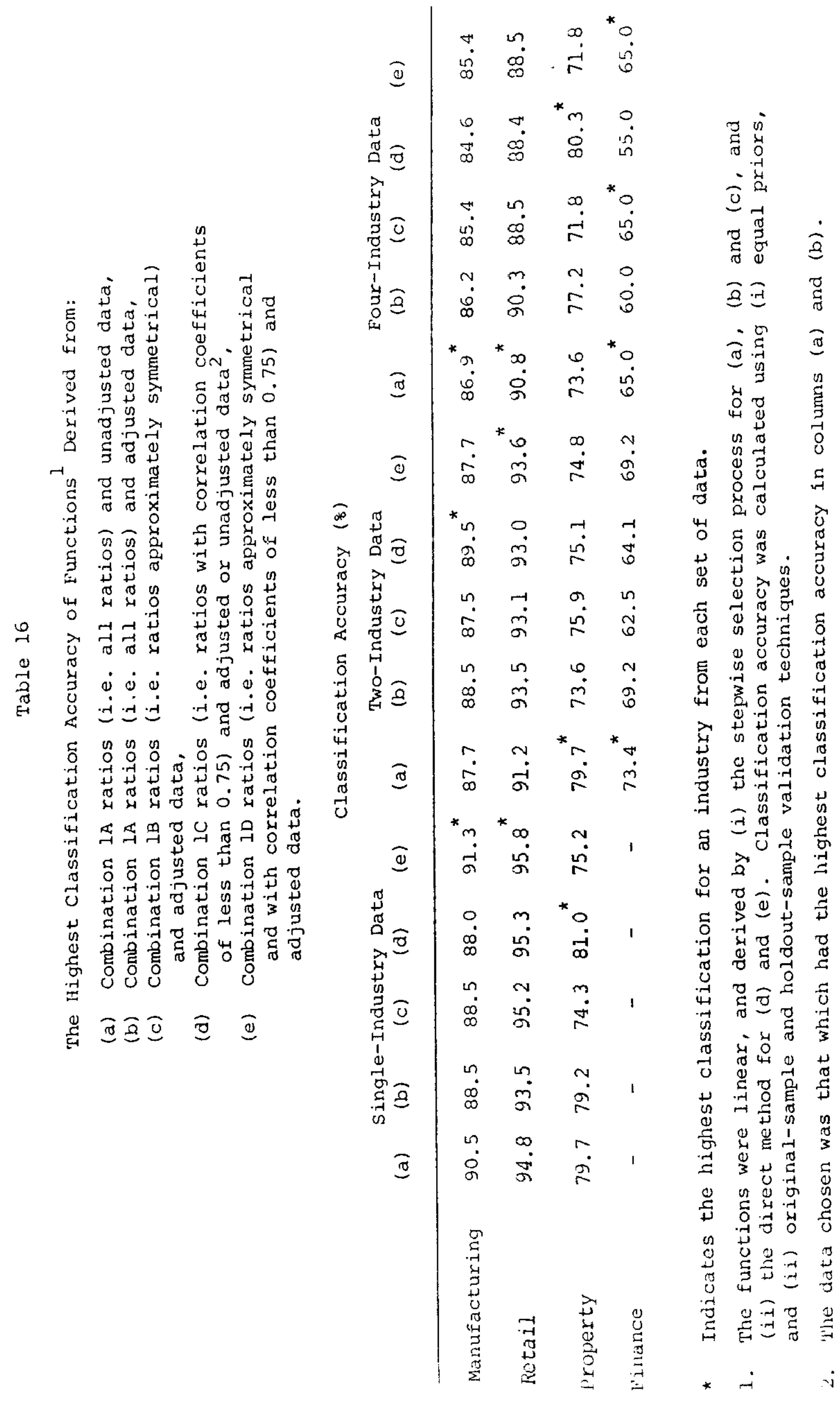


hypothesis, the year of derivation of each function in Table 16 was tabulated: Table 17 shows the years from which the functions with the highest classification accuracy were derived.

Of the 25 functions only three were derived from year 1 data. Accordingly, the hypothesis was confirmed in most instances.

\section{Selection of Best Functions}

There were 75 functions derived from each of the manufacturing, retail and property industries and 50 for the finance industry. The criteria for selecting the function which would be used in subsequent analysis were (a) classification accuracy, and (b) absence of ambiguity in the interpretation. Because of the emphasis on unambiguous interpretation the process of selection was confined to those functions consisting of ratios with correlation coefficients of less than 0.75 ; thus there were now 30 functions available for selection from each of the manufacturing, retail and property industries and 20 from the finance industry.

The process of selection was first to find the function with the highest classification accuracy; then if there was potential for confusion in interpretation of the variables because of the effects of multicollinearity, the next function would be examined. This process would 


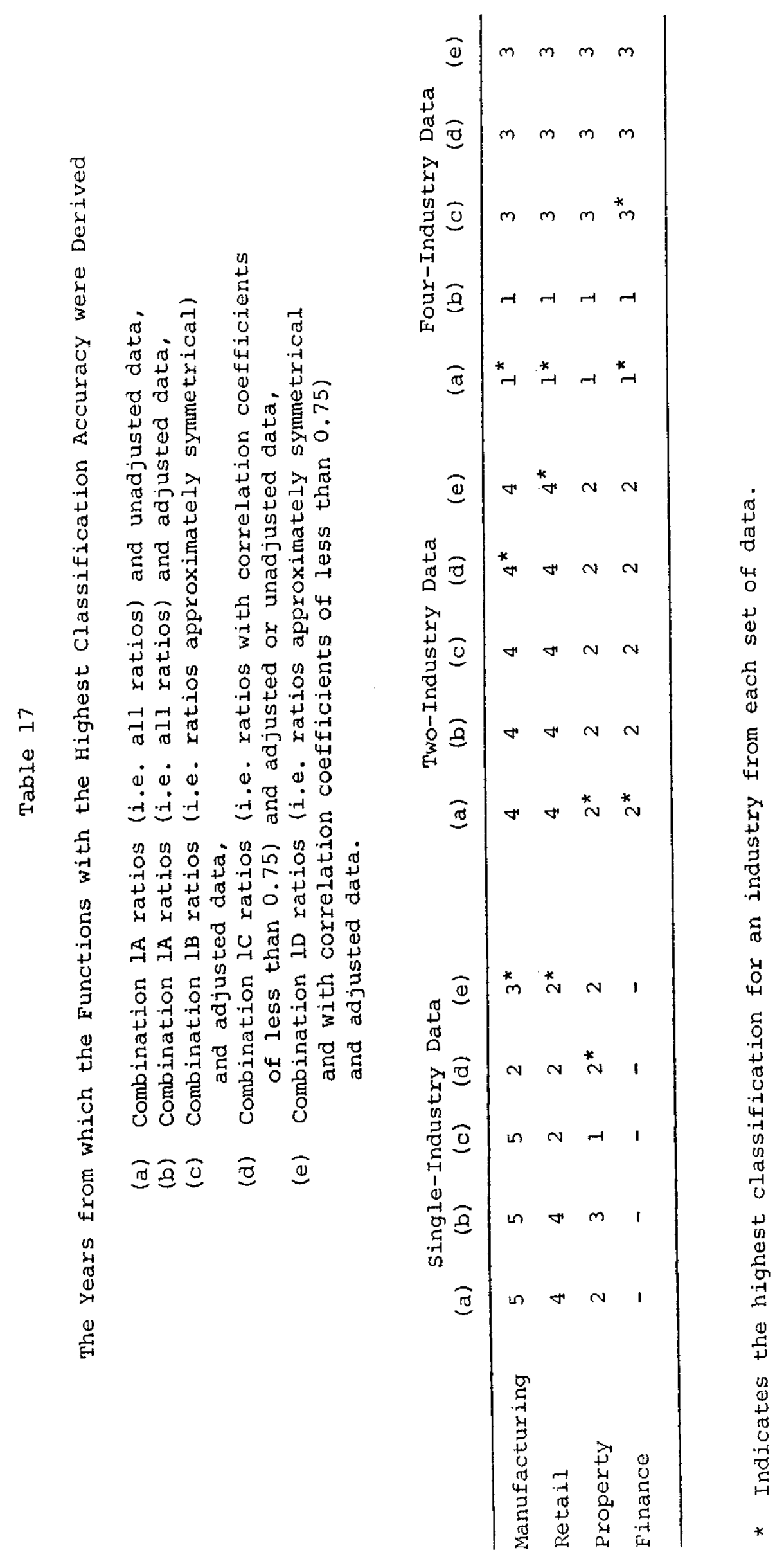


be repeated until it was judged that a function had been arrived at which would be suitable for explaining insolvency risk and developing an index of risk.

\section{Manufacturing and Retail Industries}

The function with the highest classification accuracy for the manufacturing industry was the one derived from Year 3 data using ratios which both approximated symmetry in their distributions and had coefficients of correlation less than 0.75. However, an examination of this function indicated that there was some potential for confusion when interpreting its ratios. For instance, there were two ratios, $C F B C A$ and $C F B C L$, which had different signs before their weightings: an increase in cash flow before tax had the effect, for given values of $C A$ and $C L$, of increasing the insolvency risk on the one hand (CFBCL) and decreasing it on the other $(C F B C A)$. A similar situation arose with CLTL, QLTL, and QLCL, which had conflicting signs before their weightings: the net contribution of the three ratios to the discriminant score would have to be used to assess their impact on insolvency risk. This would be less satisfactory for interpretation than if the signs attached to the weightings were logical. An inspection of the correlation matrix for the variables indicated the role that multicollinearity plays in selecting and weighting ratios: $C F B C L$ and $C F B C A$ had a correlation coefficient of 0.72 while CLTL - QLTL had 0.60 and QLTL - QLCL had 0.72 . Because of the complexity of this function, it was 
discarded although it had the highest classification accuracy.

A similar situation prevailed with the retail industry. The function with the highest classification accuracy suffered from potential confusion in interpretation since the gearing ratio had a sign to its weighting which resulted in a firm with a higher level of borrowings having a lower level of insolvency risk. As in the manufacturing industry, this function was discarded and other functions with a lower classification accuracy examined.

The chosen function. Following an examination of successive functions for both industries (manufacturing and retail), it was judged that the one which best satisfied the criteria was derived from the two-industry adjusted data for Year 4, and whose ratios approximated symmetry with coefficients of correlation less than 0.75 . This function was as follows:

$$
\begin{aligned}
\mathrm{Z}= & 1.925610-0.8792301 \mathrm{CFBCL}+3.470254 \text { CATAI - } \\
& 2.452595 \text { QACA }+1.367974 \text { CLTL }-3.859222 \\
& \text { QLCL }-4.150311 \text { RPTAI }+0.024270 \text { TLTAI. }
\end{aligned}
$$

The group centroids were: failed group +1.67680 , nonfailed group -0.64718 . It would be expected that the average failed firm would have a higher contribution to $\mathrm{Z}$ for each weighted variable: a negative weighting would be accompanied by a smaller ratio value and a positive weighting by a higher ratio value. An inspection of the 
group means of the ratios in Appendix $C$ indicated that the contribution of each ratio to the $\mathrm{Z}$-score was positive or negative according to expectations. For instance, taking the ratios in the order in which they appear in the function, failed firms had a lower CFBCL, higher CATAI, lower QACA, higher CLTL, lower QLCL, lower RPTAI and higher TLTAI: the signs were consistent with the ratio values and the group centroids.

The ratios. The following are the ratios comprising the function:

CFBCL: cash flow before tax to current liabilities. This ratio measures the ability of a firm to meet its shortterm commitments from cash flow. Higher-risk firms would have a lower coverage of current liabilities.

CATAI: current assets to total assets. This ratio represents the extent of a firm's lease commitments ${ }^{7}$ and investment both in stock and in uncollected debts. Companies increase their level of insolvency risk as (a) they lease more assets, (b) their rate of stock turnover declines and there is a build up in stock levels, and (c) their rate of debtors turnover declines and there is a build up in uncollected debts.

QACA: quick assets to current assets. The immediate

7. Leasing and borrowing have the same effect on risk: borrowing is captured in liability ratios but the nondisclosure of leasing means that it is not. The value of CATAI is that it helps overcome the problem of not knowing the extent of leasing: firms with a higher level of leasing would have fewer fixed assets and a higher CATAI ratio. 
liquidity of a company is evidenced by the amount of funds in cash or which will be quickly converted into cash. The mean of this ratio was lower for failed firms indicating that, on the average, they have less immediate claim to cash.

CLTL: current liabilities to total liabilities. This ratio is the proportion of a firm's total borrowings which is payable within a short term. High-risk firms have a higher short-term-debt commitment. QLCL: quick liabilities (current liabilities minus bank overdraft) to current liabilities. This shows the amount of short-term funding provided by creditors, and implicitly, the role of bank overdraft. Higher-risk firms place greater reliance on bank overdraft.

RPTAI: retained profits to total assets. This ratio reflects the age of the firm, its dividend policy, and its profitability record over time. Those companies with a low ratio would have higher risk because their retained profits and the paid-up capital of shareholders would be more quickly eroded in case of a trading loss.

TLTAI: total liabilities to total assets. This ratio indicates the level of borrowings in relation to the total funds used by an organization: the higher the level of borrowings, the greater the insolvency risk.

Contribution of ratios. The matrix of the correlation coefficients for the ratios (see Table 18) shows that the highest correlation was 0.60 : this limited the possible scope for multicollinearity to distort the relative contribution a ratio makes to the discriminant function. 
Table 18

Manufacturing and Retail

Correlation Matrix of Ratios in Selected Function

CFBCL CATAI QACA CLTL QLCL RPTAI TLTAI

\begin{tabular}{|c|c|c|c|c|c|c|}
\hline CFBCL & 1.00 & & & & & \\
\hline CATAI & -0.22 & 1.00 & & & & \\
\hline $\mathrm{QACA}$ & -0.10 & 0.60 & 1.00 & & & \\
\hline CLTL & -0.03 & 0.27 & -0.03 & 1.00 & & \\
\hline QLCL & 0.35 & 0.15 & -0.11 & 0.05 & 1.00 & \\
\hline RPTAI & 0.58 & -0.18 & -0.04 & 0.22 & -0.07 & 1.00 \\
\hline TLTAI & -0.53 & 0.22 & 0.07 & -0.19 & -0.03 & -0.59 \\
\hline
\end{tabular}


The contributions of ratios to the discriminatory power of a function can be assessed by comparing the absolute values of the discriminant coefficients (after ignoring signs) in the standardized function: ratios with relatively larger absolute weights contribute more to the discriminatory power of the function than do ratios with smaller weights. However there is still a debate in the literature on what measures are appropriate to use and the standardized coefficient is but one of many alternatives ${ }^{8}$. Acknowledging the controversial nature of tests on the relative importance of individual variables, Altman and Izan (1982, pp.17-18) compared the ranking of variables by four tests: univariate F, Wilks Lambda, standardized coefficient and forward stepwise selection. Table 19 shows the ranking by three of those tests: the forward stepwise is not appropriate because the chosen function was derived by the direct method of selecting variables.

There is dispute among the measures on the ratio which should be ranked highest in relative contribution: this contrasts with Altman and Izan (1982, p.18) who had two ratios consistently ranked 1 and 2 . This lack of consistency in the rankings across the tests leaves some doubt on the importance of, in particular, CFBCL compared with QLCL.

8. See Joy and Tollefson $(1975,1978)$, Altman and Eisenbeis (1978), Scott (1978). 


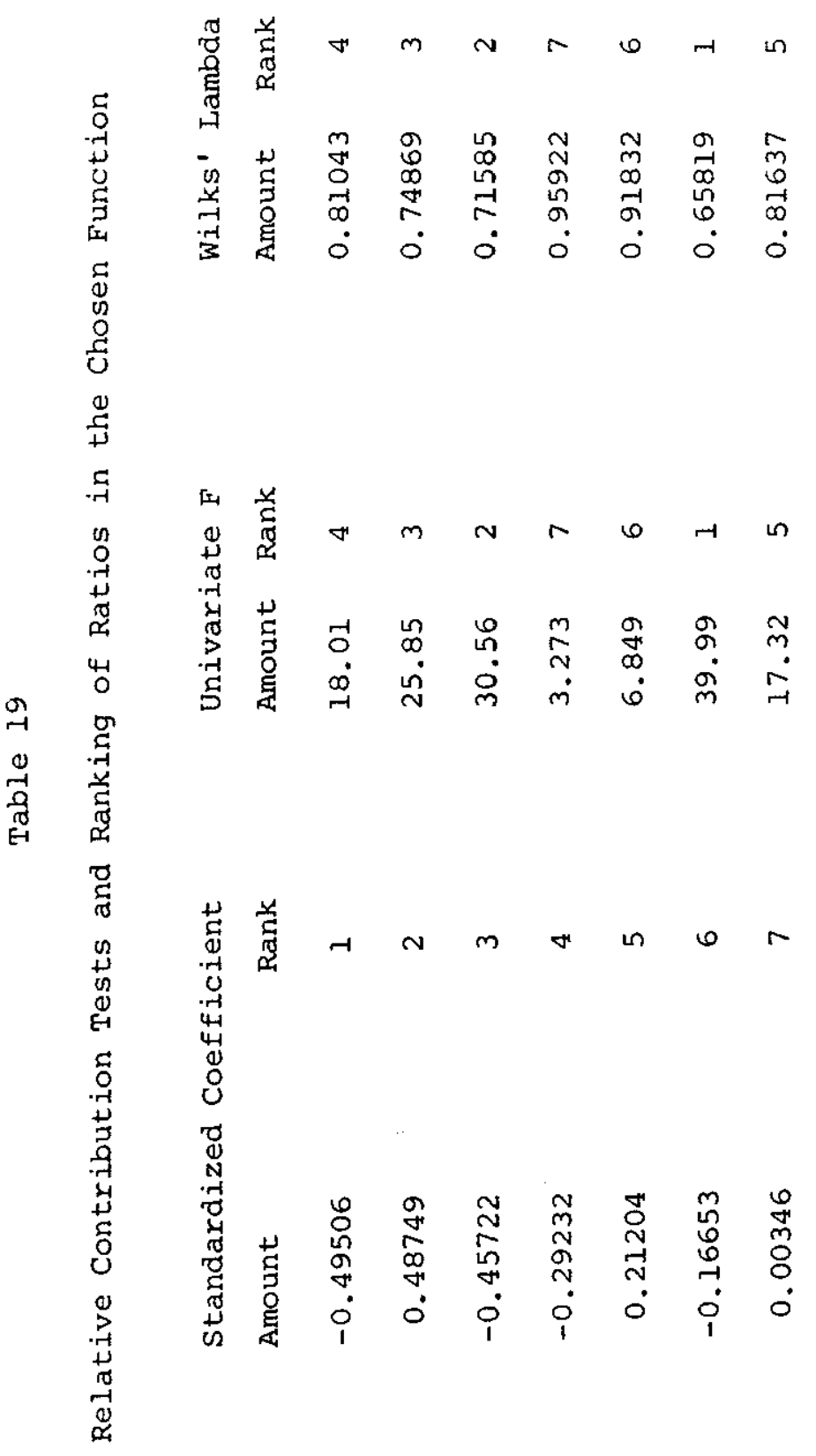

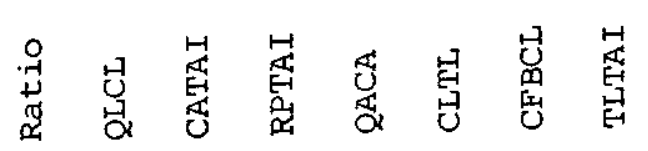


From Table 19, it appears that the main characteristics of a high-risk firm are: (a) the firm is close to the limit of its borrowing capacity, and hence could be pressed to meet its short-term liabilities in times of a profit downturn or heavy build up of stock, and (b) it lacks accumulated profits, either because it is a young firm, or as the result of a poor profit record or of a policy of high dividend payouts. This situation is easily understood and suggests that the chosen function will be most useful for subsequent analysis.

Classification accuracy. The classification accuracy of the function is shown in Table 20 .

Table 20

Manufacturing and Retail Classification Accuracy ( $(8)$ of the Chosen Function

\begin{tabular}{ccccccc}
$\begin{array}{c}\text { Yr. before } \\
\text { failure }\end{array}$ & Manufacturing & \multicolumn{2}{c}{ Retail } & \multicolumn{2}{c}{$\begin{array}{c}\text { Manfacturing \& } \\
\text { Retail }\end{array}$} \\
& $\begin{array}{c}\text { Failed } \\
(\%)\end{array}$ & $\begin{array}{c}\text { Nonfailed } \\
(8)\end{array}$ & $\begin{array}{c}\text { Failed } \\
(\%)\end{array}$ & $\begin{array}{c}\text { Nonfailed } \\
(\%)\end{array}$ & $\begin{array}{c}\text { Failed } \\
(8)\end{array}$ & $\begin{array}{c}\text { Nonfailed } \\
(8)\end{array}$ \\
\hline 1 & 100 & 87.2 & 88.9 & 89.5 & 95.5 & 87.9 \\
2 & 92.3 & 84.7 & 100 & 94.7 & 95.5 & 87.9 \\
3 & 92.3 & 84.7 & 100 & 94.7 & 95.5 & 87.9 \\
4 & 84.6 & 89.7 & 100 & 94.7 & 90.9 & 91.4 \\
5 & 84.6 & 77.0 & 88.9 & 89.5 & 86.4 & 81.0 \\
Average & 86.1 & 83.6 & 95.6 & 91.6 & 92.8 & 87.2
\end{tabular}


The function was derived from Year 4 data and predicted with a consistently high level of accuracy for all years. This confirmed the previously stated hypothesis that if the model could be derived from data which predicted well some years out from failure, then it could be a better model than that derived from data at the year before failure ${ }^{9}$.

Comparison with Year 1 function. Most other research has adopted the "year prior to failure" as the benchmark year for data assessment and use. An exception was Deakin (1972): he also derived a discriminant function for each of the five years. However, Deakin differed from this study in that he used the same variables in the function for each of the five years, with only their parameters changing to reflect the differences in data as bankruptcy became more remote, whereas this study included completely separate models in each of the five years of analysis. Deakin found that the Year 2 function had the highest level of classification accuracy over the five-year period.

Altman et al (1977) and Castagna et al (1981) experimented with Deakin's approach. Altman et al found that the Year 1 model was more accurate than the Year 2-5 models. Castagna et al, however, found that the Year 2-5 models

9. See p. 109 for the previous statement of this hypothesis. An examination of the patterns of insolvency risk (Chapter 8) will explain why (a) the accuracy of the retail failed group declined as failure approached (pattern 2, p. 208) and (b) the nonfailed group's accuracy diminished so much in year 5 (patterns 8,9 and 10, pp. 219-221). 
tended to perform better than the Year 1 model, but suggested that this discrepancy in findings could be due to the smallness of their sample in comparison with Altman's.

Since most other research has adopted the Year 1 model, the Year 1 function with the highest classification accuracy will be compared with the chosen function derived from Year 4 data: Table 21 shows the classification accuracy of both functions.

The average classification accuracy for the five years was 90 per cent for the Year 4 function compared with 81.6 per cent for the Year 1 function. The Year 4 function was superior in classifying failed firms - 92.8 per cent to 70.0 per cent - but the Year 1 function correctly classified more surviving firms - 93.1 per cent to 87.2 per cent. Comparing their classification accuracy in the year before failure both functions correctly classified the same number of failed firms but the Year 1 function correctly classified more of the surviving firms -96.6 per cent to 87.9 per cent.

An argument for favouring the Year 1 function would be the importance of having the highest classification accuracy one year prior to failure, particularly for failed firms. In this study the Year 1 function does not classify failed firms any more accurately in the year before failure: the Year 4 function has the advantage of giving earlier warning signals of corporate distress, because of its higher 

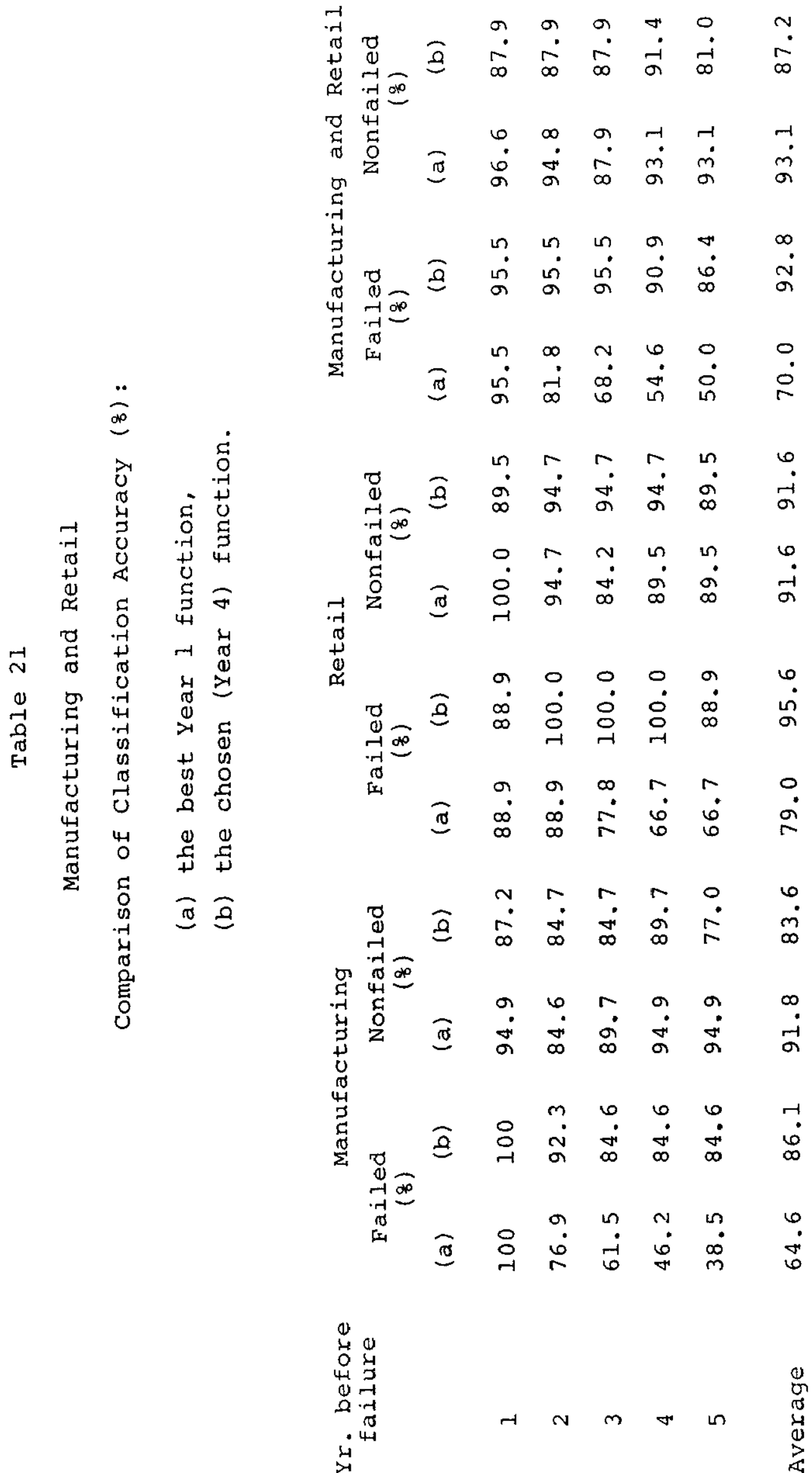
classification accuracy of failed firms in Years 2 to 5. Against this advantage there is the disadvantage that the Year 4 function classifies surviving firms less accurately in Year 1: this lower accuracy is also found in three of the other four years. It is because of this superiority in the Year 1 function for the year prior to failure, despite the possible higher overall classification accuracy of other year functions, that there can be a difference of opinion on the best benchmark year for function derivation. This study favours the selection of the benchmark data based on overall classification accuracy, provided that there is not too great a loss in the Year 1 classification accuracy. Accordingly the Year 4 function will continue to be used for further analysis in this study.

Direct $\mathrm{V}$ stepwise. The chosen function was derived by using the direct method of selecting ratios for inclusion in the function. The stepwise method was also used but this produced slightly inferior classification accuracy (see Table 22).

The stepwise method left CFBCL and TLTAI out of the function. Since the direct method produced higher classification accuracy, it was decided to continue with the function derived by this method ${ }^{10}$.

10. The fact that the stepwise method produced slightly inferior classification accuracy was not surprising. Eisenbeis (1977, p.886) has established that classification accuracy can be reduced by the stepwise process and suggest that there is the need for further work in exploring the links between the tests for significance of variables and classification results. 
Table 22

Manufacturing and Retail

Comparative Classification Accuracy $(\%)$ : Direct and Stepwise Ratio Selection Methods

\begin{tabular}{ccccc}
$\begin{array}{c}\text { Yr. before } \\
\text { failure }\end{array}$ & \multicolumn{2}{c}{ Direct } & \multicolumn{2}{c}{ Stepwise } \\
\hline 1 & Failed & Nonfailed & Failed & Nonfailed \\
\hline 2 & 95.5 & 87.9 & 90.9 & 87.9 \\
3 & 95.5 & 87.9 & 95.5 & 81.0 \\
4 & 95.5 & 87.9 & 95.5 & 87.9 \\
5 & 90.9 & 91.4 & 90.9 & 89.7 \\
Average & 86.4 & 81.0 & 90.9 & 81.0 \\
& 92.8 & 87.2 & 92.7 & 85.5
\end{tabular}

Original-sample $v$ Lachenbruch. These two validation techniques, which measure how accurately the discriminant function describes the data from which it was derived, were compared for classification accuracy in Year 4. Both classified the firms with the same level of accuracy, indicating that there was no upward bias in the originalsample method.

Equality of dispersion. The hypothesis of equality of dispersion was tested and there was a 0.22 probability that the groups had unequal dispersion. Therefore, it was decided to derive a quadratic function, and compare its classification accuracy with that of the linear function. Table 23 compares the classification accuracy of the chosen linear function with that of the derived quadratic 
function comprising the same seven ratios.

Table 23

Manufacturing and Retail

Comparative Classification Accuracy (\%): Linear and Quadratic Classification Rules

\begin{tabular}{ccccc}
$\begin{array}{c}\text { Yr. before } \\
\text { failure }\end{array}$ & \multicolumn{2}{c}{ Linear } & \multicolumn{2}{c}{ Quadratic } \\
& Failed & Nonfailed & Failed & Nonfailed \\
\hline 1 & 95.5 & 87.9 & 90.9 & 84.5 \\
2 & 95.5 & 87.9 & 90.9 & 87.9 \\
3 & 95.5 & 87.9 & 95.5 & 81.0 \\
4 & 90.9 & 91.4 & 95.5 & 84.5 \\
5 & 86.4 & 81.0 & 86.4 & 81.0 \\
Average & 92.8 & 87.2 & 91.8 & 83.8
\end{tabular}

The linear function was slightly superior to the quadratic in overall classification accuracy - there was a minor difference in the classification of failed firms but more difference in the classification of nonfailed ${ }^{11}$. A disadvantage of the quadratic function is its complexity for calculation: there are 35 different parameters in the quadratic model compared to 7 in the linear, not including the intercept ${ }^{12}$. Subsequent analysis of the

11. These results are consistent with several other studies, especially Altman et al (1977, p.38).

12. The quadratic equation is detailed in Appendix $\mathrm{K}$. 
manufacturing and retail industries will report only on the results of the linear process.

Additional variables. Three variables were then added to the seven in the linear discriminant function to ascertain if the classification accuracy could be improved. These three variables were: logarithm of tangible assets (LTAI), balance sheet decomposition measure (BSDM), and stability of earnings (PS). Using the direct method, the ten variables comprised a linear discriminant function and its classification accuracy compared with that of the previous derived seven-variable function (see Table 24).

\section{Table 24}

Manufacturing and Retail

Comparative Classification Accuracy (z): 7-Variable and 10-Variable Functions

$$
\begin{aligned}
& \text { Yr. be fore } \\
& \text { failure }
\end{aligned}
$$

7-Variable

Failed Nonfailed
10-Variable

Failed Nonfailed

$\begin{array}{ccccc}1 & 95.5 & 87.9 & 90.9 & 93.1 \\ 2 & 95.5 & 87.9 & 90.9 & 84.5 \\ 3 & 95.5 & 87.9 & 81.8 & 89.7 \\ 4 & 90.9 & 91.4 & 90.9 & 98.7 \\ 5 & 86.4 & 81.0 & 90.9 & 79.2 \\ \text { Average } & 92.8 & 87.2 & 89.1 & 87.2\end{array}$


The overall classification accuracy of nonfailed firms remained unchanged but that of failed was down in the case of the ten-variable model. In the ranking of the ratios BSDM was number 6 , ahead of $C F B C L$, while PS and LTAI were 8 and 9 respectively, ahead of TLTAI. Using the stepwise selection process, the classification accuracy was the same as for the ten-variable model, but the following ratios were deleted from the function: CFBCL, TLTAI, LTAI and PS.

In both models BSDM made a contribution to the value of the function in the opposite direction to that which would have been predicted: firms with a higher BSDM were given a lower level of insolvency risk. This was because the mean of the BSDM was higher for the nonfailed firms (539.8) than for the failed (517.3). This was not expected since it was thought that failed firms would show more variability in the relationship of the four items comprising their balance sheet structure: current assets, fixed assets, current liabilities and deferred Iiabilities plus shareholders' funds. An examination of the BSDM for all nonfailed firms showed that five had figures several times higher than the average for their group. This was because these firms had carried out a significant restructuring of their debt finance by replacing current liabilities with deferred liabilities: this increased their BSDM and these values resulted in the average of the nonfailed exceeding that of the failed. Accordingly the models would have correctly shown BSDM 
contributing to a lower level of insolvency risk for those five firms, but incorrectly shown both a higher level for all other nonfailed firms and a lower level for failed firms.

The above analysis pointed to a limitation of the traditional interpretation of BSDM as a measure of insolvency risk: it does not allow for the reduction in insolvency risk when a high BSDM is caused by a firm's replacing short-term debt with longer-term debt.'

Table 25 shows the mean values of both the size of a firm, as measured by LTAI, and the fluctuations in earnings over a six-year period.

Table 25

Manufacturing and Retail Industries

Comparison of Group Means: (a) Size of a Firm (ITAI), and (b) Stability of Earnings (PS)

Year before failure

5

$4 \quad 3 \quad 2$

1

LTAI

Failed

3.98

4.01

4.07

4.13

4.15

Nonfailed

4.40

4.43

4.47

4.51

4.60

(PS)

Failed

2. 83

3.48

4.19

7.06

7.78

Nonfailed

1.53

1. 50

1.47

1.51

1.44 
Although there was a consistent separation of the group means for each ratio in the expected direction over the five years - failed firms were smaller in size and had greater fluctuations in earnings - neither ratio improved the classification accuracy of the chosen function. Accordingly, since the inclusion of the three additional variables did not improve the explanation of differences, it was decided that subsequent analysis could be based on the seven-variable model ${ }^{13}$.

Model efficiency comparison tests. It was explained on pp. 28-30 that model efficiency tests would be performed along the lines proposed by Altman et al. (1977). Table 26 gives the results under various input assumptions for the manufacturing and retail industries; it has been assumed that the prior probability of a firm failing ranges from 0.01 to 0.05 , and that error costs vary from 0.60 to 0.80 for misclassifying a failed company and from 0.01 to 0.05 for misclassifying a nonfailed company ${ }^{14}$.

For the manufacturing-and-retail group $\mathrm{EC}_{\mathrm{z}}$ was less than both $\mathrm{EC}_{\max }$ and $\mathrm{EC}$ prop under all assumptions. This suggests that the derived model is more efficient than the alternate naive strategies, the efficiency differential ranging from 2.2 times to 8.75 times.

13. This subsequent analysis is found on pp.147-151 and Chapters 7-10.

14. The assumptions are those used by Altman et al. (1977, pp. 46-48): it seemed reasonable, in the absence of any conflicting data in Australia, to use their assumptions in this study. 


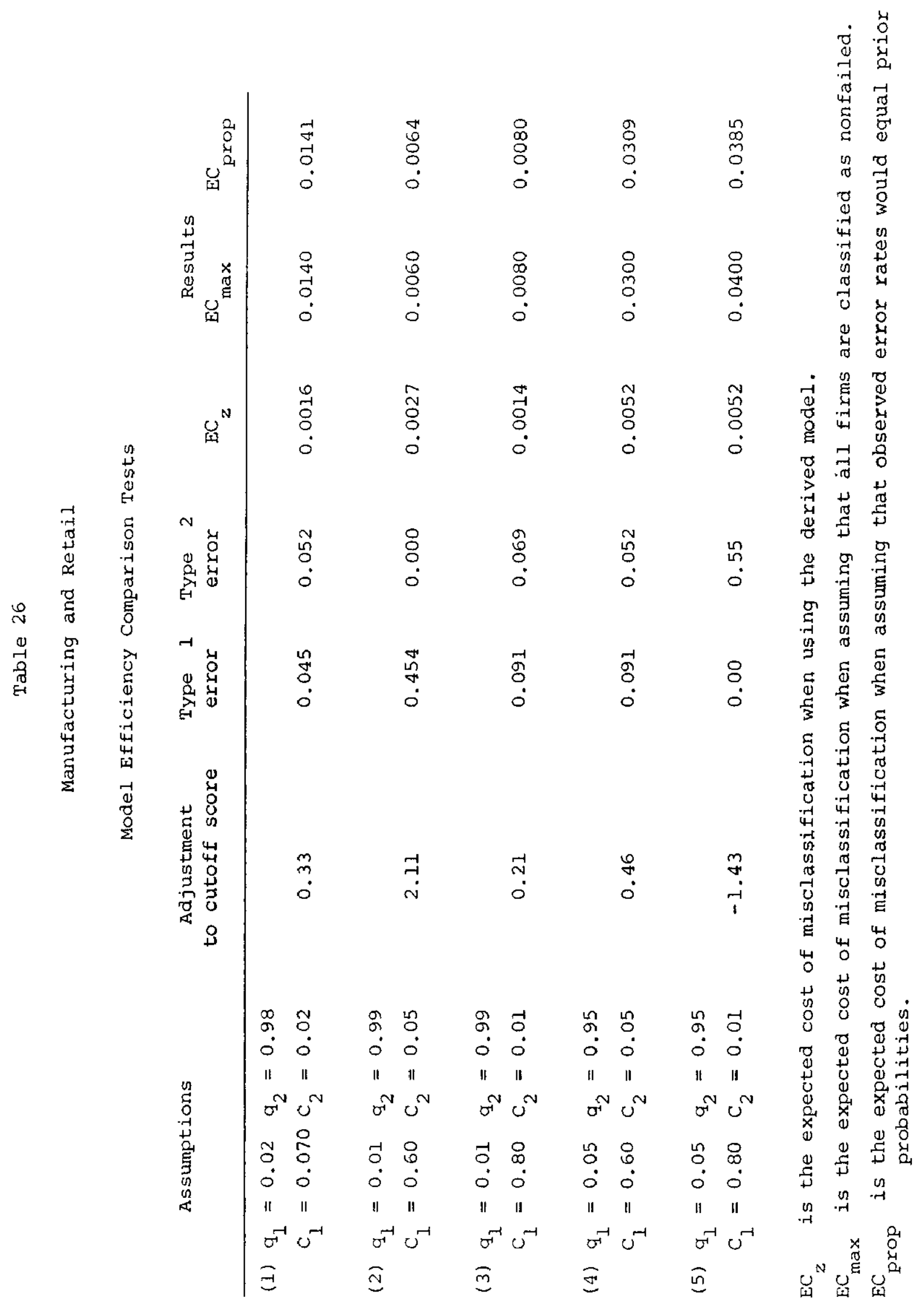


Since the derived model appears to be more efficient than chance strategies, its further use in developing profiles of failed and nonfailed companies is justified.

Comparison with other researchers. The predictive power of the above model compares favourably with that of other models. Table 27 compares, and ranks, the average classification accuracy of this study's model (referred to as Lincoln) for manufacturing and retail companies with those derived by other researchers: Beaver (1966), Altman (1968), Deakin (1972), Castagna et al. (1977), Altman et al. (1977), Castagna et al. (1981). The classification accuracy for each year, and the ratios comprising the functions, are detailed in Appendix $\mathrm{L}^{15}$.

The following conclusions can be drawn from this table:

1. The models of Deakin and Lincoln had the highest classification accuracy. Deakin's best function comprised 14 ratios compared to 7 in Lincoln's. The main difference was that Deakin included 6 ratios which involved sales figures or cash balances. Sales figures for Australian companies were not available to Lincoln. Cash balances were also unavailable because of the more frequent use of bank overdraft facilities in Australia. The amount of cash that is immediately available at the bank to Australian companies, which corresponds to cash balances in America,

15. The other Australian study (Altman and Izan, 1982) was not included because it only gave years 1,2 and 3 prior to failure results: these were 91.9 per cent (Year 1), 82.0 per cent (Year 2), 75.5 per cent (Year 3). 


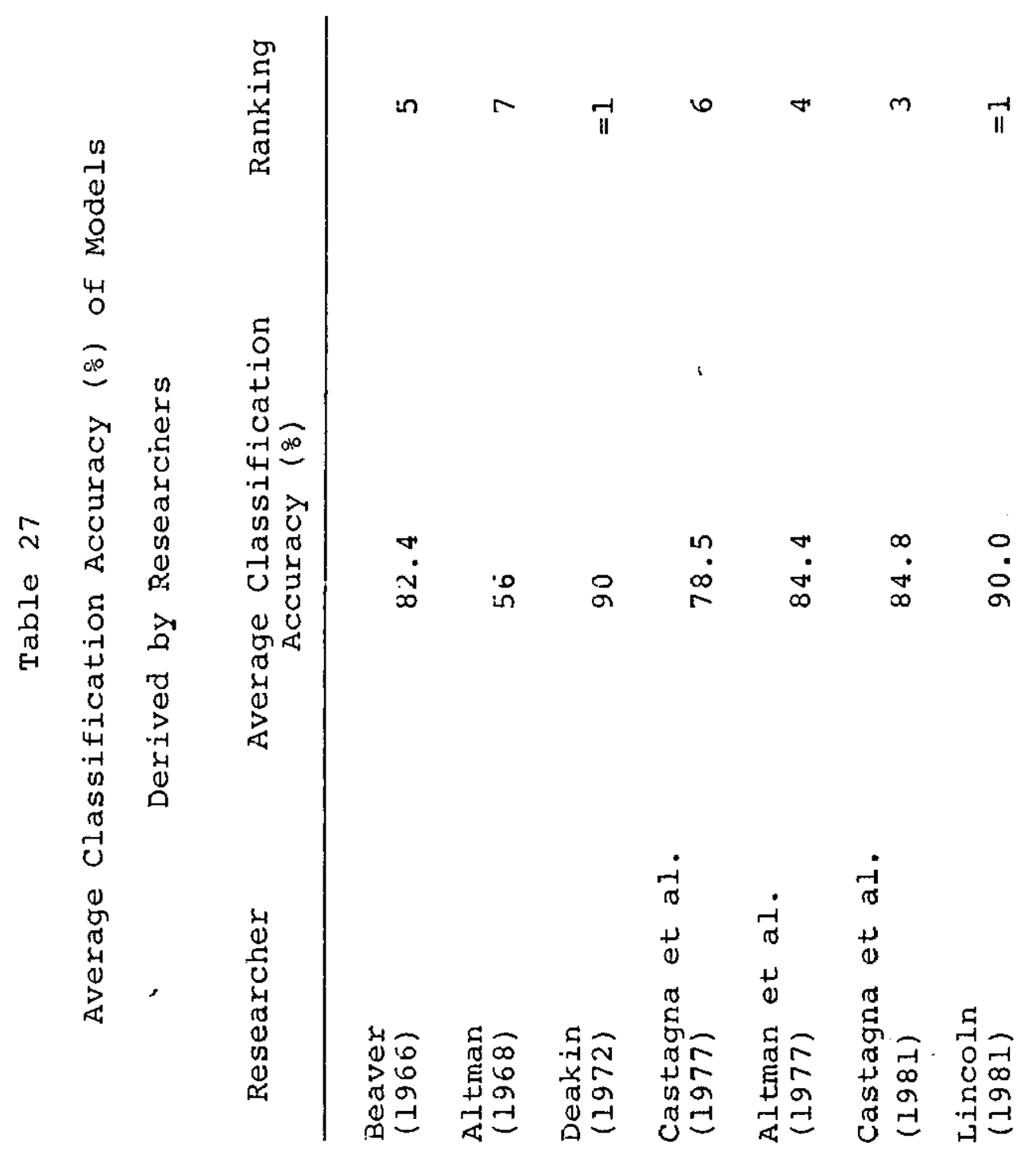


is the amount by which the overdraft limit exceeds the actual overdraft: however, this limit is not published. A notable difference in the remaining ratios used by Lincoln and Deakin was that the latter did not have any liability to liability ratios or retained profits to assets ratios: these ratios were found useful in the Lincoln study, in that excessive reliance on short-term liabilities and lack of retained profits differentiated high-risk from low-risk firms.

2. There was a limitation in Deakin's model for interpretation: many of his ratios were highly correlated and this resulted in ambiguity in the discriminant weights assigned to ratios. In fact the ratios in each of six pairs had different signs before their weights ${ }^{16}$.

3. In contrast to Deakin and Lincoln, Altman and Castagna included in their disciminant functions a variable relating to the sharemarket valuation of a company. Research by both Beaver (1968) and Castagna (1979) has found that investors only predict failure up to two years before the event. This probably explains why the Lincoln and Deakin models predicted failure with the greater accuracy in Years 3,4 and 5 . It would seem that little was to be gained by moving outside financial statement ratios to help explain the symptoms of failure.

In industries where firms are in the failure zone for

16. See p.163 for a listing of these ratios. 
some years, financial ratios appear more discriminating than sharemarket ratios. Where firms in an industry are in failure zone for a period of only two to three years, sharemarket ratios could be more useful because of the similarity of the time span of failure and the time span of the knowledge of the sharemarket. Because it seems that manufacturing and retail firms are in failure zone for up to five years before failure, then sharemarket ratios decline in importance, causing models with such ratios to lose predictive accuracy in Years 3,4 and 5 .

An advantage of the models of Deakin and Lincoln, since they do not rely on sharemarket data, is that they can be applied to unlisted companies.

4. Models derived from the technique of discriminant analysis yielded better prediction results than Beaver's univariate analysis using the cash flow to total debt ratio.

5. So far, the classification that is sought has been a simple dichotomy: a given company either will or will not fail. However, it would appear that a function could be of more value if, rather than making the absolute prediction of failure or nonfailure, the statement could express various levels of confidence. For instance, there is a difference between saying a company will fail and saying that it has a 55 per cent probability of failure. A limitation of the models in Table 27 is that they have spoken more in absolute terms rather than in relative terms. Therefore further analysis in this study of the 
model for the manufacturing and retaii industries will attempt to develop an index of risk based on the probability of being classified as a failure ${ }^{17}$.

\section{Property and Finance Industries}

A process similar to that described above for the marufacturing and retail industries was followed in selecting the function to use for further analysis of the property and finance industries. There were irstances where high correlation caused ambiguity in the discriminant weights assigned to the ratios. For instance, the property function with the highest classification accuracy had two ratios, NOPCA and CFBTL, with different signs before their weightings: an increase in profits and cash flow had the effect, for given values of $\mathrm{CA}$ and $\mathrm{TL}$, of increasing the financial risk on the one hand (CFBTL) and decreasing it on the other (NOPCA).

A further factor to hinder interpretation was the variation in the composition of assets and liabilities anong property firms. For instance one function included CLTAI and QLTL. A property firm whose business was chiefly that of investing in income-producing property had a low CLTAI: the function assigned a low level of risk to this ratio value. However, because of its low CL the firm had a low QLTL: the function assigned a high level of insolvency risk to this ratio value (a low QL was taken as indicating an excessive reliance on bank overdraft).

17. This will be cione in Chapter 7 . 
Therefore this function would have a limited usefulness in explaining the factors which contribute to a certain level of insolvency risk for a property firm whose business is in long-term investments.

Since this research is concerned not just with "results", but also with the interpretation of functions, a sacrifice in classification accuracy was required.

The chosen function. Following the examination of the functions for both industries (property and finance), it was judged that the one which best satisfied the criteria was derived from the two-industry adjusted data for Year 2 and whose ratios had coefficients of correlation less than 0.75 . This function was as follows:

$$
Z=0.4427894+18.92593 \text { PITTAI }-2.400744 \text { TLTAI }
$$

The group centroids were: failed group -1.11041, nonfailed group 0.74027 . The weightings attached to the variables were in the expected directions. Since PITTAI would be higher for the nonfailed firms, its weighting was positive, consistent with the positive centroid for the nonfailed group. Similarly, since failed firms have a higher level of borrowings, the weighting for TLTAI was negative. Therefore all signs were consistent with the ratio values and the group centroids.

It was noted that there was not a ratio in the function from the retained profits category. Accordingly 
a new function of three ratios was derived, consisting of PITTAI, TLTAI and RPTAI. This three-ratio-function, however, had both a lower classification accuracy and ambiguity in the signs to the weights.

The ratios. The following are the ratios comprising the chosen function:

PITTAI: Profit before interest and tax to total assets. This ratio measures the return a firm is earning on its investment. Since property and finance firms have a high level of borrowings, this ratio assumes added importance: firms which have borrowed heavily and suffer a setback in the return on their investment are more susceptible to financial difficulties.

TLTAI: Total liabilities to total assets. This is known as the "gearing ratio": it indicates the proportion of funds used by a firm which have been borrowed.

Contribution of ratios. The more important ratio was PITTAI $^{18}$. The two ratios indicate that the insolvency risk of a firm is best explained by how much it borrows and how well it puts its funds to use. It is perhaps surprising that the cost of borrowing does not appear in the function: it would be expected that firms would have to offer different interest rates and that a PITTAI value may be acceptable for one firm and not another. In order

18. The three tests of relative contribution - standardized coefficient, Wilks Lambda, and univariate F statistic all ranked PITTAI ahead of TLTAI. 
to allow for differences in the cost of borrowing, cash flow before tax (but after interest) to total assets CFBTAI - was substituted for PITTAI. However, there was a decline in classification accuracy suggesting that the cost of debt did not possess any added discriminatory power.

Even though the chosen function comprises only two ratios, it will be useful as it will explain the relation between borrowings, return on funds and insolvency risk. In view of the high level of borrowings which prevails in the property and finance industries, the relationship of that level to the rate of profit and to insolvency risk is an important one. This relationship has not emerged from previous studies, which have concentrated on other industries.

\section{Classification accuracy. The classification accuracy} of the chosen function is shown in Table 28 .

\section{Table 28}

Property and Finance

Classification Accuracy (z) of Chosen Function

\begin{tabular}{ccccccc}
$\begin{array}{c}\text { Yr. before } \\
\text { failure }\end{array}$ & \multicolumn{2}{c}{ Property } & \multicolumn{2}{c}{ Finance } & \multicolumn{2}{c}{$\begin{array}{c}\text { Property \& } \\
\text { Finance }\end{array}$} \\
\hline 1 & Failed & Nonfailed & Failed & Nonfailed & Failed & Nonfailed \\
\hline 2 & 66.7 & 95.0 & 75.0 & 100.0 & 68.4 & 96.9 \\
3 & 60.0 & 100.0 & 50.0 & 100.0 & 57.9 & 100.0 \\
4 & 53.3 & 75.0 & 50.0 & 100.0 & 52.6 & 84.4 \\
5 & 46.2 & 73.7 & 25.0 & 100.0 & 41.2 & 83.9 \\
Average & 50.0 & 94.1 & 25.0 & 100.0 & 42.9 & 96.6 \\
& 55.2 & 87.6 & 45.0 & 100.0 & 52.6 & 92.4
\end{tabular}


The function was derived from Year 2 data. The figures indicate: (a) failed finance firms were in the failure zone for a shorter period of time than the failed peroperty firms, (b) the overall level of classification accuracy was less than for manufacturing and retail firms, indicating that property and finance firms are not in the failure zone for the same length of time - their industries are subject to more severe swings in level of activity.

Direct v. Stepwise. The function with the highest classification accuracy was derived by applying the stepwise selection process to those ratios with coefficients of correlation less than 0.75. However this function, derived from Year 2 data, did not meet the selection criteria because of ambiguity in the discriminant weights. It was found that the functions derived from year 2 data had a markedly higher level of classification accuracy than those derived from other years. Therefore, it was decided to carry out numerous computer runs - using both the direct and stepwise methods - of the different ratioprofiles with the functions being derived from Year 2 data. The function which satisfied the criteria for selection, and has been chosen for subsequent analysis, was derived by the direct method.

Original-sample v. Lachenbruch. Both techniques correctly classified the same number of failed firms in Year 2, but the original-sample method correctly classified all 32 nonfailed firms compared to the Lachenbruch 
correctly classifying 30. The upward bias in these results appears to be slight, since the Lachenbruch results are only 6.5 per cent less for the nonfailed group ( 2 of the 32 surviving firms) and identical for the failed group. Accordingly subsequent analysis will use the results from the original-sample method.

Equality of dispersion. The hypothesis of equality of dispersion was tested and there was a 0.17 probability that the groups had unequal dispersion. Therefore, a quadratic function was derived and its classification accuracy compared with that of the linear (see Table 29).

Table 29

Property and Finance

Comparative Classification Accuracy $(8)$ :

Linear and Quadratic

r. before

Classification Rules

failure

Linear

Quadratic

Failed Nonfailed Failed Nonfailed

\begin{tabular}{crrrc}
\hline 1 & 68.4 & 96.9 & 68.4 & 89.7 \\
2 & 57.9 & 100.0 & 64.3 & 89.7 \\
3 & 52.6 & 84.4 & 52.6 & 84.4 \\
4 & 41.2 & 83.9 & 41.2 & 83.9 \\
5 & 42.9 & 96.6 & 42.9 & 89.7 \\
Average & 52.6 & 92.4 & 53.9 & 87.5
\end{tabular}


Although the quadratic function classified failed firms with higher classification accuracy for the year from which the function was derived (Year 2), overall the linear function was slightly the more accurate. Because of its simplicity for interpretation, it was decided to use the linear function in subsequent analysis.

Additional Variables. Two variables were then added to those in the linear discriminant function to see if its classification accuracy could be improved. The variables were logarithm of tangible assets (LTAI) and earnings stability (PS). Because of the limitation of the balance sheet decomposition measure - it does not allow for the reduction in financial risk when a firm replaces shortterm borrowings with longer-term borrowings (see pp.143-144) - it was not considered as an additional variable. Table 30 shows the mean values of both LTAI and PS.

Table 30

Property and Finance

Comparison of Group Means: (a) Size of a Firm (LTAI), and (b) Stability of Earnings (PS)

Year before failure

$\begin{array}{lllll}5 & 4 & 3 & 2 & 1\end{array}$

LTAI

$\begin{array}{llllll}\text { Failed } & 5.07 & 5.02 & 4.99 & 4.99 & 5.03 \\ \text { Nonfailed } & 5.21 & 5.04 & 5.14 & 5.16 & 5.24 \\ \text { (PS) } & & & & & \\ \text { Failed } & 1.96 & 2.02 & 1.89 & 3.11 & 4.09 \\ \text { Nonfailed } & 1.17 & 1.44 & 1.78 & 1.19 & 1.41\end{array}$


The expectation was confirmed that failed firms, on the average, would be smaller in size and have greater fluctuations in earnings.

The classification accuracy of the two-variable and four-variable models are compared in Table 31.

Table 31

Property and Finance

Comparative Classification Accuracy $(q)$ :

2-Variable and 4-Variable Functions

Yr. before

2-variable

4-variable

failure

Failed Nonfailed Failed Nonfailed

\begin{tabular}{crrrr}
\hline 1 & 68.4 & 96.9 & 57.9 & 93.8 \\
2 & 57.9 & 100.0 & 52.6 & 93.8 \\
3 & 52.6 & 84.4 & 47.4 & 93.8 \\
4 & 41.2 & 83.9 & 52.9 & 83.9 \\
5 & 42.9 & 96.6 & 28.6 & 93.1 \\
Average & 52.6 & 92.4 & 47.9 & 91.7
\end{tabular}

of the four variables LTAI was ranked number 1 and PS number 4. The effect of the high ranking of asset size was to increase the misclassification rate of failed finance firms: this was because these firms were large in size, and the impact of the size variable in the function was to reduce their overall level of insolvency risk. Although there was little difference in the overal classification accuracy by including the two variables, it was 
decided to continue with the two-variable model because of the higher misclassification rate of failed finance firms caused by the inclusion of LTAI: its inclusion would not assist the explanation of the failure process.

Model efficiency comparison tests. Table 32 gives the results of model efficiency tests prepared under different input assumptions.

For the property-and-finance group, $\mathrm{EC}_{z}$ was less than $E_{\max }$ and $\mathrm{EC}_{\text {prop }}$ under all assumptions: the efficiency differential ranged from 1.3 times to 5.6 times.

These results are disappointing in that the model is only marginally better than some chance strategies: a marked loss in classification accuracy resulted from an endeavour to obtain a model containing unambiguous ratios. For instance the highest classification accuracy for the property industry is 81.0 per cent (see Table 16 on p.125): this compares with 71.4 per cent for the chosen model ${ }^{19}$. The loss in classification accuracy for the chosen property and finance function is to be contrasted with that for the chosen function for the manufacturing and retail industry: the decline in classification accuracy was only from 91.3 per cent 20 to 90.0 per cent ${ }^{21}$. The chosen manufacturing and retail function met the requirements of a user who was

\footnotetext{
19. See Table 28 on p.154: $71.4 \%=(55.28+87.6 \%) \div 2$

20. See Table 16 on p.125:91.3\% $=(89.58+93.0 \%) \div 2$

21. See Table 20 on p.135:90.0\% $=(92.8 \%+87.2 \%) \div 2$
} 


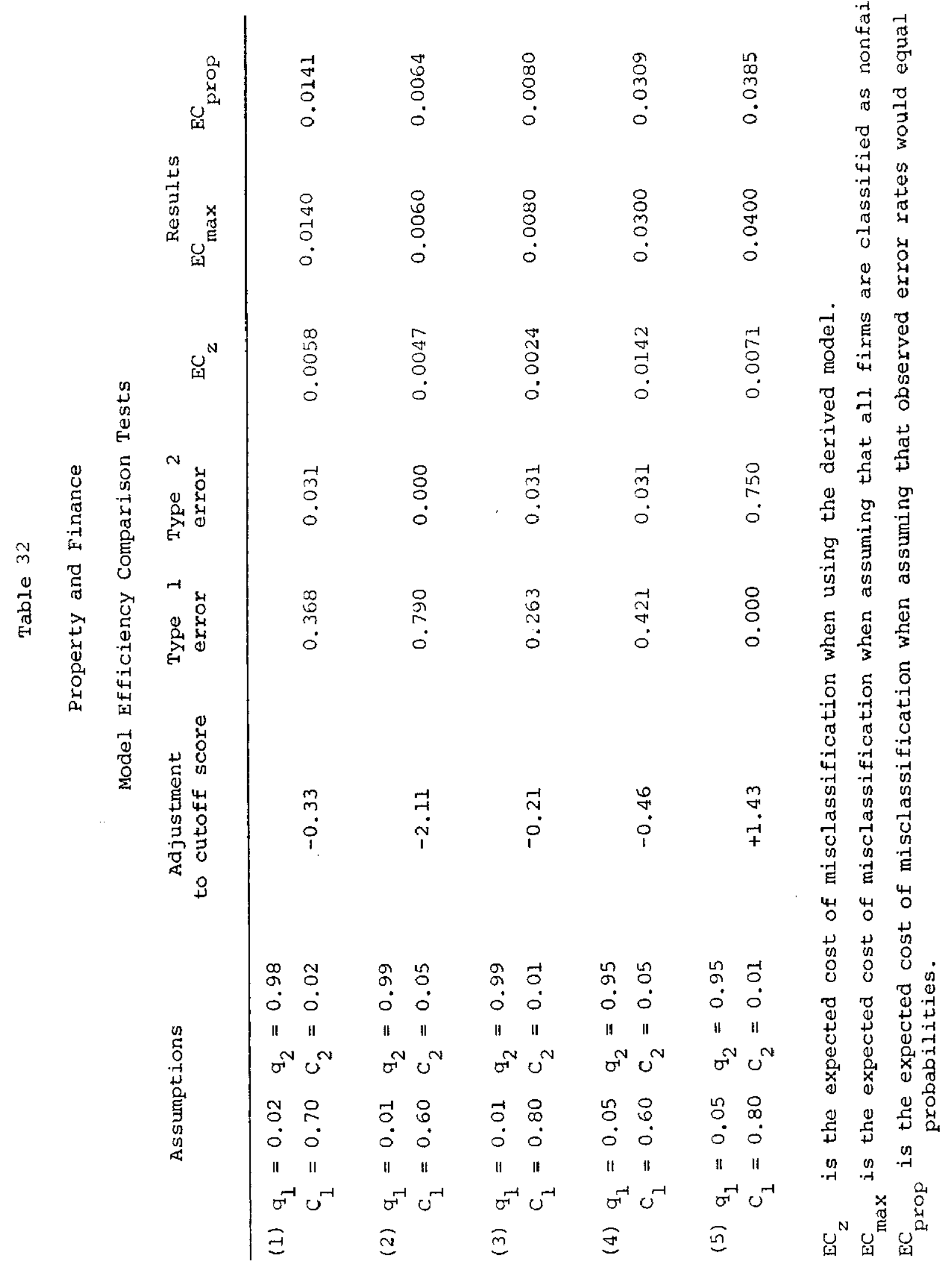


interested in both "results" and consistency of signs for interpretation. The chosen property and finance function is useful for interpretation but is not helpful to the user primarily interested in results because of its low classification accuracy. Therefore the functions with the highest classification accuracy for the property and finance industries will be re-examined, in spite of their lack of clarity for interpretation, because of their greater usefulness to the person interested in results.

\section{Property Industry}

Table 16 (p.125) showed that the property function with the highest classification accuracy - 81.0 per cent was derived from ratios with correlation coefficients of less than 0.75 . This function was as follows:

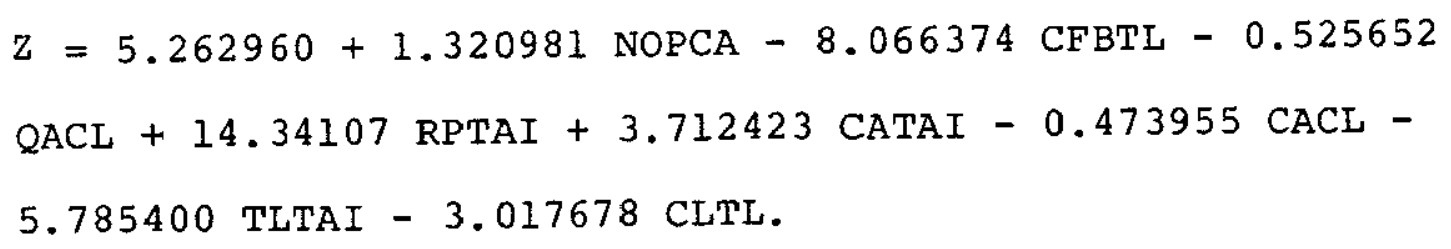

The group centroids were: failed group -1.61612, nonfailed group +1.21209 . The function contains ratios which would be useful for interpretation: ratios which illustrate (a) profitability (NOPCA) and cash flow (CFBTL), (b) liquidity (QACL, CATAI, CACL), (c) level and composition of borrowings (TLTAI, CLTL), and (d) funds provided by retained profits (RPTAI). It would be expected that surviving firms would have (a) a higher return on current assets (NOPCA), (b) a higher cash-flow 
coverage of their borrowings (CFBTL), (c) more liquid assets to meet commitments (QACL, CACL, CATAI), (d) less reliance on borrowings, particularly short-term borrowings (TLTAI, CLTL) and (e) a higher level of retained profits (RPTAI). Although the function contains ratios which could explain why some firms have a higher level of insolvency risk than others, an examination of the signs before the weightings shows that three ratios have negative weightings - CFBTL, QACL, CACL - when it would be expected that they would have positive weightings: the group means of these ratios in Appendix $C$ are higher for nonfailed firms than for failed firms. These negative signs create a difficulty for interpretation. For instance, according to the function an improvement in the cash flow coverage of liabilities increases a firm's level of insolvency risk.

One possible way around the confusion in interpretation which is caused by the illogicality of some of the signs is to take the net contribution to the $z$-score for the sets of ratios which have conflicting signs: that is, to find the net contribution to the $z$-score of the two profit ratios - NOPCA and CFBTL - and the three liquidity ratios QACL, CATAI, CACL. An increase in the net contribution to the $z$-score would reduce a firm's level of insolvency risk and a decline in the net contribution to the $z$-score would increase a firm's level of insolvency risk. However even this "netting" does not overcome the possibility of confusion in all instances. For example a firm may 
hold its level of profit and current assets, but replace some borrowings with share capital: NOPCA would remain the same value but CFBTL would increase and the net effect would be to increase, incorrectly, a firm's level of insolvency risk.

It is not unusual for similar studies to have chosen discriminant functions with conflicting signs. For instance Deakin (1972), in his 14-ratio model, had a different sign before the weightings of each ratio in the following six pairs, (a) cash flow to total debt and net income to total assets, (b) cash to total assets and cash to total liabilities, (c) current assets to current liabilities and quick assets to current liabilities, (d) working capital to sales and cash to sales, (e) current assets to sales and quick assets to sales. (f) current assets to total assets and quick assets to total assets: the group means for the ratios in each set indicated that in the absence of multicollinearity they would have the same sign. Castagna and Matolcsy (1981, p.50), in their linear function had four of the ten ratios with signs different to those which might have been expected ${ }^{22}$.

Classification accuracy. Table 33 shows that the classification accuracy of the above property function was quite high for the first three years before failure, but declined significantly for Years 4 and 5 .

22. These ratios were NPBITTA, QAQL, CACL and RPTA. See glossary, Appendix L, p. 298, for a description of these ratios. 
Table 33

Property Industry

Highest Classification Accuracy

Year before

failure

1

2

3

4

5

Average
Failed

(8)

80.0

86.7

80.0

61.5

60.0

73.8
Nonfailed

$\left(\frac{\circ}{8}\right)$

90.0

95.0

90.0

84.2

82.4

88.3
Average

(o)

85.0

90.9

85.0

.72 .9

71.2

The average classification accuracy was 87.0 per cent for Years 1-3 before failure but declined to 72.1 per cent for Years $4-5$ before failure. The significant decline in the classification accuracy of failed firms further out from the date of failure confirms the earlier findings (see p. 155) that property firms, because of the nature of their industry, are in the failure zone for a shorter period of time than manufacturing and retail firms.

Model efficiency comparison tests. Table 34 shows the results of comparison tests of the model's efficiency, prepared under differing input assumptions, for the property function with the highest classification accuracy. 


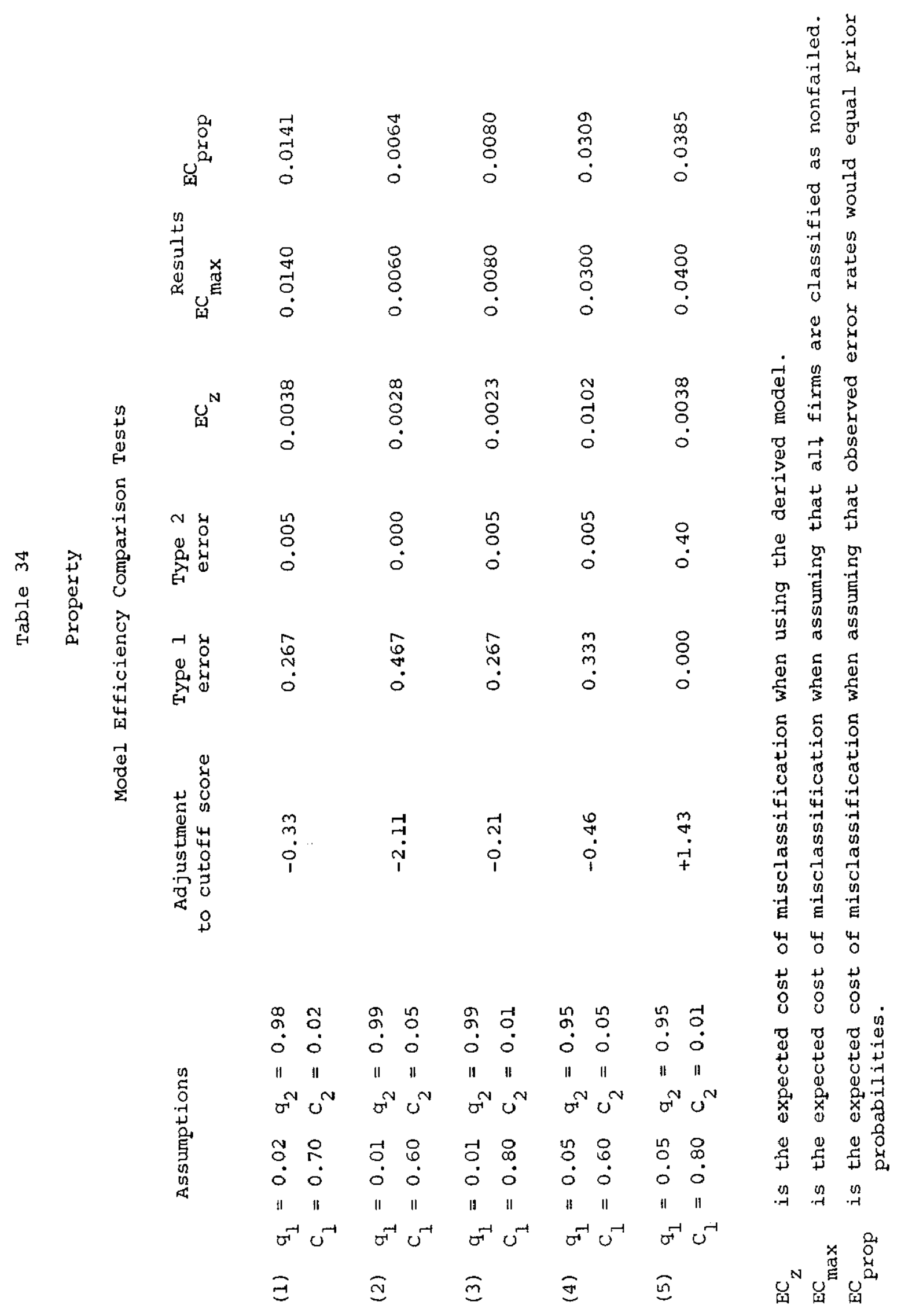


$\mathrm{EC}_{z}$ was less than $\mathrm{EC}_{\max }$ and $\mathrm{EC}_{\text {prop }}$ under all assumptions. This suggests that the derived model is more efficient than the alternative naive strategies, the efficiency differential ranging from 2.1 times to 10.5 times: this differential, as expected was greater than the 1.3 times to 5.6 times for the combined property and finance industry model (see Table 32, p.160).

Since the property model is more efficient than chance strategies a user interested only in classification accuracy would find this model useful.

Year of function derivation. Both the property function with the highest classification accuracy and the chosen function were derived from Year 2 data. Reference has previously been made to the fact that most other research has adopted the "year prior to failure" as the benchmark for data assessment and use: this was because of the importance of classification accuracy in the year before failure (see p.136). There was one function derived from Year 1 data which classified more accurately in that year than the year 2 function with the highest level of classification accuracy over the five years: it had a Year 1 classification accuracy of 96.7 per cent compared with 85.0 per cent for the above function. However that Year 1 function only had an overall classification accuracy of 77.8 per cent. Table 35 compares the classification accuracy of these Year 1 and Year 2 functions. 
Table 35

Property Industry

Highest Classification Accuracy of

(a) Year 1 function,

(b) Year 3 function.

Yr. before failure

Average
Failed

(a)

8

93.

73.3

53.

53.961 .5

$40.0 \quad 60.0$

$62.8 \quad 73.8$
Nonfailed

(a) (b)

웅

\&

$100.0 \quad 90.0$

$95.0 \quad 95.0$

$90.0 \quad 90.0$

84.2

84.2

94.1

82.4

$92.7 \quad 88.3$

77.8

(a) (b)

8 (a) (b)

$\begin{array}{ll}\text { a) } & \text { (b) } \\ 8 & q\end{array}$

Average

Although the Year 2 function correctly classifies more failed firms, particularly over the three years before failure (82.2 per cent compared with 73.3 per cent) it has the disadvantage of correctly classifying fewer failed firms immediately prior to failure. Accordingly some users could prefer the Year 1 function which is as follows: $Z=1.509202+8.953261 \mathrm{CFBQL}+17.56265$ NOPTAI -28.40654 NOPQL - 1.672163 TLTAI - 0.0360 RPQA - 14.28010 RPTAI + 3.18262 RPCL.

The group centroids were: failed group + 1.62404, nonfailed group -1.21803 . Four of the ratios had signs before them which were different to those expected: CFBQL, NOPTAI, TLTAI and RPCL. It would be expected that (a) 
TLTAI would have a positive sign, indicating that the level of insolvency risk increases as a firm obtains a larger proportion of its funds from borrowings, CFBQL and NOPTAI would have negative signs as a higher cash-flow coverage of liabilities and better return on investment would reduce the level of risk, and (c) RPCL would have a negative sign because a higher level of retained profits would reduce the level of risk. Accordingly, the Year 1 function is limited in its usefulness for interpretation purposes.

Further analysis of the property industry. Three functions for the property industry have been detailed: (a) that with the highest classification accuracy but with some conflicting signs before the ratios, (b) that with the highest classification accuracy for the year prior to failure but again with some conflicting signs before the ratios, and (c) the chosen function with a classification accuracy only marginally better than the classification accuracy obtained by chance strategies but with signs and ratios useful for interpretation.

Since this study is concerned not only with "results" but also with interpretation, the previously chosen function, comprising two ratios, PITTAI and TLTAI, will be the one used to gain an understanding of why some firms have a higher level of insolvency risk than others. However the two other functions will not be totally discarded. In the next chapter an index of risk will be developed for 
each function: the relevant index will then help the user of that particular function, but only the index for the chosen function will be further used in this study for analysis of the property industry.

\section{Finance Industry}

Since only four finance firms were in the failed group it was not possible to obtain a statistically acceptable discriminant function from finance industry data alone. Accordingly the sample of firms in the finance industry was combined with the sample of firms from (a) the property industry, and (b) the property, manufacturing and retail industries. The function with the highest classification accuracy for the finance industry was that derived from all ratios using the property and finance industry data: this function had an accuracy of 73.4 per cent (see Table 16, p.125), not much higher than the 72.5 per cent for the chosen function ${ }^{23}$.

The function with the classification accuracy of 73.4 per cent was as follows:

$Z=5.002825+2.351505$ CFBCA -6.111662 CFBTL -3.035531 CFBCL - 1.401567 QACA - 2.263766 TLTAI - 2.894899 QLCL +0.006674 RPCA + 15.73687 RPTAI.

The group centroids were: failed group -1.42848 , nonfailed group 0.84816 . An examination of the means of the eight ratios in the function (see Appendix $\mathrm{C}$,

23. See Table 28 on p.154: 72.5\% $=(45.0 \%+100.0 \%) \div 2$. 
pp. 273-275) indicated that three had conflicting signs before their weights: CFBCL, CFBTL, QACA. It was this potential confusion for interpretation, caused by the impact of multicollinearity on the signs before the weights, that had resulted in the above function being rejected.

Classification accuracy. Because the classification accuracy of the above two functions only differed by 0.9 per cent it was decided to test the impact of variations in cutoff scores on their classification accuracy ${ }^{24}$. Only minor changes took place in the accuracy of the above 8-variable function but significant improvement was recorded in the chosen 2-variable function. By shifting the cutoff score from -0.21 to 0.00 , i.e., increasing the expected cost of misclassifying a failed finance firm, the number of Type 1 errors was reduced and the classification accuracy was improved to 78.4 per cent: the four failed firms were now correctly classified one year before failure. Table 36 shows the classification accuracy of the chosen function using a cutoff score of 0.0 : the classification accuracy of the function using the previous cutoff score of -0.21 is also shown.

There is a gain in the classification accuracy of the failed firms and a loss in the classification accuracy of the surviving firms: this was because the cutoff score

24. The reasons for adjusting a cutoff score are outlined on pp.198-200. 
was shifted closer to the centroid for the nonfailed group since the expected cost of a Type 1 error was regarded as being greater than the expected cost of a Type 2 error. Accordingly a user who establishes that $\frac{q_{1} C_{1}}{q_{2} C_{2}}=1.234$ will find a distinct improvement in the classification accuracy of the 2-ratio function: the chosen function can therefore be helpful to this user, who is primarily concerned with classification accuracy. It will also be used throughout the remainder of this study in an attempt to gain a better understanding of what causes some finance firms to have a higher level of insolvency risk than. others.

\begin{tabular}{|c|c|c|c|c|}
\hline \multicolumn{5}{|c|}{ Finance Industry } \\
\hline \multicolumn{5}{|c|}{ Classification Accuracy $(8)$ of Chosen Function } \\
\hline \multicolumn{5}{|c|}{ Using Two Cutoff Scores: } \\
\hline & (a) & 0.21 & & \\
\hline & (b) & 0.00 & & \\
\hline \multirow{3}{*}{$\begin{array}{c}\text { Year before } \\
\text { failure }\end{array}$} & \multicolumn{2}{|c|}{ Failed } & \multicolumn{2}{|c|}{ Nonfailed } \\
\hline & (a) & (b) & (a) & (b) \\
\hline & 部 & 8 & 8 & 8 \\
\hline 1 & 75.0 & 100.0 & 100.0 & 83.4 \\
\hline 2 & 50.0 & 75.0 & 100.0 & 83.4 \\
\hline 3 & 50.0 & 50.0 & 100.0 & 100.0 \\
\hline 4 & 25.0 & 50.0 & 100.0 & 91.7 \\
\hline 5 & 25.0 & 50.0 & 100.0 & 100.0 \\
\hline
\end{tabular}


Developing an Index of Risk

Having developed models which best explain the financial characteristics of failed and surviving firms, the next stage is to construct an index of risk. Up until now a cutoff score has been calculated, and, depending on whether a company's Z-score is above or below that cutoff score, the company is classified as failed or nonfailed. However, a limitation of this analysis is that it has ignored the extent to which a firm's z-score differs from the cutoff score. For instance, two firms could be correctly classified as nonfailed but if the $z$-score for one is much nearer the cutoff score then the financial characteristics of these two firms would be markedly different: quite clearly, the one nearer the cutoff score would have the higher level of insolvency risk.

Since management, lenders and investors are interested in degrees of insolvencyrisk, it would seem desirable to be more precise about the position of a firm in the failed or nonfailed zone. To this end a transformation will be developed which yields, for any z-score, an associated index of insolvency risk: the index will range from 0 to 1 and $a$ point on the scale will represent a level of insolvency risk $^{1}$. As the measurement moves above zero the level of

1. This index will be developed by making use of additional information provided by discriminant analysis: the probability of group membership. 
insolvency riskincreases: the nonfailure zone will have index values ranging from 0 to 0.49 (firms in this zone are recognized by the model as having the financial characteristics of those which have not failed), and the failure zone will have index values ranging from 0.5 to 1.0 (firms in this zone are recognized by the model as having the financial characteristics of those which have failed). It is this identification of the level of insolvency risk for a firm which will assist management, lenders and investors in their decision making.

The interpretation of a firm's level of insolvency risk would be assisted by analysing the trend in its levels of risk over a minimum of, say, five years. For example, consider a failed company which had the following levels of insolvency risk for the five years before failing:

$\begin{array}{cc}\text { Year before failure } & \text { Insolvency Risk } \\ 1 & .80 \\ 2 & .66 \\ 3 & .45 \\ 4 & .30 \\ 5 & .10\end{array}$

The insolvency-risk level of 0.45 in Year 3 indicates that the company has the financial characteristics of surviving firms. But the trend in the insolvency-risk levels from Years 5 to 3 shows that movement into the failure zone is a distinct possibility since the company has been rapidly 
moving towards it. Therefore, the interpretation of the insolvency risk of this firm would be different from that of a firm which has the same risk level (0.45), but it has come from the failure zone into the nonfailure zone. The conclusion is that just as financial analysts look at the trend in univariate ratios, there is also the need to look at the trend in the levels of insolvency risk.

The analysis can then go a vital step further. By calculation of the contribution of each ratio to the $\mathrm{z}$-score for several years, those ratios with the most significant variations can be highlighted, thus explaining the trend in the levels of insolvency risk. Knowing where the problem is then enables possible remedies to be appraised. Further, the effect of those remedies can be forecast by assessing their impact on the $\mathrm{z}$-score, i.e., whether the proposed remedies will reduce insolvency risk to the desired level.

For analysis, the insolvency-risk level of a firm could be expressed in graph form, the vertical axis being the scale of insolvency-risk levels and the horizontal axis representing the year for which the insolvency-risk level was calculated. Graphs have the advantage of ease of comparison, both with previous years and with other firms. For example, a company may just move out of failure zone, but to gain an understanding of the significance of this movement, it would be helpful to compare its graph with that of firms in a similar industry. If the improvement of these other firms was more pronounced, then this is an important piece of information 
for analysis: a better indication can be gained of the relative performance of companies.

The rest of this chapter reviews the approach of previous researchers to developing an index of insolvency risk, and then details how this study derived its index.

Previous Research

At least two previous studies have constructed an index to measure the insolvency risk of a firm.

For instance, Tamari (1964) developed the following index of risk:

1. Shareholders funds/Total liabilities

2. Profit trend

3. Current ratio

4. Value of production/Inventory

5. Sales/Receivables

6. Value of production/Working capital
25 points

25 points

20 points

10 points

10 points

10 points

100 points

He then gave a firm a certain number of points for each ratio, according to its value. For example, his key for the ratio shareholders funds/Total liabilities was as follows: 


$\begin{array}{ll}\text { over } 50 \% & 25 \text { points } \\ 41 \%-50 \% & 20 \text { points } \\ 31 \%-408 & 15 \text { points } \\ 21 \%-30 \% & 10 \text { points } \\ 11 \%-20 \% & 5 \text { points } \\ \text { up to } 108 & 0 \text { points }\end{array}$

He had similar keys for the other five ratios: a range of values was assigned a points score. A total score was obtained for a firm and interpreted as follows:

61 points or more: high index with firms unlikely to fail, 31 - 60 points: medium index with firms having a greater risk, less than 30 points: low index with firms likely to go bankrupt. He tested his index on samples of failed and surviving firms in three countries: Israel, the United Kingdom and the United States of America. He found that the above cutoff points were not suitable for firms in the United states and made some upward adjustments to them.

Tamari's approach has been criticized because his weights were subjectively determined. However he believes his approach may be superior to objective, mechanically derived indices: " . . an index built independently of actual data would, a priori, be more applicable to a wide range of dissimilar firms, to those operating in other economies, or operating in the one economy at a different point of time, or under changed economic conditions." (1978, p.194).

Another approach to assessing the insolvency risk of a 
firm has been the "scorecard" approach. Many financial institutions and credit departments of firms have a scorecard involving ratios to assess the insolvency risk of a potential or existing client. One such scorecard which has been given prominence was that developed by Argenti (1977). He developed a method, called the "A-score", for - assessing business risk. The factors taken into this scorecard are both ratios and qualitative factors: his approach was similar to Tamari's in that he subjectively determined the weights for each factor. Argenti's scorecard is shown in Table 37 .

One difficulty in applying Argenti's technique is that much of the information is such that the analyst would need either to be a member of the firm or have a very good knowledge of its structure and internal operations.

Whereas Tamari and Argenti based their assessments of risk on subjective determination, Altman based his on a statistical study. In his ZETA model (1977), he refers to an overlap zone (or zone of indifference). The overlap area is the range of scores where errors in classification are observed. However Altman does not attempt to assign insolvency-risk levels to companies in this overlap area: instead he declared them marginal and worthy of further examination. Ohlson (1980) appears to be the first published study to develop a probabilistic estimate of failure: he used the statistical technique of logit analysis to estimate the probability of a firm failing, believing that 
Table 37

SCORECARD FOR THE A-SCORE: ARGENTI (1977, P.52)

\section{Defects}

Management

-

1. Autocratic chief executive who dominates his colleagues and will hear no advice

$-0.5$

2. The chief executive is also the chairman.

3. The skills on the board are unbalanced, e.g. there are too many engineers.

4. There is no strong finance director.

5. Most members of the board do not actively participate in the big decisions.

6. There is no depth of professional management below the board.

Accounting

1. There is no budgetary control system - there may not even be a budget.

$-0.2$

2. There is no cash flow plan if there is it is out of date.

3. There is no costing system, no one knows what each product really costs nor knows its contribution.

Response to change

The company exhibits some clear and vital example of failing to respond to change - an ageing product, old fashioned plant, out-of-date attitude to employees, etc.

$-1.0$

Total for Defects
$-0.15$

$-0.15$

$-0.15$
$-0.2$

$-0.2$

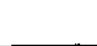

$-3.0$
Depending upon the perceived severity, score up to a maximum of: 
Table 37 (continued):

\section{Mistakes}

Depending upon the perceived severity, score up to a maximum of:

Leverage

The capital gearing or the income gearing of the company is noticeably high.

overtrading

The turnover is rising at a much faster rate than profits or cash flow.

$-1.0$

Projects

The company has launched a project of such a size that if it goes wrong it will more than exceed any possible cash available from all sources.

$$
-1.0
$$

Total for Mistakes

$$
-3.0
$$

\section{Symptoms}

Financial Signs

The traditional ratios will deteriorate and cash will be extremely scarce. The share price will fall versus the index.

Creative Accounting

The Accounts will show evidence of window dressing to "improve" profits.

Non-financial signs

The office needs painting, quality and morale falls, etc.

Nose-dive

It becomes impossible to hide the last gasp scramble for cash.

Total for symptoms

$-1.0$

$$
-7.0
$$

Grand total for A-score 
this technique overcame the statistical limitations of discriminant analysis. Altman and Izan (1982), using discriminant analysis, translated the discriminant scores for firms in their study into a probability of being classified into the failed group: they suggest that this will be "a useful statistic in assessing the failed propensities of new firms and might be thought of as a measure of insolvency-risk." (p.22)

The conclusion is that there has been little published work developing an index of risk from a statistical study of the financial characteristics of failed and nonfailed firms. The aim of this study is now to construct such an index from the functions previously derived by the statistical technique of discriminant analysis ${ }^{2}$.

\section{Construction of Index of Risk}

The Statistical Package for Social Sciences (SPSS) was used to derive the linear discriminant functions, using the original-sample and hold-out-sample validation techniques, which best discriminated between failed and nonfailed groups. As previously explained (see p.17) the z-scores for the sampled groups - failed and nonfailed firms - are assumed to be normally distributed. Since normal distributions cannot be totally separated - by definition, a normal distribution

2. In this study the statistical limitations of discriminant analysis suggested by Ohlson $(1980)$ have been reduced by (a) using ratios which are symmetrical in distribution, and (b) considering prior probabilities. 
has the range $(-\infty,+\infty)$ - there will be overlap where firms could be in either group: SPSS measures the probability for each firm being in either group. If its $z$-score is on the failed group side of the cutoff score its probability of having the financial characteristics of failed firms will be in excess of 0.5: if its $z$-score is on the nonfailed group side of the cutoff score its probability of having the financial characteristics of failed firms will be less than 0.5 .

The intention is to construct an hdex of insolvency risk from the $\mathrm{z}$-scores, and their probability of being classified in the failed group, according to the chosen functions for (a) the manufacturing-retail industries, and (b) the property-finance industries. This method of construction assumes that insolvency risk can be defined as being equal to the probability of being classified in the failed group: the assumption will now be tested.

\section{An Analysis of the Probability of Group Membership}

This analysis is to test the assumption that the probability of a firm's being classified in the failed group could be regarded as a measure of its probability of failure through insolvency, i.e., as a measure of insolvency risk. The assumption will be tested by examining to what extent different discriminant functions affect a firm's probability of being classified in the failed group: this probability will subsequently be 
referred to as $P(F)$. Insolvency risk could be defined as being equal to $P(F)$ if there is insignificant variability in the $P(F)$ for a firm among different discriminant functions: $P(F)$ is independent of the discriminant function. If, however, $P(F)$ is a function of the choice of discriminant function, then this exposes a limitation when using the statistical probability of failure - P(F) as a measure of insolvency risk: significant variation in the insolvency-risk measure for a firm would not accord with reality where a firm's insolvency risk is fixed at a particular time.

Variation in $P(F)$ measures for manufacturing and retail firms. To find how sensitive $P(F)$ is to the choice of discriminant function, the $P(F)$ measures from six different functions were compared, for fourteen randomly selected manufacturing and retail firms (seven failed and seven surviving). The discriminant functions used in the comparison were:

(a) the three functions with the highest level of classification accuracy derived from single-industry data (functions [a], [e] and [c] for the manufacturing industry and functions [e], [d] and [c] for the retail industry, in Table 16 on p.125),

(b) the two functions with the highest level of classification accuracy derived from combined manufacturingretail industry data (functions [a] and [b] in Table 16 on p.125), and

(c) that function which had previously been chosen as the 
one which best described the level of insolvency risk for manufacturing and retail firms (see p.129 for this function).

The comparison could be regarded as valid because there was not a large difference between the classification accuracy of the six functions for each industry: if one function had significantly more misclassifications than another then it would be expected that this could bias the comparison test because the deficiency of the function would be a factor influencing the probability measures. The classification accuracy of each of the six functions compared was as follows:

(a) manufacturing firms: $91.38,90.5 \%, 89.58,88.58$, $88.5 \%$ and $84.9 \%$;

(b) retail firms: $95.8 \%, 95.3 \%, 95.28,93.6 \%, 93.5 \%$ and $93.0 \%$.

The $P(F)$ figures from the functions were listed for the fourteen firms for each of the five years. From this list the highest and lowest $P(F)$ figures for each firm for each year were extracted and 1isted. The lowest $P(F)$ figure for a year was subtracted from the corresponding highest and the difference, called the range, was also listed: it is the range of the $P(F)$ figures which indicates the impact of the different discriminant functions on the level of insolvency risk. Appendix $M$ sets out the $P(F)$ figures for the fourteen firms, obtained from the six discriminant functions: the range of probability measures 
is also given in Table 38 to assist in further analysis.

Table 38

The Range of the Probability of a Firm's being Classified in the Failed Group as Measured from Six Discriminant Functions

Firms

Failed

A.G. Healing

Federated Ind.

International Footwear

James Miller Holdings

Favelle Mort

Walsh Holdings

Gollin Holdings

Average

Nonfailed

Kelvinator

Duncan Holdings

Coates and Co.

Mascot Ind.

Kinnears

Lowes

J.B. Young

Average

Average of Failed

and Nonfailed
Year Before Failure

$\begin{array}{llllll}5 & 4 & 3 & 2 & 1 & 5 \text { Year } \\ \text { Average }\end{array}$

0.15

0.14

0.10

0.04 .

0.14

0.17

0.14

0.17

0.10

0.10

0.14

0.130 .16

0.03

$0.10 \quad 0.11$

0.11

0.16

0.15

0.16

0.130 .05

0.13.

0.19

0.06

0.17

0.120 .02

0.11

0.12

0.12

0.19

0.11

0.13

0.13

0.1

0.14

0.11

0.170 .10

0.14

0.16

0.13

0.15

$0.12 \quad 0.05$

0.12

\begin{tabular}{llllll}
0.12 & 0.12 & 0.08 & 0.09 & 0.06 & 0.09 \\
0.19 & 0.20 & 0.09 & 0.09 & 0.10 & 0.13 \\
0.06 & 0.06 & 0.29 & 0.04 & 0.03 & 0.10 \\
0.08 & 0.05 & 0.05 & 0.08 & 0.13 & 0.08 \\
0.17 & 0.13 & 0.18 & 0.17 & 0.18 & 0.17 \\
0.01 & 0.01 & 0.02 & 0.03 & 0.02 & 0.02 \\
0.22 & 0.13 & 0.18 & 0.09 & 0.08 & 0.14 \\
\hline 0.12 & 0.10 & 0.13 & 0.08 & 0.09 & 0.10 \\
\hline 0.14 & 0.12 & 0.14 & 0.10 & 0.07 & 0.11 \\
\hline
\end{tabular}

Source: Appendix M

Table 38 shows that the average annual range of $P(F)$ for all firms is 0.11 . This difference between the highest and lowest $P(F)$ indicates that different discriminant functions, with approximately the same classification accuracy, 
can have different $P(F)$ measures for a firm. Accordingly, $P(F)$ is a function of the choice of discriminant function although there does not appear to be a marked difference say greater than 0.20 - in the $P(F)$ for a firm among the different discriminant functions. Because of these differences in $P(F)$ it would be useful to know (a) the position at any given time of the chosen function in relation to others, and (b) the shape in the patterns of $P(F)$ traced by all functions.

1. Relative position of chosen function. An attempt was made to see where the $P(F)$ measures from the chosen. function were ranked in relation to the $P(F)$ measures from the other functions: the distribution of the rankings is shown in Table 39.

Table 39

Distribution of Rankings from 1 (lowest $P(F)$ ) to 6 (highest $P(F)$ ) of Chosen Function Ranking Number of Years Failed Firms

$\begin{array}{lr}1 & 19 \\ 2 & 11 \\ 3 & 5 \\ 4 & - \\ 5 & - \\ 6 & = \\ & 35\end{array}$

Nonfailed Firms

$\begin{array}{lc}1 & 19^{(a)} \\ 2 & 2 \\ 3 & - \\ 4 & 4 \\ 5 & 4 \\ 6 & 6 \\ & \frac{6}{35}\end{array}$

(a) Fourteen of these were equal 1 ranking with at least one other function. 
On a ranking scale from 1 (lowest $P(E)$ measure) to 6 (highest $P(F)$ measure), the chosen function ranked in most instances either 1 or 2 in the failed group, and in the nonfailed group 1 or 2 in sixiy per cent of the cases and 4,5 or 6 in forty per cent. This indicates that, with some exceptions in the case of surviving firms, the chosen function had the lowest $P(F)$ measures. Two conclusions can be drawn from this finding to help the user of the chosen model:

(a) Failed firms. Since in most instances the functions correctly classified - and misclassified the same firms, the chosen function tended to place the failed firms in the same zone as the other functions, but at a lower $P(F)$ : however, the difference in the $P(F)$ measures narrowed appreciably as the date of failure approached.

(b) Nonfailed firms. If a firm significantly increased its reliance on bank overdraft, its $P(F)$ would increase far more from the chosen function than the other functions, to the extent that the chosen function would often produce the highest $\mathrm{P}(\mathrm{F})$ measure. Otherwise the chosen function tended to rank as the lowest $P(F)$.

2. Patterns traced by $P(F)$ measures. Although the $P(F)$ for a firm can vary, depending upon the discrminant function from which it is derived, a factor that is fairly consistent is the trend in a firm's $P(F)$ measure. An examination of the $P(F)$ measures for each firm in Appendix $M$ 
provides evidence of consistency in the pattern - although not the level - of $P(F)$ measures. For instance, Figure 9 depicts the pattern of $P(F)$ traced from each of the six discriminant functions for a failed manufacturing firm, A.G. Healing.

The patterns all show an upward trend from five years before failure, with any deviation from trend during this period not being so severe as to make one pattern clearly different from the others. The patterns of the remaining thirteen companies in the sample are traced in Appendix $N$ : these confirm that the pattern of $P(F)$ for a firm is similar for each of the six discriminant functions. This consistency of patterns suggests that the pattern traced for each firm from the chosen function can be used to discern general patterns of $P(F)$ for failed and nonfailed firms: although the $P(F)$ measure for a firm is peculiar to a discriminant function, the pattern of that measure is applicable to all discriminant functions.

A consequence of the functions tracing similar patterns of $P(F)$ measures for a firm is to enable the user of a model to make general statements on the trend in the financial standing of a firm. For instance, if the chosen function shows that the $\mathrm{P}(\mathrm{F})$ for a firm has increased, this can confidently be taken as an adverse situation because all functions would probably have recorded this trend; what differs are the points on the scale from 0 to 1 where the movement started and finished. As previously stated the 

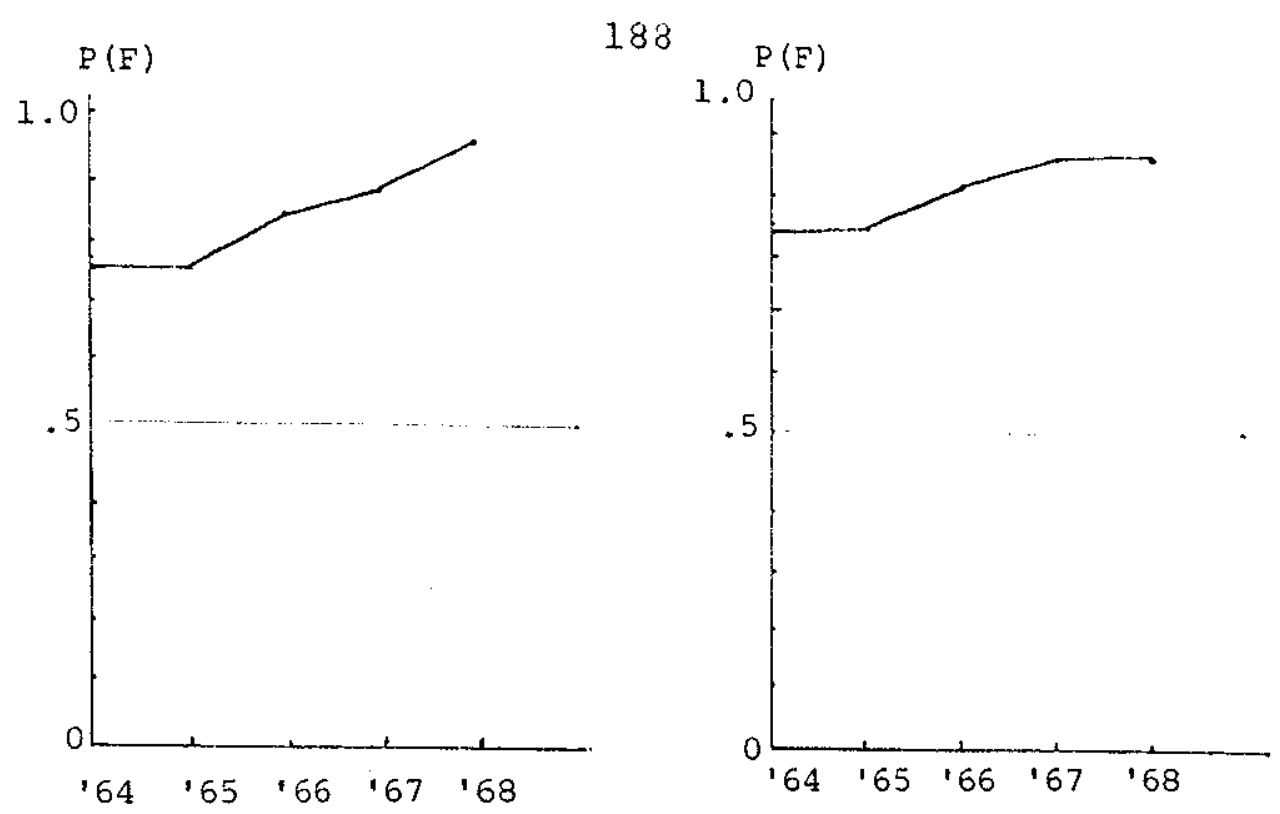

$P(F)$

$P(F)$
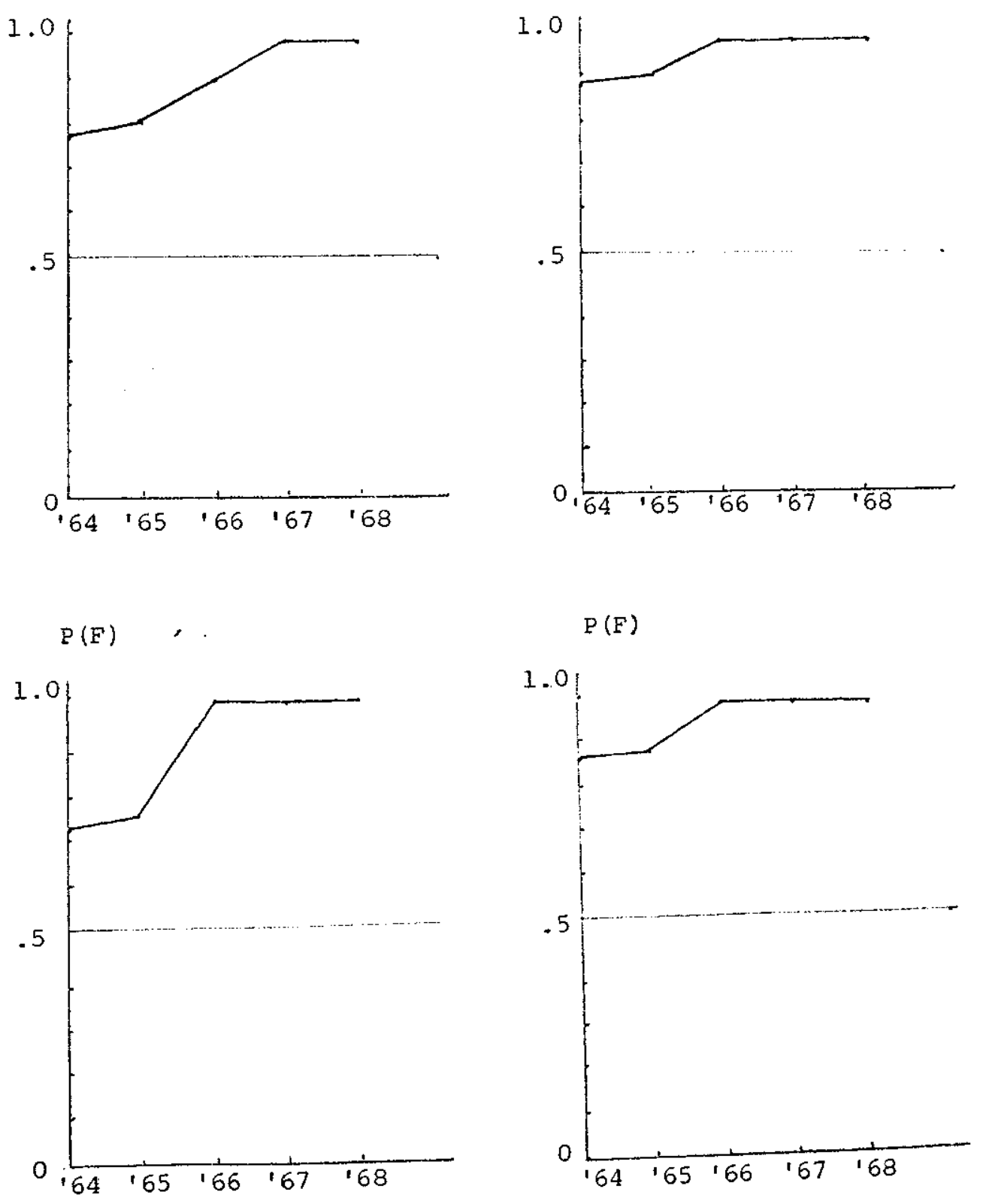

Figure 9: Patterns of $P(F)$ for A.G. Healing Traced from Each of Six Discriminant Functions 
$P(F)$ may be lower for the chosen function except where a firm significantly increases its reliance on bank overdraft.

\section{Variation in $P(F)$ measures for property and finance}

firms. A similar analysis to that described above for manufacturing and retail firms was carried out on a random sample of six property and four finance firms with an equal number of these firms being failed and nonfailed.

The six discriminant functions used in the comparison were:

(a) the three functions with the highest level of classification accuracy derived from property-industry data (functions [d], [a] and [b] in Table 16 on p. 125),

(b) the two functions with the highest level of classification accuracy derived from combined property and finance industry data (functions [a] and [e] in Table 16 on p.125), and

(c) the function which had previously been chosen as that which best described the level of insolvency risk for property and finance firms (see p.152 for this function).

The classification accuracy of each of the functions compared was as follows:

(a) property firms: $81.0 \%, 79.7 \%, 79.2 \%, 79.28,74.8 \%, 71.4 \%$.

(b) finance firms: $73.4 \%, 72.5 \%, 69.2 \%$.

The listing of the $P(F)$ figures for each firm from the functions is in Appendix 0 : the range of these figures for each firm is indicated in Table 40 . 
Table 40

The Range of the Probability of Property and Finance Firms being Classified in the Failed Group as Measured from Six Discriminant Functions

Firms

Failed

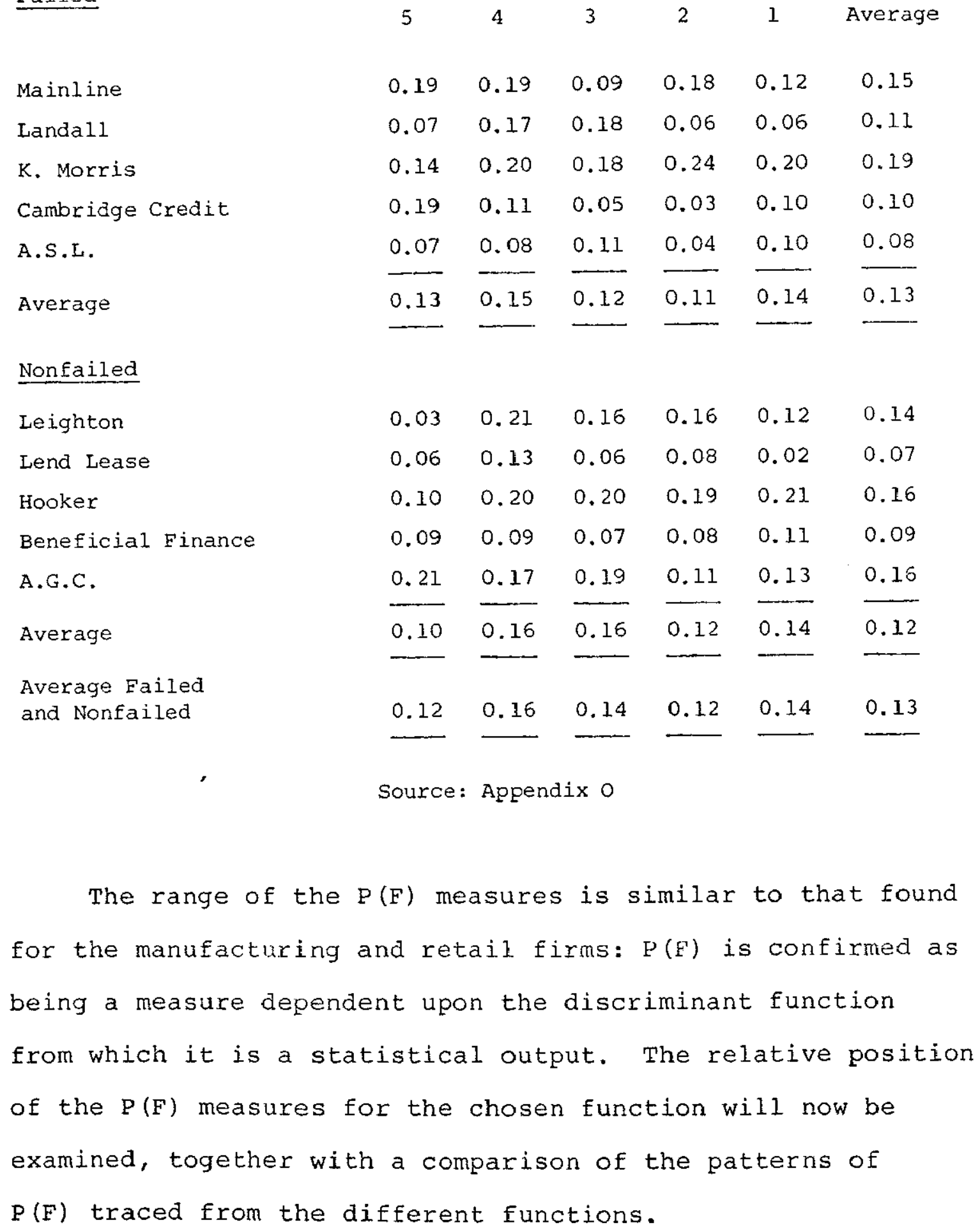

$\begin{array}{llllll}5 & 4 & 3 & 2 & 1 & \\ & 4 & \text { Average }\end{array}$

Year Before Failure 
1. Relative position of the chosen function.

Table 41 shows the ranking of the $P(F)$ measures for the chosen function.

Table 41

Distribution of Rankings from 1 (lowest $P(F)$ ) to 6 (highest $P(F)$ ) for Property Firms and 1 (lowest $P(F)$ ) to 3 (highest $P(F)$ ) for Finance Firms from Chosen Function

\begin{tabular}{|c|c|c|c|c|}
\hline & Pro & erty & Fin & hee \\
\hline & Ranking & No. of Years & Ranking & No. of Years \\
\hline Failed Firms & 1 & 5 & 1 & 3 \\
\hline & 2 & 3 & 2 & - \\
\hline & 3 & 2 & 3 & 7 \\
\hline & 4 & - & & \\
\hline & 5 & - & & \\
\hline & 6 & 5 & & \\
\hline Nonfailed Firms & 1 & - & 1 & - \\
\hline & 2 & - & 2 & 1 \\
\hline & 3 & - & 3 & 9 \\
\hline & 4 & - & & \\
\hline & 5 & 4 & & \\
\hline & 6 & 11 & & \\
\hline
\end{tabular}

For suryiving property firms the $P(F)$ from the chosen function tended to be the highest, but for failed property firms the $P(F)$ of the chosen function was spread from highest to lowest. This finding is consistent with the fact that, of the six functions, the chosen function had the highest misclassification rate for property firms. The high ranking for surviving firms meant that the chosen function misclassified more of these firms, and the low ranking for some failed firms meant that it misclassified more of these firms than the other functions. 
For the finance industry the chosen function tended to have the highest $P(F)$ figures for both groups of firms.

2. Patterns traced by $P(F)$ measures. The patterns of $P(F)$ traced for the ten property and finance firms from the different discriminant functions are contained in Appendix P. An examination of these patterns shows that there is a consistency in the patterns: this consistency of patterns suggests that the pattern traced for each firm from the chosen function can be used to discern general patterns of $P(F)$ for both failed and nonfailed firms.

Conclusion. The aim of this section was to test the assumption that insolvency risk could be defined as equal to $P(F)$. It was found that because of the variation in a firm's $P(F)$ measures among the discriminant functions, $P(F)$ does have some limitations as a measure of insolvency risk: $P(F)$ is influenced by the choice of discriminant function. However, the fact that the variations in $P(F)$ were not large suggests that it can still be useful as an estimate of a firm's insolvency risk. Further, the finding that the patterns of risk traced by the $P(F)$ measures from the different functions were similar, suggests that $P(F)$ can be used for the interpretation of patterns of insolvency risk.

Index of Insolvency Risk

It has been shown that the probability of a firm being classified in the failed group is a useful measure of 
insolvency risk: this probability will now be used to develop an index of insolvency risk.

The z-scores and their probability of being in the failed group were graphed according to the best functions for (a) the manufacturing-retail industries, and (b) the property-finance industries. The horizontal axis is the $\mathrm{z}$-score and the vertical axis is the level of insolvency risk (or the probability that a firm has the financial characteristics of failed firms). The graphs for these industry categories are shown in Figure 10 (manufacturingretail) and Figure 11 (property-finance): for ease of interpolation normal-probability graph paper was used.

It will be noted that the two functions slope in opposite directions. This was caused by an operating characteristic of SPSS: the failed-group centroid for the manufacturing and retail firms was positive and the same centroid for the property and finance firms was negative. Therefore, for manufacturing and retail firms a decrease in a firm's Z-score indicates a reduction in the level of insolvency risk. But for property and finance firms a decrease in a firm's Z-score indicates an increase in the level of insolvency risk. The reason for this difference is that SPSS constructs functions which provide the best separation of the group centroids, and those centroids need not be consistently positive or negative for all industries within the failed or the nonfailed group.

With these graphs a firm's level of insolvency risk could be assessed from its $\mathrm{Z}$-score. Alternatively, a table could be constructed showing the relationship between the $z$-scores 


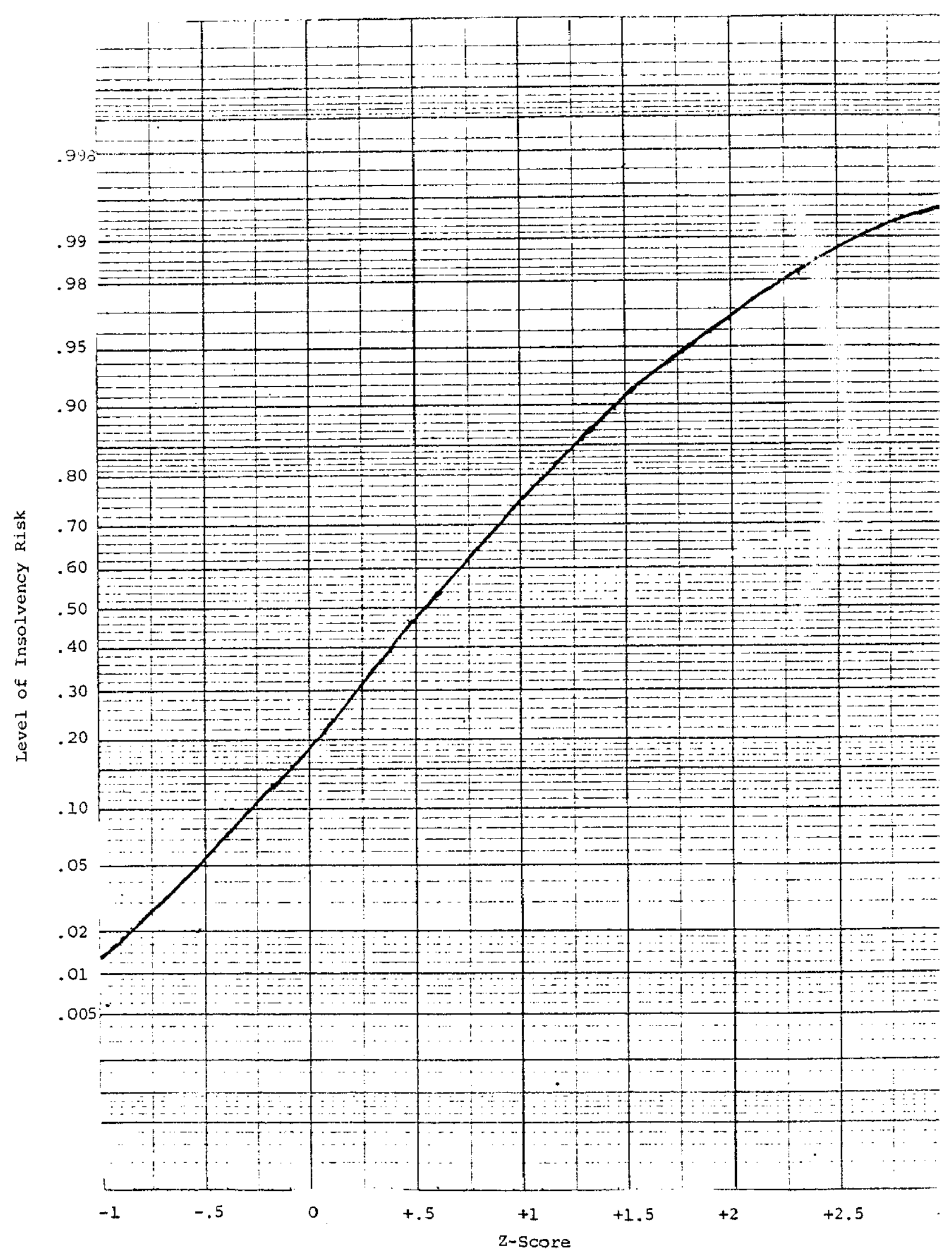

Figure 10. Graph of Relationship Between Z-Score and Level of Insolvency Risk for Manufacturing and Retail Firms. 


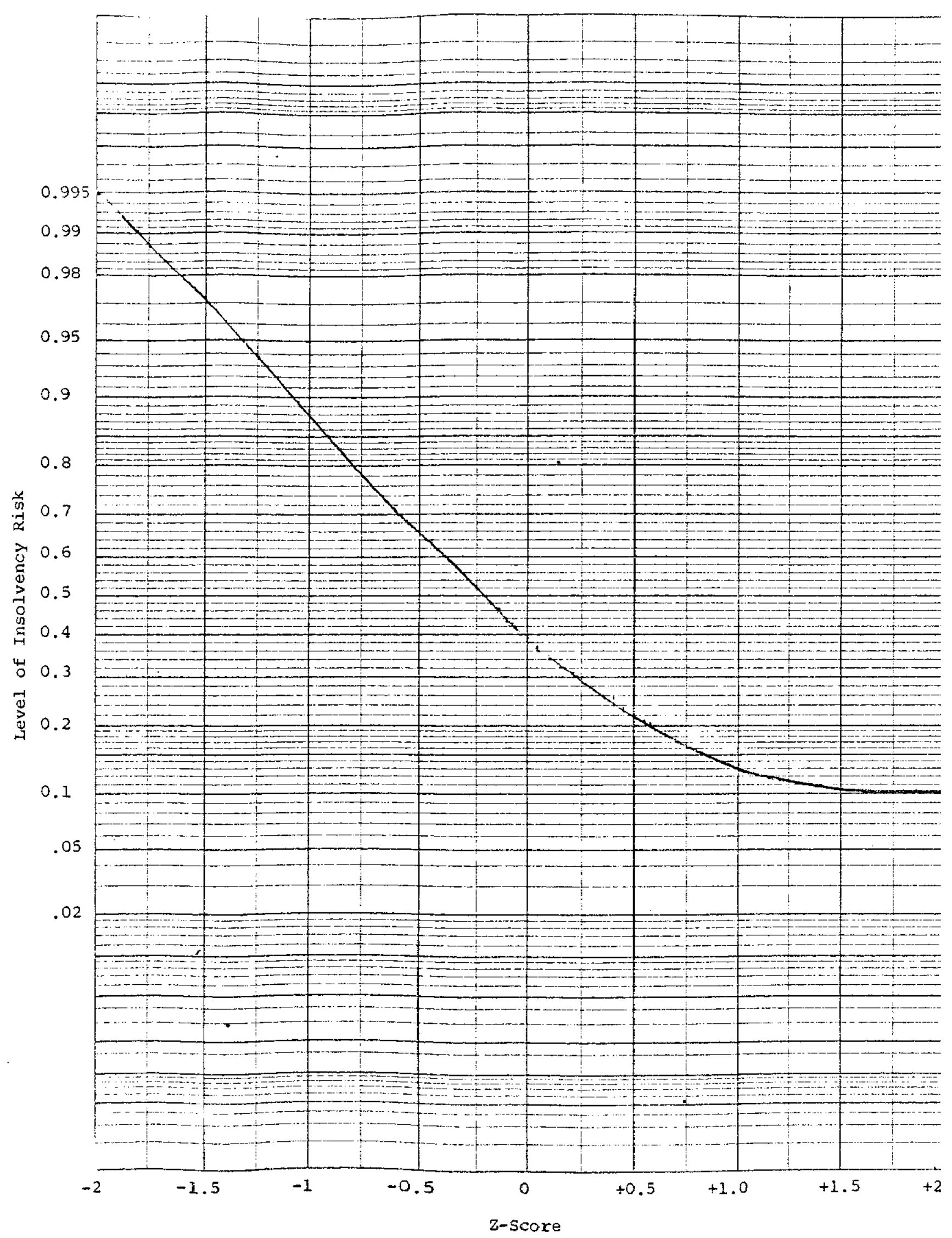

Figure 11. Graph of Relationship Between z-Score and Level of Insolvency Risk for Property and Finance Firms. 
and risk levels. Tables for both industry categories have been compiled by interpolation from the graphs: these are Tables 42 and 43 , and would be used either to assess the insolvency risk of a firm which had not been included in this study at the model derivation stage, or to test the impact of changes in ratio values on insolvency risk ${ }^{3}$.

\section{Table 42}

Manufacturing and Retail

$$
\text { Index of Insolvency Risk }
$$

$\begin{array}{cccc}\text { Z-Score } & \text { Insolvency Risk } & \text { Z-Score } & \text { Insolvency Risk } \\ 2.80 & 0.993 & 1.0 & 0.76 \\ 2.7 & 0.991 & 0.9 & 0.71 \\ 2.6 & 0.989 & 0.8 & 0.66 \\ 2.5 & 0.988 & 0.7 & 0.60 \\ 2.4 & 0.986 & 0.6 & 0.53 \\ 2.3 & 0.982 & 0.5 & 0.48 \\ 2.2 & 0.98 & 0.4 & 0.41 \\ 2.1 & 0.975 & 0.3 & 0.35 \\ 2.0 & 0.965 & 0.2 & 0.29 \\ 1.9 & 0.963 & 0.1 & 0.22 \\ 1.8 & 0.96 & 0.0 & 0.19 \\ 1.7 & 0.94 & -0.1 & 0.15 \\ 1.6 & 0.925 & -0.2 & 0.12 \\ 1.5 & 0.91 & -0.3 & 0.09 \\ 1.4 & 0.89 & -0.4 & 0.07 \\ 1.3 & 0.86 & -0.5 & 0.06 \\ 1.2 & 0.83 & -0.6 & 0.04 \\ 1.1 & 0.80 & -0.7 & 0.03 \\ & & -0.8 & 0.025 \\ & & -0.9 & 0.018 \\ & & -0.9 & 0.01\end{array}$

3. It was stated on p.168 that an index of insolvency risk would also be constructed for each of two property functions: these appear in Appendix $Q$. 


\section{Table 43}

Property and Finance

\section{Index of Insolvency Risk}

\begin{tabular}{|c|c|c|c|}
\hline Z-Score & Insolvency Risk & z-Score & Insolvency \\
\hline$>1.7$ & 0.10 & -0.4 & 0.60 \\
\hline 1.6 & 0.10 & -0.5 & 0.66 \\
\hline 1.5 & 0.1 .05 & -0.6 & 0.70 \\
\hline 1.4 & 0.107 & -0.7 & 0.76 \\
\hline 1.3 & 0.11 & -0.8 & 0.82 \\
\hline 1.2 & 0.115 & -0.9 & 0.85 \\
\hline 1.1 & 0.12 & -1.0 & 0.88 \\
\hline 1.0 & 0.13 & -1.1 & 0.905 \\
\hline 0.9 & 0.14 & -1.2 & 0.93 \\
\hline 0.8 & 0.155 & -1.3 & 0.945 \\
\hline 0.7 & 0.17 & -1.4 & 0.96 \\
\hline 0.6 & 0.19 & -1.5 & 0.97 \\
\hline 0.5 & 0.22 & -1.6 & 0.98 \\
\hline 0.4 & 0.24 & -1.7 & 0.985 \\
\hline 0.3 & 0.27 & -1.8 & 0.99 \\
\hline 0.2 & 0.31 & $<-1.8$ & 0.99 \\
\hline 0.1 & 0.34 & & \\
\hline 0.0 & 0.38 & & \\
\hline-0.1 & 0.44 & & \\
\hline-0.2 & 0.49 & & \\
\hline-0.3 & 0.54 & & \\
\hline
\end{tabular}




\section{Adjustment to the cutoff score}

The z-scores from which the graphs and tables have been constructed were calculated from an equation of weighted ratios. This equation was found to discriminate best between failed and nonfailed firms. The calculation of the cutoff z-score by SPSS, to determine whether a score belonged to the failed or nonfailed group, incorporated a priori probabilities to account for (a) the relative occurrence of failure and nonfailure in the population of firms, and (b) the costs to adjust for the fact that misclassifying a nonfailed firm will be less costly than misclassifying a failed firm.

The probabilities shown in the graphs and tables, and which were generated by the $\mathrm{Z}$-scores, are referred to as posterior probabilities: they combine the facts about the company with the a priori probabilities as assessed. In these circumstances the posterior probabilities is a function of the a priori probabilities, i.e., a function of the proportion of firms which fail and survive, and the costs of misclassifying firms. These two factors are now considered.

1. Proportion of firms which fail. As a guide to determining the prior probability of failure $\left(q_{1}\right)$, and hence nonfailure $\left(q_{2}\right)$, there is some objective data available (see Table 4 on p.59). This can provide a basis for determining $q_{1}$ and $q_{2}$. The final figures used, however, will be influenced by the assumptions of the user: for instance, the period of time a user is interested in a company. As previously 
outlined (see p.27), on the basis of a given set of facts about a company, a long-term lender would assign a higher probability of failure than a short-term lender. Table 4 refers to a 10-year period and adjustment would be made to the percentage figures for any lesser period. However, as Table 3 (p. 58) indicated, failure is not uniformly spread over a time span. This is particularly so for property companies. A user may adjust the probability of failure further to allow for short-term economic influences. For example, if a tight money policy is forecast, this could influence the user's assessment of the probability of failure ${ }^{4}$.

2. Cost of misclassification. The values assigned to the cost of misclassifying a surviving firm $\left(C_{1}\right)$ and a failed firm $\left(\mathrm{C}_{2}\right)$ will depend upon the assumptions of the user. For instance, as outlined on p.27, a lender secured by a mortgage debenture would be expected to lose less in a failed company than an unsecured creditor, who in turn would lose less than a shareholder. Altman et al. (1977, pp.44-46) and Altman (1980), as a guide to establishing a priori probabilities, researched the cost of misclassification to bankers. Attempts were made to obtain objective data, similar to Altman's, from Australian banks. However, this was not possible because of the lack of historical data.

4. This provides an argument for developing a model incorporating macro-economic variables, e.g. effect of interest rates, money supply growth, economic growth, on business failure. However, those aspects are not explored in this study which is concerned only with accounting variables. 
It has been established that the a priori probabilities, upon which the posterior probabilities (or levels of insolvency risk) depend, are influenced by the assumptions of the user. In deriving the graphs and tables for measuring insolvency risk this study has assumed a cancelling out of the probabilities of failure-nonfailure and costs of misclassification. Therefore the posterior probabilities were derived on the assumption that the a priori probabilities were equal to one. This is in accordance with practical experience; the proportion of companies that fail is low, and the financial loss in doing business with a company which fails is greater than the loss from not doing business with a company which does not fail. The cancelling out assumption will be the basis for further analysis of the factors contributing to different levels of insolvency risk.

\section{Method of Analysis}

The method of analysis for each firm in the four industries consisted of the following steps.

1. Drawing a graph of its insolvencyrisk for the five-year period.

2. Constructing a table comprising, for the five-year period: (a) z-scores, (b) insolvency risk, (c) weighted ratios, (d) change in weighted ratios, (e) unweighted ratios. 
By way of illustration of the role of the graph and the accompanying table, an analysis of a surviving manufacturing firm, simpson-pope Holdings Ltd, will now be carried out. Figure 12 shows the trend in the insolvency risk of this firm from 1972 to 1976 , and Table 44 presents the relevant data.

Simpson-Pope Holdings Ltd. The graph indicates that the level of insolvency risk of this company has been fluctuating. For three of the five years it was in the failure zone. For the two years in which the company was not in the failure zone, its level of insolvency risk was high for a nonfailed firm.

By reference to Table 32 , the ratios contributing to the marked annual change in insolvancy risk can be analysed year by year.

1972-1973: During this 12 months there was a significant decline in insolvency risk because of the reduced dependence on bank overđraft as a source of short-term borrowing, and a decline in short-term debt relative to total debt. This was achieved by replacing short-term borrowings with long-term borrowings, and an improved coverage of current liabilities from cash flow. The effect was to make the firm more liquid, as evidenced by a higher proportion of its short-term assets being in liquid assets.

1973-1974: Insolvency risk increased because of a build up in short-term assets, financed largely by bank 
SIMPSON-POPE HOLDINGS LTD.

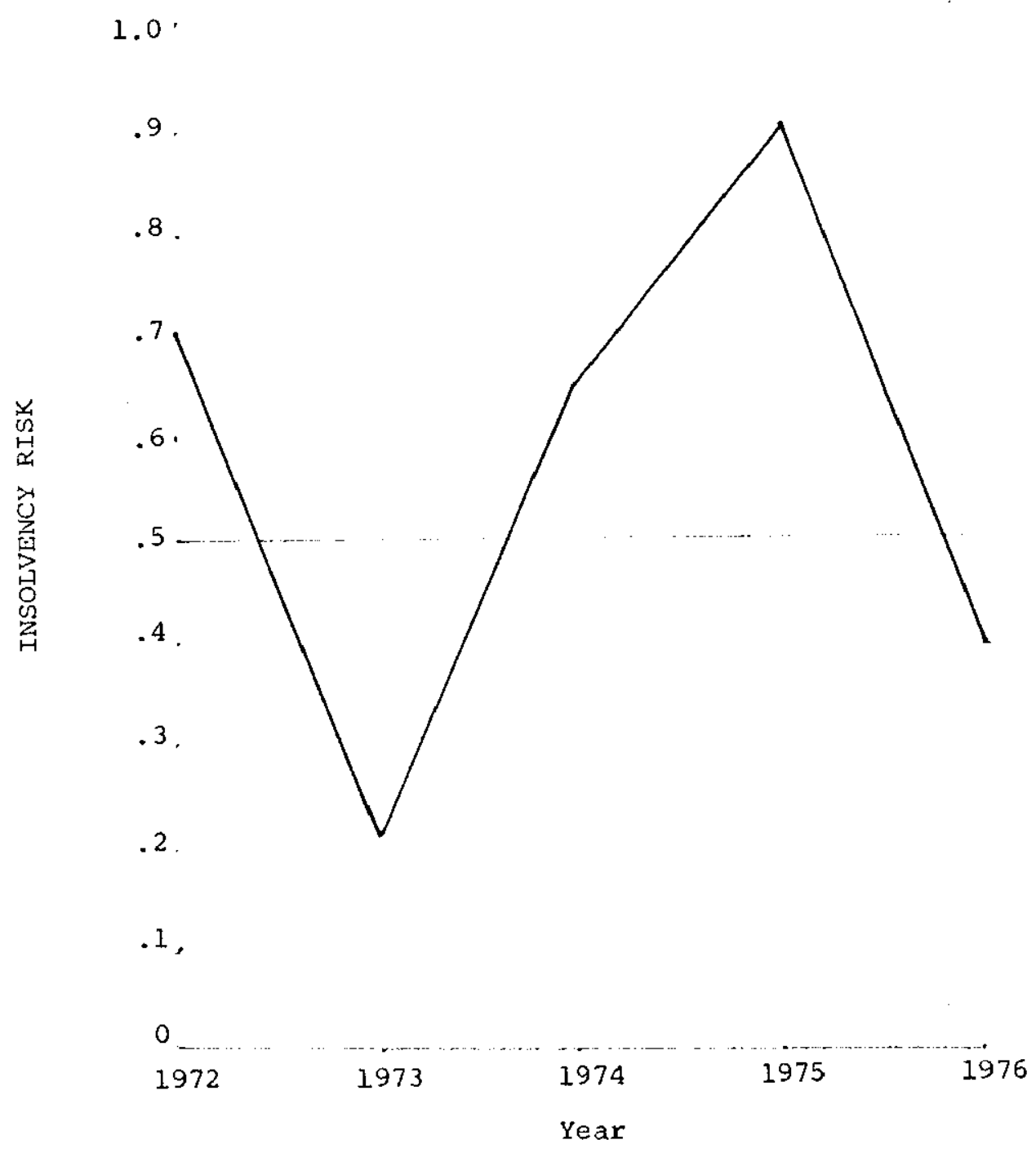

Figure 12. Graph of Insolvency Risk of Simpson-Pope Holdings Ltd. 
Table 44

Analysis of Insolvency Risk

Simpson-Pope Holdings Ltd

Z-score

$\begin{array}{ccccc}1972 & 1973 & 1974 & 1975 & 1976 \\ +0.8441 & +0.0676 & +0.8328 & +1.4685 & +0.3741 \\ & -0.7765 & +0.7652 & +0.6357 & -1.0944 \\ 0.68 & 0.22 & 0.66 & 0.91 & 0.39\end{array}$

Weighted ratios

$\begin{array}{llllll}\text { CFBCL } & -0.1802 & -0.2597 & -0.2319 & -0.0706 & -0.2503 \\ \text { CATAI } & +2.3174 & +2.3195 & +2.4279 & +2.4720 & +2.5442 \\ \text { QACA } & -0.7242 & -0.8417 & -0.8477 & -0.7112 & -0.7621 \\ \text { CLTL } & +1.1424 & +1.0292 & +1.1163 & +1.1475 & +1.0436 \\ \text { QLCL } & -3.3622 & -3.8600 & -3.3360 & -3.1238 & -3.8600 \\ \text { RPTAI } & -0.2851 & -0.2567 & -0.2341 & -0.1845 & -0.2809 \\ \text { TLTAI } & +0.0098 & +0.0104 & +0.0117 & +0.0124 & +0.0125\end{array}$

Change in weighted ratios $^{1}$

CFBCL

CATAI

QACA

CLTL

QLCL

RPTAI

TLTAI

$\begin{array}{llll}-0.0795 & +0.0178 & +0.1613 & -0.1797 \\ +0.0021 & +0.1084 & +0.0441 & +0.0722 \\ -0.1175 & -0.0060 & +0.1365 & -0.0509 \\ -0.1132 & +0.0871 & +0.0312 & -0.1039 \\ -0.4978 & +0.5240 & +0.2122 & -0.7362 \\ +0.0284 & +0.0226 & +0.0496 & -0.0964 \\ +0.0006 & +0.0013 & +0.0007 & +0.0001\end{array}$

Unweighted ratios

$\begin{array}{llllll}\text { CFBCL } & 0.2048 & 0.2951 & 0.2635 & 0.0802 & 0.2844 \\ \text { CATAI } & 0.6678 & 0.6684 & 0.6997 & 0.7124 & 0.7332 \\ \text { QACA } & 0.2956 & 0.3436 & 0.3460 & 0.2903 & 0.3111 \\ \text { CLTL } & 0.8339 & 0.7513 & 0.8148 & 0.8376 & 0.7617 \\ \text { QLCL } & 0.8710 & 1.0000 & 0.8643 & 0.8093 & 1.0000 \\ \text { RPTAI } & 0.0687 & 0.0619 & 0.0564 & 0.0445 & 0.0677 \\ \text { TLTAI } & 0.4983 & 0.5222 & 0.5854 & 0.6181 & 0.6255\end{array}$

1. - is a decrease in insolvency risk;

+ is an increase in insolvency risk. 
overdraft, and an increase in the proportion of short-term debt to total debt. The cash-flow coverage of short-term debt declined while the level of total debt increased and the funding from retained profits declined.

1974-1975: The insolvency risk increased to a dangerous level with all seven ratios moving in the direction of an increase in insolvency risk. This was a repetition of the previous year but with a more drastic cut in cash-flow coverage of short-term debt and a build up of stocks. This resulted in increased reliance on short-term debt, especially bank overdraft, while the amount of retained profits to total funds continued to weaken.

1975-1976: The insolvency risk of the firm moved out of failure zone. This was due to replacement of all the bank overdraft by longer-term finance and an improvement in the coverage of short-term debt from cash flow. The funding from retained profits increased. The two ratios which went against trend were TLTAI and CATAI: there was an increased reliance on debt, and an increased proportion of funds in short-term assets.

The company still had a high-risk rating relative to some other firms in a similar industry, e.g. Vulcan and Kelvinator. The main difference was a lower cash-flow coverage of current liabilities and a proportionately higher investment in stocks. Simpson-Pope increased its reliance on debt, especially shortterm debt, and reduced its reliance on profits as a source of funds. 
In summary, to assume a lower-risk profile simpson-Pope must improve its cash flow coverage of current liabilities, reduce its investment in stock, and increase its equity base. The remedies would be inter-related to some extent. For example, rationalization of product lines and assets would improve cash flow, and reduce stock investment and hence current liabilities, while an increase in the equity base would further reduce the dependence on debt finance.

The model can be used by the company in its planning process to reduce insolvency risk. It can calculate the impact of alternative courses of action on its $z$-score, and hence on its insolvency risk. This will be an aid to management in deciding the approach to lowering its risk profile.

\section{$\underline{\text { Summary }}$}

Graphs similar to that in Figure 12, and tables similar to that in Table 44, were prepared for each of the 131 firms included in this study. These graphs and tables illustrate the insolvency risk process for failed and nonfailed firms in the four industry categories, and will provide the information for subsequent analysis. 


\section{Chapter 8}

\section{Patterns of Insolvency Risk}

Graphs depicting the insolvency-riskpattern for each of the 131 firms included in this study are contained in Appendix R. From an investigation of these graphs several patterns are discernible for both failed and nonfailed firms. The aim of this chapter is to analyse these patterns: this will contribute to an improved understanding of the financial characteristics of failed and nonfailed firms. The patterns of insolvency risk for the failed group will be analysed first, followed by those for the nonfailed group.

\section{Patterns of Insolvency Risk for Failed Firms}

Five patterns of failure can be identified.

Pattern 1. The most frequent pattern was that of a firm in the failure zone during all five years before failure (see Figure 13).
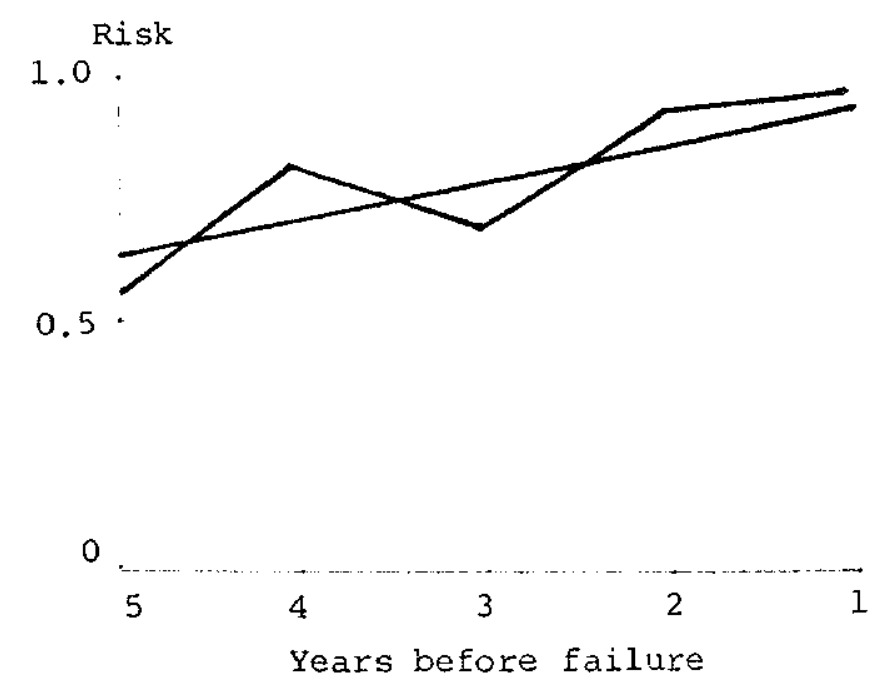

Figure 13. Pattern of Insolvency Risk : 1 
There is either a steady adverse trend in the insolvency risk because management is unable to take any successful corrective action, or there is a zig-zag pattern with some minor gains in reducing exposure to insolvency risk which are quickly lost. seventy.-seven per cent of the failed manufacturing and retail companies and twenty-one per cent of the failed property and finance companies conformed to this pattern. This suggests that in most cases failure is a culmination of bad decisions by management over a number of years; if management is sufficiently capable it has adequate time to improve its firm's level of insolvency risk.

The prevalence of this pattern suggests that lenders are either unaware of the seriousness of the financial position, or are hopeful that management can turn the firm around, thus avoiding the need to take the action of putting it into receivership. Even where the index of insolvency risk keeps moving further into the failure zone, the company is not put into receivership until the probability of failure is almost at its maximum. In this situation providers of funds run the risk of losing more of their money.

The prevalence of this pattern shows that most companies do not fail "overnight". As most have been in existence for a long time they have probably both a steady line of "bread and butter" business which does not suddenly disappear, and 
financiers who have been associated with them for years and are sympathetic to their needs. However, these advantages are gradually lost by the cumulative effect of bad management decisions in such areas as product mix, pricing, marketing, quality control and diversification. Economic factors could not be included in this list because many firms survived despite varied economic conditions.

Big company collapses which conform to this pattern of insolvency risk include Gollin Holdings Ltd. and Cambridge Credit Ltd.

Pattern 2. The pattern illustrated in Figure 14 could be referred to as a "bogus recovery" pattern.

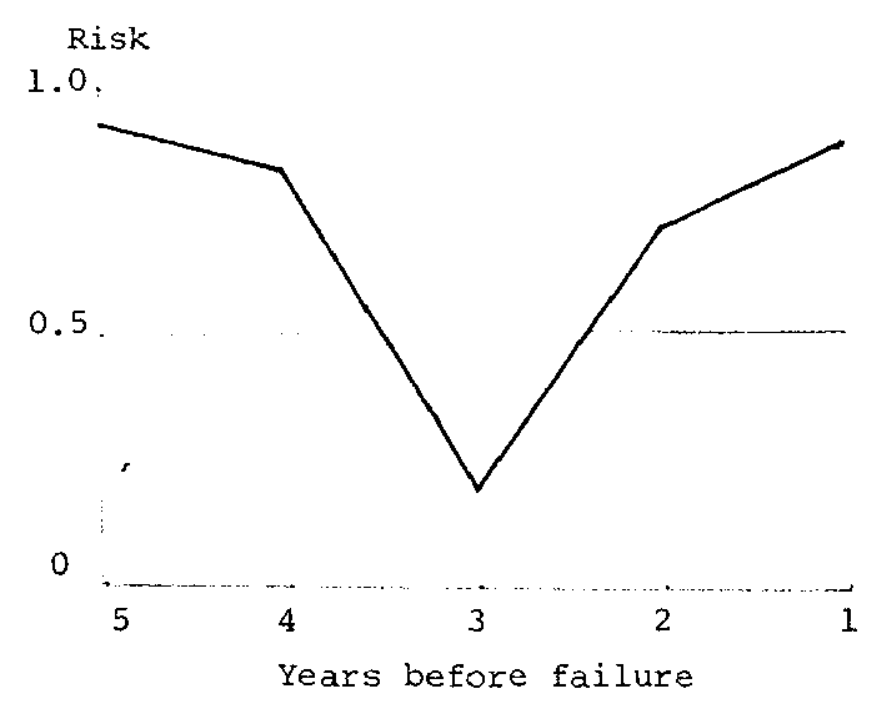

Figure 14. Pattern of Insolvency Risk : 2

This pattern shows a company having an abrupt improvement in its insolvency risk but losing this advantage in the following year. It applied to 26 per cent of the failed property - finance firms, and 9 per cent of the failed manufacturing - retail firms. 
During the short period of the property boom, the insolvency risk of some property and finance firms swiftly declined and they moved from the failure to the nonfailure zone. This was caused by a strong profit performance, resulting in improved earnings on funds employed. However, those companies which had a high level of borrowings were not prepared for a slow down in property sales; when this happened they returned to a higher level of risk, and as the property market remained depressed, they failed.

The manufacturing-retail companies conforming to this pattern reduced insolvency risk by restructuring their sources of finance - in particular, by replacing short-term debt with a mix of long-term debt and equity. However, this restructuring of finance was not accompanied by successful management action to improve cash flow and the liquidity situation quickly deteriorated.

This pattern illustrates the need for the analyst to temper his enthusiasm for a company which moves swiftly out of the failure zone. It suggests that the restructuring of a company to permanently reduce its insolvency risk is not a short-term process, but requires a steady effort over a number of years. A company which achieves a rapid improvement may not have established the stability to maintain the lower level of risk. The frequency with which this pattern occurs warrants the generalization that a steep decline from failure zone may be followed by an equally sharp upward movement of the risk level in the very next year. 
Pattern 3. The remaining 14 per cent of the manufacturing-retail firms were in failure zone three to four years before failing, as shown in Figure 15: this pattern also applied to 11 per cent of property-finance firms.

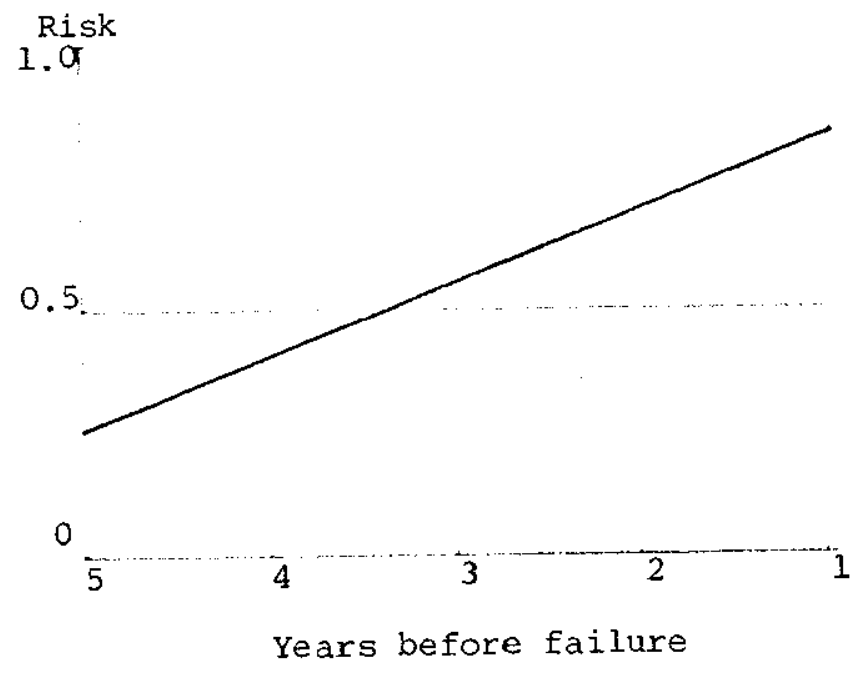

Figure 15. Pattern of Insolvency Risk : 3

These companies entered the failure zone quickly and failed within three years. A typical example of a firm which conformed to this pattern was James Miller Holdings Ltd, a large'manufacturing company. After it had been a successful, low-risk company for some years, a strategic management decision led to a sharp deterioration in cash flow and increased short-term debt. The business moved into the failure zone, and management was unable to reverse the trend in the key financial ratios. The firm had involved itself in a "big project" by taking over a large company in the depressed plastics industry - an industry in which it had not previously operated - at a time when its own traditional business was under pressure following an economic 
downturn. Inability to recognize the business and economic trends, coupled with a heavy capital outlay during a depressed business period, resulted in a rapid increase in its insolvency risk, and eventual failure.

This firm had been in existence for more than one hundred years and had been an industry leader during most of that time. This shows that old companies are not immune to failure, and that management should be careful of the "big project" which stretches the financial and management resources of a firm, especially when the investment is in an unfamiliar industry.

The three patterns so far described account for all the failed manufacturing and retail firms. There were two additional patterns applicable to failed property-finance firms.

Pattern 4. This pattern, which gave late warning of failure, covered 50 per cent of the failed finance companies (see Figure 16).

Risk

$1.0^{\circ}$

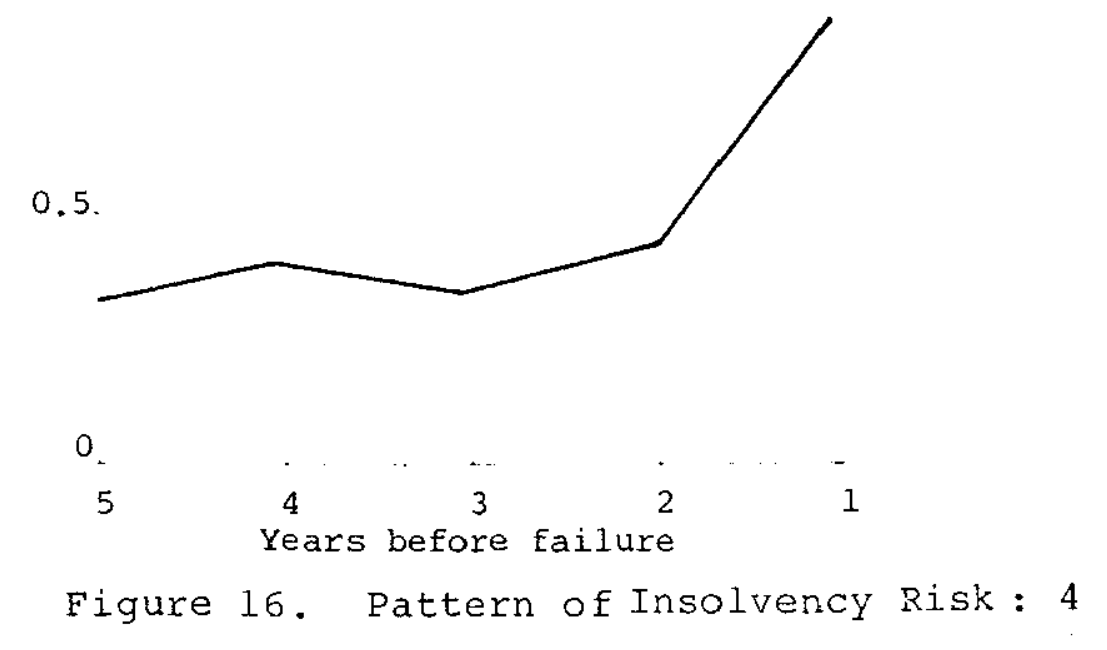


These companies were in nonfailure zone up to two years prior to failure. However, they were still characterized by a higher degree of insolvency risk than most other finance firms. This was because their return on funds employed was lower than average. These failed finance firms also invested more of their borrowings in the volatile property market and less in the more stable area of consumer credit. When the property boom was over and the demand for land and buildings declined, these companies experienced a high level of bad debts from clients who were unable to realize assets. Although these assets were held as security by the finance firms, they also could not sell them at a sufficiently high price to cover the debt. With the value of the debt increasing through accrual of unpaid interest, and the property market failing to recover, significant write-offs were subsequently necessary to bring the book figures of the debt back to the market value of the unrealized security. This had an adverse effect on the profits of these finance firms and immediately put them into the failure zone. A consequence was the difficulty in raising funds from the public to meet continuous redemptions of borrowings, and rescue operations were necessary.

A slight modification to Pattern 4 applies to another failed finance company, Associated securities Ltd (ASL). The company was in failure zone three years before failure: its insolvency riskwas 0.59. Appreciating its difficulties, management sought a merger with a firm with access to considerable finance: Ansett Transport Industries Ltd (ATI). 
This was achieved and in the next year there was a heavy write-down of assets, which had the effect of increasing the company's insolvency risk to 0.98 . The new owner then set about both investing large sums in ASL and selling properties where possible, and this reduced the insolvency risk to 0.46 : still quite high by finance company standards. At this stage, ATI was not in a position to invest any more funds, and, with the saleable assets sold, funds were no longer readily available from internal sources. ASL's relatively high level of insolvency risk was due to a poor return on funds, and this made it difficult for the company to raise funds from the public. Accordingly the company was placed in receivership. Obviously, ASL was a higher insolvency risk than ATI thought at the time of the takeover, and ATI was not a large enough company, in terms of financial resources, to cope with ASL's financial needs.

The patterns of the failed finance firms indicate that, once they enter the failure zone, it is very difficult for them to recover by means other than a forced merger with a firm much bigger than themselves with ample financial resources.

Pattern 5. The remaining pattern for failed firms is more applicable to property companies (see Figure 17). 
Risk

1.0 .

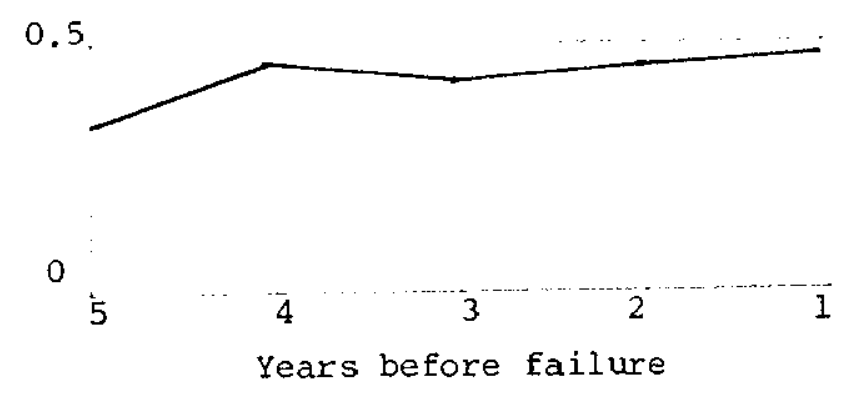

Figure 17. Pattern of Insolvency Risk: 5

The typical firm belonging to this pattern is at fairly high risk when compared to many of its competitors but never really moves into the failure zone. However with its marginal-risk rating it is not ready for the shakeout when the industry risk increases. Furthermore, it has some other factors which may exacerbate the situation: these other factors can be illustrated by reference to Mainline Corporation Ltd which was one of Australia's largest property firms to collapse and was typical of the above pattern. At the time of the industry downturn it was involved in a "big project", with financial resources fully utilized; this then reduced its ability to cope with problems occasioned by the industry downturn. This was exacerbated by unforeseen delays caused by union problems on the big project. These delays on a big project for a high-risk company in a high-risk industry led to a liquidity crisis. The depressed state of the property industry prevented assets being sold to overcome the 
liquidity problem, and the company was forced into receiver-ship.

This graph indicates that some property companies can fail "overnight". However, there is a warning that this may happen because of their marginal level of insolvency risk some years before failure.

Conclusions. From the above analysis the following conclusions can be drawn.

1. Most manufacturing and retail firms were in the failure zone during all five years before failure. The exceptions were firms which showed either (a) a "bogus" recovery caused by a restructuring of finance but not accompanied by an improvement in cash flow, or (b) a major diversification in a difficult economic period resulting in a shorter interval between entry into failure zone and actual failure.

2. Most property and finance firms were in the failure zone for less than five years before failure. They had a spectacular performance for the short period of the property boom, but over-extended their borrowings and were not prepared for the industry downturn. Some indication that this might happen was provided by the fact that, before the boom period, failed firms tended to have a higher level of insolvency risk. 
Those firtas which were in the failure zone for five years were not able to take advantage of the property boom to move out of the failure zone for any year before failing.

\section{Patterns of Insolvency Risk for Nonfailed Firms}

It is possible to distinguish six patterns for nonfailed firms: these will be numbered as Patterns 6 to 11 .

Pattern 6. More than half the surviving companies followed the pattern of a consistently low level of insolvency risk, as illustrated in Figure 18.

$$
\begin{aligned}
& \text { Risk } \\
& 1.0
\end{aligned}
$$

0.5

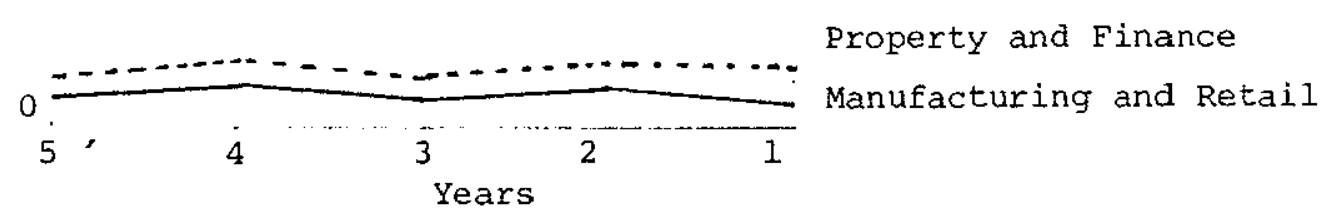

Figure 18. Pattern of Insolvency Risk : 6

These companies could be divided into two types:

(a) those marked by a stability in their ratios resulting in little variation in their pattern of insolvency risk, and (b) those marked by less stability in their ratios, which remained in the nonfailure zone despite some fluctuation in their levels of insolvency risk. 
Among the safest companies, the base-risk level of the property and finance firms exceeded that of the manufacturing and retail companies. None of the property or financefirms had a: insolvency-risk level less than 0.1. However, a risk level less than 0.04 was common for the manufacturing and retail firms. The higher figure for property and finance firms was caused by the greater overlap of 2 -scores between the two groups. This higher base-risk level given to property and finance firms accords with reality in that investors perceive a higher level of business and insolvency risk associated with property firms. This is because of these companies' greater reliance on debt finance and the susceptibility of the industry to changes in economic direction: these two factors cause property-finance firms to be more subject to financial distress in a period of economic difficulties.

The firms that had isolated variations of insolvency risk within the nonfailure zone were characterized by swift action from management to correct the adverse trend. Other firms had continuous variation in their level of insolvency risk within the nonfailed zone because of the nature of their industries, e.g., those involved in the electrical and textile industries.

Pattern 7. Another pattern concerns that group of companies whose business is Iinked to the farming sector, which suffers severe economic downturns because of climatic factors, especially drought (see Figure 19). 


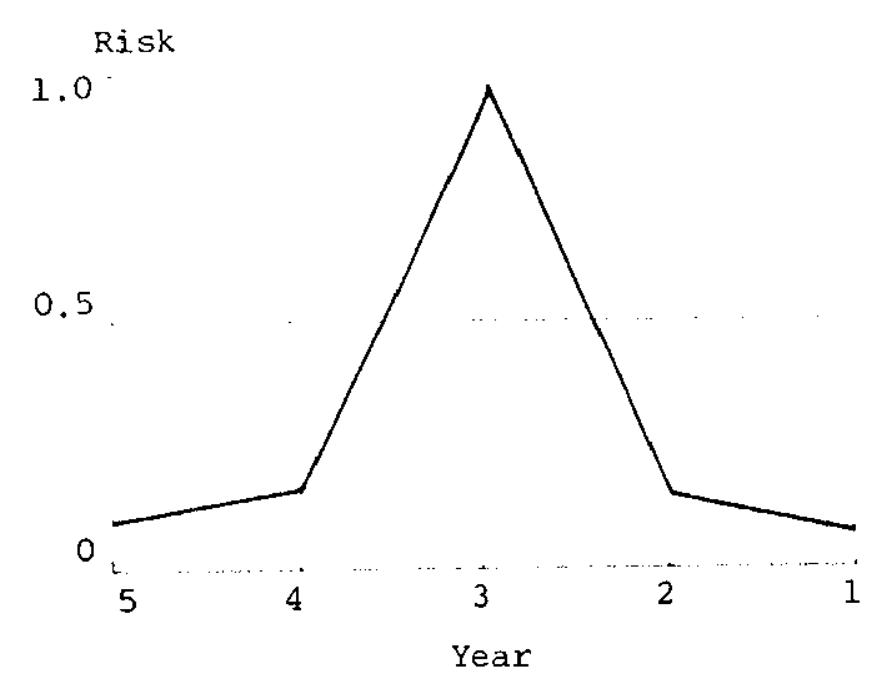

Figure 19. Pattern of Insolvency Risk: 7

Pattern 7 demonstrates a marked short-term change in insolvency risk, typical of companies with an agricultural base. Bad farming conditions can cause a poor profit year for suppliers of materials and equipment to farmers. This leads to a significant increase in the level of a firm's insolvency risk, but the position quickly recovers with the return of more buoyant conditions. The movement into the high-insolveńcy-risk zone for such companies is temporary, provided the "act of God" disturbance is not prolonged, and the companies have the financial resources to survive the difficult period.

No firms in other industries experienced as dramatic a change in their insolvency risk as those linked to the rural economy. 
Pattern 8. There are some companies which slowly but surely work their way out of the failure zone, as illustrated in Figure 20.

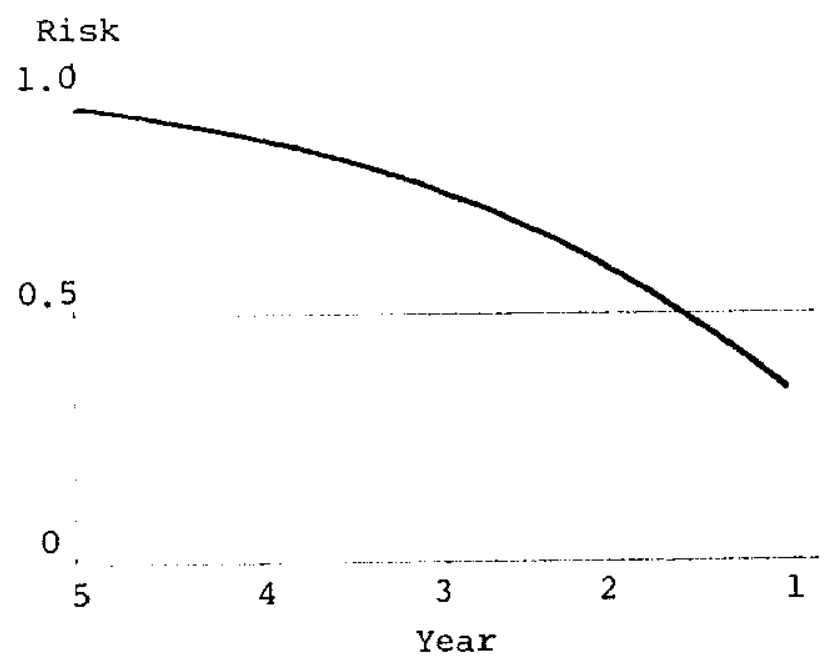

Figure 20. Pattern of Insolvency Risk: 8

This pattern is accompanied by a steady improvement in cash-flow coverage of current liabilities, and a reduction in borrowings, particularly short-term debt including bank overdraft, while there is a gradual accumulation of retained profits.

This pattern indicates that firms can recover from a high level of insolvency risk. However, the recovery is generally slow as the high level of insolvency riskmeans that most additional funds have to be gained from internal sources. This requires a company to completely rationalize its operations, and it can't take advantage of possible growth areas for the future until it is in better shape. 
Pattern 9. Some firms are a little more spectacular in moving out of the failure zone, but it is extremely rare to find such instantaneous success as illustrated in Figure 21.

Risk $^{\text {. }}$

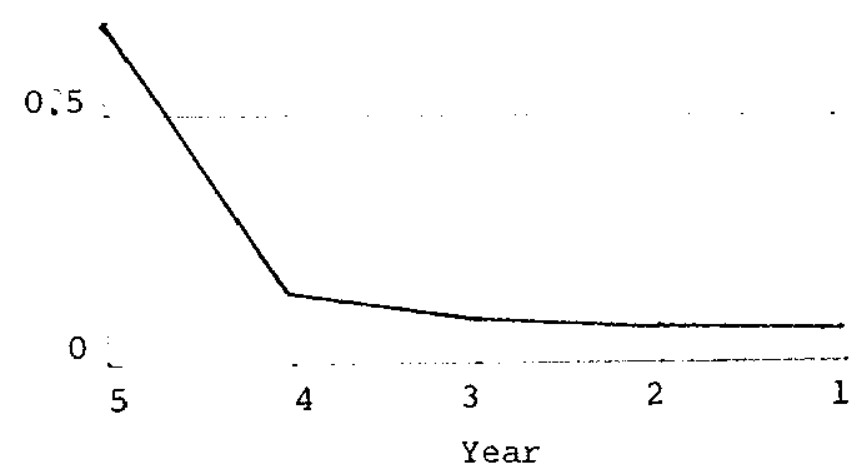

Figure 21. Pattern of Insolvency Risk: 9

Only one retail firm followed this pattern. The company was Katies Ltd, which, after a year during which it lost an important share of the market and incurred a trading loss, significantly changed its approach to retailing with rapid success.

Pattern 10. The company particularly troublesome to management and investors is that which follows a pattern marked by sudden changes in levels of risk between the two zones (see Figure 22). 
Risk

1.0

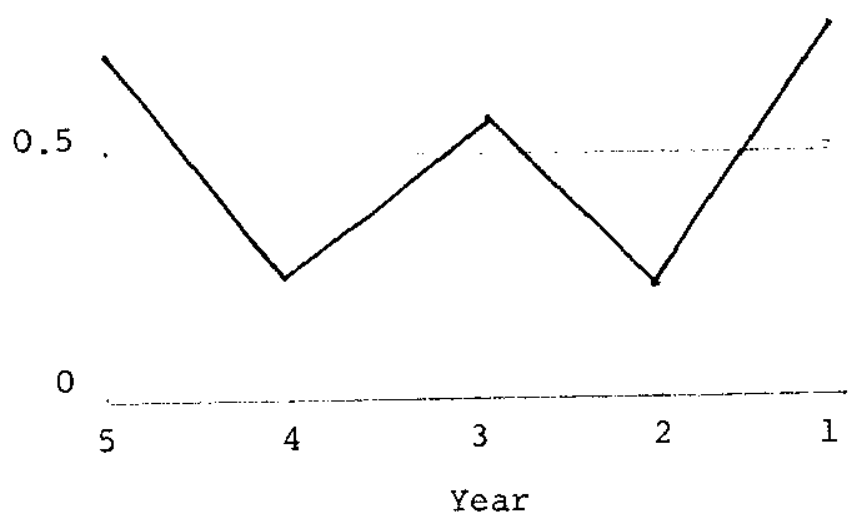

Figure 22. Pattern of Insolvency Risk: 10

The company is continually moving in and out of the failure zone, virtually walking a "financial tightrope". Some manufacturing firms in the electrical industry followed this pattern. The pattern appears to have a limited life as eventually the firm goes one way or the other. The companies in the sample eventually survived and settled down to a more sedate pattern of insolvency risk. However, this only happened after drastic action by management. For some companies in the sample, the solution was a merger with a more financially-strong firm; for others, it was a complete restructuring of their product line, asset base, finance mix, and management team.

Pattern 11. The last pattern for nonfailed companies occurs where the company is caught unprepared by outside interference in the market place and, from having a low- 
risk profile, it suddenly becomes a marginal-risk firm (see Figure 23).

Risk

1.0

0.5 .

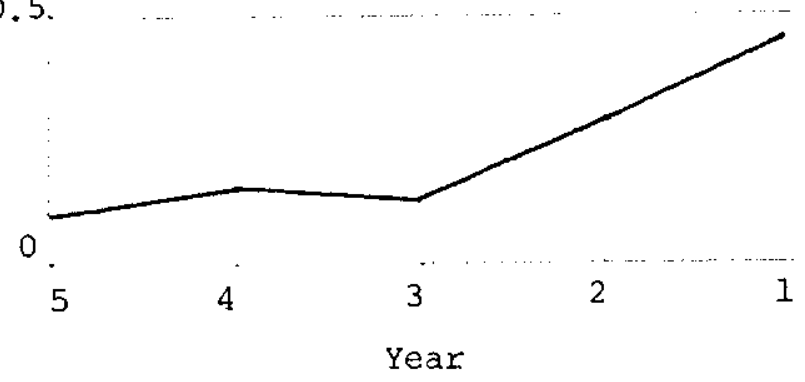

Figure 23. Pattern of Insolvency Risk : 11

This pattern applied particularly to textile companies in the sample. During the period under review, the textile industry experienced, in quick succession, a reduction in protective tariffs, a revaluation of the currency, and the granting of equal pay; the result was greatly reduced ability to meet the competition from imports. Fortunately, all companies were subsequently able to rationalize their operations, which prevented the upward trend in their insolvency risk from continuing.

The same pattern was also followed by some property firms which were caught unprepared by the "credit squeeze" and subsequent industry shakeout in 1973. Their insolvency risk increased as their profit margin to service outstanding debt declined. However these companies survived because of prompt 
and effective management action which included securing backup finance from financial institutions.

Conclusions. The following conclusions can be drawn from this analysis of the graphs of surviving firms:

1. Firms can recover from a high level of risk, though recovery is generally slow. An important question for analysis in this study will be why some firms can reduce their level of insolvency risk to move out of the failure zone, while others cannot and eventually fail.

2. It is important for a correct interpretation of the risk patterns to have an understanding of industry characteristics. For instance, a sudden movement into the failure zone would be the least serious for firms involved in the agricultural industry.

3. There are firms which have a consistently low level of insolvency risk, irrespective of the general economic situation.

\section{Summiry}

This chapter has outlined the patterns of insolvency risk which can be traced by both failed and nonfailed firms. The analysis of these patterns, produced from discriminant functions, has contributed to an improved understanding of 
the financial characteristics of failed and nonfailed firms. The fact that the patterns are informative lends support to the use of accounting ratios to assess the insolvency risk of a firm. 
Analysis of Ratios in Best Functions

The previous chapter examined the patterns of insolvency risk which applied to the 131 companies in the sample. The aim of this chapter is to explain the factors which give rise to these patterns: it will show the roles played by the various ratios in determining the level of financial risk.

Tables similar to Table $44(p .203)$ were constructed for each of the 131 companies. This chapter will present the results from an analysis of the ratios in these tables. The ratios will be reviewed for the manufacturing-retail industry in the order of their discriminating power, this being: QLCL, CATAI, RPTAI, QACA, CLTL, CFBCL, and TLTAI. The two ratios for the property-finance industry, PITTAI and TLTAI, will be considered together because of the interaction, between them. During the course of this analysis some ratios of particular companies will be referred to by way of illustration: where a company is mentioned, the table of its ratios is included in Appendix S (pp.332-354). 


\section{Manufacturing-Retail Industry}

\section{QLCI, (Quick liabilities to current liabilities)}

This ratio shows the proportion of short-term funding provided by creditors, the balance being provided by bank overdraft. Higher-risk firms place greater reliance on bank overaraft, so that this ratio was lower for these firms. In other words, firms increase their level of insolvency risk as they increase their reliance on bank overdraft and rely less on creditors. The explanation for this increase in insolvency risk is that there is a limit to the amount of the overaraft banks will provide, and as a firm nears this point it is more vulnerable if it should have a profit setback : it might not be able to get as much as it needs from the bank to help it through a difficult period.

A company whose history from 1966 to 1970 illustrates the importance of this ratio's effect on insolvencyrisk is speedo Holdings. This firm, despite a steady recovery which brought most of its ratios to values characteristic of nonfailed firms, remained marginally in the failure zone because of its heavy reliance on bank overdraft: its QLCL ratio was still a low 0.63 in 1970 (so that the ratio of bank overdraft to current liabilities was a high 0.37). The firm could have therefore reduced its level of insolvency risk by funding a higher proportion of its short-term financial needs from long-term finance (i.e., by replacing some bank overdraft with long-term debt). If, for instance, 
in 1970 it had obtained some long-term borrowing which increased QLCL to 0.75 , this would have had the effect (after allowing for the impact on CEBCL and CLTL) of reducing its insolvency risk in that year to approximately 0.25 .

The impact on the level of insolvency risk of increasing and then eliminating bank overaraft was illustrated by Chamberlain Holdings. Just as the decline in QLCL from 1.00 to 0.5564 contributed most to moving this company into the failure zone, so the elimination of bank overdraft in the following year contributed most to its return to the nonfailure zone.

\section{CATAI (Current assets to total assets)}

This ratio reflects the extent of a firm's lease commitments and its investment in both stock and uncollected debts. These three items will now be considered.

Extent of lease commitments. Even though leased assets do not appear on a balance sheet, the presence of lease comilitments does have an effect on balance sheet structure. The ratio which most clearly recognizes this effect is CATAI: firms with a higher level of leasing have fewer fixed assets and hence a higher CATAI ratio. The model increases a firm's level of insolvency risk the higher this ratio becomes. Therefore firms which rely more on leasing will have their level of insolvency risk increased. This is 
appropriate for the following reason: if the leased equipment were included in the balance sheet, it would be matched by a corresponding liability representing the lease commitment, and an increase in liabilities exposes the firm to more risk (as shown, for instance, by the effect of the ratio TLTAI). The value of CATAI, then, is that it helps to overcome the difficulty created by the omission of lease commitments from the balance sheet.

An illustration of the effect on insolvency risk from leasing is provided by Clark Rubber. The company steadily improved all its ratios from 1970 to 1974 and so brought, its level of insolvency risk down from 0.97 to 0.61 . However, there was one ratio that was still keeping it in the failure zone: the company had a very high CATAI ratio. A comparison of its balance sheets with those of Coles and Woolworths, both low-risk firms, showed that Clark was assigned a higher level of insolvency risk because it leased a much higher proportion of its retail outlets than Coles and Woolworths did. The CATAI for Clark was around 0.85 compared to the 0.30 for Coles and Woolworths. The model had detected this increased reliance on leasing (which is a fixed financial commitment similar to debt), and had accordingly assigned to Clark Rubber a higher level of insolvency risk. It could be argued, therefore, that the model is not Iimited by the absence of information on lease commitments. The ratio CATAI detects the extent to which companies employ leasing (as compared with others in the same industry) and the model reveals the higher level of insolvency risk for a firm with a high CATAI. 
Investment in stock and uncollected debts. Firms increase their level of insolvency risk as (a) their rate of stock turnover declines and there is a build up in stock levels, or (b) their rate of debtor turnover declines and there is a build up in uncollected debts. A decline in the rate of turnover for stock and debtors indicates that management is having difficulties in controlling the funds invested in these assets. The model detects these difficulties through changes in CATAI, and regards them as serious: CATAI has more discriminating power than all ratios except QLCL.

The extent to which CATAI can act as an indicator of poor stock control and/or credit control is illustrated by two footwear manufacturers: International Footwear which failed, and nonfailed Julius Marlow. If International Footwear, with a CATAI of 0.83 , had had the same CATAI as Julius Marlow, 0.61 , its insolvency risk would have dropped from in excess of 0.80 to approximately 0.48 . There would have been additional favourable effects on insolvency risk through the impact upon other ratios of the reduced reliance on short-term debt to finance stock and debtors. These ratios would be CFBCL, QLCL, CLTL, and TLTAI.

\section{RPTAI (Retained profits to total assets)}

RPTAI was chosen by the model because it found that surviving firms had a significantly higher proportion of their assets financed from profits than did failed firms: 
lower-risk firms had a higher RPTAI. This would have been expected since the ratio seems to indicate a record of past successes: a high ReTAI would result from a past record of good profits coupled with a conservative dividend policy. It would also have been expected that the ratio would be more favourable with older firms: the older the company the more time has it had to accumulate reserves. However RPTAI does not appear to be strongly associated with age. For instance, two companies which had been in existence for more than 50 years, A.G. Healing and Gollin Holdings, had a low RPTAI from 5 years before failure. In view of the substantial age of these companies it was surprising that the ratio was so low for both firms. This would suggest that the firms had had a fluctuating, but on the whole poor, profit record for some time.

The significance of RPTAI in the model - it was the third most important ratio - indicates the dilemma facing firms with an unacceptable level of insolvency risk, but which are making profits: to pass a dividend would mean a lower level of insolvency risk - RPTAI would be higher but the benefit to the company from the favourable reaction of shareholders to receipt of a dividend would be lost. For instance, if Simpson-Pope in 1976 had not paid a dividend almost half its profit was distributed in dividends - then RPTAI would have been 0.0848 instead of 0.0678 . This would have reduced its level of insolvency risk from 0.39 to 0.22 . If the extra retained profits had been used to reduce current liabilities then the level of insolvency risk would have been 
lower still - approximately 0.19. The dilemma for management is that if it omitted a dividend investors could take this as suggesting management expects a difficult trading year, and this would react adversely on the firm's share price. If, however, investors were to understand the favourable impact upon the level of insolvency risk of not declaring a dividend then the share price should rise because of the increase in net tangible asset backing per share. The benefit of the model is that it allows management to see the effect of paying various rates of dividend on the firm's level of insolvency risk; accordingly it has additional information for making a decision on dividends.

\section{QACA (Quick assets to current assets)}

The immediate liquidity of a company is evidenced by the amount of funds in cash or quickly convertible into cash. This ratio was lower for failed firms, indicating that they háve less immediate access to cash.

Since $Q A=C A-S T O C K$, the relation between stock and debtors is implicit in this ratio: a decline in QACA indicates an accumulation of stock, causing increased insolvency risk, whilst an increase in the ratio is usually the result of faster turnover of stock, associated with a reduction in the level of risk. For instance, the level of insolvency risk for McPhersons increased from 0.1188 in 1974 to 0.2835 in 
1975: this increase was mainly due to a build up of stocks as evidenced by QACA decreasing from 0.4626 to 0.3289 . However, in 1976 QACA increased to 0.3656 and this, accompanied by a reduction in CATAI, resulted in the firm's insolvency risk declining to 0.0692 .

The model included this ratio because of the adverse impact on Iiquidity caused by an increase in the proportion of current assets invested in stock.

\section{ClTI, (Current liabilities to total liabilities)}

This ratio is the proportion of a firm's total borrowings which is payable within 12 months from the date of the balance sheet. High-risk firms have a higher short-term-debt commitment. The model included this ratio because firms with a higher proportion of short-term debt are more susceptible to financial difficulties in the event of a profit downturn.

A common cause for a rise in this ratio is an accumulation of stock accompanied by a decline in profits, requiring an increase in short-term funds to finance the extra investment in inventory. If a firm can finance some of this need from long-term debt, this will lower its CLTL and its level of insolvency risk.

An example of the impact on insolvency risk of substituting short-term debt for long-term debt is Duncan 
Holdings, This company derived more than $80 \%$ of its borrowings from short-term sources. However, it then reduced its reliance on short-term debt to less than $60 \%$ and this contributed to a significant decline in its level of insolvency risk. The model deemed it a safer firm because it had reduced its more pressing debt commitments.

\section{CFBCL (Cash flow before tax to current liabilities)}

This ratio measures the ability of a firm to meet its short-term commitments from cash flow. The model identified those firms with a lower coverage of current liabilities as having a higher level of insolvency risk: their margin of safety for meeting the demands of the providers of short-term funds would be less.

A firm can increase CFBCL and hence reduce its level of insolvency risk by (a) earning a higher level of profits, (b) substituting some short-term debt with long-term debt or equity, and, (c) reducing investment in assets and using the funds to reduce its short-term debt. The effect of (a) is to increase the numerator $\mathrm{CFB}$ and the effect of (b) and (c) is to reduce the denominator CL.

An example of a firm improving the ratio by all three methods is coates and Co. In 1968 its level of insolvency risk was 0.95 . The company then improved CFBCL over two years from 0.3049 to 0.6673 by both increasing cash flow and placing less reliance on current liabilities: it achieved 
the latter by releasing funds from current assets (CATAI declined from 0.8165 to 0.4592 ) and increasing its use of long-term debt (CLTL dropped from 0.9849 to 0.7232 ). The combined effect was to reduce the firm's level of risk to 0.01: from an extremely high-risk firm, the company became a very safe one.

CFBCL has not been used by previous researchers: some have used instead cash flow to total liabilities. However, CFBCL was found to be more useful in this study because it emphasizes the importance of meeting the more immediate commitments, i.e., the obligations to trade creditors and banks. There is evidence from this ratio that both the banks and trade creditors were very accommodating to failing firms. For instance, although the cash-flow coverage of current liabilities was consistently less than 0.1 for Gollin and A.G. Healing - compared to at least 0.4 for the average surviving firm - they continued to make more funds available to these firms.

\section{TLTAI (Total liabilities to total assets)}

This ratio indicates the level of borrowings in relation to the total funds used by an organization: the higher the level of borrowings, the greater the insolvency risk.

Firms which rely more on debt finance are more susceptible to financial difficulties in times of a downturn 
in profits. Unlike equity capital, which does not have to be repaid and on which dividends do not have to be declared, liabilities have a fixed date for payment while many also carry a fixed-interest commitment. If a firm suffers a trading setback to the extent that it cannot meet an interest commitment or repay the liability on the due date, then the firm will be placed in receivership. The more the firm relies on debt finance, therefore, the greater is the risk of its being forced into receivership.

The history of John Shearer illustrates the reduction in insolvency risk achieved by placing little reliance on borrowings. Although this agriculture-based firm suffered two years of negative cash flow, this did not lead to a crisis since the company had a high proportion of equity funds (accumulated through retention of profits). This can be compared with that of another agriculture-based company, David shearer, which went through a similar period of loss making but then failed. The difference was that the failed firm relied'much more on debt finance: TLTAI was 0.75 for David Shearer compared with 0.21 for John Shearer. This contrasting pair of companies illustrates well the fact that firms which rely more on debt finance are more susceptible to financial difficulties in times of a profit downturn.

\section{Conclusions}

The model has established two main characteristics of a firm with a high level of insolvency risk in the 
manufacturing and retail industries.

1. It is close to the limit of its borrowing capacity because of: (a) a decline in cash flow from trading operations, which results in less funds being available from internal sources to finance its operations, (b) a build up of stock and debtors caused by inefficient management, which requires an increase in borrowings to cover the slower turnover of these assets, (c) a policy of placing greater reliance on debt finance than is normal for the industry.

2. It lacks accumulated profits because of a poor profit record or of a policy of high-dividend payouts.

The model estimates the combined impact of these two characteristics on the level of risk.

\section{Property-Einance Industry}

The two ratios comprising the best function for the property-finance industry are PITTAI and TLTAI. An important feature of the model for the companies in this industry is the interaction between the two ratios: therefore PITTAI and TLTAI will be considered together.

\section{Definitions}

PITTAI (Profit before interest and tax to total assets) 
measures the return a firm is earning on its investment.

TLTAI (Total liabilities to total assets) is known as the "gearing ratio": it indicates that proportion of the funds used by a firm which have been borrowed.

\section{Interaction Between the Two Ratios}

According to the model, a firm with a high level of borrowings would require a higher PITTAI than a firm with a lower level of borrowings. The firm with more of its TAI financed by debt would have a higher interest bill and hence the need to earn a higher profit before interest and tax.

An example of the interaction of PITTAI and TLTAI is provided by Cambridge credit, a failed finance company. For the year ended June 30 th, 1973, the company recorded a 33 per cent increase in profit and maintained its PITTAI at the level of previous years. This was given a favourable reception by the media and led to the general conclusion that the company had had a good year. However, this appraisal ignored the fact that borrowings had increased 55 per cent, taking TLTAI from 0.8456 to 0.9289 . Since the firm's borrowing commitments were higher, but it had not improved its PITTAI, the level of insolvency risk for Cambridge credit increased from 0.5032 to 0.6194. This emphasizes the importance of not considering a ratio - in the above case PITTAI - in isolation: firms can have the same PITTAI, but different levels of insolvency risk because of different gearing ratios. 
Similarly, if two firms have the same level of borrowings then their comparative levels of insolvency risk will be determined by the profit earned on those borrowings. For instance, two finance firms, A.G.C. and Cambridge Credit, had approximately the same level of borrowings but A.G.C. put its funds to a more profitable use: Cambridge Credit was in the failure zone and A.G.C. was in the nonfailure zone. Among the property companies, Hooker and Lend Lease had approximately the same proportion of their assets financed by borrowings, but Lend Lease had a PITTAI between 0.10 and 0.142 while Hooker's fluctuated between 0.044 and 0.08 ; hence in some years Hooker was in the failure zone whilst Lend Lease consistently had a low level of insolvency risk.

\section{Importance of Short-Term and Stable Profits}

The model, by increasing the level of insolvency risk for a firm which suffers a decline in profits, indicates that profitability is important in the short term and that stability of profits can be critical. The reason is that borrowing commitments are continuous; not only are interest payments continuous, but the loans must be rolled over, and this may become difficult or impossible unless the company is seen to be healthy. Therefore property and finance firms take a risk in putting too much of their funds into assets which will not produce an immediate income. This was characteristic of some of the firms in the sample who invested (a) on a deferred interest basis, or (b) as a principal with the intention of making a capital gain. The 
difficulty with a portfolio too heavily involved in deferredincome investments is that it could increase a firm's insolvency risk to a dangerous level. The investinent might have been hugely profitable in the long run, but could still get the company into deep trouble because the income is not visible soon enough.

An example of a firm with a higher level of borrowing, but surviving because of stability in its income, is Westfield: it had invested its borrowings in mainly incomeproducing property. Westfield had a gearing ratio above the average for failed firms but its PITTAI fluctuated within a narrow range -0.076 to 0.086 . This resulted in its level of insolvency risk being around the boundary for the failed and nonfailed zones, but the stability of its income minimized the possibility of its insolvency risk increasing in the event of a downturn in the property industry. This can be compared with a failed firm, Landall Holdings, which had a similarly high gearing, but was engaged in ṕroperty trading: consequently the volatility of this market placed its level of income at greater risk. Landali's PITTAI dropped to a negative figure when the property market collapsed, and this resulted in its failing.

Accordingly, the interpretation of the level of insolvency risk for a highly-geared firm with a stable income from rented properties would be different to that of a highlygeared firm which operated as a trader in property: in the above example there would be less concern about Westfield 
than about a property trader which had a similar level of insolvency risk.

Danger of the "big project"

A firm which commits a high proportion of its funds to a single project takes the risk that a setback on that project could affect its ability to meet borrowing commitments. An illustration of the impact on insolvency risk caused by a delay in the "big project" is Mainline. It was the construction company for the biggest property development project in Australia in 1974, and the project employed a significant proportion of Mainline's assets. There were industrial problems on the project and this led to delays in construction. These delays, causing the deferment of cash receipts, and accompanied by rapidly escalating costs, reduced the return the firm was earning on its assets, and hence its ability to meet borrowing commitments. The firm found it difficult to arrange additional finance because of a severe "credit squeeze", while the depressed property market made it difficult to sell assets as a source of funds: the firm consequently failed.

A firm similar to Mainline was Keith Morris Constructions. Both firms were included in the nonfailure zone by the model, but suddenly failed because of problems on a big project. The fact that the model misclassified these two large firms should not be taken as a sign of its weakness. To the extent that the failure of these firms was due to outside 
forces coming within the definition of "disaster", the model could not have forecast such a situation: these profitable firms were suddenly pushed into failure zone by the unforcasal cint of a delay on a "big project" during difficult economic times.

\section{Conclusion}

In view of the high level of borrowings which prevails in the property and finance industries, the relationship of that level to the rate of profit is an important one. 
Actions to Reduce the Level of Insolvency Risk

Dewing (1941) in his study of the financial policy of corporations observed firms following the pattern of getting further and further into debt until failure became inevitable. This pattern was followed by most of the failed firms in this study. The prevalence of this pattern shows the need for management to recognize when the situation is becoming grave, and to realize that they need to do something about it. Several appropriate courses of action are then available to them.

If the trend in a firm's level of insolvency risk, and/or the level of insolvency risk is unfavourable, Altman $(1971$, p.95) suggests that there are five alternatives facing management. These are: (a) changes in product line and/or management personnel, (b) sale of unprofitable equipment and/or entire unprofitable divisions, (c) active solicitation of a merger agreement, (d) financial arrangements - debt changes and equity adjustments, (e) receivership or liquidation. Altman suggests that the first three actions are recommended when the threat of failure is clear, but not necessarily imminent. The fourth is advisable when the danger of failure is extremely imminent but expected to be temporary. The fifth action is the most drastic and difficult step that can be taken, but the decision, if made early enough, can be extremely 
beneficial to all concerned.

The aim of this chapter is to evaluate these five general courses of action facing management of a firm whose level of insolvency risk has an unacceptable, upward trend.

\section{Product Iine and Management Changes and/or Sale of Assets}

Altman suggests that of his first three alternatives, (a) and (b) overlap and so can be considered together here. policy on changes in the product lines and management personnel, and on the sale of unprofitaile assets, needs to be increasingly drastic as a firm moves further into the failure zone.

If a firm's level of insolvency risk is not too much out of step with the rest of the industry, then the solution may be confined to the area of product mix. An examination of the contribution of each product line to overheads and profit would indicate those products which are not making a satisfactory financial contribution to the firm. The deletion of those items would improve the profitability of a firm and bring its insolvency risk back to the desired level.

However, as a firm's insolvency risk moves out of the normal range, then harder decisions would be necessary. The approach required then would be to assess the return on 
investment for each segment of the business, segments being defined by product lines or by geographical location. The rates of return would be divided into three categories: (a) satisfactory, (b) marginal, (c) unsatisfactory. The policy would be to sell off those assets which are earning an unsatisfactory return, and to further investigate those which are achieving a marginal return; if the latter cannot be improved in the short term then the assets involved should also be sold. This process would leave the company smaller, but with a lower level of insolvency risk; lossmaking products would have been excluded from the product mix, thus improving cash flow, and the sale of assets would generate cash to improve the liquidity position of the firm.

These decisions, to abandon product lines and to sell off assets, are hard ones, and Argenti (1976,p.177) believes that existing management, which led the firm into the position of high insolvency risk, would be unlikely to be the one that will take the necessary hard decisions to correct the situation; therefore, there is the need for a complete management shakeup if the necessary corrective action is to be taken.

The failed firms, and those surviving firms which either had been in the failure zone, or had shown a sharp increase in their level of insolvency risk in one year, with an equally marked decrease within the following two years, were examined to test two hypotheses: 
1. If firms with an adverse trend in their level of insolvency risk don't sell off their unprofitable assets to reduce their level of borrowings then they will fail.

2. The firms that do sell off their unprofitable assets have changed their management.

Sale of assets. In this study there were 41 failed firms. Where a decision had been taken to sell off unprofitable segments, one would expect that the value of total assets would have been reduced. ${ }^{1}$. Table 45 sets out the movement in total assets of the 41 failed firms from five years before failure.

Table 45

Total Assets of Failed Firms

No. of firms whose asset size increased to date of failure
No. of firms whose asset size decreased from one to five years before failure

Yr.l Yr. 2 Yr. 3 Yr. 4 Yr.5 Total

\begin{tabular}{|c|c|c|c|c|c|c|c|}
\hline Manufacturing & 7 & 2 & 4 & - & - & - & 6 \\
\hline Retail & 6 & 1 & 2 & - & - & - & 3 \\
\hline Property & 10 & 3 & 2 & - & - & - & 5 \\
\hline Finance & 2 & 1 & 1 & - & - & - & 2 \\
\hline Total & 25 & 7 & 9 & - & - & - & 16 \\
\hline
\end{tabular}

of the 41 failed firms, 25 increased their investment in assets up to the date of failure. Of the other 16, seven reduced their total assets one year before failure and nine liabilities, and hence level of insolvency risk. 
two years before failure: there were no failed firms that reduced their assets from 3 to 5 years before failing. For the 16 which reduced their total assets one year before failure, the magnitud of the cutback did not appear to be very significant. The timing of the sale of assets is important: if it is forced by impending insolvency, then the full market value may well not be obtained. This could have been the problem of the management of the 16 failed firms which tried too late to improve the situation by selling assets.

An analysis was also performed of the movements in the total assets of 26 surviving firms which, from the graphs in Appendix $R$, had either been in the failure zone or showed a sharp increase in their level of insolvency risk in one year with an equally marked decrease within the following two years ${ }^{2}$. The results are shown in Table 46.

Table 46

Total Assets of Twenty-six Surviving Firms During the Period, they Reduced their Level of Insolvency Risk

\author{
Total Assets \\ Increased
}

8

\author{
Total Assets \\ Decreased
}

18

2. These 26 firms were: Braemar, ANI, Duncan, Alstergren, Yarra Falls, Speedo, Coates, Hills, John Shearer, Bowra, Chamberlain, Swift, Supertex, Kinnears, SimpsonPope, Email, Vulcan, Osbourne Metals, Mauri Bros. and Thompson, McPhersons, Johns Consolidated, Jaques, Katies, Clark Rubber, J.B. Young, Metro Industries. 
This table indicates that in the majority of instances, the total assets of surviving firms declined during the period in which they reversed an adverse trend in their level of insolvency risk. This provides so: ? indication of management having taken steps to reduce stocks and/or selling fixed assets. The management of these firms were not only aware of the adverse trend in their finances, but quickly took corrective action before the problem became too serious: this could have included the sale of some loss-making segments which were a burden to the profitability of the firm. Most of those that increased their assets continued to experience an erratic risk pattern. This indicates that not only must action on assets be taken, but it must be taken early to ensure realizing them at a reasonable price. This emphasizes the need for a model to convey an early warning signal of higher insolvency risk, a signal which leads management to promptly review its operations and take action to rid itself of the loss-making products and assets earning a poor return.

Management. Altman $(1971$, p.96) believed tinat the decisions on changing management may have to precede any significant courses of action - such as the sale of assets - and that the requisite management change is at the very top.

In an endeavour to test Altman's hypothesis, an investigation was carried out to ascertain if there were any changes in the chief executives of: (a) the failed firms during the five years before they failed, and (b) the 26 surviving firms during the year in which their adverse trend 
was first reversed. The results are presented in Table 47 for the failed firms.

Table $4 /$

Number of Failed Firms which Changed Chief Executives up to Five Years Before Failure

Year 1 Year 2 Year 3 Year 4 Year 5 Total

2 3

2

7

Of the 41 failed firms only 7 changed their chief executive up to five years before failure. This can be compared with the sampled 26 surviving firms where 4 chief executives were replaced during the year in which the level of insolvercy risk was reduced. The directors of failing firms were reluctant to change their chief executives as a part of the process to reduce insolvency risk. However, the directors of surviving firms were similarly reluctant. Therefore, there is no evidence from this study to support the hypothesis that a change of management may have to precede any significant action to reduce a firm's level of insolvency $r i s k$.

\section{Merger Solicitation}

If the company's financial problems are serious, the most simple and effective cure may be through a merger with a financially sounder company. The most desirable type of merger is where a firm realizes its own shortcomings early enough to still be a relatively vibrant enterprise, thereby 
able to command a respectable price from the buyer. This takes a considerable degree of management skill. If the model convinces management that its financial position is worsening, and management feels that it is unable to reverse its adverse financial trend, then the earlier it seeks the merger the better.

The extent to which firms have opted for this solution is not discernible from this study; it is not known whether the failed manufacturing, retail and property firms sought a merger as a solution to their problems. To assess the extent to which high-risk firms have sought the merger to reduce insolvency risk, it would be necessary to obtain a sample of companies which merged or were taken over, and assess the trend in their insolvency risk leading up to the transaction.

Financial Arrangements

Because of the weighting given to liquidity by the manufacturing-retail industry model, firms in the failure zone can reduce their level of insolvency risk in the short term by replacing some short-term debt with long-term debt and equity. However, that gain will be short-lived unless it is accompanied with swift and successful action by management to improve the cash flow of the business. An example from this study can be used to illustrate that 
financial restructuring by itself is insufficient to solve the problems of a company in the failure zone.

Wrigit:'; Ltd, a failed retail firm, moved out of the failure zone one year before failure because of a sizeable injection of share capital which reduced the company's funding from debt, especially short-term debt. The result was to improve the liquidity ratios and hence reduce its level of insolvency risk. However, Wright's lost any benefit of the financial restructuring because management was unable to take effective action to reverse the trend in its cash flow at the same time. Therefore the benefit of the changed financial profile was soon lost as the company quickly increased its short-term debt.

The working of the model indicates that additional finance is provided to a company in the failure zone on the assumption that there will be an improvement in profit. However, a significant financial characteristic of the failed firms in this study is that lenders were prepared to make ever increasing sums of debt finance available to failing firms which were unable to improve their cash flow (see Table 48).

of the 41 failed firms, the total liabilities of 28 continued to increase to the last balance date before failure: most of the additional debt was short term. The other 13 showed only a slight reduction in total debt, and this mostly occurred just one year before failure. 
Table 48

Change in Liabilities of Failed Firms

from Five Years Before Failure

No. of firms whose
liabilities in-
creased

Yr.1 Yr.2 Yr.3 Yr.4 Yr.5 Total
No. of firms whose liabilities decreased

$\begin{array}{lrrrrrrr} & & \text { Yr.1 Yr.2 } & \text { Yr.3 } & \text { Yr.4 Yr.5 } & \text { Total } \\ \text { Manufacturing } & 10 & 2 & 1 & - & - & - & 3 \\ \text { Retail } & 4 & 4 & - & 1 & - & - & 5 \\ \text { Property } & 12 & 3 & - & - & - & - & 3 \\ \text { Finance } & 2 & 1 & - & 1 & - & - & 2 \\ \text { Total } & 28 & 10 & 1 & 2 & - & - & 13\end{array}$

Overall there appeared to be little change in the proportions of short-term and long-term debt. This suggests that lenders to the failed firms either were unaware of the financial plight of the firms, or hoped that the availability of more funds would solve their problems. This does not say much for the ability of financial institutions to recognize the problems of firms, or to play any meaningful role in averting their collapse even if they foresee $\mathrm{it}^{3,4}$.

Shareholders were more cautious than lenders in making additional funds available to failing firms. Table 49 shows that only 13 of the 41 failed companies had capital raisings from shareholders up to five years before failure.

3. The results of recent research on the ability of bank loan officers to identify failing firms has been inconsistent: Libby (1975) and $\mathrm{Zimmer}$ (1980) found loan officers to be fairly accurate predictors of corporate failure but Casey (1980) found that the majority of loan officers could not predict results better than chance. Accordingly, further research is appropriate.

4. Since banks lend more to failed than nonfailed firms the impact that this has on a widely used ratio, QAQL, is examined in Appendix $\mathrm{T}$. 
Table 49

Change in Ordinary Capital. of Failed Firms

fru Eive Years Before Failuce

No. of firms whose ordinary
capital increased

Yr. 1 Yr. 2 Yr. 3 Yr. 4 Yr. 5 Total

$\begin{array}{llllllll}\text { Manufacturing } & - & - & 1 & - & 1 & 2 & 11 \\ \text { Retail. } & - & 3 & 1 & - & - & 4 & 5 \\ \text { Property } & 3 & 2 & - & - & - & 5 & 10 \\ \text { Finance } & 1 & - & 1 & - & - & 2 & 2 \\ \text { Total } & 4 & 5 & 3 & - & 1 & 13 & 28\end{array}$

Seven of the thirteen were property and finance firms which took advantage of the property boom to raise additional capital. The manufacturing and retail companies were apparently not in a position to have an underwritten issue of shares to shareholders, yet financial institutions were prepared to lend the companies increasing sums of money.

\section{Receivership}

Altman (1971) suggests that the essential factor here is timing. "A firm should not throw in the towel if it can possibly avoid it, but at the same time, it must not unduly delay the situation. If none of the previous courses of action can be accomplished, then receivership should be entered into as soon as possible to prevent losses continuing to mount and financiers/investors losing more money." (p.98) 
There is evidence of companies unduly delaying receivership, in that only two of the 41 failed firms Wilcox Mofflin and Hecla Rowe - were traded out of their problems by the receiver, with the lenders being repaid in full. All the other failed firms were liquidated, with creditors receiving something less than full payment on amounts outstanding at the date of receivership.

It would be expected that a receiver would try to do what management failed to do: reduce the level of insolvency risk by deleting loss-product lines, selling off unprofitable assets, seeking a merger, and restructuring finance. He would prefer this course of action because this would be in the best interests of all lenders and investors: they would have a better chance of recovering their monies if the firm could be traded out of its problens. If a receiver has to liquidate the company, then probably not all people will be repaid in full: it is very difficult to sell stock or plant at anywhere near its book value. However, the receiver can only trade the firm out of its problems if he takes over the management before the firm is too far into the failure zone. The fact that only two firms were traded out of their difficulties suggests that a receiver is usually called in, either by the management or lenders, when it is too late for him to be very effective. Consequently, there is much financial loss and social distress as people lose their jobs. 
Since a successful receiver must do what management has been unable to do, there is a strong argument for his being called in earlier than he apparently is, either by management or lenaes. A difficulty which often exists here is that an executive of a lending institution is reluctant to have a receiver appointed because it adversely reflects on his, and to a lesser extent, the firm's lending policy. A further difficulty is that management itself tends to remain extremely optimistic that it can correct the adverse situation. These two factors result in receivers being appointed too late to be very effective.

\section{Summary}

This chapter has examined the alternative courses of action available to management when the trend in a firm's insolvency risk and/or level of insolvency risk is unfavourable.

A conclusion is that as a firm's level of insolvency risk increases so the necessary remedial actions become more drastic. Therefore a benefit from a model which measures insolvency risk is the provision of an early-warning signal to give management the opportunity to take corrective action before the situation becomes more serious. Altman and La Fleur (1980) described how a failure model - that developed by Altman (1968) - was successfully used by a chief executive to assist in turning around his firm. 
The aim of this study was to characterize the financial standing of a firm by a single figure. This figure was derived by combining and weighting those ratios which were found to discriminate best between failed and surviving firms. To assist in the interpretation of the resulting figure, an index-of-risk table was computed from which could be read the probability at a particular time of the firm failing: this probability was referred to as the firm's level of insolvency risk.

The level of insolvency risk for each firm was graphed for a period of five years, and this showed the range of insolvency risk patterns traced by failed and nonfailed firms. An examination of the movements in the weighted ratios behind these patterns then provided information on the factors which caused changes in the levels of insolvency risk. This examination highlighted the sources of change and enabled problem areas to be accurately identified; this would assist in the formulation of a policy when it was necessary to reduce the level of risk.

Separate ratio models were developed for the manufacturing-retail and property-finance industries: this was necessary because of the different financial characteristics of these industries. The manufacturing- 
retail industry function comprised seven ratios while the property-finance industry function consisted of two ratios: the ratio TLTAI, representing the proportion of assets financed from borrowings, was included in both functions.

\section{Limitations of this study}

1. The most serious limitation of this study lies in the small number of failed firms on which data is publicly available. Although a large number of business entities fail every year, a high proportion of them are small private enterprises which do not disclose their operating results. Because of the small number of failed firms there is the risk that the results are sample-sensitive.

2. Most public companies did not disclose figures on sales and on their operating expenses. Hence the research was necessarily restricted to balance sheet figures and a few profit and loss items.

\section{Implications of Findings}

This study has implications both for groups concerned with the assessment of a particular firm's insolvency-risk level and for future research into insolvency risk.

For users. Four groups can be identified which would have interest in the application of the model: lenders, management, auditors and financial analysts. 
1. Lenders. One finding of this study has been that lenders continue to make additional funds available to most failing firms. The model would be useful to them both in assessing the level of insolvency risk of a firm and in understanding the factors which have caused that level of insolvency risk, It is important for lenders to realize that the mere provision of additional finance does not solve the problems of a firm which is in the failure zone, and the model could make a valuable contribution here.

2. Management. The model will be a valuable tool for monitoring the performance of a firm and arawing attention to problem areas. A chart of its level of insolvency risk over several years, and a table containing the values of ratios underlying the charts would increase the usefulness to management of financial statements; the analysis and interpretation of accounts would be more precise.

The model would also be of benefit to company management when preparing budgets: it could reveal the impact of alternative budgets on insolvency risk.

The credit departments of industrial firms will be able to make use of the model in a manner similar to that recommended earlier for lenders. It would be useful in the management of accounts receivable, not only in the determination of acceptable customers but in important factors such as determining the period over which credit will be extended. 
3. Auditors. As increasing pressure is being put on auditors in deciding whether the business can be assessed as a going concern - i.e., whether the "going-concern convention (assumption)" is applicable - the model would be useful to them in forming their opinion. Currently the accounting profession in Australia has an exposure draft on this problem but this is notable for its lack of reference to ratios.

4. Financial analysts. Many analysts doubt the usefulness of ratios to analyse the performance of a company. They argue that the financial statements of firms are often unreliable and that this casts doubt on the adequacy of ratios. This attitude has been reinforced by the findings of some researchers. For instance, an Australian study by Bird and McHugh (1974) questioned the practice of using ratios to analyse the performance of companies. They argued that the underlying data from which the ratios are derived are themselves unreliable and subject to manipulation, and that valid standards of comparison are non-existent, so that it is impośsible to view any given ratio as "good". They did suggest that there might be some benefit from a critical and sophisticated use of groups of ratios considered together; they concluded, nevertheless, that in most circumstances the use of ratios can be seriously misleading and is therefore dangerous.

This study has shown that the use of a combination of ratios gives extremely helpful information; that ratios, when combined and weighted, are a powerful means for 
assessing the performance of a company. Even if a firm's reported figures are open to question, the model was clearly able to handle the situation, because the combining and weighting of ratios reduced the effects of any manipulation. There was no evidence of accounting reports being manipulated to the extent that the value of the results was unduly affected.

It has been shown that many of the doubts which have been expressed about the usefulness of ratios are unjustified. Use of the model by analysts should enable them to place greater reliance on financial statements than they have in the past. This reliance is important because all the factors influencing the success of a company are reflected in its financial statements. Poor management will be reflected in the profit and loss statement, in the same way that economic downturns will be shown in the company's declining cash flow. Tight credit or low levels of money supply growth will be reflected in the balance sheet. The fact that the model has been shown to state the level of insolvency risk of a firm with a high degree of accuracy indicates that it has been able to highlight the combined impact of all the factors which lead to the reported figures. This, therefore, makes the model a significant development in the analysis of financial statements.

\section{For future research. As changes occur both in} accounting reporting standards and in sources of finance, research will be required into the effect of these changes 
on the continuing usefulness of the model, For instance, the current trend in the financing of business activities is towards the replacing of bank overdraft by commercial. bills: this may require the definition of quick liabiliti to be amended. The continuous review of the model, in the light of new information, can be made with confidence because this study has shown that accounting ratios can adequately explain the financial health of a business.

A suggestion for future research is to use the model as the starting point for the development of a more complete theory of insolvency risk. It was stated that there is no established theory of financial distress: accordingly the decision was taken not to place any arbitrary limit on the number of financial ratios that were available for inclusion in the model (see p.69). The fact that the components of the best function conformed to a logical analysis of factors causing different levels of insolvency risk indicates that the findings could be used in the development of a theory of insolvency, risk, a theory that would include both nonfinancial and financial variables. The nonfinancial variables to be considered would be economic ones. The task would be to establish if there was any correlation between failure statistics and any other economic indicators. If there were such economic variables they could be included in the model to build on the theory of insolvency risk developed in this study . 
Altman, E.I. Financial ratios, discriminant analysis and the prediction of corporate bankruptcy. The journal of finance, vol. XXIII, no. 4, september 1968, pp. $589-609$.

Altman, E.I. Corporate bankruptcy in America. Lexington, Massachusetts: Heath Lexington Books, 1971.

Altman, E.I. Predicting railroad bankruptcies in America. Bell journal of economics and management science, vol. 4, no. 1, Spring 1973, pp.184-211.

Altman, E.I. \& Lorris, T. A financial early warning system for over-the-counter broker-dealers. The journal of finance, vol. XXXI, no. 4, September 1976 , pp.1201-1217.

Altman, E.I. Predicting performance in the savings and loan association industry. Journal of monetary economics, vol. 3, 1977, pp. 443-46.

Altman, E.I., Haldeman, R.G., \& Narayanan, P. Zeta analysis, a new model for identifying bankrupcty risk of corporations. Journal of banking and finance, vol. 1,1977 , pp. 29-54.

Altman, E.I. \& Eisenbeis, R.A. Financial applications of discriminant analysis: a clarification. Journal of financial and quantitative analysis, vol. XIII, no. 1 , March 1978, pp.185-195.

Altman, E.I., Baidya, T.K.N. and Ribeiro-Dias, L.M. Assessing potential financial problems for firms in Brazil. Journal of international business studies, vol. 10, no. 2, Fall 1979, pp.19-24.

Altman, E.I. and La Fleur, J.K. Managing a return to financial health. Journal of business strategy, Summer 1980, pp. $31-38$.

Altman, E.I. Commercial bank lending: process, credit scoring, and costs of errors in lending. Journal of financial and quantitative analysis, vol. $\overline{X V}$, no. 4, November 1980, pp.813-832.

Altman, E.I. \& Izan, H.Y. Identifying corporate distress in Australia: an industry relative analysis. A working paper published by the Australian Graduate School of Management, August 1982 .

Argenti, J. Corporate collapse: the causes and symptoms. London: McGraw-Hi11, 1976 . 
Argenti, J. Company failure: long range planning not enough. Accountancy, vol. 88, no. 1008, August 1977, pp. 46-52.

Australian Bureau of Statistics. Consumer price index. Quarterly Reports, 1969-1978.

Bazley, J.D. An examination of the ability of alternative accounting measurement models to predict failure. Review of business and economic research, Fall, 1976, pp. $32-46$.

Beaver, W.H. Financial ratios as predictors of failure. Empirical research in accounting: selected studies 1966 . Supplement to vol. 4, no. 1, Journal of accounting research, 1966, pp.71-111.

Beaver, W.H. Market prices, financial ratios, and the prediction of failure. Journal of accounting research, vol. 6 , no. 1, Autumn 1968, pp.179-192.

Bird, R.G. \& McHugh, A.J. Financial ratios - why? Accounting Education, vol. 14, 1974, supplement pp.D1-D 45 .

Bird, R.G. \& McHugh, A.J. Financial ratios: an empirical study. Journal of business finance and accounting, vol. 4, no. 1, 1977, pp.29-45.

Bliss, J.H. Financial and operating ratios in management. New York: Ronald Press, 1923.

Blum, M. Failing company discriminant analysis. Journal of accounting research, vol. 12, no. 1, Spring 1974, pp. $1-25$.

Casey, C.J. The usefulness of accounting ratios for subjects' predictions of corporate failure: replication and extensions. Journal of accounting research, vol. 18, no. 2, Autumn 1980.

Castagna, A.D. \& Matolcsy, Z.P. The prediction of corporate failure. The journal of the Australian society of security analysts, no. 1, 1977, pp.9-11.

Castagna, A.D. \& Matolcsy, Z.P. An examination of company failures in efficient capital markets. Accounting Association of Australia and New Zealand: 1979 Conference. $27 \mathrm{th}$ to 29 th August, University of Melbourne.

Castagna, A.D. \& Matolcsy, Z.P. The prediction of corporate failure: testing the Australian experience. Australian journal of management, vol. 6 , no. 1 , June 1981, pp.23-50. 
Deakin, E.B. A discriminant analysis of predictors of business failure. Journal of accounting research, vol. 10, no. I, spring 1972, pp.167-179.

Deakin, E.B. On the nature of the distribution of financial accounting ratios: some empirical evidence. The accounting review, vol. LI, no. 1, January 1976 , pp. $90-96$.

Deakin, E.B. Business failure prediction: an empirical analysis, In Altman \& Sametz (eds.), Financial Crises, J. Wiley, 1977, pp.72-78.

Dewing, A.S. The financial policy of corporations. New York: Ronald Press, 1941.

Dillon, W.R. \& Goldstein, M. On the performance of some multinomial classification rules. Journal of the American statistical association, no. 73, June 1978, pp. 305-313.

Dillon, W.R. The performance of the linear discriminant function in nonoptimal situations and the estimation of classification error rates: a review of recent findings. Journal of marketing research, vol. XVI, August $1979, \mathrm{pp} .370-381$.

Durand, D.D. Risk elements in consumer instalment financing. Studies in consumer instalment financing, National bureau of economic research, New York, 1941, pp. 105-142.

Edmister, R.O. An empirical test of financial ratio analysis for small business failure prediction. Journal of financial and quantitative analysis, vol. VII, no. 2, March 1972, pp.1477-1493.

Eisenbeis, R.A. \& Avery, R.B. Discriminant analysis and classification procedures: theory and applications. Lexington, Massachusetts: D.C. Heath and Co., 1972 .

Eisenbeis, R.A. Pitfalls in the application of discriminant analysis in business, finance and economics. The journal of finance, vol. XXXII, no. 3, June 1977, pp.875-900.

Fisher, R.A. The use of multiple measures in taxonomic problems. Annals of Eugenics, no. 7, September, 1936 .

Fitzpatrick, P.J. A comparison of the ratios of successful industrial enterprises with those of failed companies. New York: The Accountants Publishing Coy., 1932.

Foster, G. Financial statement analysis. New Jersey: Prentice-Hall, 1978 . 
Gilbert, E.S. On discrimination using qualitative variables. Journal of the American statistical association, vol. 63,1968, pp.1399-1412.

Hair, J.H., Anderson, R.E., Tatham, R.L. \& Grablowsky, B.J. Multivariate data analysis with readings. Tulsa, Oklahoma: PPC Books, 1979 .

Harris, R.J. A primer of multivariate statistics. New York: Academic Press, 1975.

Hoeven, J.A. Predicting default of small business loans. The journal of commercial bank lending, vol. 61 , no. 8 , April 1979, pp. 47-60.

Horrigan, J.O. Some empirical bases of financial ratio analysis. The accounting review, vol. XI, no. 3, July 1965 , pp.558-568.

Horrigan, J.O. A short history of financial ratio analysis. The accounting review, vol. XLIII, no. 2, Apri1 1968, pp.284-294.

Jobson's investment year book of public companies of Australia and New Zealand. Sydney: Jobson's publications, 1964-1979.

Joy, O.M. \& Tollefson, J.O. On the financial applications of discriminant analysis. Journal of financial and quantitative analysis, vol. X, no. 5, December 1975 , pp. $723-739$.

Joy, O.M. \& Tollefson, J.O. Some clarifying comments on discriminant analysis. Journal of financial and quantitative analysis, vol. XIII, no. 1, March 1978, pp. 197-200.

Korobow, L. \& Stuhr, D. Toward early warning system of changes in banks. Federal Reserve Bank of New York Review, vol. 57, no. 7, July 1975, pp.177-183.

Lachenbruch, P.A. An almost unbiased method of obtaining confidence intervals for the probability of misclassification in discriminant analysis. Biometrics, vol. 23, no. 4, 1967, pp.639-645.

Lachenbruch, P.A. \& Mickey, M.R. Estimation of error rates in discriminant analysis. Technometrics, vol. 10, no. 1, February 1968, pp.1-11.

Lev, B. Financial failure and informational decomposition measures. Accounting in perspective: contributions to accounting thought by other disciplines, R.R. Sterling \& W. Bentz (eds.), Cincinnatti: Southwestern, 1971 .

Lev, B. Financial statement analysis: a new approach. New Jersey: Prentice-Hall Inc., 1974. 
Libby, R. Accounting ratios and the prediction of failure: some behavioral evidence. Journal of accounting research, vol. 15, no. 1, Spring 1975, pp.150-161.

Littleton, A.C. The 2 to 1 ratio analysed. Certified public accountant, vol. 6 , August 1926 , pp. 24-32.

Marks, S. \& Dunn, O.J. Discriminant functions when covariance matrices are unequal. Journal of the American statistical association, vol. 69, 1974, pp. 555-559.

Mathews, R. Report of committee of inquiry into inflation and taxation. Canberra: Australian government publishing service, May 1975.

Moore, D.H. Evaluation of five discrimination procedures for binary variables. Journal of American statistical association, vol. 68, June 1973, pp.399-404.

Nie, N.H., Hadlai, H.G., Steinbrenner, K. \& Brent, D.H. statistical package for the social sciences. New York: MCGraw-Hill, 1975.

Ohlson, J.A. Financial ratios and the probabilistic prediction of bankruptcy. Journal of accounting research, vol. 18, no. 1, spring 1980, pp.109-131.

Ramser, J.R. \& Foster, L.O. A demonstration of ratio analysis. Bulletin no. 40, Urbana, Illinois:

University of Illinois, Bureau of Business Research, 1931.

Ross, J.E. \& Kami, M.J. Corporate management in crisis. New Jersey: Prentice-Hall, 1973.

Schumpeter, J.A. Business cycles: a theoretical, historical and statistical analysis of the capitalist process. New York: McGraw-Hill, 1939.

scott, E. On the financial applications of discriminant analysis: comment. Journal of financial and quantitative analysis, vol. XIII, no. 2, March 1978, pp.201-205.

Sheehan, P.R. \& Rose, P.J. Company profits, finance and capital expenditure: manufacturing and non-manlifacturing companies. The Australian economic review, no. 32 , 4 th Quarter 1975, pp.9-16.

Sinkey, J. A multivariate statistical analysis of the characteristics of problem banks. Journal of finance, vol. XXX, no. 1, March 1975, pp. 21- $\overline{36}$.

Smith, K.V. Classification of investment securities using MDA. Institute paper, purdue University, Institute for Research in the Behavioral, Economic, and Management Sciences, 1965. 
Smith, R.F. \& Winakor, A.H. A test analysis of unsuccessful industrial corporations. Bulletin no. 31, Urbana, Illinois: University of Illino $\overline{i s, ~ B u r e a u ~ o f ~ b u s i n e s s ~}$ research, 1930.

Smith, R.F. \& Winakor, A.H. Changes in the financial structure of unsuccessful industrial corporations. Bulletin no. 51, Urbana, Illinois: University of Illinois, Bureau of business research, 1935.

Strebel, P.J. \& Andrews, G.S. A simple predictor of company failure: a preliminary comment. Fact and opinion papers, no. 2, 1977, Graduate school of business administration, University of the Witwatersrand, Johannesburg.

Taffler, R. \& Tisshaw, H. Going, going, gone - four factors which predict. Accountancy, vol. 88, no. 979, March 1977, pp.50-54.

Tamari, M. Financial ratios as a means of forecasting bankruptcy. Economic review, no. 21, Bank of Israel, 1964, pp.15-21.

Tamari, M. Financial ratios as a means of forecasting bankruptcy. Trends in financial decision-making, Cees Van Dam (ed.). Nijenrode studies in business, vol. 2, Martinus Nijhoff social services division (Leiden/Boston), 1978, pp.189-199.

The Sydney Stock Exchange Ltd. Delisted companies.

A publication of the research department, 1979.

The Sydney Stock Exchange Ltd. The stock exchange financial and profitability study 1979. Produced by the research department.

Wall, A. \& Dunning, R.W. Ratio analysis of financial statements. New York: Harper and Brothers, 1928 .

Wall, A. How to evaluate financial statements. New York: Harper and Row, 1936.

Walter, J.E. Determination of technical solvency. Journal of business, vol. 30, 1956-57, pp.30-43.

Walter, J.E. A discriminant function for earnings price ratios of large industrial corporations. Review of economics and statistics, vol. XLI, February 1959, pp. 44-52.

Wilcox, J.W. A prediction of business failure using accounting data. Empirical research in accounting: selected studies, 1973, pp.163-179. 
Williams, A.J. The plight of small business. An occasional paper. Department of accounting, University of Western Australia, August 1975.

Zimmer, I. A lens study of the prediction of corporate failure by bank loan officers. Journal of accounting research, vol. 18, no. 2, Autumn 1980, pp.629-636. 
Sample failed firms by industry; year founded, year listed, year of failure, age at failure and highest asset figure during the three years before failure.

MANUEACTURING

A.G. HEALING LTD.

FEDERATED

INDUSTRIES LTD.

HUDSON (GEO.)

HOLDINGS LTD.

INTERNATIONAL

FOOTWEAR LTD.

JEFFRIES

INDUSTRIES LTD.

SHEARER (DAVID)

LTD.

WILCOX-MOFF LIN

LTD.

COLUMBIA CARPET

INDUSTRIES LTD.

JAMES MIILER

HOLDINGS LTD.

HECLA-ROWE

LTD.

HANCOCK \& GORE

LTD.

PROLINE HOLDINGS

LTD.

FAVELLE MORT

LTD.

$\begin{array}{ccccc}\text { Year } & \text { Year } & \text { Year } & \text { Age } & \text { Assets } \\ \text { Founded } & \text { Listed } & \text { Failed } & \text { (yrs.) } & (\$ \text { '000) }\end{array}$

$$
1912
$$

1927

June 169

57

$41,1.95$

1956

1956

Dec $\quad 69 \quad 13$

20,097

1951

1954

Dec $\quad 171$

17

8,207

1951

1951

Mar 171

20

4,821

1950

195

Mar $171 \quad 21$

3,343

1922

1956

sept $\cdot 72$

50

4,066

1917

191

Apr 174

57

9,034

1952

1952

May 175

23

4,852

1862

1955

Dec $\quad 176 \quad 114$

54.199

1926

1960

July $176 \quad 50$

20,438

1904

1937

$\operatorname{Jan} \cdot 71$

67

4,444

1944

196

Aug 17

33

2,998

1875

195

Nov

' 75

100

4,987 
APPENDIX A (continued):

RETAIE

WALSH'S HOLDINGS

LTD.

WRIGHT'S LTD.

BINTANG LTD.

GOLLIN HOLDINGS LTD.

EPSTEIN \& CO. LTD.

OLIMS CONSOLI-

DATED LTD.

QLD. GROCERS LTD.

CUNNINGHAM， R.E.

LTD.

PONSFORD, NEWMAN

$\&$ BENSON LTD.

$\begin{array}{ccccc}\text { Year } & \text { Year } & \text { Year } & \text { Age } & \text { Assets } \\ \text { Founded } & \text { Listed } & \text { Failed } & \text { (yrs.) } & (\text { (\$000) }\end{array}$

1926

1970

May $\cdot 75$

49

12,922

1949

1957 Nov $\quad 75$

26

1,309

1925

1925

Mar $\quad 75$

50

3,206

1845

1957

June $176 \quad 131$

143,016

1946

1960 Feb '69

23

4,564

1962

1962

Sept $\cdot 72$

10

10,717

1961

1962

Oct $\quad 172$

11

307

1927

1929 Aug $\quad 70$

43

1,831

1925
May 172

47

1,265
EINANCE

CAMBRIDGE CREDIT CORPORATION LTD.

ASSOCIATED

SECURITIES ITD.

INDUSTRIAL

ACCEPTANCE

CORPORATION LTD.

FINANCE

CORPORATION OF

AUSTRALIA LTD.

\begin{tabular}{ccccc}
\hline $\begin{array}{c}\text { Year } \\
\text { Founded }\end{array}$ & $\begin{array}{c}\text { Year } \\
\text { Listed }\end{array}$ & $\begin{array}{c}\text { Year } \\
\text { Failed }\end{array}$ & $\begin{array}{c}\text { Age } \\
(\text { yrs. })\end{array}$ & $\begin{array}{c}\text { Assets } \\
\left(\text { ('O00 }^{\prime}\right)\end{array}$ \\
\hline
\end{tabular}

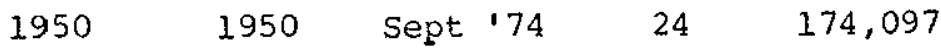

1926

Sept $\cdot 78$

52

283,942

1954

1954 Sept '77

23906,614

1954

$1954 \operatorname{Max} 179$

25

508,031

$1,872,684$ 
APPENDIX A (continued):

\section{PROPERTY}

MAINLINE LTD.

MORRIS (KEITH)

CONSTRUCTION LTD.

GRANT (ALFRED)

HOLDINGS LTD.

REGIONAL LAND

LTD.

MUNDANA

INVESTMENTS LTD.

REINVESTMENT

(AUST.) LTD.

LANDALI HOLDINGS

LTD.

FUTURE

DEVELOPMENT LTD.

CONTOUR

DEVELOPMENTS LTD.

COMF IN (AUST.)

LTD.

WESTHAVEN

SECURITIES LTD.

PACIFIC

ACCEPTANCE LTD.

TALGA LTD,

ACRE PROPERTIES

LTD.

1970

GLENDALE LAND LTD. 1969

1955

1960

1970

1959

1955

1959

1953

1935

1954

1950

1969

\begin{tabular}{|c|c|c|c|c|}
\hline $\begin{array}{l}\text { Yoar } \\
\text { Founded }\end{array}$ & $\begin{array}{c}\text { Yeat } \\
\text { Listed }\end{array}$ & $\begin{array}{c}\text { Yatr } \\
\text { Euilod }\end{array}$ & $\begin{array}{l}\text { Age } \\
\text { (yrs.) }\end{array}$ & $\begin{array}{l}\text { Assets } \\
(\$, 000)\end{array}$ \\
\hline
\end{tabular}

$1961 \quad 1968 \quad$ Apr $\quad \begin{array}{llll} & 74 & 13 & 65,595\end{array}$

$1945 \quad 1955 \quad$ June $75 \quad 30 \quad 13,268$

1973 Mar $\cdot 76$

21

27,524

1960

Aug $\quad .76$

16

40,146

1970 Nov 175

5

2,342

1959

June ' 75

16

5,043

1965 Oct '74

19

21,086

1959

Apr 176

17

799

1960

June 177

24

6,404

1973 Sept 177

42

11,401

1954 Mar ' 77

23

6,219

1950 June $\cdot 77$

27

6,269

1969

Sept 174

5

8,698

\begin{tabular}{llll}
1970 & Sept 177 & 7 & 7,080 \\
1969 & Sept 178 & 9 & 5,195 \\
\hline & & & 227,069
\end{tabular}


APPENDIX 8

MATCHED FAILED AND YONFAILED COMPANIES, BY INDUSTRY AND YEARS

MANUFACTURING

Yayrs Before Failurg

\section{Falled Conpanies}

A.G. Healing Ltd.

Federated Industries Ltd.

Hudson (Geo.) Holdings Led.

International Footwear litd.

Jeffries Industries Led,

Yancock \& Gore Ltd.

Shearer (Dayid) Led.

Wilcox-Mofflin Ltd.

Columbia Carpets Ltd.

Eavelle-Mort Led.

James Miller Holdings Ltd.

Hecla-Rove Ltd.

Prolline Holdiags lid.

$\begin{array}{lll}2 & 3 & 4\end{array}$

$1967 \quad 1966 \quad 1965 \quad 1964$

$\begin{array}{lllll}1968 & 1967 & 1966 & 1965 & 1964 \\ 1968 & 1967 & 1966 & 1965 & 1964\end{array}$

$\begin{array}{lllll}1968 & 1967 & 1966 & 1965 & 1964\end{array}$

$\begin{array}{lllll}1969 & 1968 & 1967 & 1966 & 1965\end{array}$

$\begin{array}{lllll}1969 & 1968 & 1967 & 1966 & 1965\end{array}$

$\begin{array}{lllll}1969 & 1968 & 1967 & 1966 & 1965\end{array}$

$\begin{array}{lllll}1970 & 1969 & 1968 & 1967 & 1956\end{array}$

$\begin{array}{llllll}1970 & 1969 & 1968 & 1967 & 1966\end{array}$

$\begin{array}{lllll}1970 & 1969 & 1968 & 1967 & 1956\end{array}$

$\begin{array}{lllll}1970 & 1969 & 1968 & 1967 & 1966\end{array}$

$\begin{array}{lllll}1970 & 1969 & 1968 & 1967 & 1966\end{array}$

$\begin{array}{lllll}1970 & 1969 & 1968 & 1967 & 1966\end{array}$

$\begin{array}{lllll}1970 & 1969 & 1968 & 1967 & 1966\end{array}$

$\begin{array}{lllll}1970 & 1969 & 1968 & 1967 & 1966\end{array}$

$\begin{array}{llllll}1970 & 1969 & 1960 & 1967 & 1966\end{array}$

$\begin{array}{lllll}1970 & 1969 & 1968 & 1967 & 1966\end{array}$

$\begin{array}{lllll}1970 & 1969 & 1968 & 1967 & 1966\end{array}$

$\begin{array}{lllll}1970 & 1969 & 1968 & 1967 & 1966\end{array}$

$\begin{array}{lllll}1971 & 1970 & 1969 & 1968 & 1967\end{array}$

$\begin{array}{lllll}1971 & 1970 & 1969 & 1968 & 1967\end{array}$

$1971 \quad 1970 \quad 2969 \quad 1960 \quad 1967$

$\begin{array}{lllll}1971 & 1970 & 1969 & 1968 & 1967\end{array}$

$\begin{array}{lllll}1973 & 1972 & 1971 & 1970 & 1969\end{array}$

$\begin{array}{lllll}1973 & 1972 & 1972 & 1970 & 1969\end{array}$

$\begin{array}{lllll}1974 & 1973 & 1972 & 1971 & 1970\end{array}$

$\begin{array}{lllll}1974 & 1973 & 1972 & 1971 & 1970\end{array}$

$\begin{array}{lllll}1974 & 1973 & 1972 & 1971 & 1970\end{array}$

$\begin{array}{lllll}1975 & 1974 & 1973 & 1972 & 1971\end{array}$

$\begin{array}{lllll}1975 & 1974 & 1973 & 1972 & 1971\end{array}$

$\begin{array}{lllll}1975 & 1974 & 1973 & 1972 & 1971\end{array}$

$\begin{array}{llllll}1976 & 1975 & 1974 & 1973 & 1972\end{array}$

$\begin{array}{llllll}1976 & 1975 & 1974 & 1973 & 1972\end{array}$

$\begin{array}{lllll}1976 & 1975 & 1974 & 1973 & 1972\end{array}$

$\begin{array}{lllll}1976 & 1975 & 1974 & 1973 & 1972\end{array}$

$\begin{array}{lllll}1976 & 1975 & 1974 & 1973 & 1972\end{array}$

$\begin{array}{llllll}1976 & 1975 & 1974 & 1973 & 1972\end{array}$

$\begin{array}{lllll}1976 & 1975 & 1974 & 1973 & 1972\end{array}$

$\begin{array}{lllll}1976 & 1975 & 1974 & 1973 & 1972\end{array}$

$\begin{array}{lllll}1976 & 1975 & 1974 & 1973 & 1972\end{array}$

\section{Noníalled_Companies}

Kelvinator ltd.

Pye Industies Lted.

A.W.A. Ltd.

Oliver J. Vilsen. Ltd.

Braemar Holdtags Led.

Australian Natlonal Industries ted.

Duncan's Holdengs Ltd.

Alstergren Holdings Ltd.

Cenac Ltd.

Julius Marlow Holdings ted.

Yarra Falls ltd.

Speedo Holdings Ltd.

Coates \& Co. Ltd.

Hills Industries ltd.

Larke Consolidated Ltd.

A.V. Wehl Led.

Softwood Holdings Ltd.

Stranit Ltd.

Sohn Shearer \& Sons Led.

Bowra Holdings Led.

Chamberlain Holdings Led.

Mascot Industrles Ltd.

Swift \& Co. Led.

Parbury-Henty Ltd.

Supertex Industries Ltd.

Carpet Manufacturers Ltd.

Bruck Mills Ltd.

Acrow Aust. Ltd.

Johns Consolldated Ltd.

Jaques Ltd.

KInnears Lid.

$\mathrm{J}$. Gadsen Ltd.

Gerrard Led.

simpsor-Pope Ltd.

Enail Lto.

Vulcan Ltd.

Osborne Metals Ltd.

Mauri Bros. \& Thompson Ltd.

McPhersons Eed. 
Appendix 8: Matched Failed and Noncailed Companies, by Industry and Years

RETAIL

Failed Companies

Queensland Grocers Ltd.

Cunningham (R.E.) Investments Ltd.

Ponsford, Newtat \& Benson Ltd.

Olims Consolidated Led.

Walsh's Holdings Ltd.

Wright's Led.

Bintang Ltd.

Collin Holdings Ltd.

Epstein \& Co. Led.
Yeazo Pegoce Falluro

12345

Ac =ual Yoars

$1971 \quad 1970 \quad 1969 \quad 1963 \quad 1967$

$\begin{array}{lllll}1971 & 1970 & 1969 & 1950 & 1967\end{array}$

$\begin{array}{lllll}1971 & 1970 & 1959 & 1968 & 1967\end{array}$

$\begin{array}{lllll}1971 & 1970 & 1969 & 1968 & 1967\end{array}$

$\begin{array}{lllll}1971 & 1970 & 1969 & 1963 & 1967\end{array}$

$\begin{array}{lllll}1971 & 1970 & 1969 & 1963 & 1967\end{array}$

$\begin{array}{lllll}1974 & 1973 & 1972 & 1971 & 1970\end{array}$

$\begin{array}{lllll}1974 & 1973 & 1972 & 1971 & 1970\end{array}$

$\begin{array}{lllll}1974 & 1973 & 1972 & 1971 & 1970\end{array}$

$\begin{array}{lllll}1974 & 1973 & 1972 & 1971 & 1970\end{array}$

$\begin{array}{lllll}1974 & 1973 & 1972 & 1971 & 1970\end{array}$

$\begin{array}{lllll}1974 & 1973 & 1972 & 1971 & 1970\end{array}$

$\begin{array}{lllll}1974 & 1973 & 1972 & 1971 & 1970\end{array}$

$\begin{array}{lllll}1974 & 1973 & 1972 & 1971 & 1970\end{array}$

$\begin{array}{llllll}1975 & 1974 & 1973 & 1972 & 1971\end{array}$

$\begin{array}{lllll}1975 & 1974 & 1973 & 1972 & 1971\end{array}$

$\begin{array}{lllll}1978 & 1977 & 1976 & 1975 & 1974\end{array}$

$\begin{array}{lllll}1979 & 1977 & 1976 & 1975 & 1974\end{array}$

$\begin{array}{lllll}1978 & 1977 & 1976 & 1975 & 1974\end{array}$
Vontailed Compantes

Wal cons Ltt.

Woolworths Led.

David Jones Ltd.

John Martin \& Co. Ltd.

Boans Led.

Charles Moore Ltd.

Lowes Ltd.

G.J. Coles Ltd.

Katzes litd.

Clark Rubber Ltd.

Gowing Bros. Ltd.

Grace Bros, Led.

Buckley \& *unn letd.

Halns Munkin Ltd.

Lord Kelth (Holdings) Ltd.

Young (J.B.) Holdings Lid.

Charles Darts Led.

Met:o Industrles Ltd.

Nock \& KIrby Led.

\section{FINANCE}

Years Before Fallure

\section{Failed Companies}

Cambridge Credittod.

I.A.C. Holdings Led.

Associated Securities Itd.

Finance Corporation of Aust. Ltd.
Actual Years

$\begin{array}{lllll}1973 & 1972 & 1971 & 1970 & 1969\end{array}$

$\begin{array}{lllll}1973 & 1972 & 1971 & 1970 & 1969\end{array}$

$\begin{array}{lllll}1973 & 1972 & 1971 & 1970 & 1969\end{array}$

$\begin{array}{lllll}1977 & 1976 & 1975 & 1974 & 1973\end{array}$

$\begin{array}{lllll}1977 & 1976 & 1975 & 1974 & 1973\end{array}$

$\begin{array}{lllll}1977 & 1976 & 1975 & 1974 & 1973\end{array}$

$\begin{array}{lllll}1979 & 1977 \quad 1976 & 1975 & 1974\end{array}$

$\begin{array}{lllll}1978 & 1977 & 1976 & 1975 & 1974\end{array}$

$\begin{array}{lllll}1978 & 1977 & 1976 & 1975 & 1974\end{array}$

$\begin{array}{lllll}1978 & 1977 & 1976 & 1975 & 1974\end{array}$

$\begin{array}{llllll}1978 & 1977 & 1976 & 1975 & 1974\end{array}$

$\begin{array}{lllll}1978 & 1977 & 1976 & 1975 & 1974\end{array}$

\section{Nonfailed Companies}

Beneficial Finance Ltd.

Direct Acceptance Ltd.

All lance Holdings Ltd.

Mercantile Credits Ltd.

United Dominions Corp. Ltd.

Network Finance Ltd.

Australian Cuarantee Corp. Ltd.

Lensworth Einance Ltd.

Mutual Acceptance ttd.

Lombard (Aust.) Led.

Midiand Credit Led.

All lance Holdings Led.

\section{PROPERTY}

\section{Years Before Railure}

\section{Failed Companies}

Matnitine Ltd.

Morris (Keith) Cons. Ltd.

Talga Ltd.

Munduna Investments Ltd.

Reinvestment Aust. Let.

Landall Holdings Led.

Grant (Alfred) Holdings ted.

Regional Land Led.

Future Development Corp. Ltd.

Acre Properties Led.

Concour Development idoldings Led.

Westhayen Securities Ltd.

Comfin Aust. led.

Pacific Acceptance Corp. Ltd.

Glendale Land Development Ltd.
244

Actual Years

$\begin{array}{llllll}1973 & 1972 & 1971 & 1970 & 1969\end{array}$

$\begin{array}{lllll}1973 & 1972 & 1971 & 1970 & 1969\end{array}$

$\begin{array}{lllll}1973 & 1972 & 1971 & 1970 & 1969\end{array}$

$\begin{array}{lllll}1973 & 1972 & 1971 & 1970 & 1969\end{array}$

$\begin{array}{lllll}1973 & 1972 & 1971 & 1970 & 1969\end{array}$

$\begin{array}{lllll}1973 & 1972 & 1971 & 1970 & 1969\end{array}$

$\begin{array}{lllll}1974 & 1973 & 1972 & 1971 & 1970\end{array}$

$\begin{array}{lllll}1974 & 1973 & 1972 & 1971 & 1970\end{array}$

$\begin{array}{lllll}1974 & 1973 & 1972 & 1971 & 1970\end{array}$

$\begin{array}{llllll}1974 & 1973 & 1972 & 1971 & 1970\end{array}$

$\begin{array}{lllll}1975 & 1974 & 1973 & 1972 & 1971\end{array}$

$\begin{array}{lllll}1975 & 1974 & 1973 & 1972 & 1971\end{array}$

$\begin{array}{lllll}1975 & 1974 & 1973 & 1972 & 1971\end{array}$

$\begin{array}{lllll}1975 & 1974 & 1973 & 1972 & 197\end{array}$

$\begin{array}{llllll}1976 & 1975 & 1974 & 1973 & 1972\end{array}$

$\begin{array}{llllll}1976 & 1975 & 1974 & 1973 & 1972\end{array}$

$\begin{array}{lllll}1976 & 1975 & 1974 & 1973 & 1972 \\ 1975 & 1975 & 1974 & 1973 & 1972\end{array}$

$\begin{array}{lllll}1976 & 1975 & 1974 & 1973 & 1972 \\ 1976 & 1975 & 1974 & 1973 & 1972\end{array}$

$\begin{array}{lllll}1976 & 1975 & 1974 & 1973 & 1972\end{array}$
Vonfailed Comparies

Jenniazs Industrles ted.

Lend-Lease lid.

E.A. Watts Ltd.

Whittle (T.C.) Ltd.

Stacks and Holdings Ltd.

Wood-Hall Ltd.

Batchelor Investments Ltd.

D.J. Properties Ltd.

E. Long Ltd.

D.U.L. Ltd.

orlit Holdings Led,

Westfield Ltd.

Peter Kurts Ltd.

Is herwood $\&$ Dreyfus Led.

Paynter \& Dixon Led.

tutchison Aust. Ltd.

chaprans led.

Lefghton Holdings Ltd.

R.O.C. Homes Etd. 


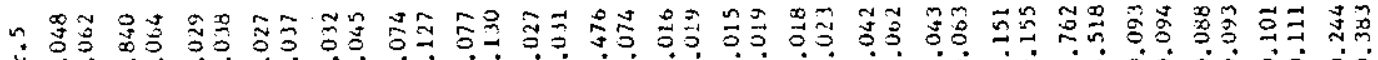
में

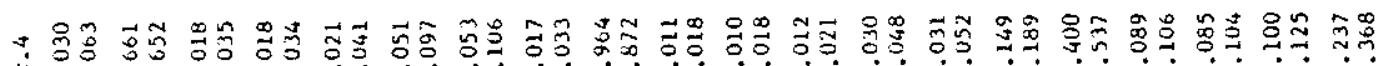

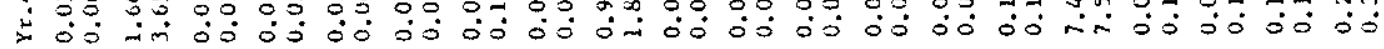

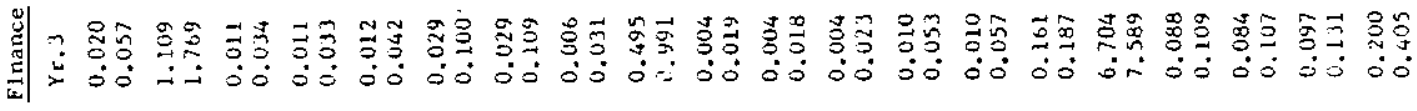

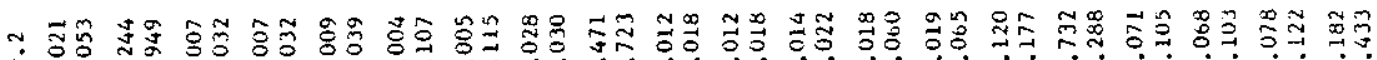

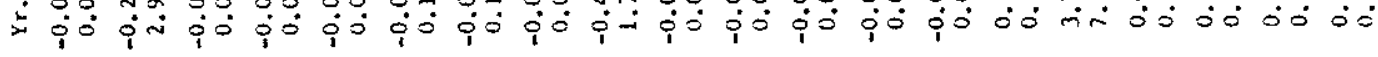

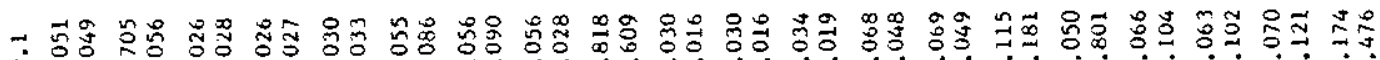

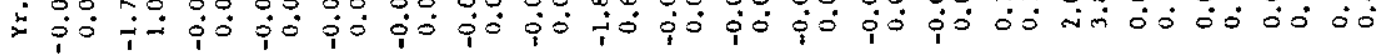

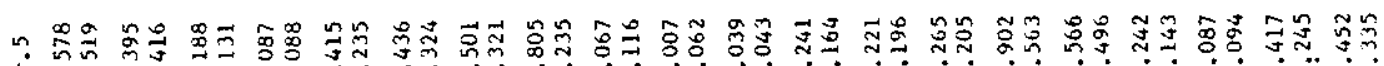

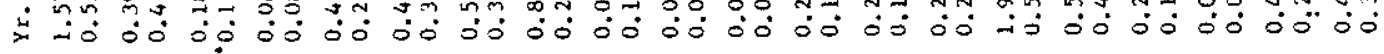

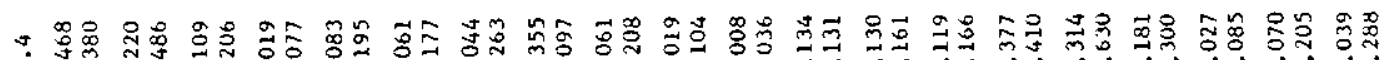
匀

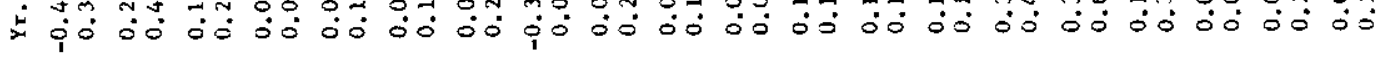

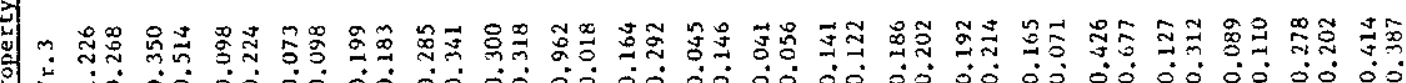

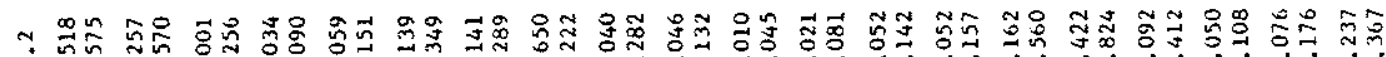

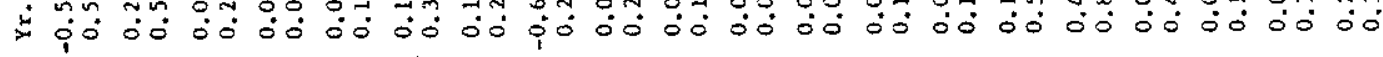

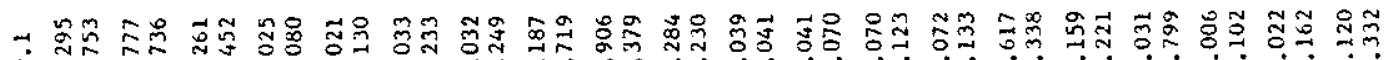

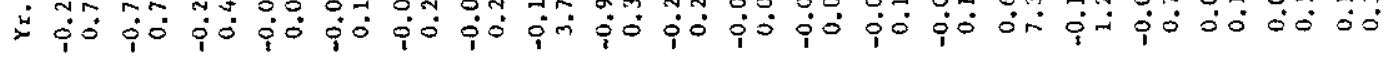

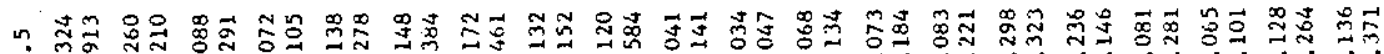

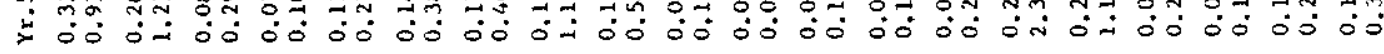

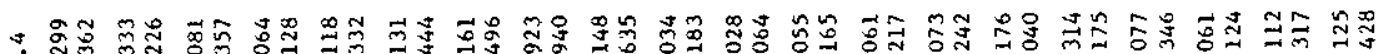

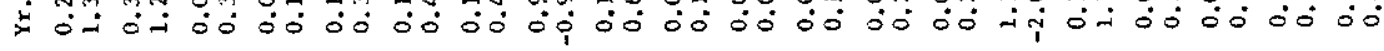

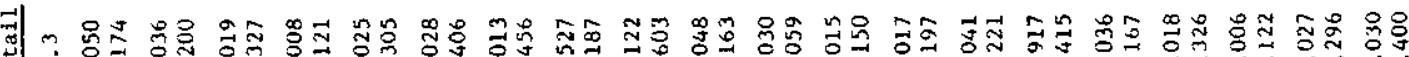
बै

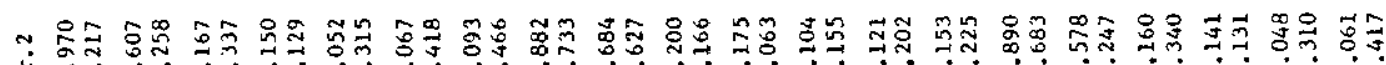

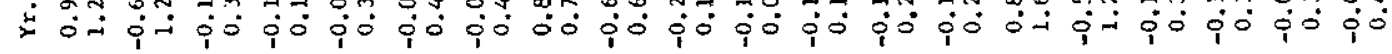

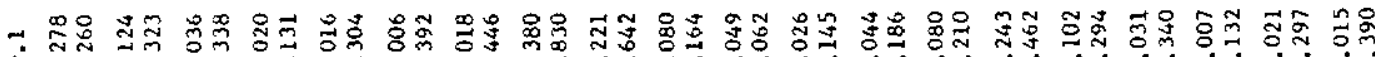

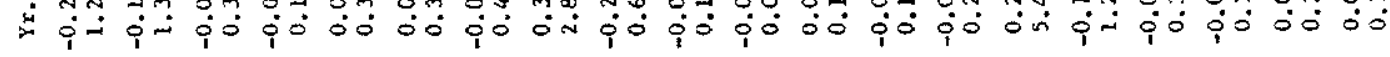

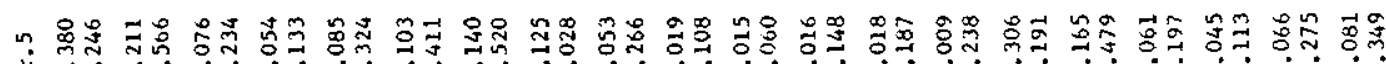

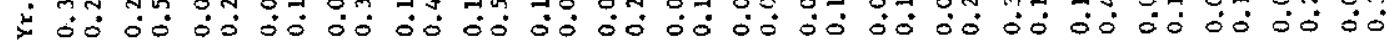

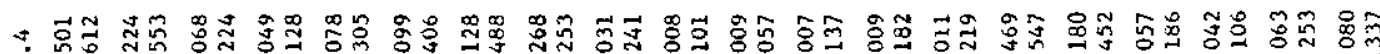

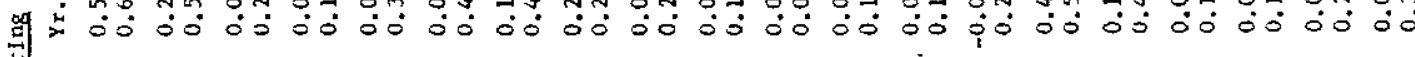

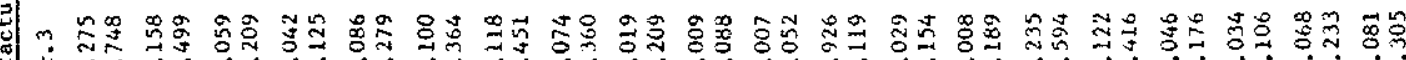

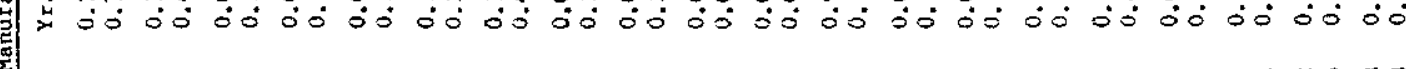

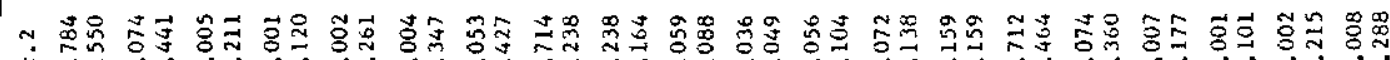

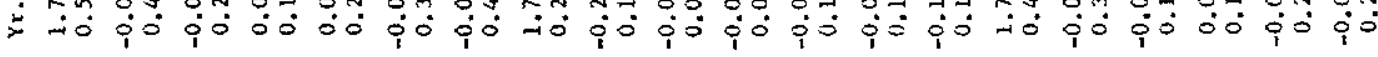

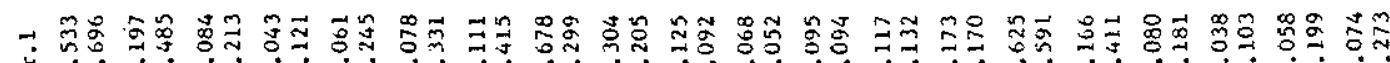

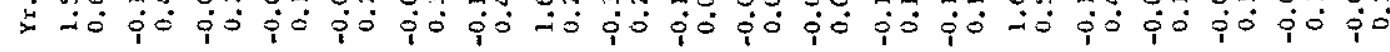

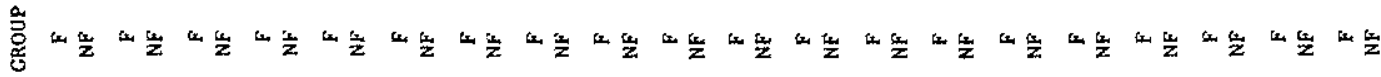

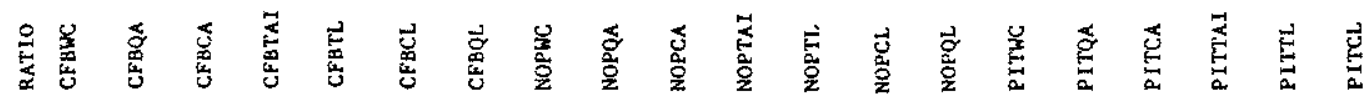




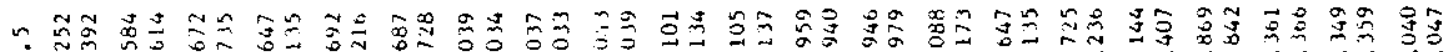

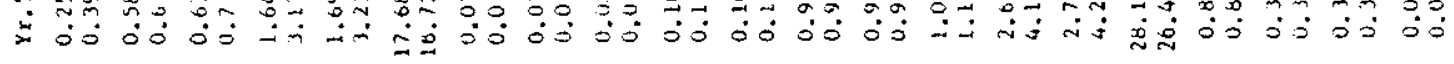

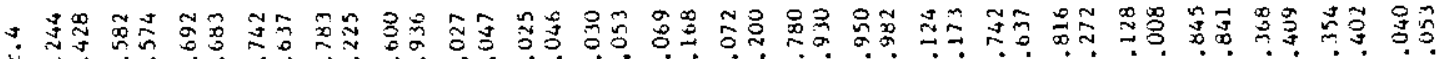
म्र

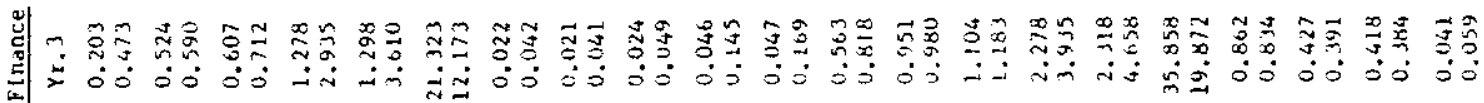

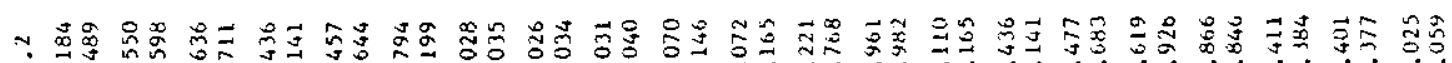
ॠ

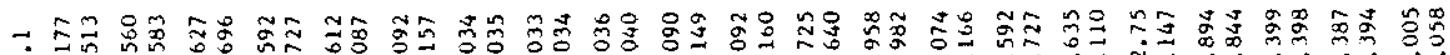

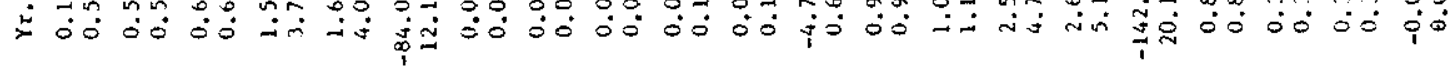

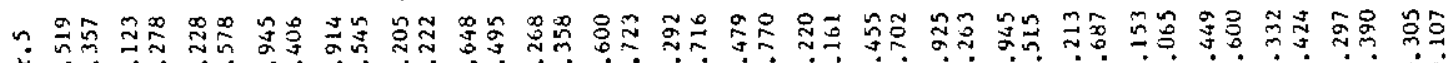

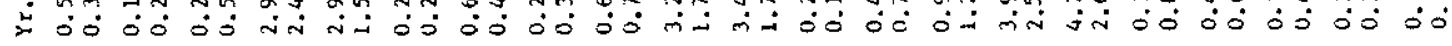

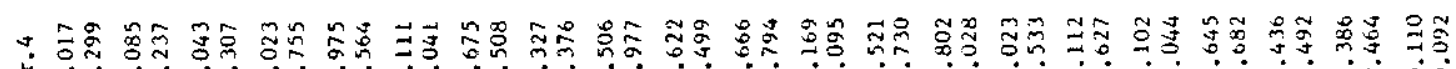

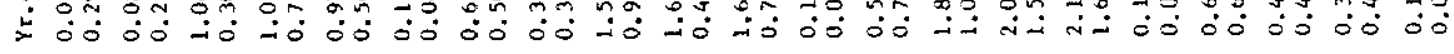

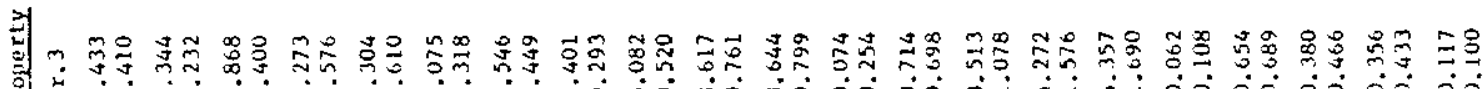
总

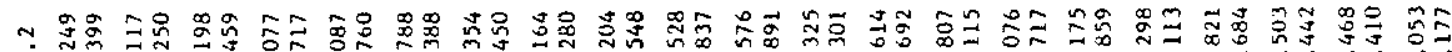

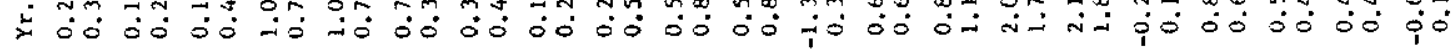

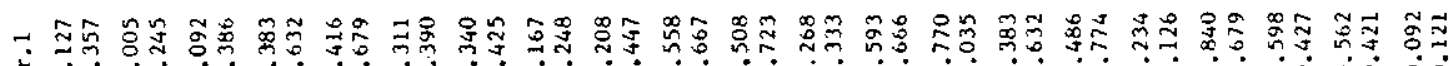
में

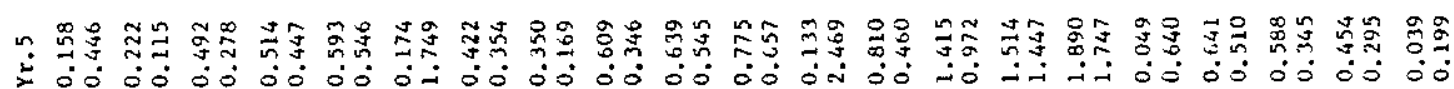

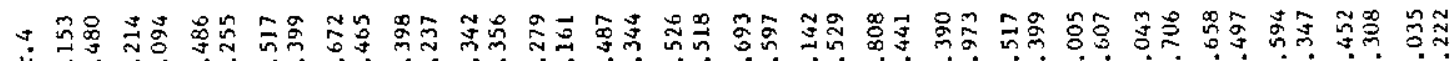

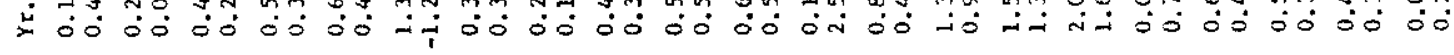

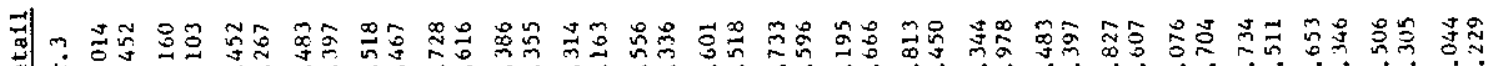

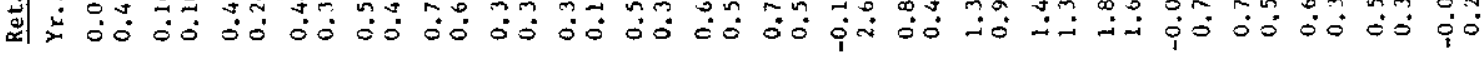

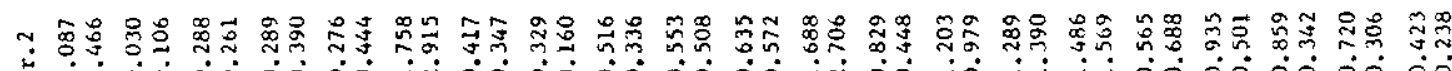
में

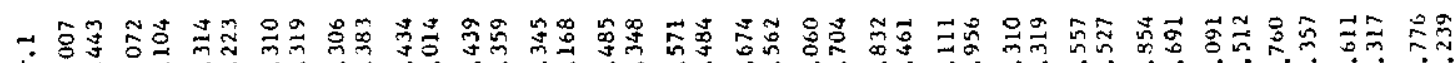
में

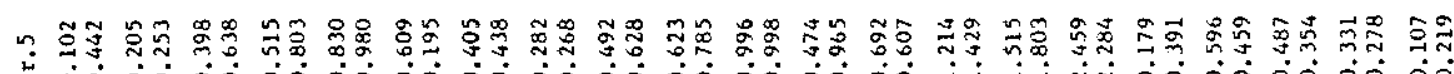

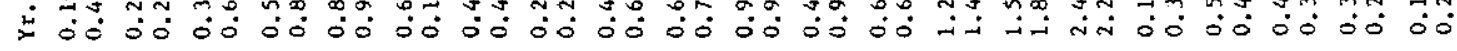

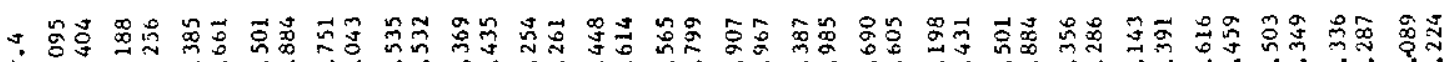

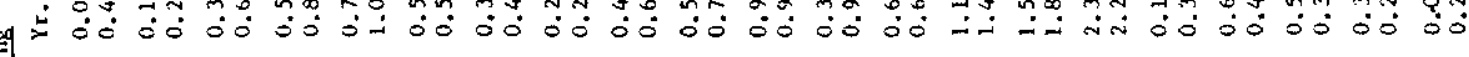

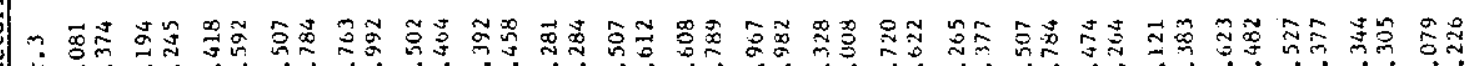
म्र

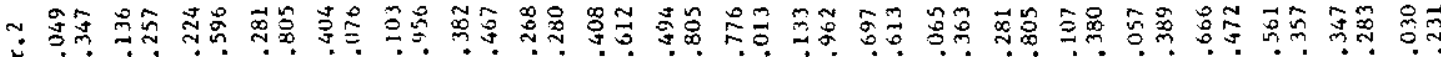
प्र

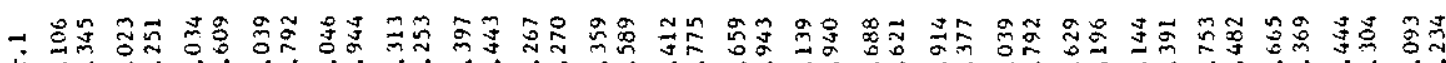

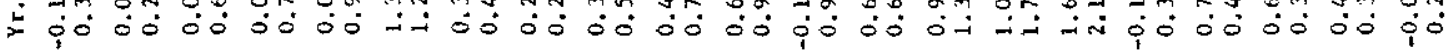

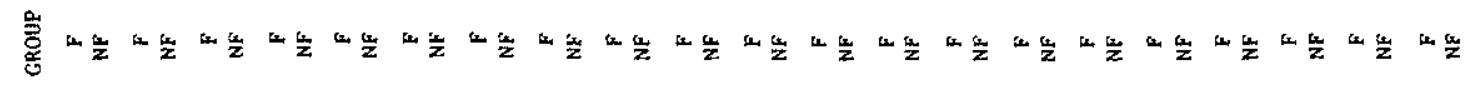

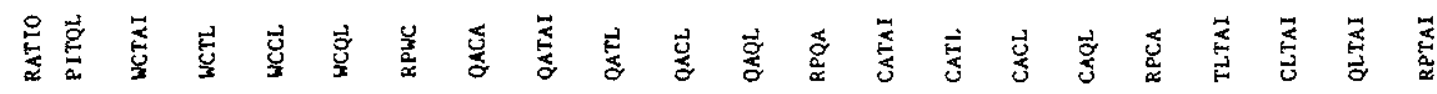




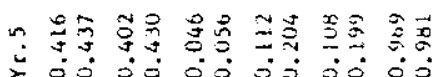

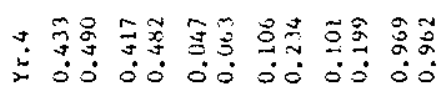

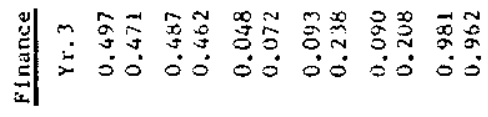

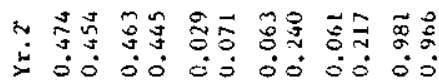

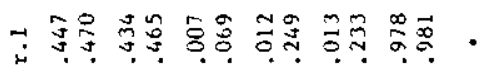

प्र

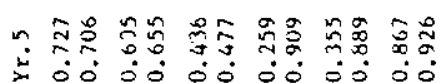

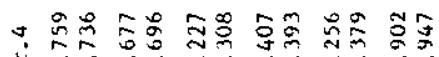

نे

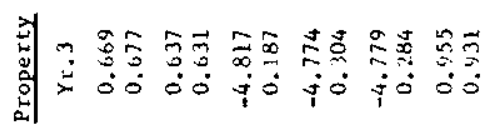

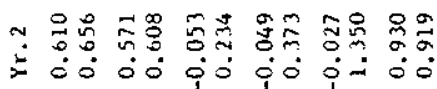

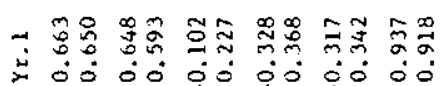

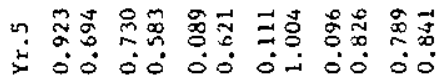

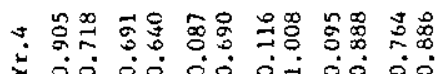

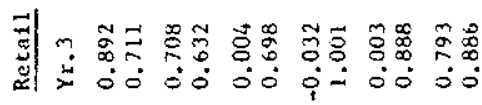

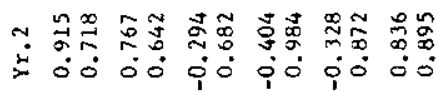

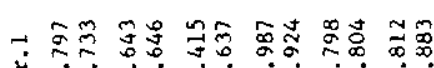

نे

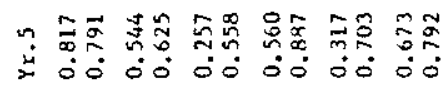

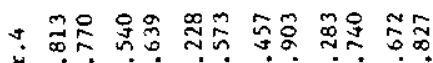

I

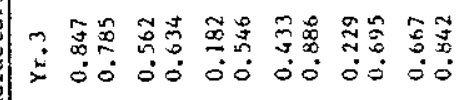

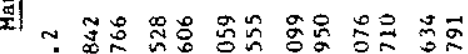

$\Rightarrow$ : 0 i 0 i.

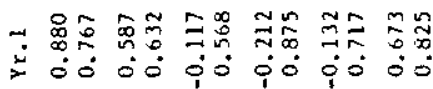

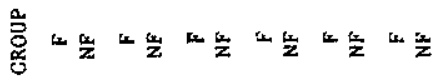

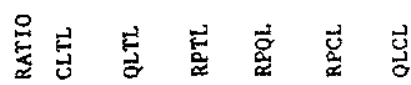




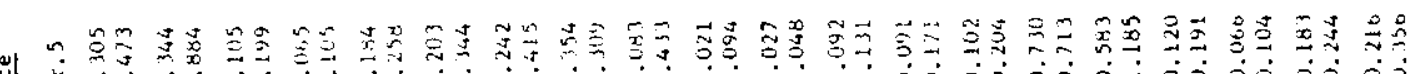

:

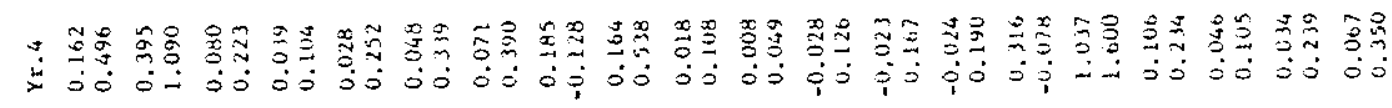

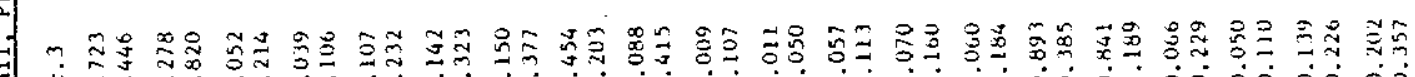

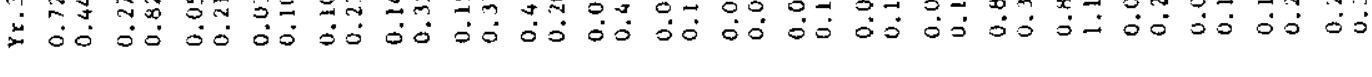

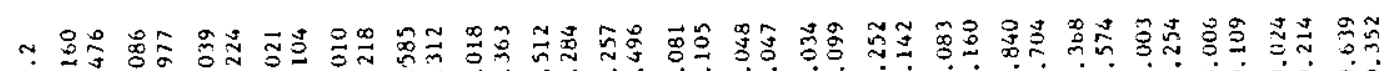

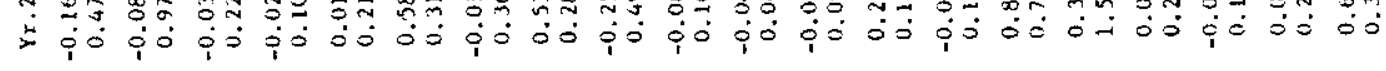

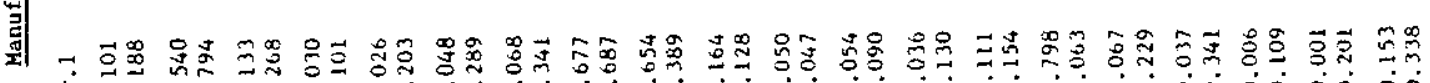

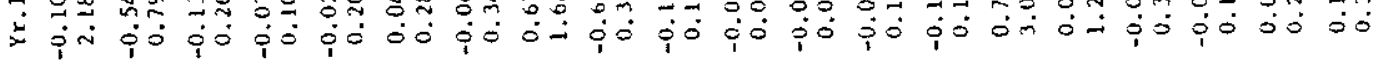

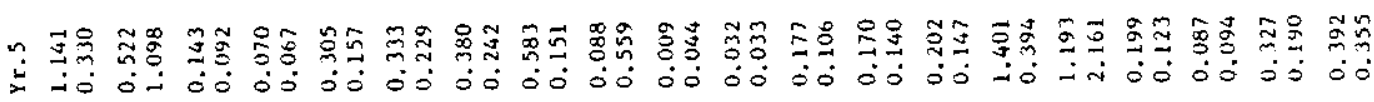

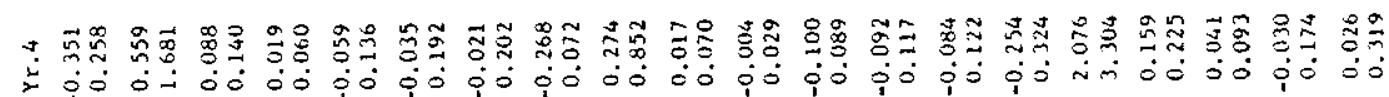
لّ

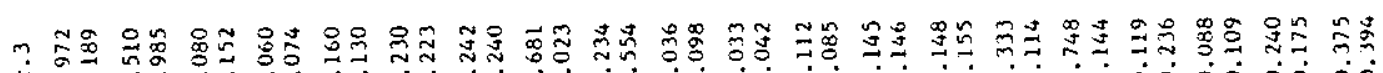
म

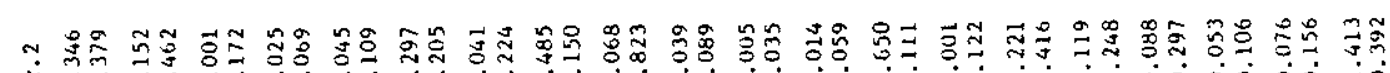

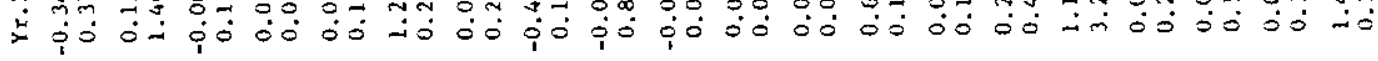

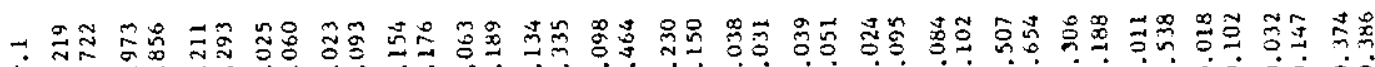

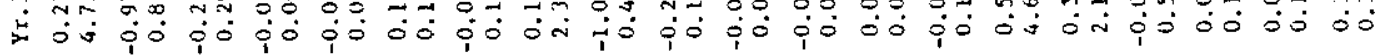

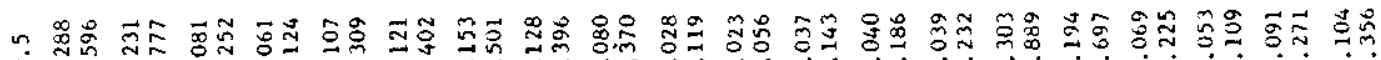

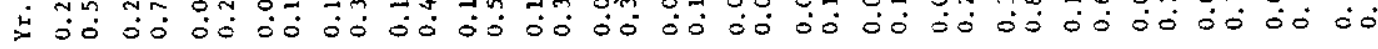

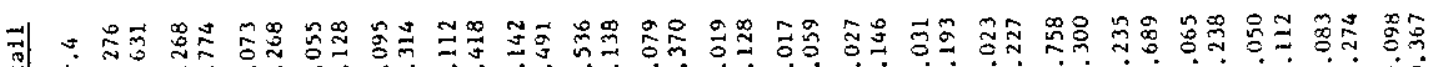

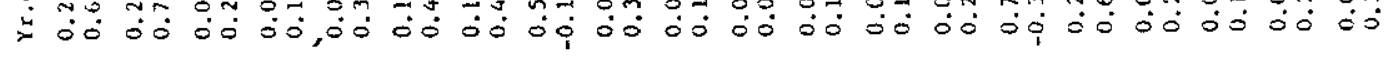

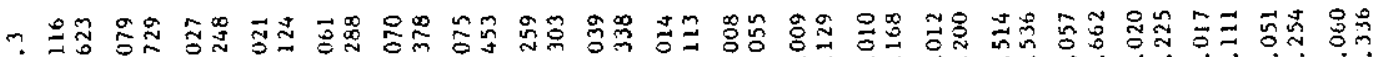

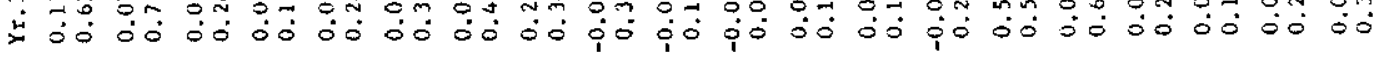

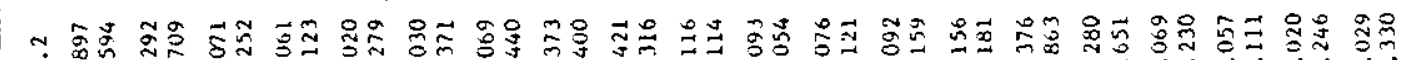

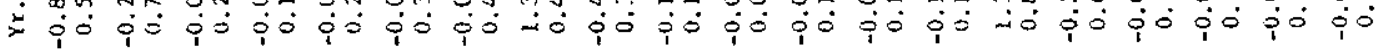

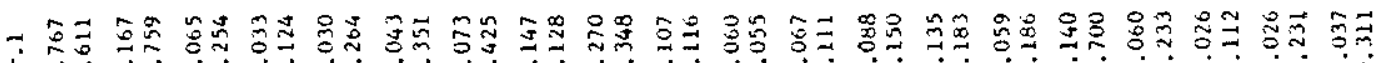
占通

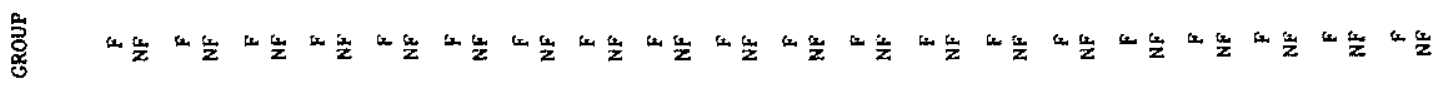

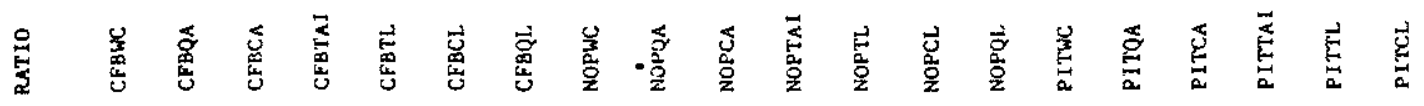




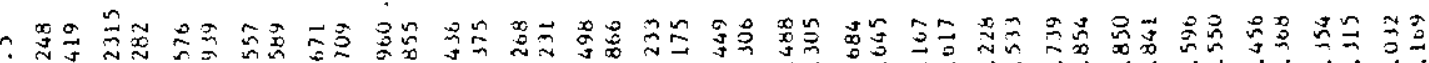

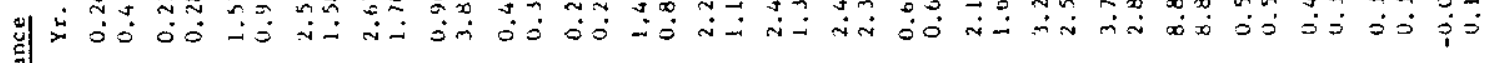

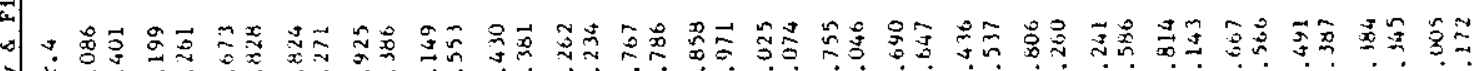

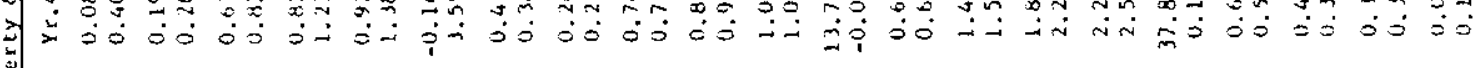

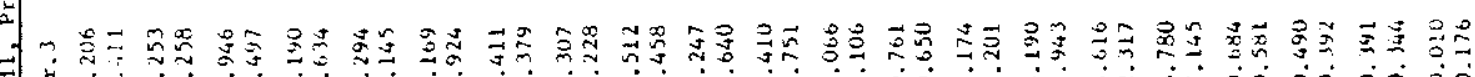

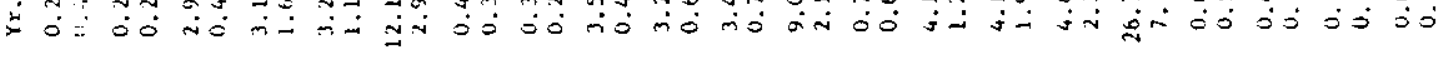

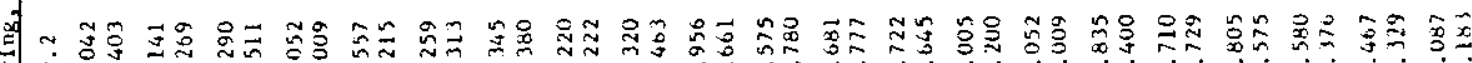

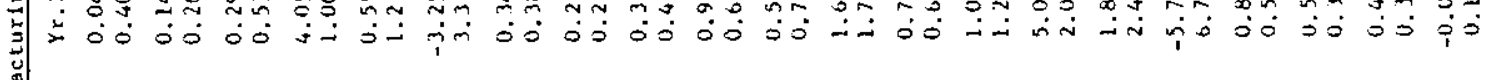

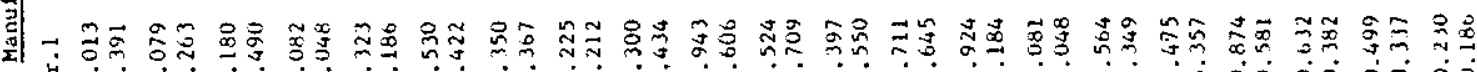

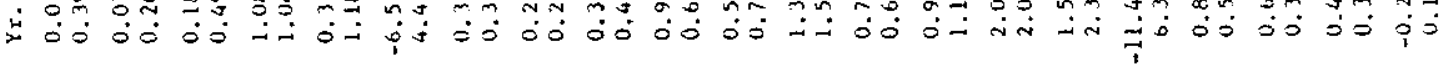

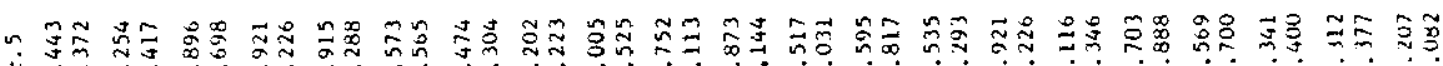

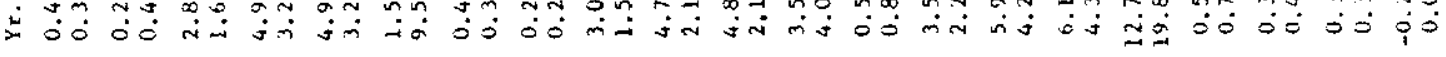

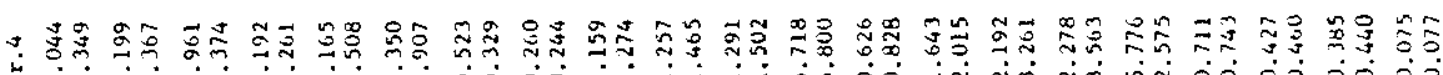

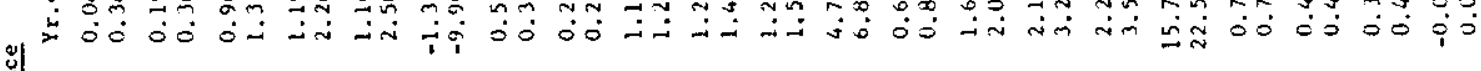

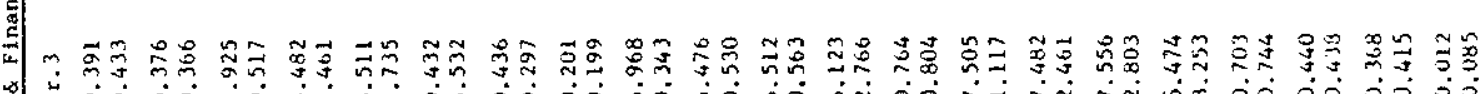

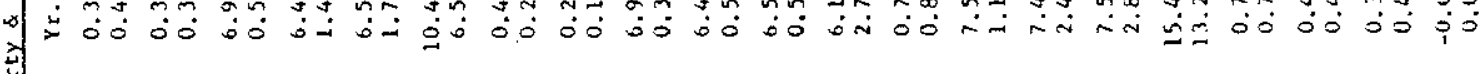

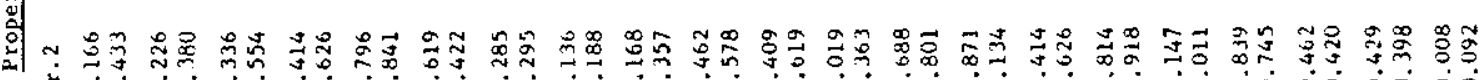
प्र

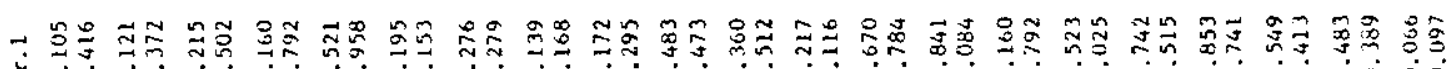

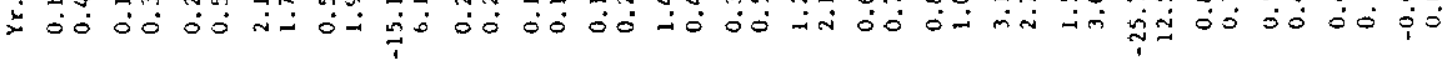

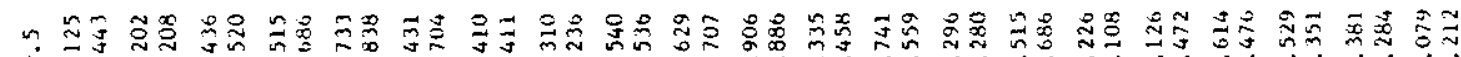

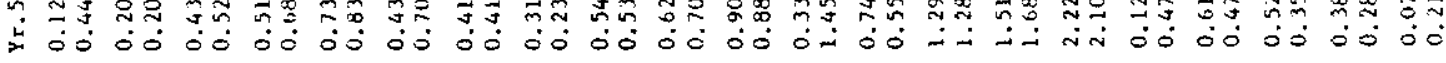

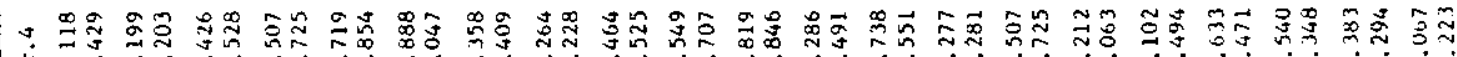
†

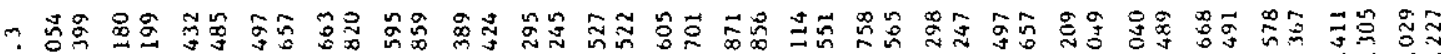

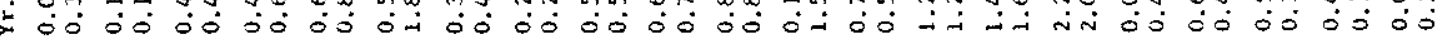

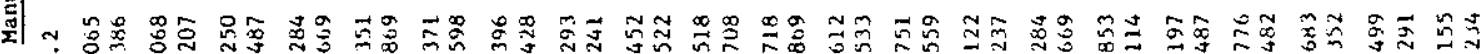

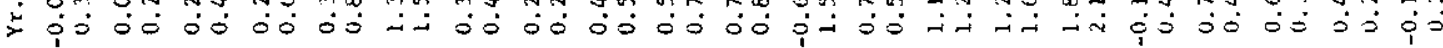

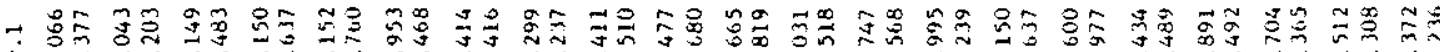

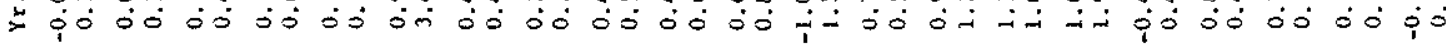

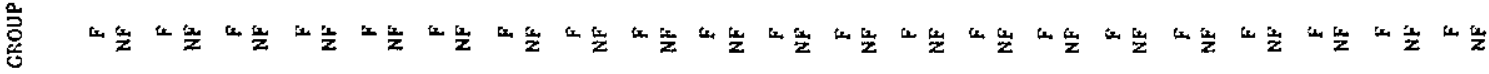

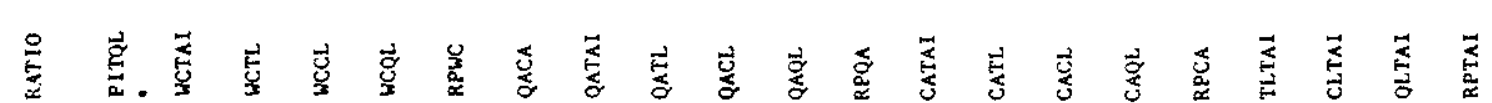




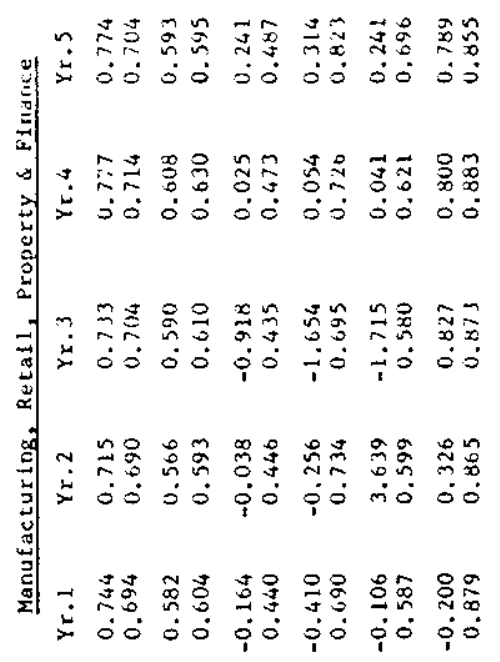

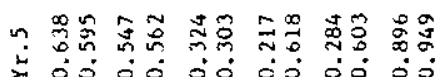

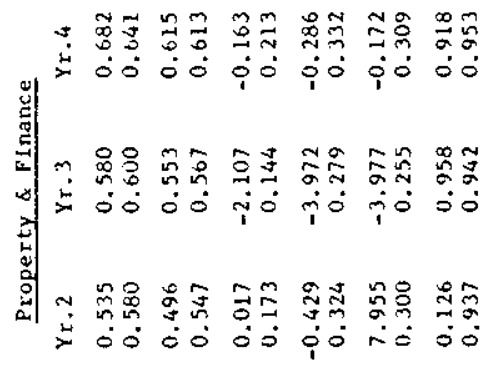

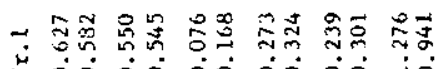

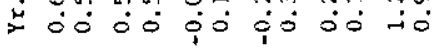

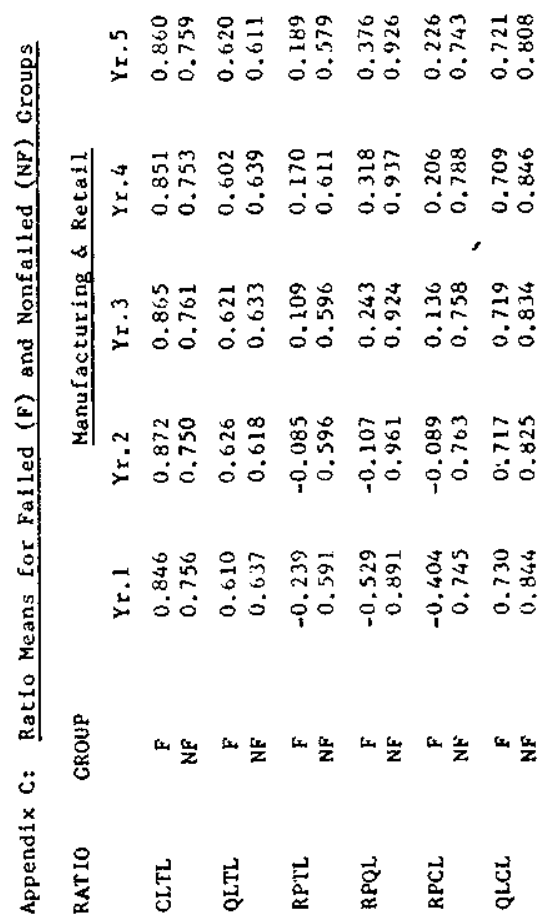


APPENDIX D

Combination $1 \mathrm{~A}$ and Combination $2 \mathrm{~A}$

These have been derived by excluding from combination 1 and combination 2 , any ratio whose group means overlap during the five year period. 1

Combination $1 \mathrm{~A}$

\section{Manufacturing}

CFBQA, CFBCA, CFBTAI, CFBTL, CFBCL, CFBQL, NOPQA, NOPCA, NOPTAI, NOPTL, NOPCL, NOPQL, PITQA, PITCA, PITTAI, PITTL, PITCL, PITQL, QACA, QATL, QACL, QAQL, RPQA, CATAI, CATL, CACL, RPCA, TLTAI, CLTAI, QLTAI, RPTAI, CLTL, QLTL, RPTL, RPQL, RPCL, QLCL.

Retail

CFBQA, CFBCA, CFBTAI, CFBTL, CFBCL, CFBQL, NOPQA, NOPCA, NOPTAI, NOPTL, NOPCL, NOPQL, PITQA, PITCA, PITTAI, PITTL, PITCL, PITQL, QATAI, QATL, QACL, QAQL, RPQA, CATAI, CATL, RPCA, TLTAI, CLTAI, QLTAI, RPTAI, CLTL, RPTL, RPQL, RPCL, QLCL.

\section{Property}

CFBQA, CFBCA, CFBTAI, CFBTL, CFBCL, CFBQL, NOPQA, NOPCA, NOPTAI, NOPTL, NOPCL, NOPQL, PITQA, PITCA, PITTAI, PITTIs, PITCL, PITQL, QATL, QACL, QAQL, RPQA, CATAI, CATL, CACL, CAQL, RPCA, TLTAI, CLTAI, QLTAI, RPTAI, RPTL, RPQL, RPCL, QLCL.

\section{Manufacturing and Retail}

CFBQA, CFBCA, CFBTAI, CFBTL, CFBCL, CFBQL, NOPQA, NOPCA, NOPTAI, NOPTL, NOPCL, NOPQL, PITQA, PITCA, PITTAI, PITTL, PITCL, PITQL, QACA, QATAI, QACL, RPQA, CATAI, CACL, RPCA, TLTAI, CLTAI, QLTAI, RPTAI, CLTL, RPTL, RPQL, RPCL, QLCL. 
Appendix D (continued):

\section{Property and Finance}

CFBQA, CFBCA, CFBTAT, CFBTL, CFBCL, CFBQL, NOPQA, NOPCA, NOPTAI, NOPTL, NOPCL, NOPQL, PITQA, PITCA, PITTAI, PITTL, PITCL, PITQL, QACL, QAQL, RPQA, CATAI, CATL, CACL, CAQL, TLTAI, CLTAI, QLTAI, RPTAI, RPTL, RPQL, RPCL, QLCL, QATAI, QATL.

\section{Manufacturing, Retail, Property and Finance}

CFBQA, CFBCA, CFBTAI, CFBTL, CFBCL, CFBQL, NOPQA, NOPCA, NOPTAI, NOPTL, NOPCL, NOPQL, PITQA, PITCA, PITTAI, PITTL, PITCL, PITQL, QATAI, QACL, QAQL, CATAI, CATL, CACL, CAQL, TLTAI, CLTAI, QLTAI, RPTAI, CLTL, QLTL, RPTL, RPQL, RPCL, QLCL.

\section{Combination $2 \mathrm{~A}$}

\section{Manufacturing}

CFBTAI, CFBTL, CFBCL, CFBQL, NOPTAI, NOPTL, NOPCL, NOPQL, PITTAI, PITTL, PITCL, PITQL, WCTAI, WCTL, WCCL, WCQE, TLTAI, CLTAI, QLTAI, CLTI, QLTL, QLCL, RPTAI, RPTL, RPCL, RPQL.

\section{Retail}

CFBWC, CFBTAI, CFBTL, CFBCL, CFBQL, NOPTAI, NOPTL, NOPCL, NOPQL, PITTAI, PITTL, PITCL, PITQL, WCTL, TLTAI, CLTAI, QLTAI, RPTAI, CLTL, QLTL, RPTL, RPQL, RPCL, QLCL.

\section{Property}

CEBTAI, CFBTL, CFBCL, CFBQL, NOPTAI, NOPTL, NOPCL, NOPQL, PITTAI, PITTL, PITCL, PITQL, WCTAI, WCTL, WCCL, TLTAI, CLTAI, RPTAI, RPTL, RPQL, RPCL, QLTL, WCQL. 
Appendix D (continued):

Manufacturing and Retail

CFBNC, CFBTAI, CFBTL, CFBCL, CFBQL, NOPTAI, NORTL, NOPCL, NORQL, PITTAI, PITTL, PITCL, PITQL, WCTAI, WCTL, WCCL, WCQI, TLTAI, CLTAI, QLTAI, CLTL, QLCL, RPTAI, RPTI, RPCL, RPQL.

\section{Property and Finance}

CFBTAI, CFBTL, CFBCL, CFBQL, NOPTAI, NOPTL, NOPCL, NOPQL, PITTAI, PITTL, PITCL, PITQL, WCTAI, WCTL, WCCL, WCQL, TLTAI, CLTAI, QLTAI, RPTAI, RPTL, RPQL, RPCL, QLCL.

Manufacturing, Retail, property and Finance

CFBTAI, CFBTL, CFBCL, CFBQL, NOPTAI, NOPTL, NOPCL, NOPQL, PITTAI, PITTL, PITCL, PITQL, WCTAI, WCTL, WCCL, WCQL, TLTAI, CLTAI, QLTAI, CLTL, QLCL, RPTAI, RPTL, RPCL, RPQL.

1. Where the overlap was caused by an extreme ratio value the ratio was not excluded. 


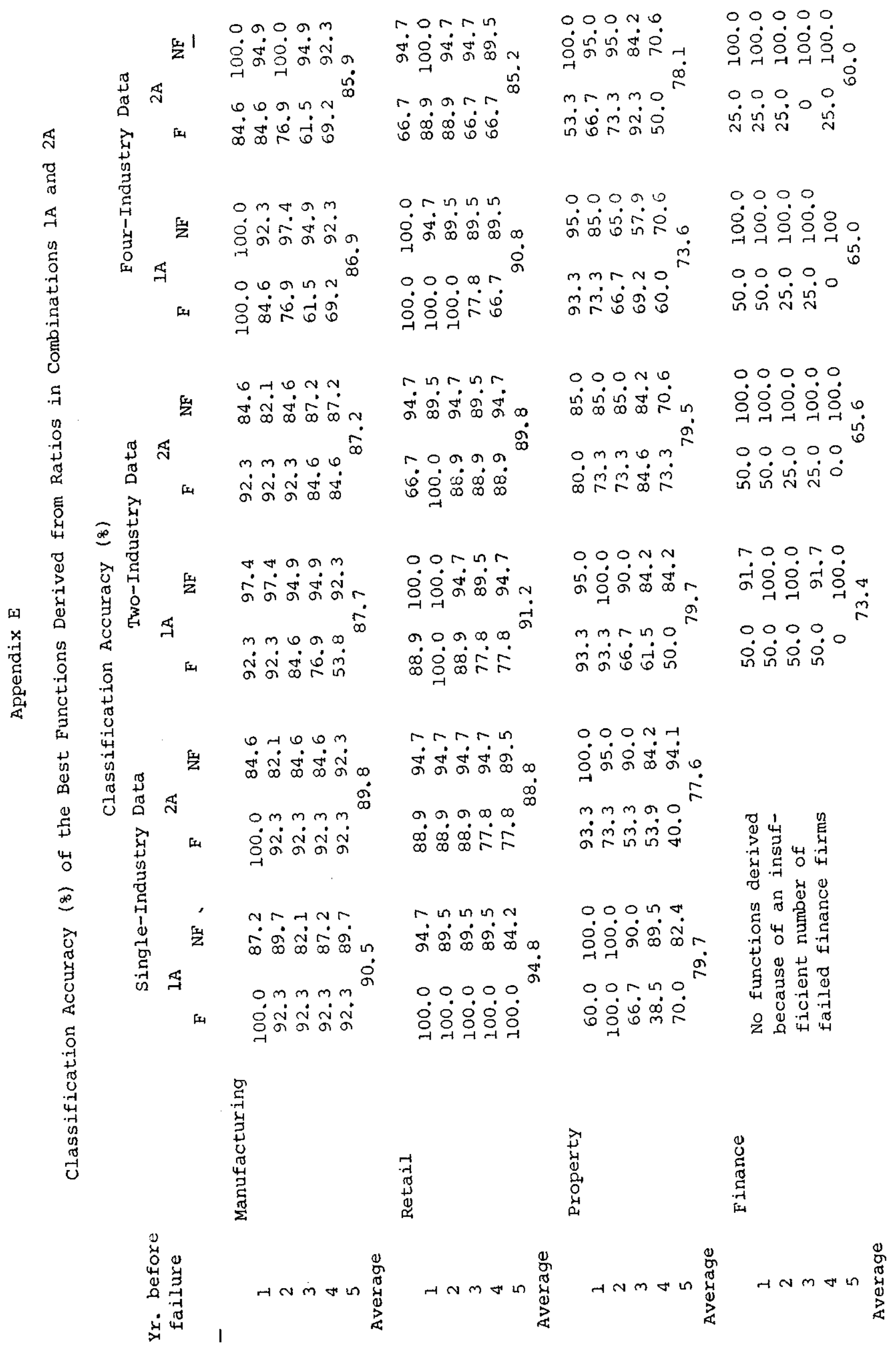




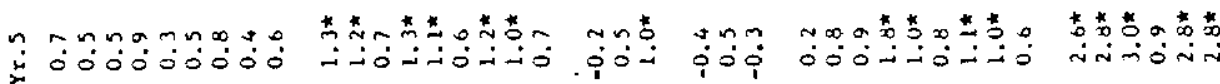

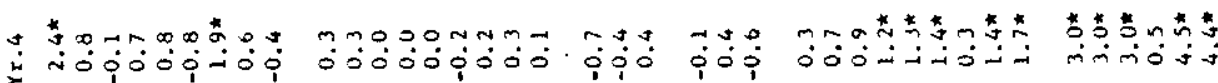

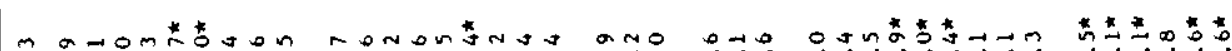

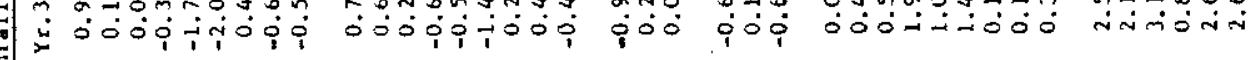

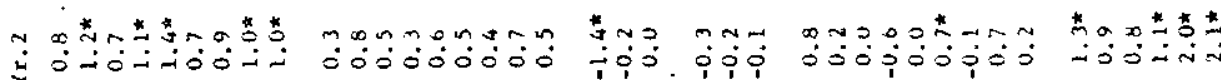

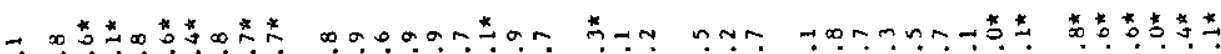

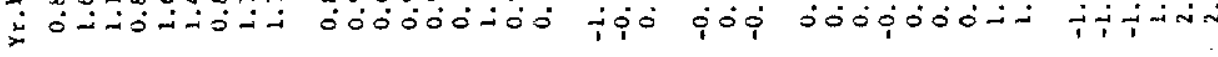
芒 芒

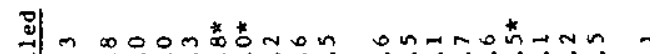

离

.

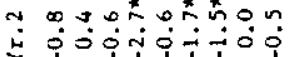

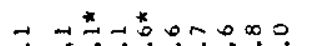

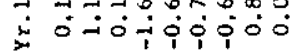

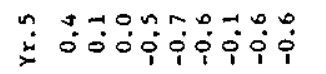

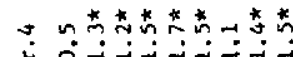

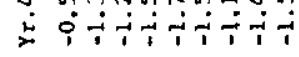

웡 궁

n-mm*nom

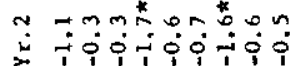

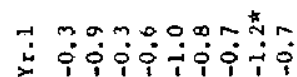

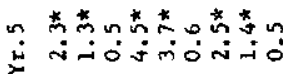

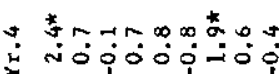

멸

$\stackrel{m}{\dot{\nu}}$

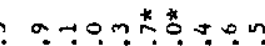

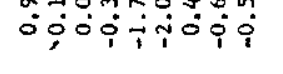
テ :

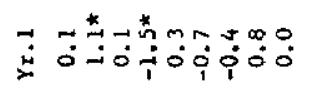

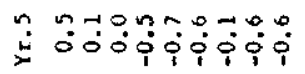

ง ง

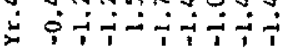

敬

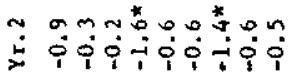

¿

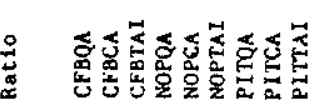

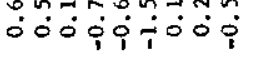

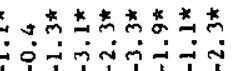

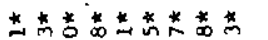

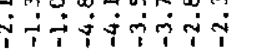

m几 *

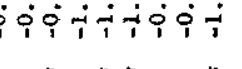

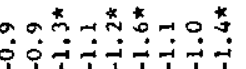

1171

*a.

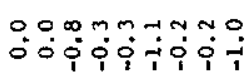

$\stackrel{1}{i}$

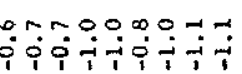

芯芯。芯芯芯。

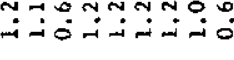

m.00000100.

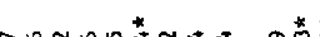

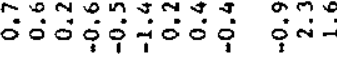

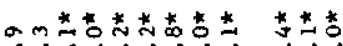

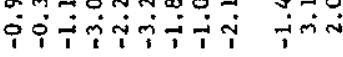

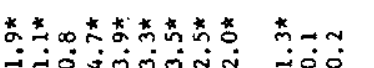

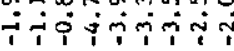

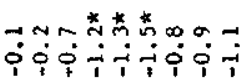

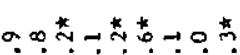

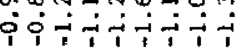

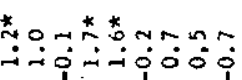

$0.00 m, 90 \div 2$

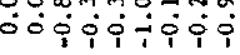

0.0 .00000

íióicion an

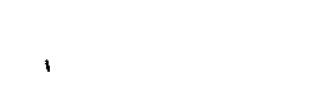


㑒

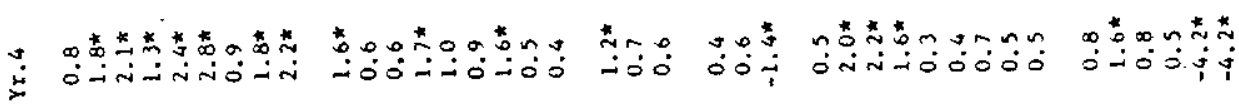
要

苞

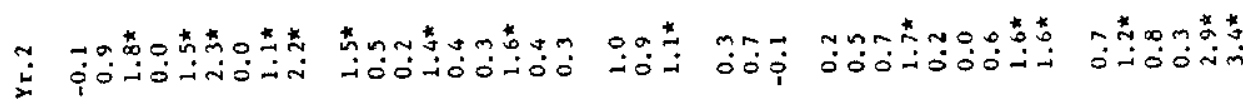
茩

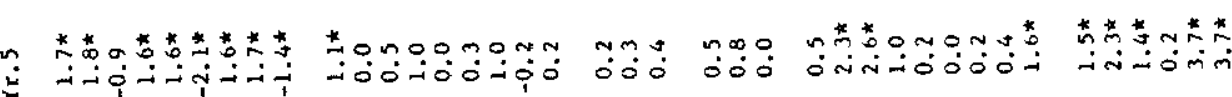
䒠

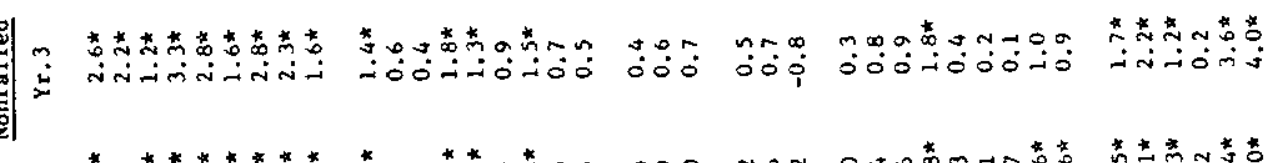
芦

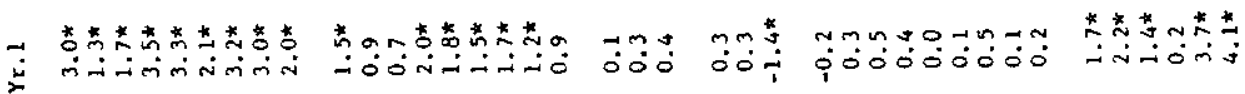

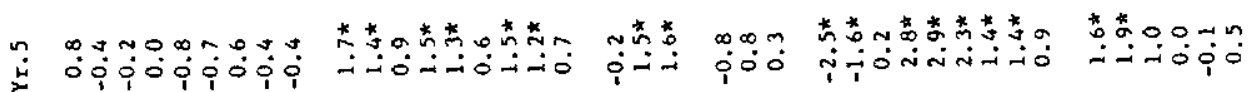

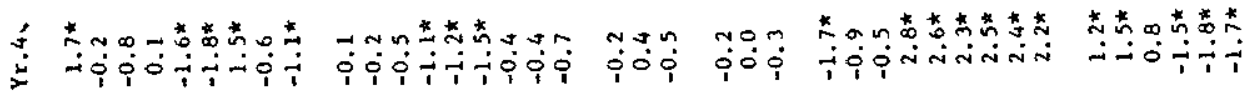

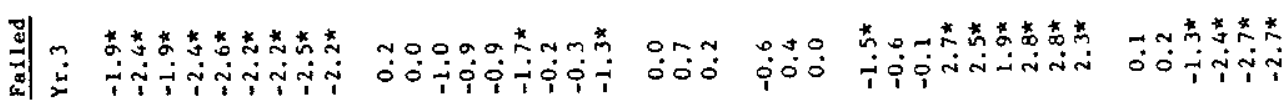

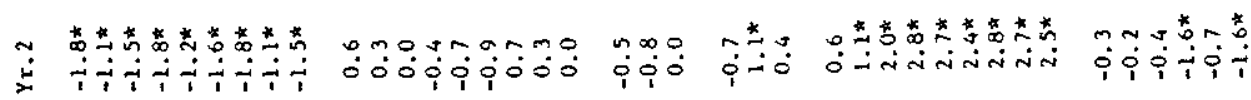

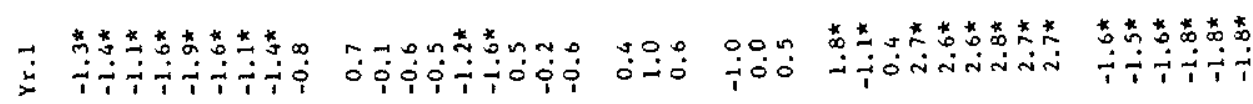

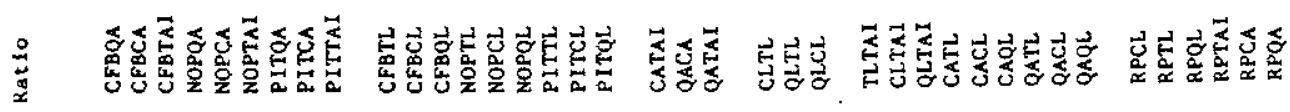




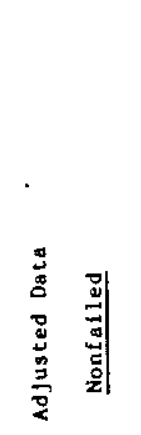

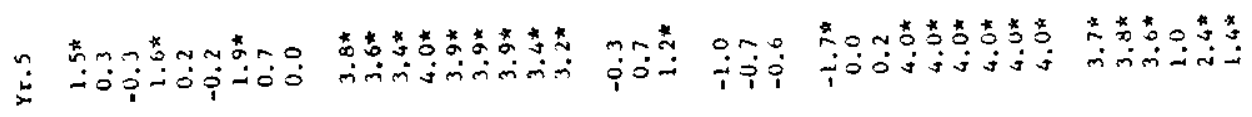

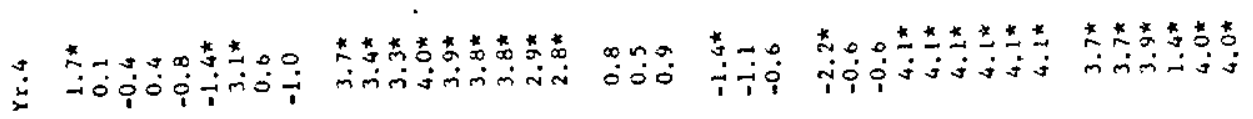

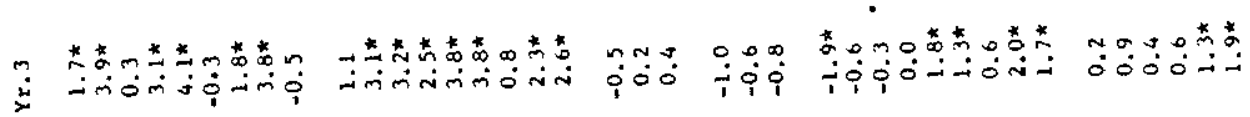

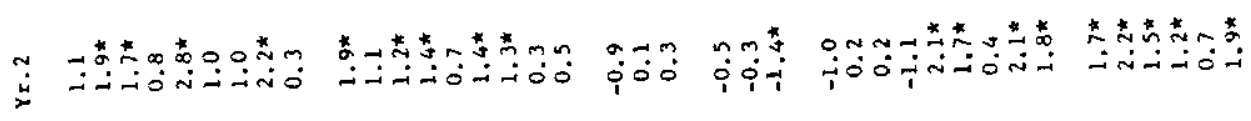
苛

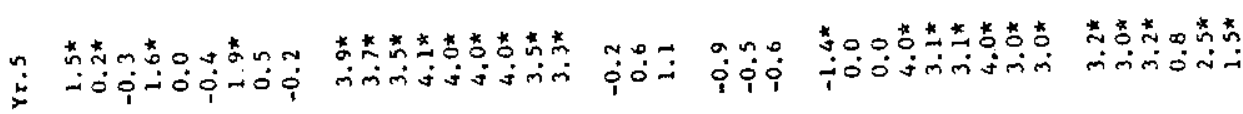

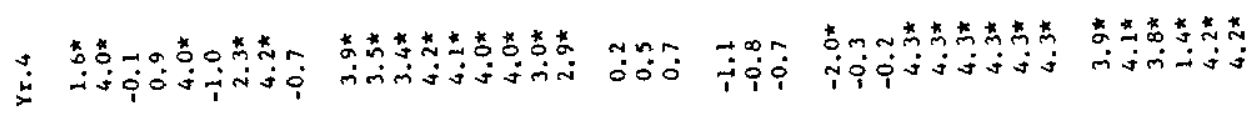
¿

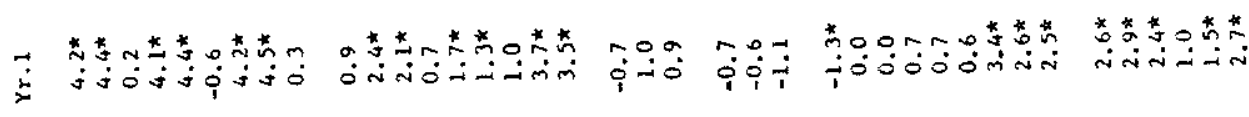

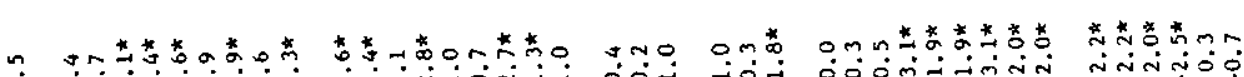

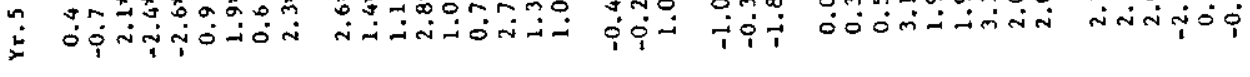

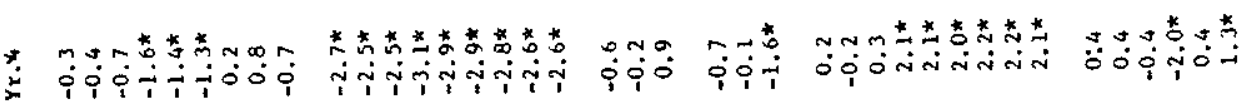

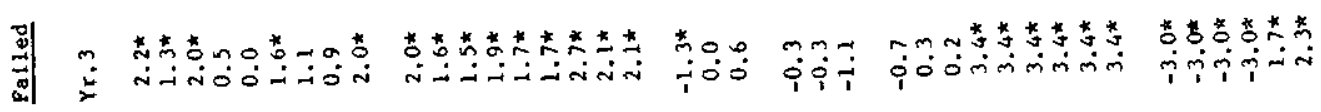

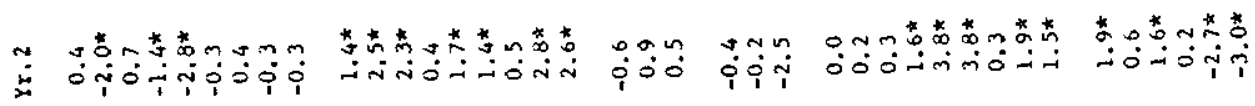

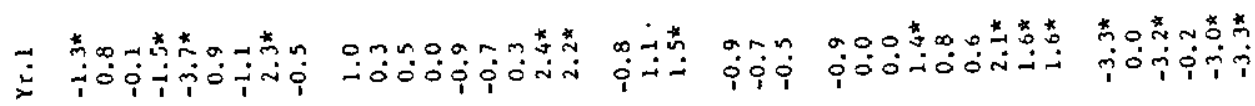

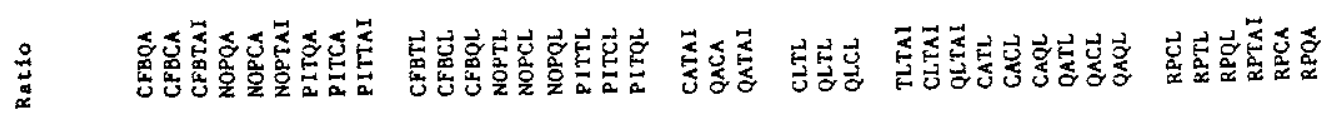




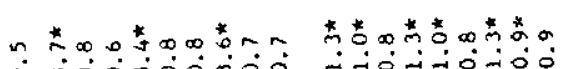

我

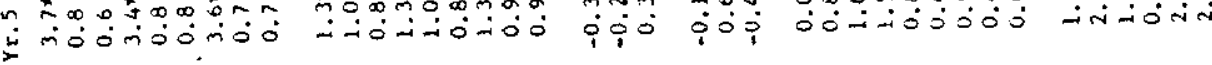

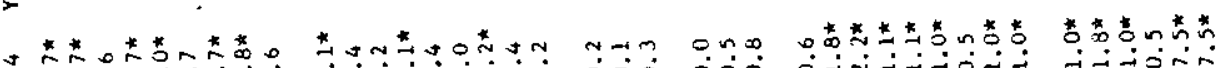

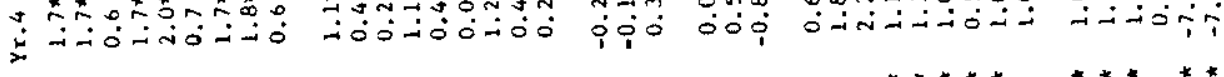

芦

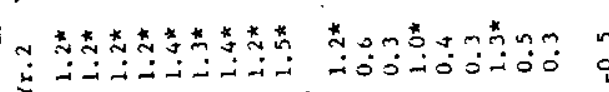

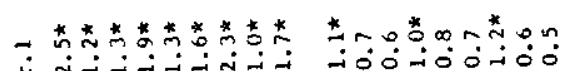

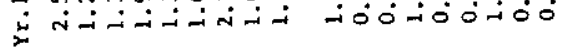

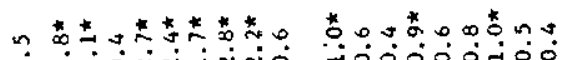

i

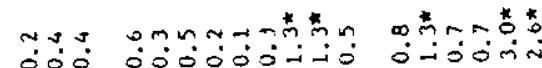

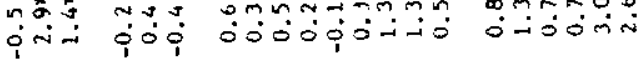

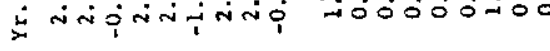

nimo.

Tna. tr.

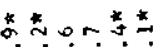
i ioo 000000000 j-jojn

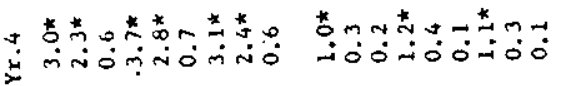

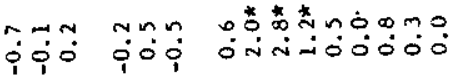

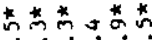
n一⿻

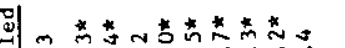
$2 n-\infty \circ N_{N}^{*} m o$

ज्ञ

ข

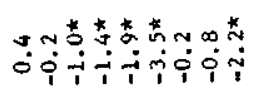

भे

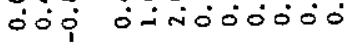

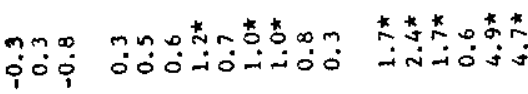

*****

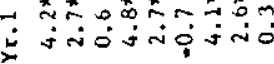

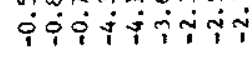

$\stackrel{\text { ind }}{\circ} \stackrel{*}{*}$

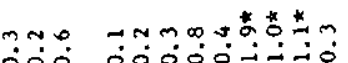

* ${ }_{i}^{*} \omega^{*} 0^{*}$

n. n.0.0.0.0.0.

Ramnd Ron

i

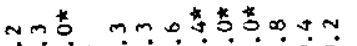

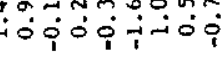

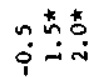

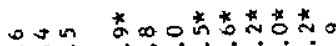

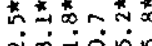

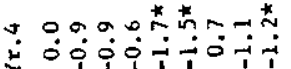

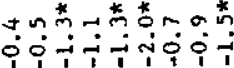

원.

敬

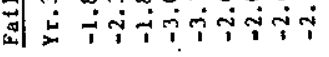

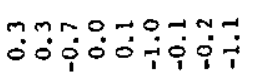

:On

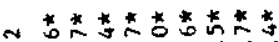

मำ

O⿻ำ

:̊m?

־

manomoovn

$\because \because r$

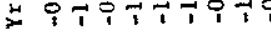

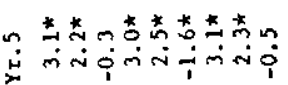

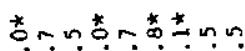

웅.

io

i००:

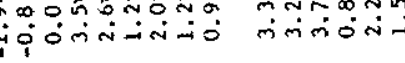

ง *

总 मेंतिंत्रिजि

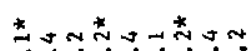

O० ठnitiogo:

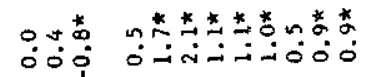

*****

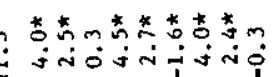

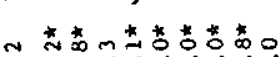
苟

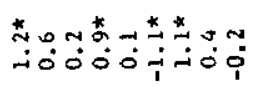

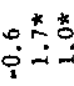

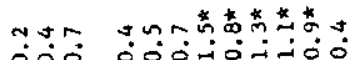

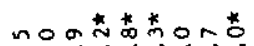

*芯芯

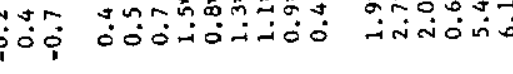

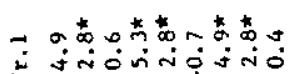

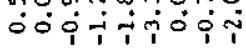

ịi

mกำ

*******

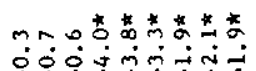

*

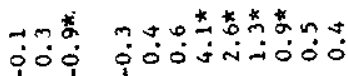

Niñ

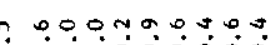

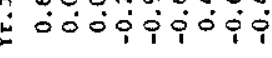

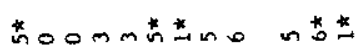

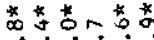

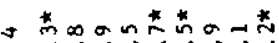

安

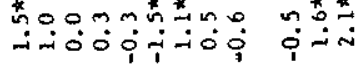

웅 *

* ${ }^{*} \sigma^{*} \sigma^{*}$

moñ

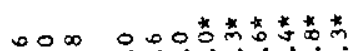

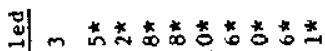

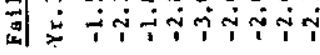

+0.0090:0

mon

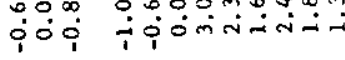

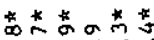

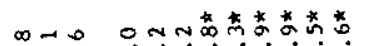

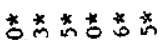

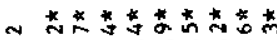

mos.0.0.0.

mimating

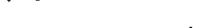

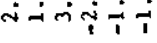

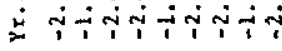

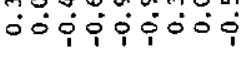

mió

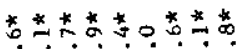

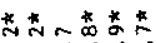

? :

T.․․․․․․․․․․․․

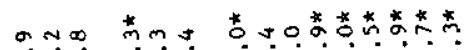

17.

* ióitifio

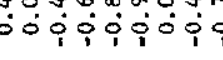

000 i००

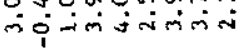

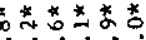

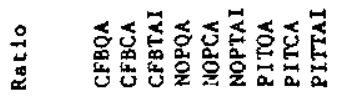

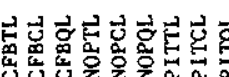

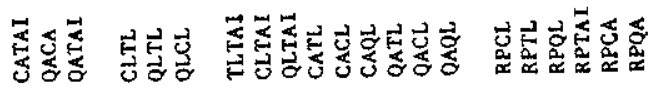




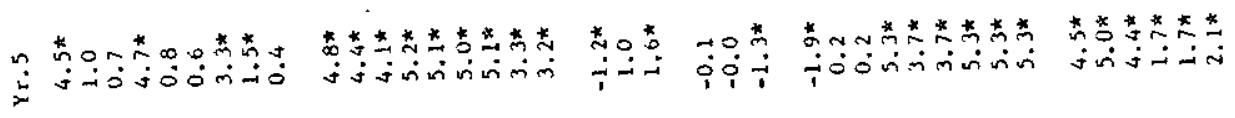

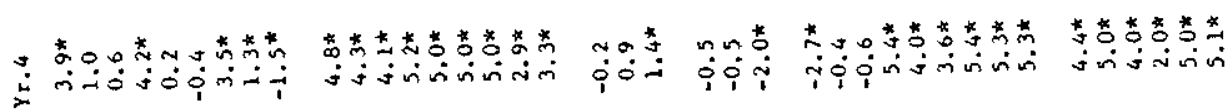

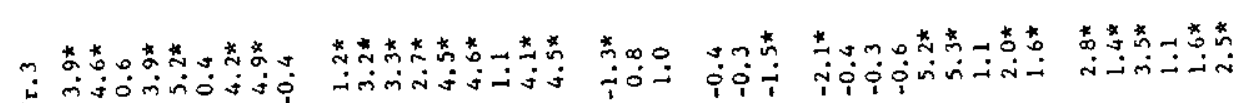

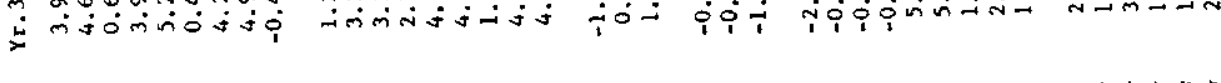

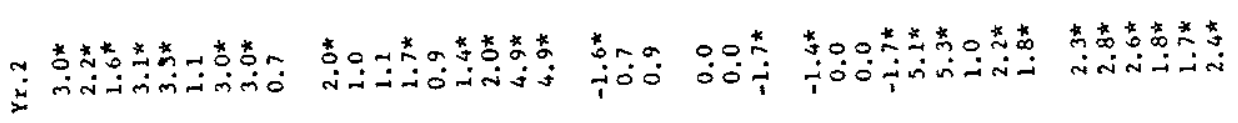

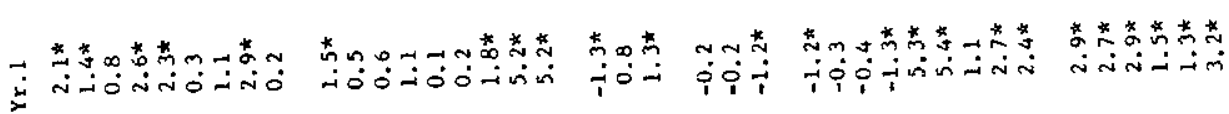

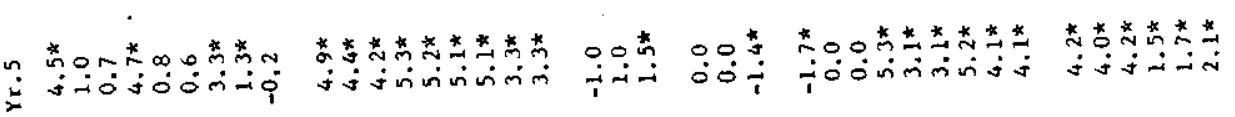

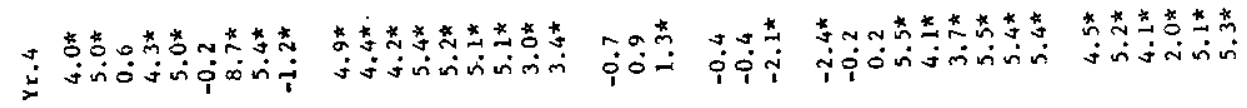
帝

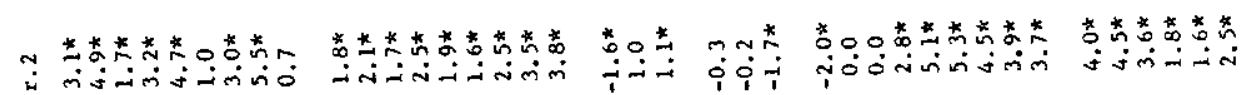

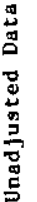
†

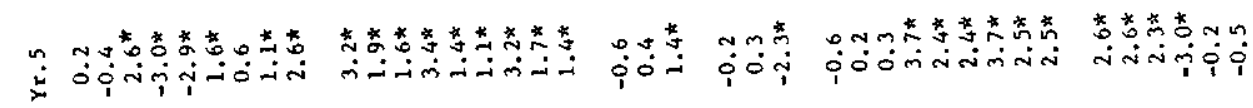

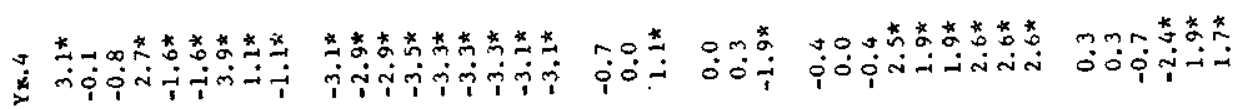
兽

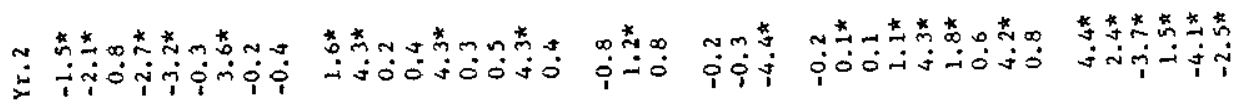

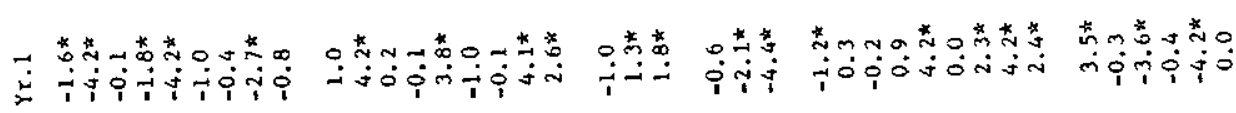

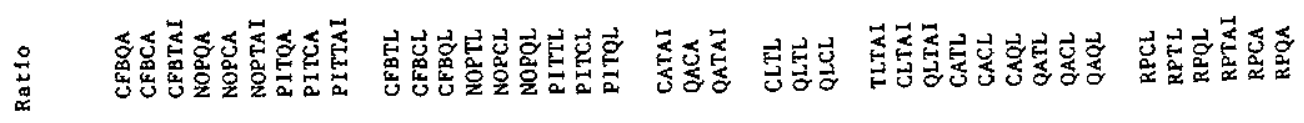




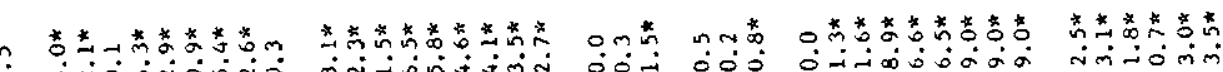

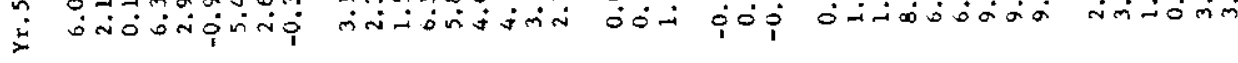

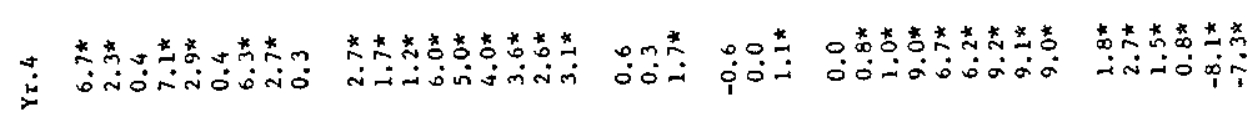

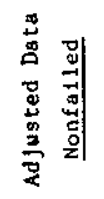

m * * *

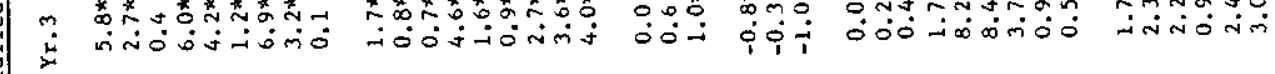

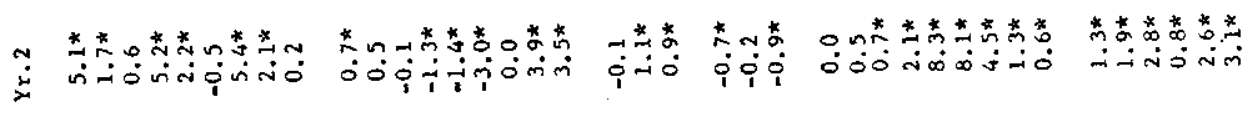

†

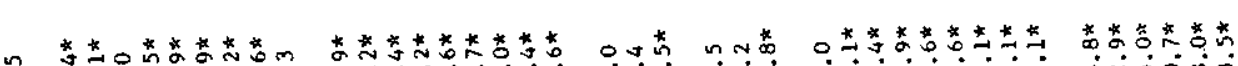

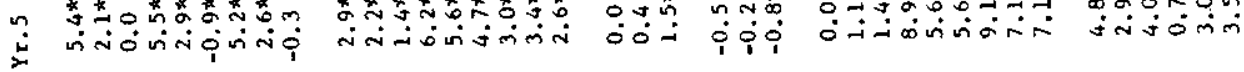

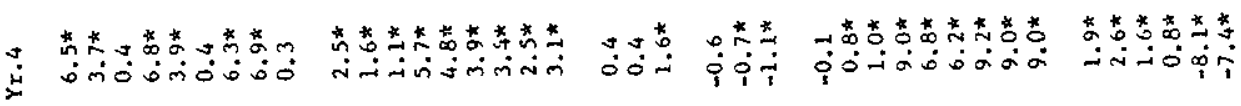

总

2

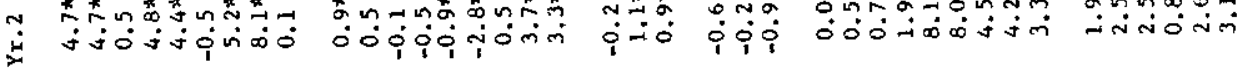
若

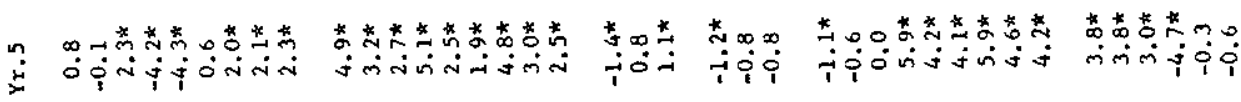

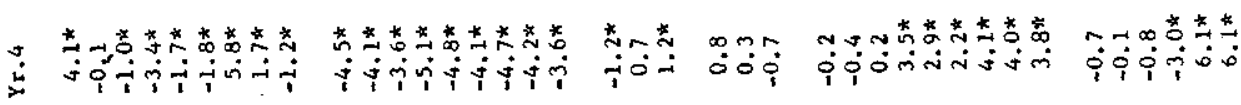

包

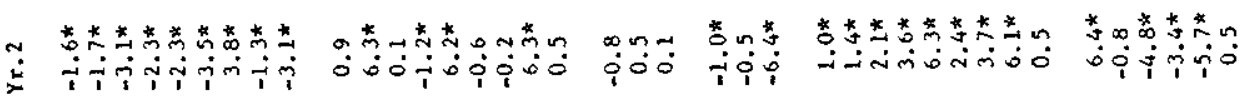
¡

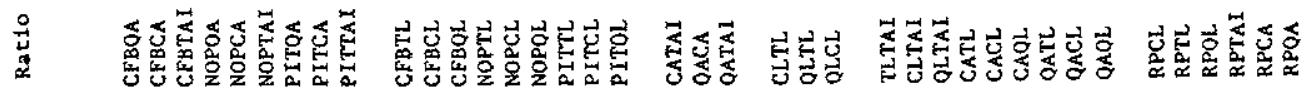




\section{APPENDIX G}

\section{Combination $1 B$}

Ratios from combination $1 \mathrm{~A}$ which are approximately symetrical.

\section{Manufacturing and Retail}

Year 1 : CFBCL, CFBQL, NOPCL, NOPQL, PITCL, PITQL, CATAI, QACA, QATAI, CLTAI, QLTAI.

Year 2 : CFBCL, CFBQL, NOPCL, NOPQL, PITCL, PITQL, CATAI, CLTL, QLCL, RPQL.

Yeax 3 : CFBCL, CFBQL, NOPTL, NOPCL, PITTL, PITCL, PITQL, CATAI, CLTL, QLCL, TLTAI, CLTAI, QLTAI.

Year 4 : CFBTAI, CFBCL, PITCL, CATAI, QACA, QATAI, CLTL, QLCL, RPTAI, TLTAI.

Year 5 : CFBCA, CEBTAI, NOPCA, NOPTAI, PITCA, PITTAI, CFBQL, PITQL, CATAI, CLTL, QLCL, CLTAI, RPTAI.

\section{Property and Finance}

Year 1 : CFBTAI, NOPTAI, PITQA, PITTAI, CFBQL, NOPTL, NOPQL, CLTAI, QLTAI.

Year 2 : NOPTAI, PITTAI, CFBQL, QATAI, CLTAI, QITAI, QATL.

Year 3 : PITTL, QATAI, CLTAI, QLTAI, RPTAI.

Year 4 : CFBCA, CFBTAI, CATAI, CLTAI, QLTAI.

Year 5 : CFBCA, CLTAI, QLTAI.

Manufacturing, Retail, Property and Finance

Year 1 : CFBTAI, PITTAI, CFBQL, CATAI, QATAI, CLTAI, QLTAI.

Year 2 : CFBQL, PITTL, CATAI, QLTL, TLTAI.

Year 3 : CFBTAI, PITTAI, TLTAI, CLTAI, QLTAI, QLTL.

Year 4 : TLTAI, CLTL, CFBTAI, QLTAI.

Year 5 : CLTL, QLTL, NOPTAI, TLTAI.

\section{Property}

Year 1 : CFBCA, CFBTAI, NOPTAI, PITTAI, CFBTL, CFBCL, CFBQL, NOPTL, NOPCL, NOPQL, PITTL, CATAI, QLCL, TLTAI, CLTAI, QLTAI, CAQL, RPTAI.

Year 2 : CEBQA, NOPTAI, PITQA, PITTAI, CATAI, QATAI, TLTAI, CLTAI, QLTAI, QATL, QLTL. 
Appendix G (continued):

Year 3 : QATAI, QLCL, CLTAI, QLTAI.

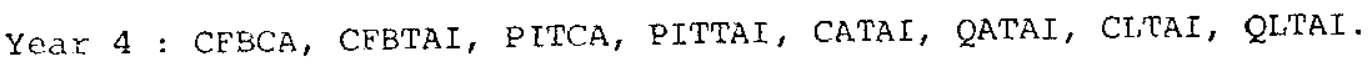

Year 5 : CFBCA, NOPTAI, PITCA, CATAI, ClTAI, QLTAI.

Manufacturing

Year 1 : CFBQA, NOPQA, PITQA, CFBTL, CFBCL, CFBQL, NOPTL, NOPCL, NOPQL, PITCL, PITQL, QACA, CLTL, QLTL, QLCL, TLTAI, CLTAI, QLTAI, CATL, CACL, QATL.

Year 2 : CFBQA, CFBTAI, NOPTAI, CFBTL, CFBCL, CFBQL, NOPTL, NOPCL, NOPQL, PITTL, PITCL, PITQL, QACA, CLTL, QLTE, QLCL, CLTAI, QLTAI, CATL, CACL, QATL, QACL, QAQL.

Year 3 : CFBQA, CFBCA, CFBTAI, NOPQA, PITQA, PITCA, PITTAI, CFBCL, CFBQL, PITTL, PITCL, PITQL, CATAI, QACA, CLTL, QLTL, QLCL, CLTAI, QLTAI, RPTAI.

Year 4 : CFBTL, CFBCL, NOPTL, PITTL, PITCL, CATAI, CLTL, QLTL, QLCL, CLTAI, QLTAI.

Yeax 5 : CFBQA, CFBCA, CFBTAI, NOPQA, NOPCA, NOPTAI, PITQA, PITCA, PITTAI, CFBQL, PITQL, QACA, CLTL, QLTL, QLCL, CLTAI, QLTAI, RPTAI.

Retail

Year 1 : CFBCL, CFBQL, PITCL, PITQL, CATAI, QATAI, CLTL, QLTAI.

Year 2 : CFBCL $_{\text {, CFBQL, NOPCL, NOPQL, PITCL, PITQL, CATAI, CLTL, }}$ QLCL, TLTAI, RPCL, RPQL.

Year 3 : CFBCL, CFBQL, NOPCL, PITCL, QATAI, CLTL, QLCL, CLTAI, QLTAI, RPCL, RPQL.

Year 4 : CFBCL, CFBQL, PITCL, PITQL, RATAI, CLTL, RPQL.

Year 5 : CFBCA, CFBTAI, NOPCA, PITCA, CATAI, CLTL, QLCL, RPQL, QAQL, RPTAI. 
APPENDIX H

Combination $1 \mathrm{C}$

Ratios from combination $1 \mathrm{~A}$ with correlation-coefficients of less than 0.75 .

Manufacturing and Retail

Year 1 : CFBTL, PITTAI, QACA, QATAI, QACL, CATAI, TLTAI, CLTAI, RPTAI, CLTL, QLCL.

Year 2 : CFBCL, PITTAI, QACA, QACL, CATAI, CACL, TLTAI, QLTAI, RPTAI, CLTL, RPCL.

Year 3 : CFBCL, NOPTAI, QACA, QACL, CATAI, TLTAI, QLTAI, RPTAI, CLTL, QLCL, RPCL.

year 4 : QLTAI, TLTAI, CAQL, CATAI, QACA, CFBTAI, CFBCL, CFBCA, CLTL, RPTAI, QLCL.

Year 5 : CFBTL, NOPTAI, QACA, QACL, CATAI, QLCL, CLTAI, RPTAI, CLTL, RPCL.

\section{Property and Finance}

Year 1 : PITTAI, PITQA, NOPTL, NOPQL, QACA, QATL, QACL, QAQL, RPQA, CATAI, CATL, CACL, CAQL, TLTAI, ClTAI, RPTAI, RPCL, RPTL.

Year 2 : CFBQA, CFBCA, PITTAI, CFBTL, CFBCL, CFBQL, QATAI, QACL, CATAI, CATL, CACL, CAQL, TLTAI, CLTAI, QLCL, RPTAI, RPCL, RPTL.

Year 3 : CFBQA, CFBCA, PITTAI, PITTL, QATL, RPQA, CATAI, CATL, TLTAI, QACL, QAQL, RPQA, TLTAI, QLTAI, RPTAI, RPTL.

Year 4 : CFBQA, CFBTE, CFBCL, PITTAI, NOPCA, QATAI, QACL, CATAI, CACL, CLTAI, RPTAI, QLCL, RPCL.

Year 5 : CFBQA, CFBTL, CFBCL, PITTAI, PITCA, QATAI, QACL, CATAI, CACL, CLTAI, RPTAI, QLCL, RTCL.

\section{Manufacturing, Retail, Property and Finance}

Year 1 : CFBQA, CFBTAI, PITCA, CFBTL, CFBCL, CFBQL, QATAI, QACL, CATAI, CATL, CAQL, TLTAI, CLTAI, CLTL, RPTAI, RPTL, QLCL, RPCL.

Year 2 : CFBQA, PITTAI, PITCA, CFBTL, QATAI, QACL, CATAI, CLTL, CAQL, TLTAI, CLTAI, RPTAI, RPCL, QLCL. 
Appendix H (continued) :

Year 3 : CFBQA, CFBTÃI, PITCA, CFBTL, CFBCL, CFBQL, QATAI, QACL, CATAI, CATL, CAQL, TLTAI, CLTAI, CLTL, RPTAI, RPTL, QLCL, RPCL.

Year 4 : CFBQA, PITTAI, PITCA, CFBTL, CFBCL, QACL, CATAI, QATAI, CLTL, CAQL, TLTAI, CLTAI, RPTAI, RPCL, QLCL.

Year 5 : CFBQA, PITTAI, PITCA, CFBTL, CFBCL, QATAI, QACL, CATAI, CLTL, CAQL, TLTAI, CLTAI, RPTAI, RPCL, QLCL.

\section{Manufacturing}

Year 1 : CFBTL, QACA, QATL, CATL, TLTAI, QLTAI, RPTAI, RPCA, QACL, QLCL.

Year 2 : CFBTL, QACA, QACL, CATAI, CATL, TLTAI, CLTAI, CLTL, QLTAI, RPTAI, QLCL.

Year 3 : CFBTL, QACA, QACL, CATAI, CATL, TLTAI, CLTAI, RPTAI, CLTL, QLTI, QLCL.

Year 4 : CFBTL, PITCA, QACA, QATL, QACL, RPQA, CATAI, CLTL, RPCA, TLTAI, CLTL, RPTAI, QLCL, RPCL.

Year 5 : CFBTAI, PITCA, QACA, QACL, QATL, RPCA, CATAI, CATL, RPCA, TLTAI, CLTL, RPTAI, QLCL, RPCL.

\section{Retail}

Year 1 : CFBQA, CEBTAI, CEBTL, QATAI, QACL, RPCA, RPTAI, RPTL, CATAI, CATL, TLTAI, CLTAI, QLCL, CAQL.

Year 2 : CFBQA, CFBQL, PITTAI, CATL, QATAI, CATAI, CLTL, QLCL, TLTAI, RPTL, CFBTAI, RPCA, CATL.

Year 3 : CFBQA, CFBTAI, PITTL, QATAI, QATL, RPCA, CATAI, CATL, RPCA, TLTAI, RPTAI, QICL.

Year 4 : CFBQA, CFBTAI, PITTL, CFBQL, QATAI, QACL, RPCA, CATAI, CATL, CLTAI, RPLAI, QLCL.

Year 5 : CFBQA, CFBTAI, CFBQL, QATAI, CATAI, QACL, RPCA, CATL, CLTAI, QLCL, CLTL, RPTAI.

\section{$\underline{\text { Property }}$}

Year 1 : CFBQA, NOPCA, CFBTL, CFBCL, PITTAI, QATL, QACL, RPCA, CATAI, CATL, CACL, TLTAI, CLTAI, RPTAI, QLCL, RPCL. 
Appendix H (continued) :

Year 2 : CFBQA, NOPCA, CFBTL, CFBCL, PITTAI, QACL, RPTAI, CATAI, CATL, CACL, TLTAT.

Year 3 : CFBQA, NOPCA, CFTBL, CFBCL, PITTAI, QACL, RPQA, CATL, CATAI, CAQL, TLTAI, CLTAI, RPTAI, QLCL.

Year 4 : CFBQA, NOPCA, CFBTL, CFBCL, PITTAI, QACL, RPQA, CATAI, CATL, RPCA, TLTAI, CLTAI, RPTAI, QLCL.

Year 5 : CFBQA, NOPCA, CFTBL, CFBCL, PITTAI, QACL, RPQA, CATAI, CAQL, RPCA, TLTAI, CLTAI, RPTAI, QLCL. 
APPENDIX I

Combination 10

Ratios from combination $1 B$ with correlation-coefficients of less than 0.75

Manufacturing and Retail

Year 1 : CFBQL, QACA, CATAI, QATAI, CLTAI.

Year 2 : CEBQL, CATAI, CLTL, QLCL, RPQL.

Year 3 : CFBQL, CATAI, CLTL, QLCL, CLTAI.

Year 4 : CFBCL, CATAI, QACA, TLTAI, CLTL, QLCL, RPTAI.

Year 5 : CFBCA, CFBQL, CATAI, CLTL, QLCL, CLTAI, RPTAI.

Property and Finance

Year 1 : PITQA, PITTAI, NOPTL, NOPQL, CLTAI.

Year 2 : PITTAI, CFBQL, QATAI, CLTAI.

Year 3 : PITTL, QATAI, CLTAI, RPTAI.

Year 4 : CFBCA, CFBTAI, CATAI, CLTAI.

year 5 : CFBCA, QLTAI.

Manufacturing, Retail, Property and Finance

Year 1 : PITTAI, CEBTL, CATAI, QACA, CLTAI.

Year 2 : CFBQL, PITTL, CATAI, QLTL, TLTAI.

Year 3 : CFBTAI, PITTAI, TLTAI, CLTAI, QLTL, QACA.

Year 4 : CFBTAI, QLTAI, CLTAI, CLTL, QACA.

Year 5 : QACA, QLTL, NOPTAI, TLTAI.

\section{Manufacturing}

Year 1 : CFBQA, QACA, CLTL, QLCL, TLTAI, QLTAI, CACL, QATL.

Year 2 : CFBCL, CATL, CACL, CLTAI, QLTAI, CLTL, QLCL, QACL.

Yeax 3 : CFBCA, CFBCL, QACA, CATAI, CLTAI, RPTAI, CLTL, QLTL, QLCL.

year 4 : CFBCL, CATAI, CLTAI, CLTL, QLTL, QLCL.

Year 5 : CFBQL, QACA, CLTAI, RPTAI, CLTL, QLTL, QLCL. 
Appendix I (continued):

\section{Retail}

Year 1 : PITQL, CATAI, QATAI, CLTL, QLTAI.

Year 2 : PITQL, CATAI, CLTL, QLCL, TLTAI, RPQL.

Year 3 : PITCL, QATAI, CLTL, CLTAI, QLCL.

Year 4 : PITCL, QATAI, CLTL, RPQL.

Year 5 : PITCA, CFBTAI, CATAI, CLTL, QLCL, QAQL, RPTAI.

\section{Property}

Year 1 : CFBCA, NOPQL, CATAI, QLCL, QLTAI, TLTAI, CAQL, RPTAI.

Year 2 : CFBQA, PITTAI, CATAI, CLTAI, TLTAI, QATI.

Year 3 : QACA, QATAI, QLCL, CLTAI.

Year 4 : CFBCA, PITTAI, CATAI, QACA, QATAI, QLTAI.

Year 5 : CFBCA, NOPTAI, CATAI, QACA, CLTAI. 


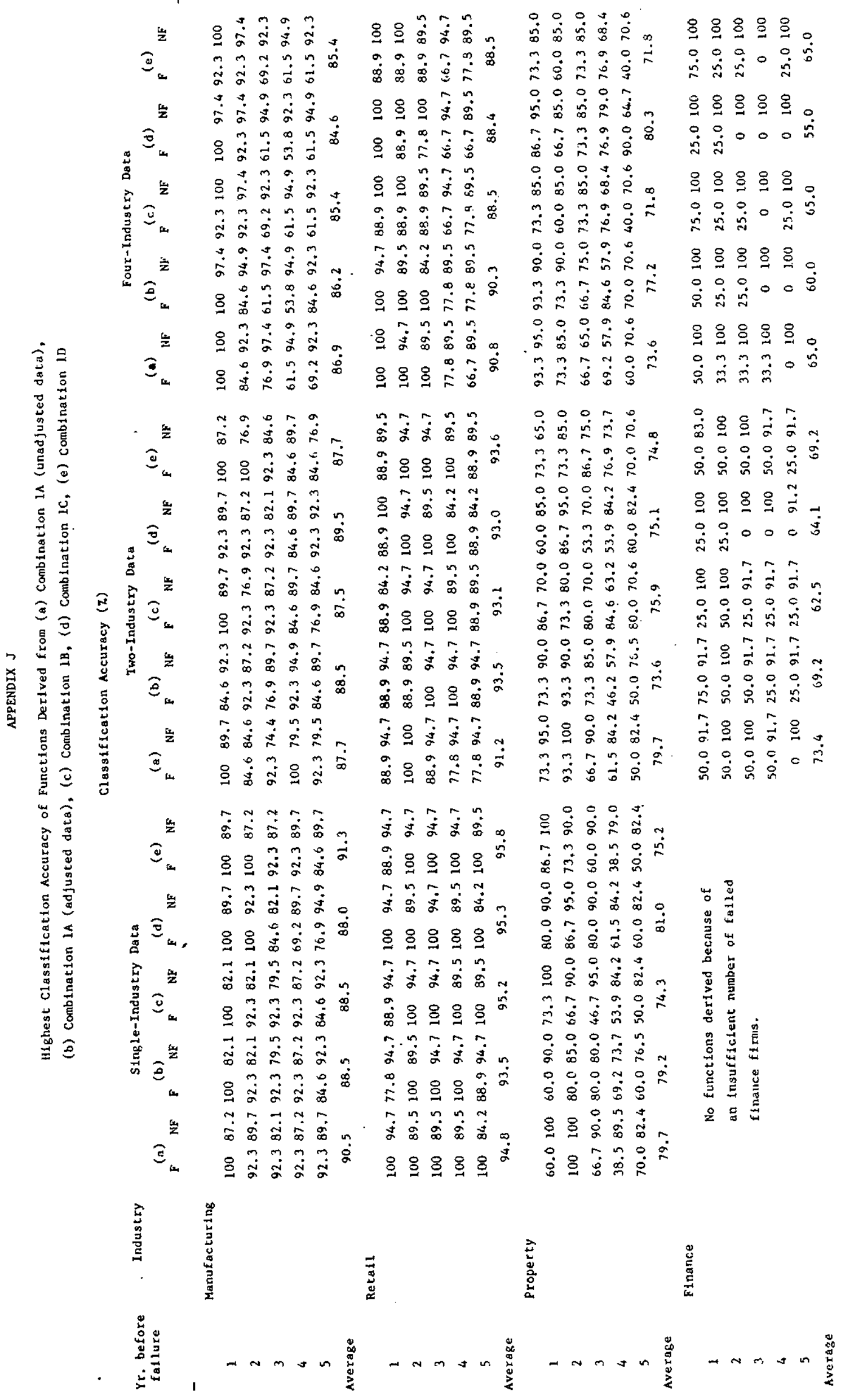


APPENDIX K

THE QUADRATIC EQUATION FOR THE MANUFACTURING AND RETAIL INDUSTRY

$$
\begin{aligned}
& \mathrm{Z}=36.279-18.826 \mathrm{CFBCL}-74.961 \mathrm{CATAI}+79.338 \mathrm{CLTL} \\
& +70.727 \text { QLCL + 99.693 QACA + } 143.79 \mathrm{RPTAI}-24.538 \\
& \text { TLTAI + 47.449 CFBCL }{ }^{2}-99.346 \mathrm{CFBCL} * \mathrm{CATAI}-7.1170 \\
& \mathrm{CFBCL}{ }^{\star} \mathrm{CLTL}+7.7576 \mathrm{CFBCL}^{\star} \mathrm{QLCL}+58.926 \mathrm{CFBCL}{ }^{*} \mathrm{QACA} \\
& \text { - } 102.92 \mathrm{CFBCL}{ }^{*} \text { RPTAI - } 70.812 \mathrm{CFBCL}{ }^{*} \mathrm{TLTAI}+94.966
\end{aligned}
$$

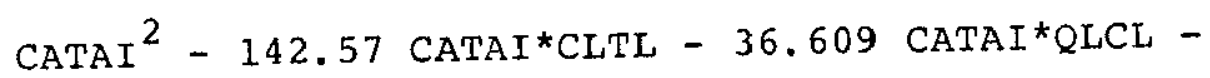

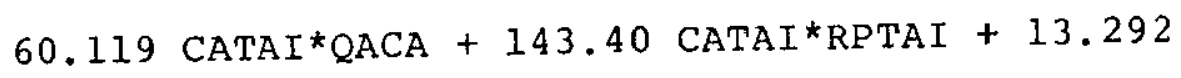

$$
\begin{aligned}
& \text { CATAI*TLTAI + 60.169 } \mathrm{CLTL}^{2}+77.564 \mathrm{CLTL}^{*} \mathrm{QLCL}+ \\
& 55.032 \mathrm{CLTL}{ }^{*} \mathrm{QACA}+24.958 \mathrm{CLTL}{ }^{*} \mathrm{RPTAI}-24.474 \\
& \text { CLTL*TLTAI - } 16.196 \mathrm{QLCL}^{2}+51.045 \mathrm{QLCL}{ }^{2} \mathrm{QACA}+ \\
& 8.2887 \mathrm{QLCL} * \mathrm{RPTAI}+26.886 \mathrm{QLCL} \text { TLTAI }+64.660 \mathrm{QACA}^{2} \\
& \text { - } 131.95 \text { QACA*RPTAI - } 23.504 \text { QACA*TLTAI + } 151.12
\end{aligned}
$$

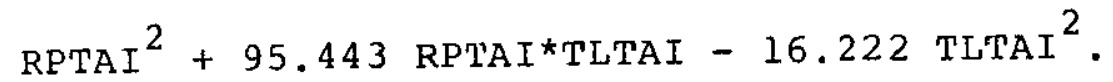




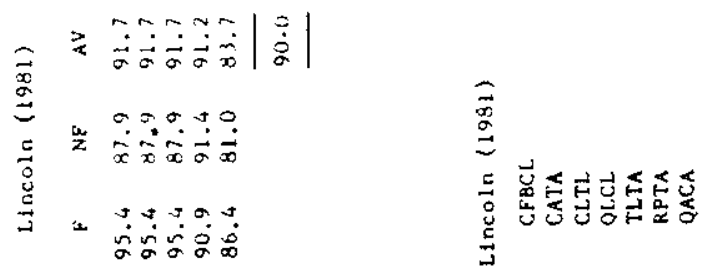

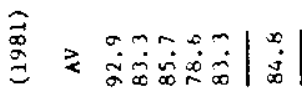

बे

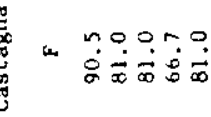

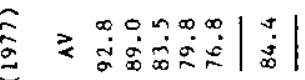

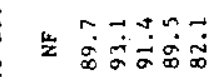

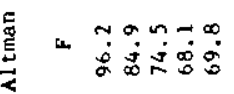

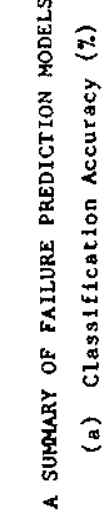

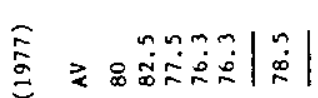

¿

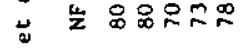

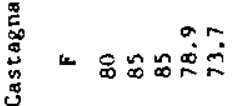

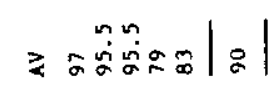

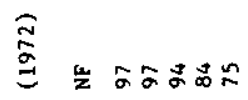

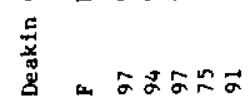

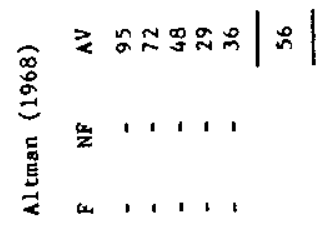

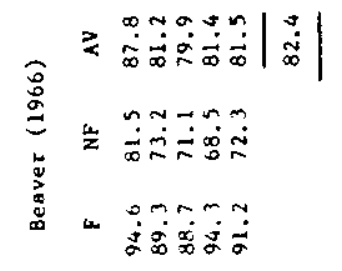

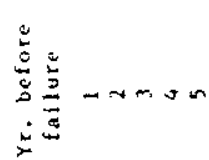

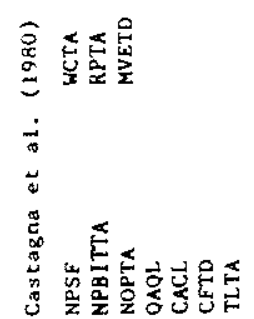

点

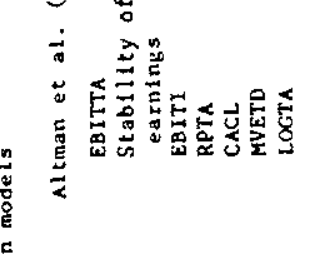

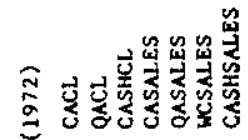

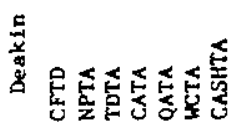

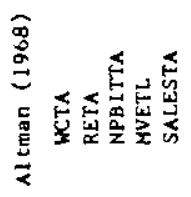

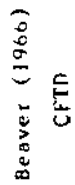

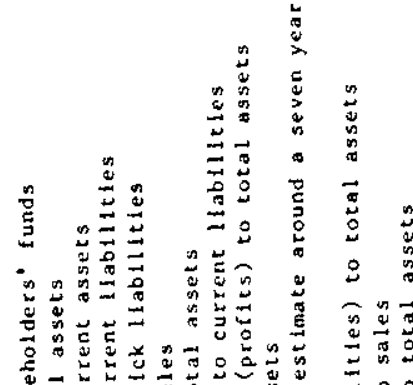

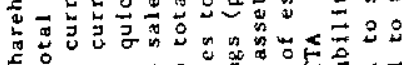

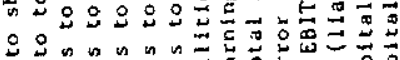

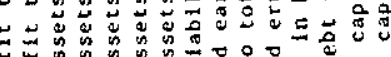

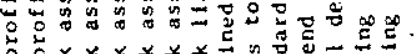

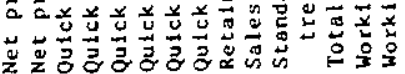

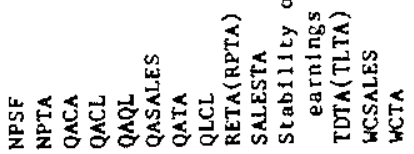

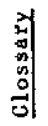

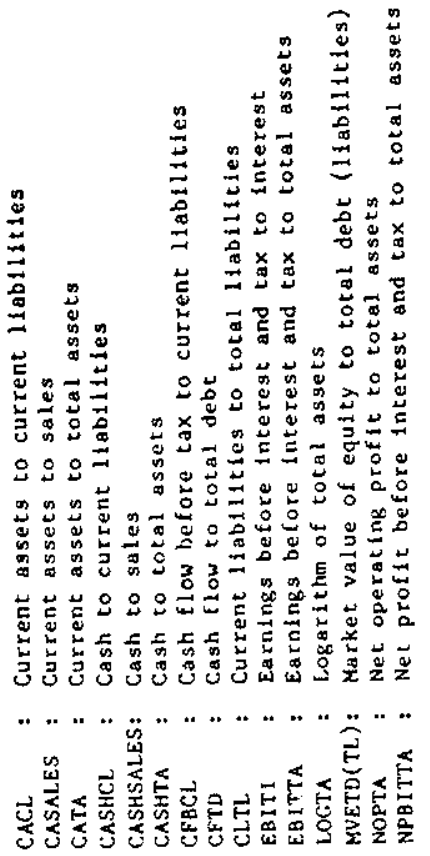




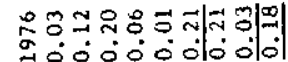

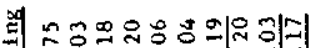

깅

\section{装告}

勿

氧

管

혀

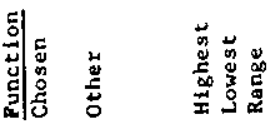

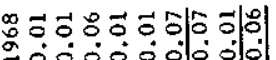

형후웅 훙의 히잉

3

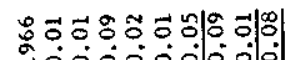

离

武

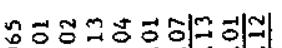

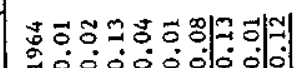

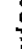

Кลร.

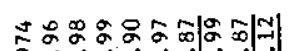

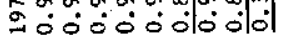

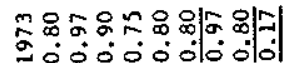

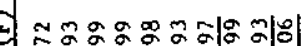

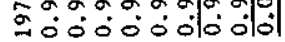

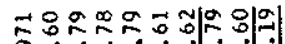

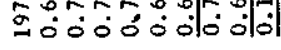

됭

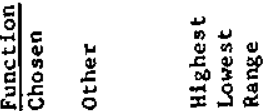

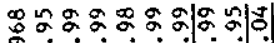

열

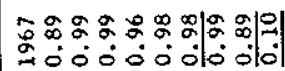

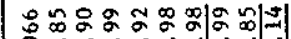

20 $0: 0$ : 0 olo jlol

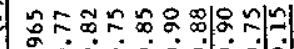

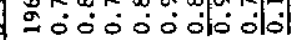

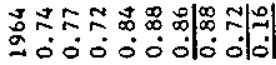

휜

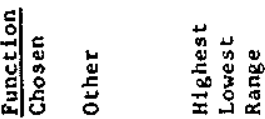

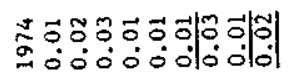

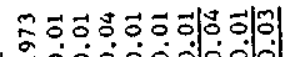

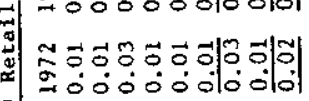

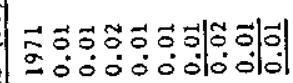

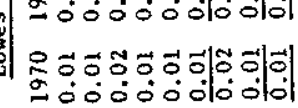

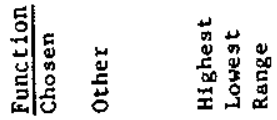

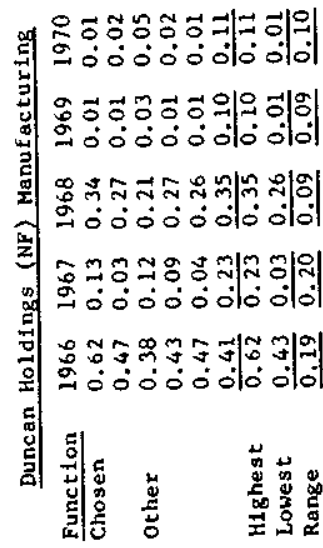

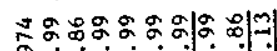
a ó0 co cilo dol

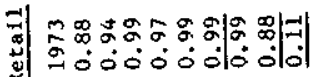

(2.)

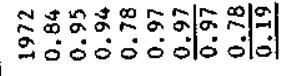

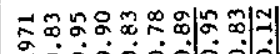

위

永

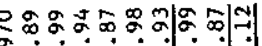

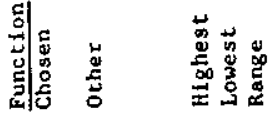

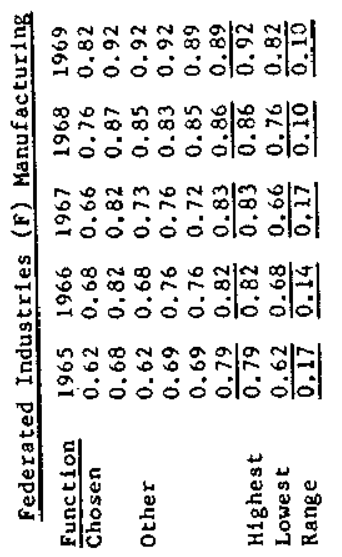

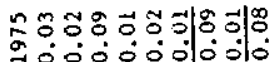

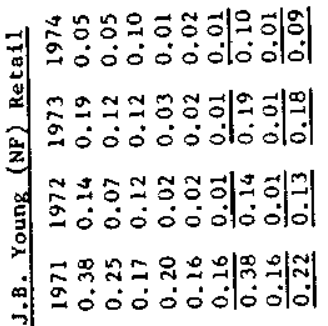

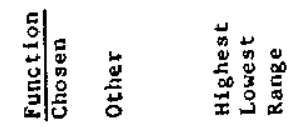

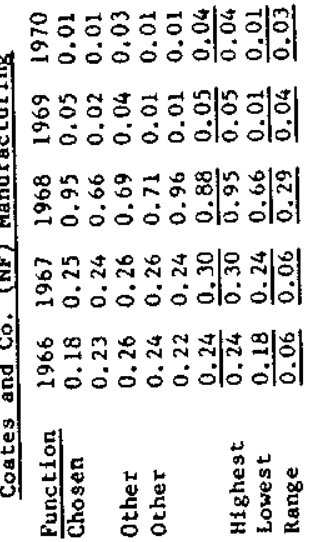

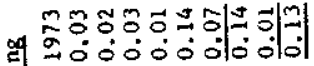

氙

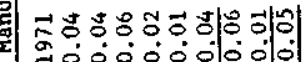

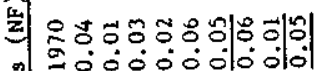

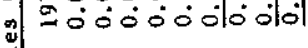

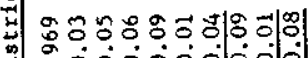

s

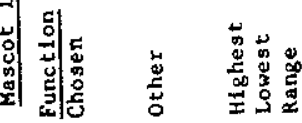

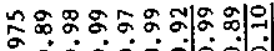

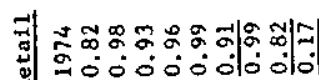

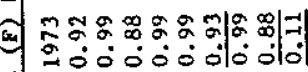

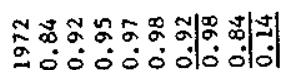

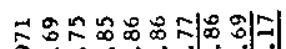

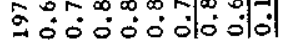

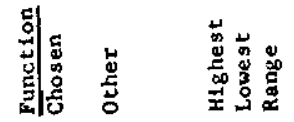

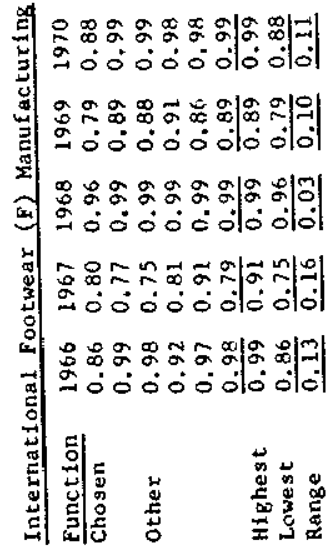

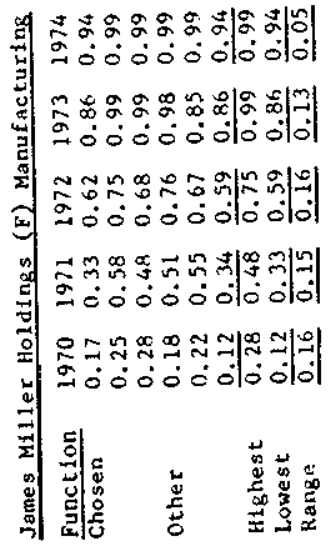




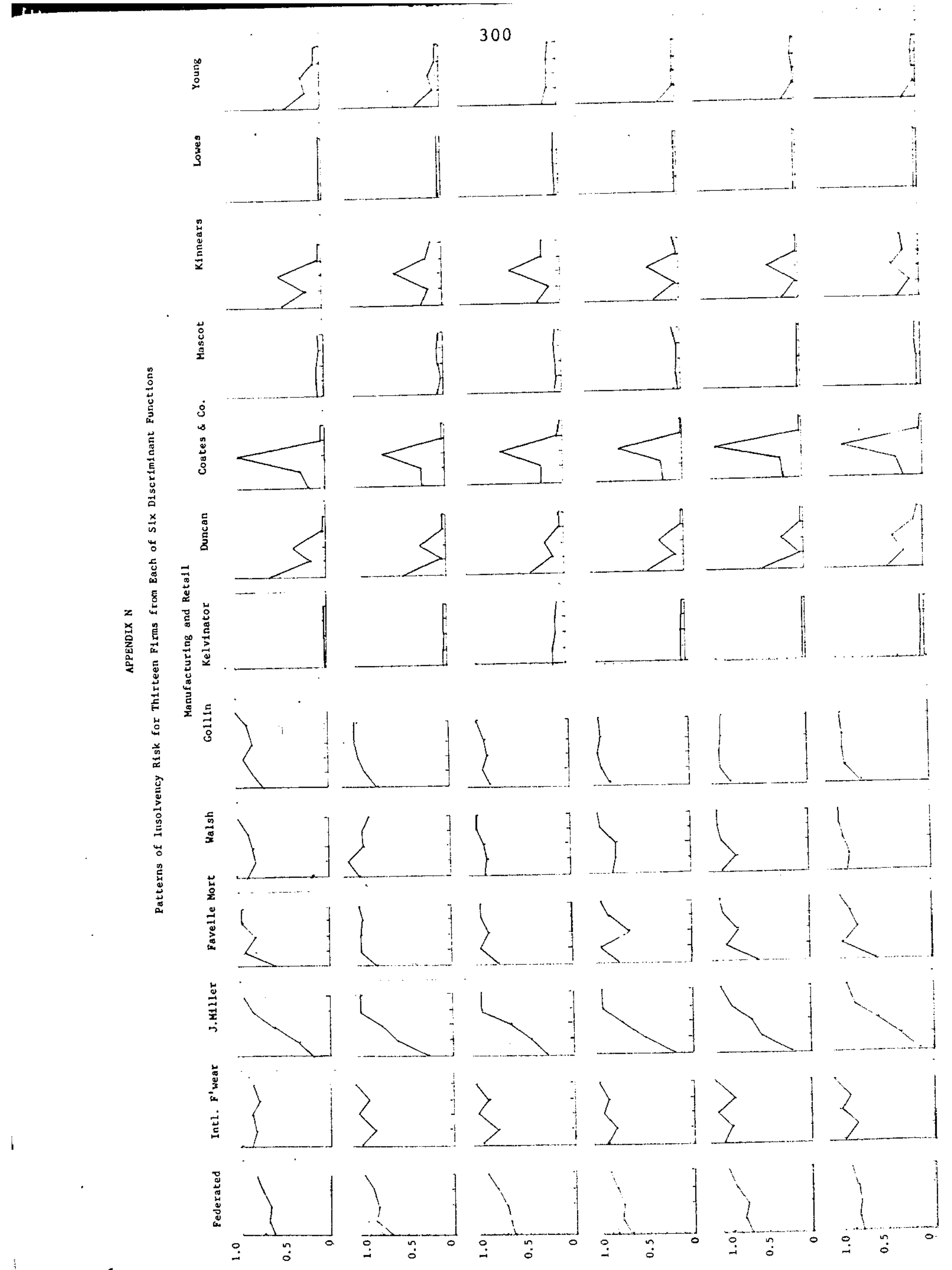




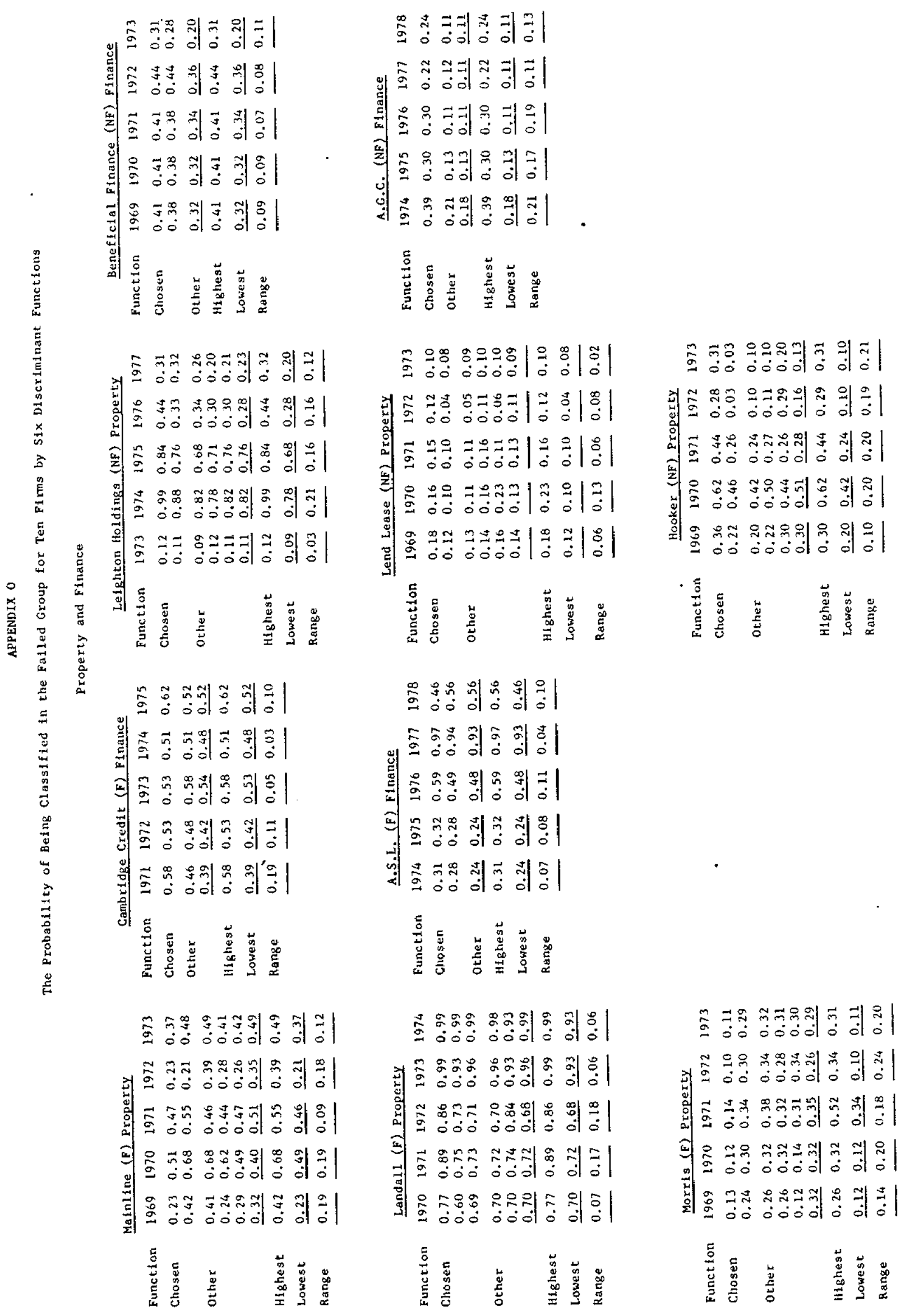


$+1$

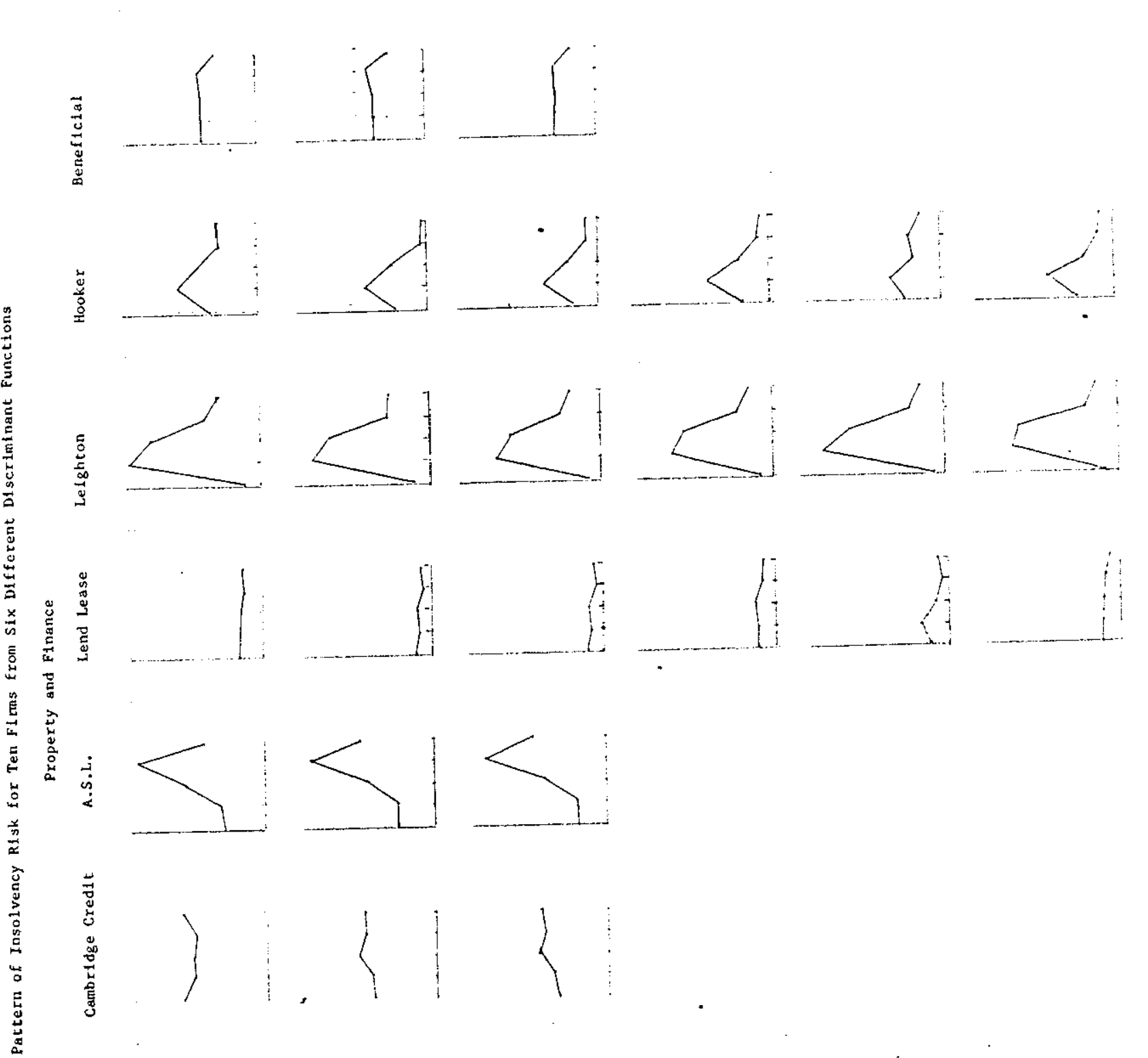

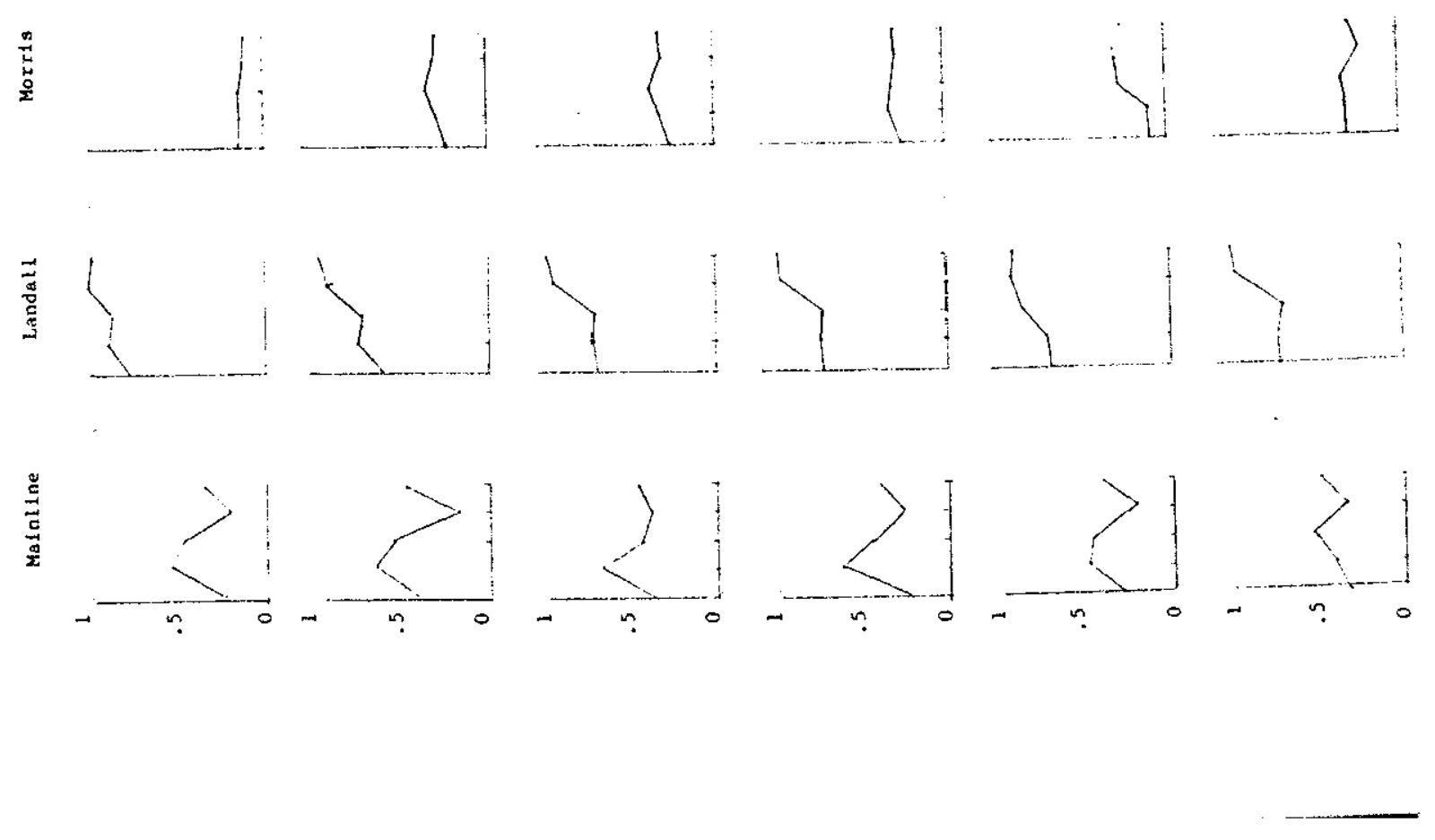


Appendix $Q$

1. Property Function with Highest Classification Accuracy.

(a) Grapis of relationship wetween $4-5 c o r e$ and level of insolvency $=i s k$

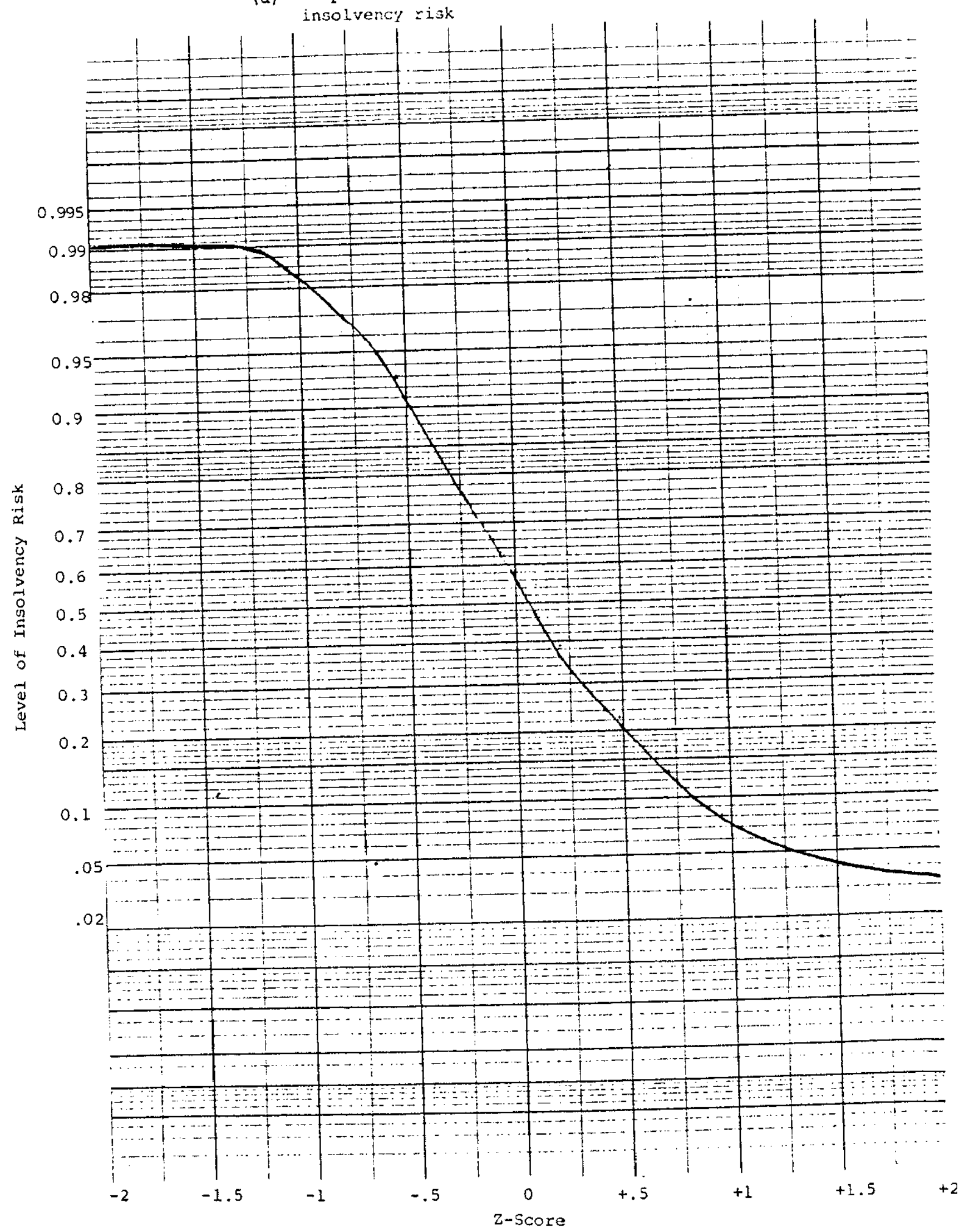


Appendix Q (continued):

(b) Index of Insolvency Risk

\begin{tabular}{|c|c|c|c|}
\hline z-Score & Insolvency Risk & z-Score & Insolvency Risk \\
\hline$<-1.5$ & 0.995 & +0.1 & 0.48 \\
\hline-1.4 & 0.993 & +0.2 & 0.38 \\
\hline-1.3 & 0.991 & +0.3 & 0.30 \\
\hline-1.2 & 0.989 & +0.4 & 0.26 \\
\hline-1.1 & 0.987 & +0.5 & 0.20 \\
\hline-1.0 & 0.982 & +0.6 & 0.17 \\
\hline-0.9 & 0.978 & +0.7 & 0.13 \\
\hline-0.8 & 0.97 & +0.8 & 0.11 \\
\hline-0.7 & 0.95 & +0.9 & 0.09 \\
\hline-0.6 & 0.94 & +1.0 & 0.07 \\
\hline-0.5 & 0.91 & +1.1 & 0.06 \\
\hline-0.4 & 0.86 & +1.2 & 0.055 \\
\hline-0.3 & 0.80 & +1.3 & 0.05 \\
\hline-0.2 & 0.74 & +1.4 & 0.045 \\
\hline-0.1 & 0.68 & +1.5 & 0.04 \\
\hline \multirow[t]{2}{*}{0.0} & 0.58 & +1.6 & 0.03 \\
\hline & & $>+1.7$ & 0.03 \\
\hline
\end{tabular}


Appendix \& (continued)

2. Property Function with Highest Classification Accuracy one Year Prior to Failure

(c) Graph of relationship between $z$-score and level of insolvency risk

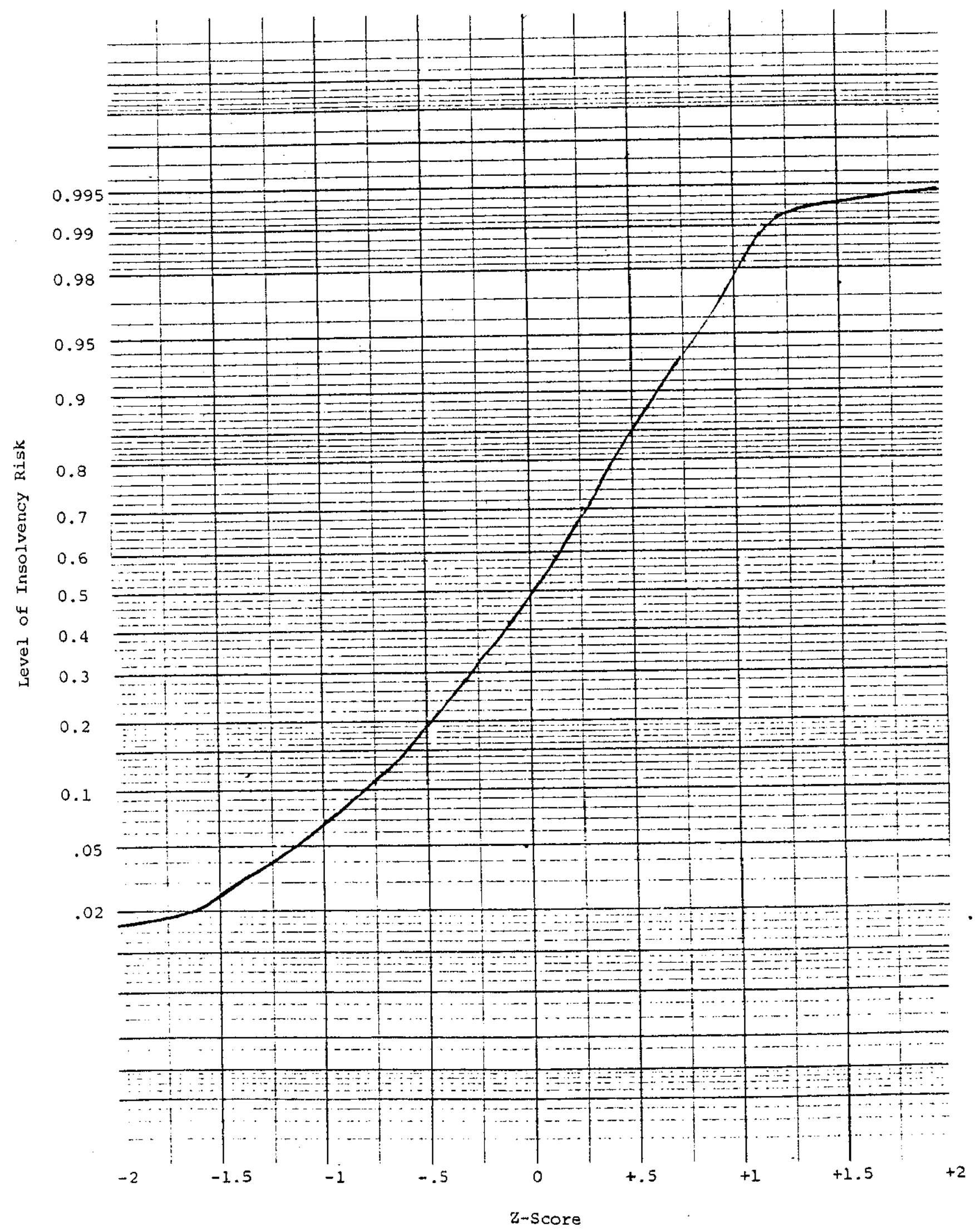


Appendix Q (continued):

(d) Index of Insolvency Risk

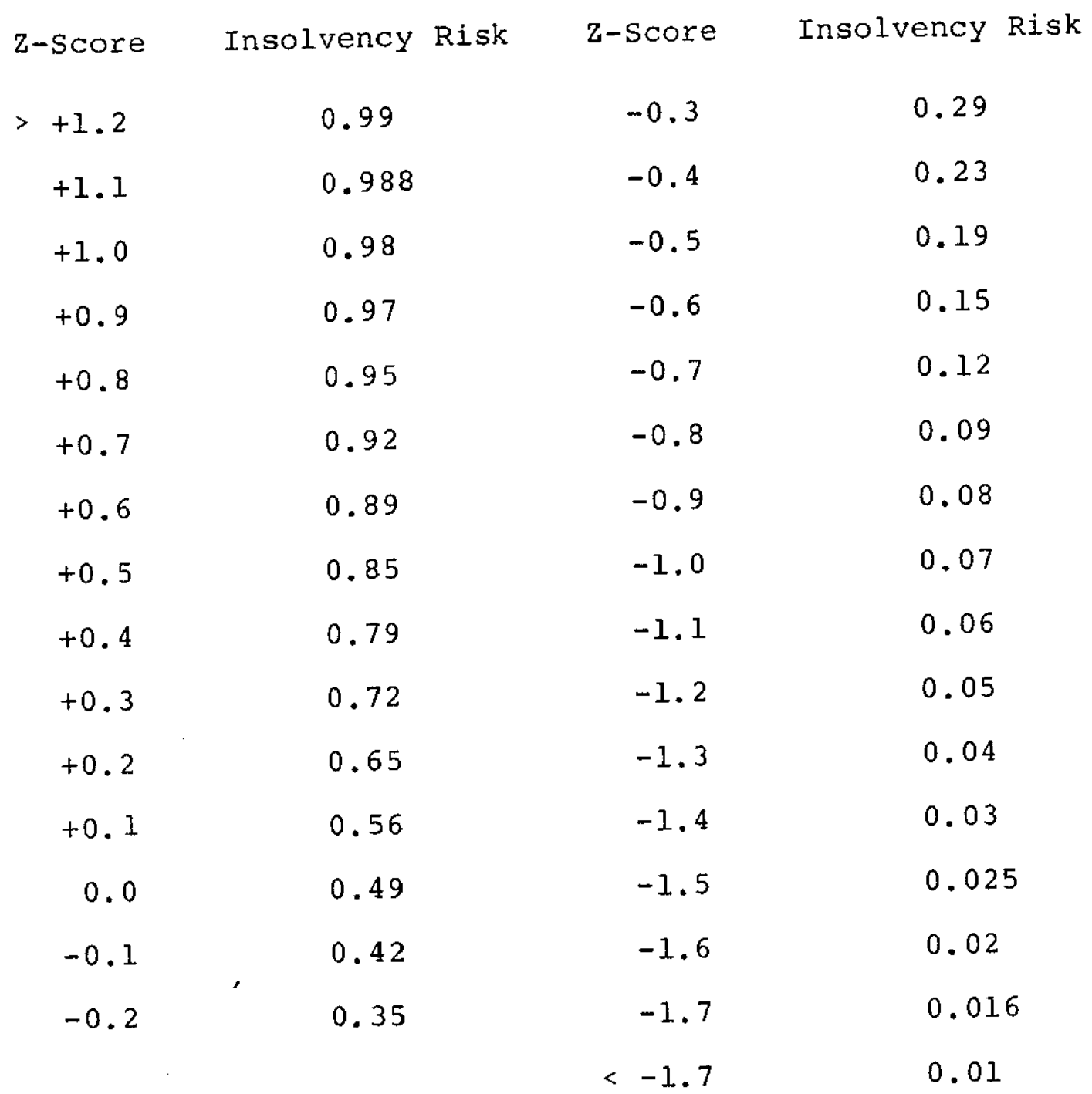




\section{APPENDIX R \\ Graphs of Insolvency Risk}

Pages 308-311 : Failed Manufacturing and Retail Firms Pages 312-321 : Nonfailed Manufacturing and Retail Firms Pages 322-325 : Failed Property and Finance Firms Pages 326-331 : Nonfailed Property and Finance Firms 

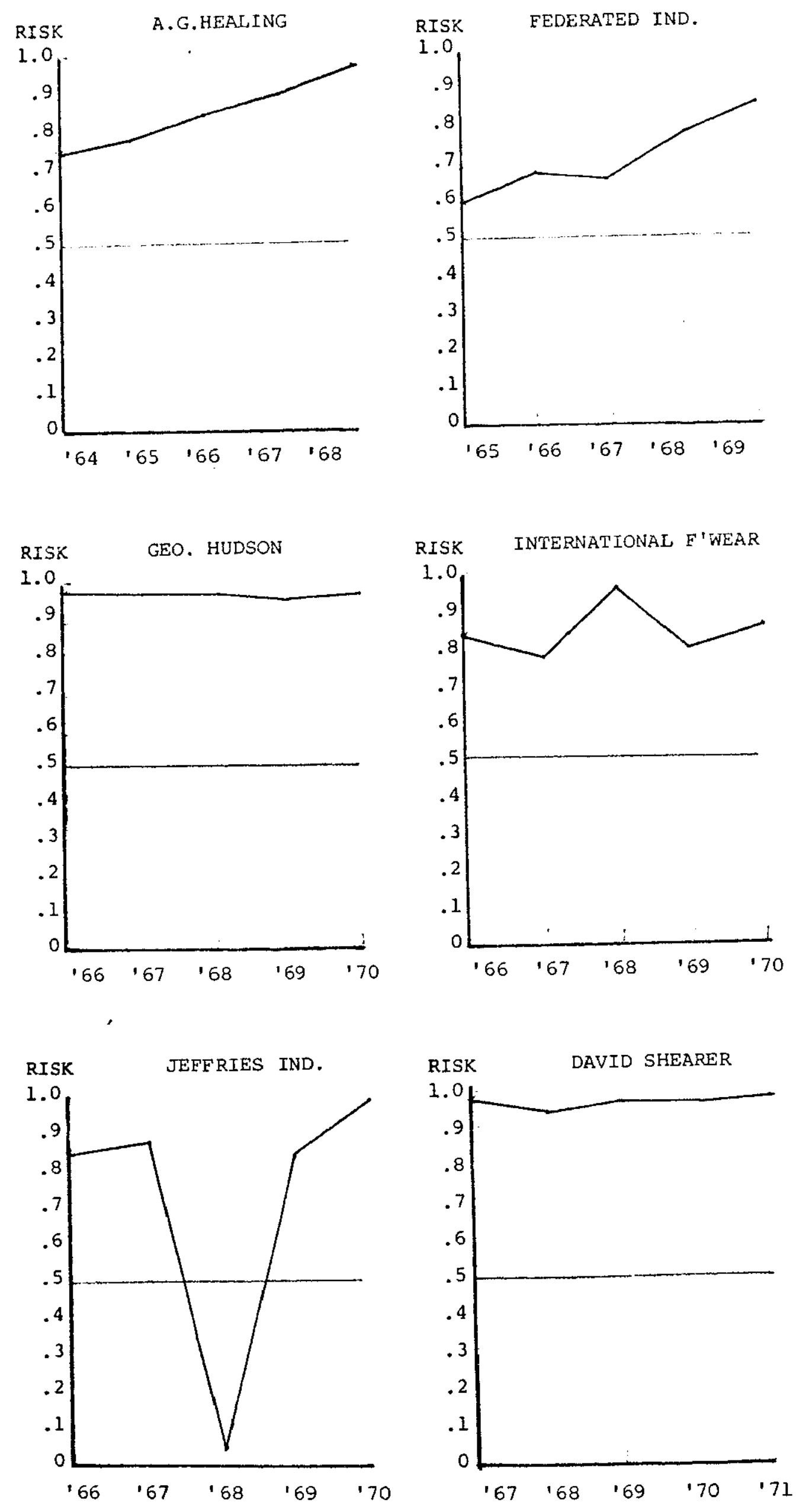

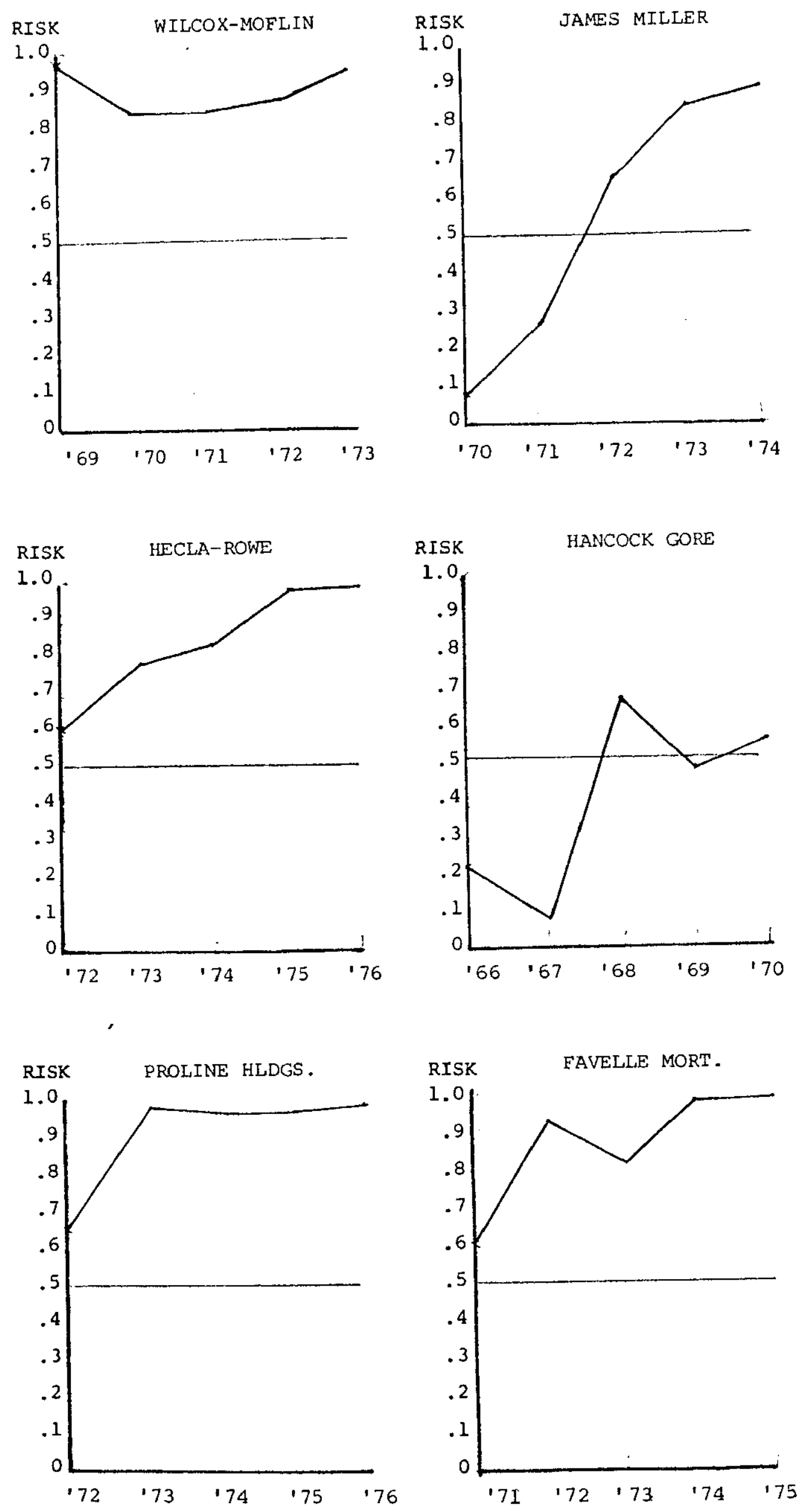

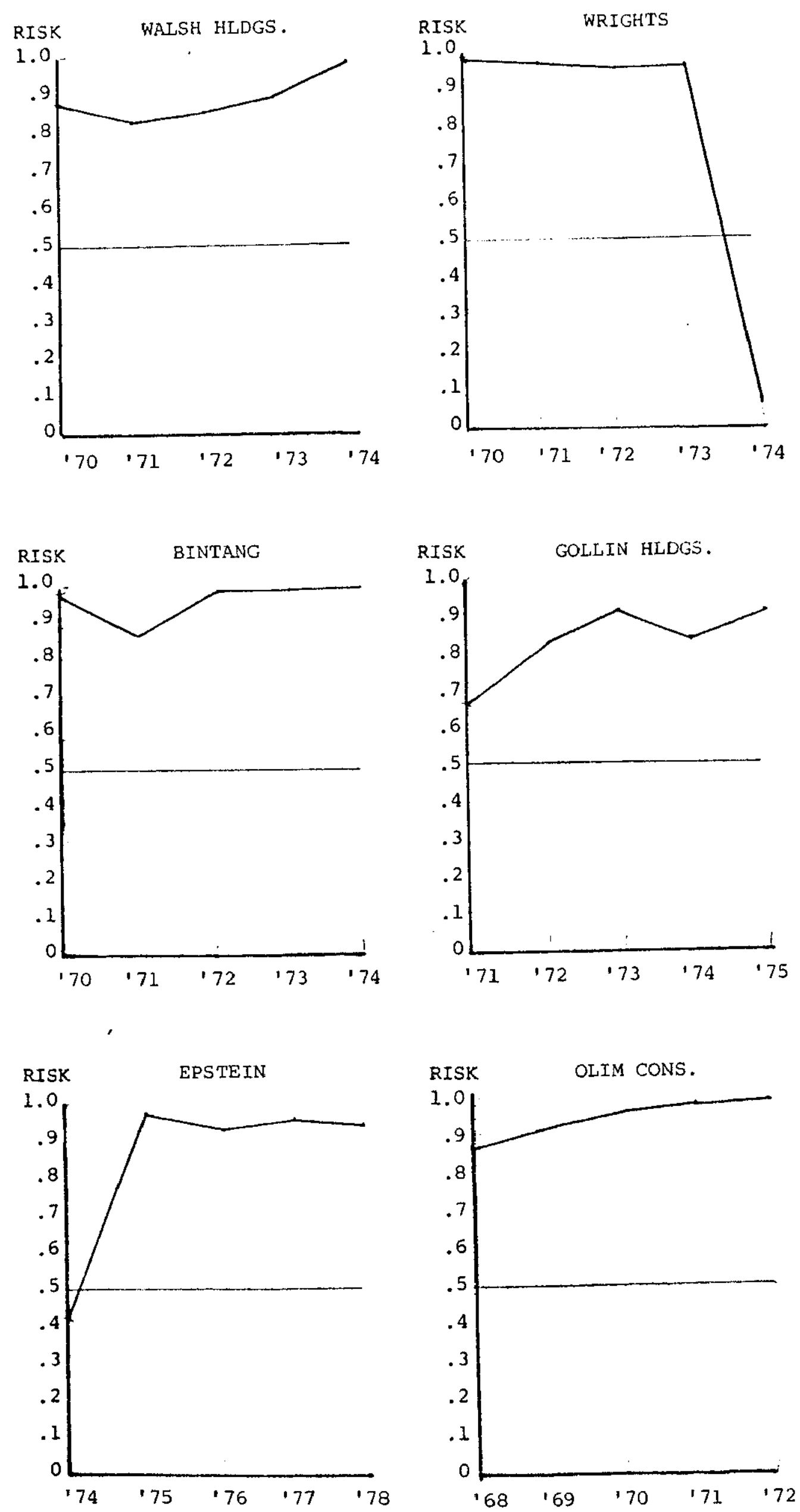

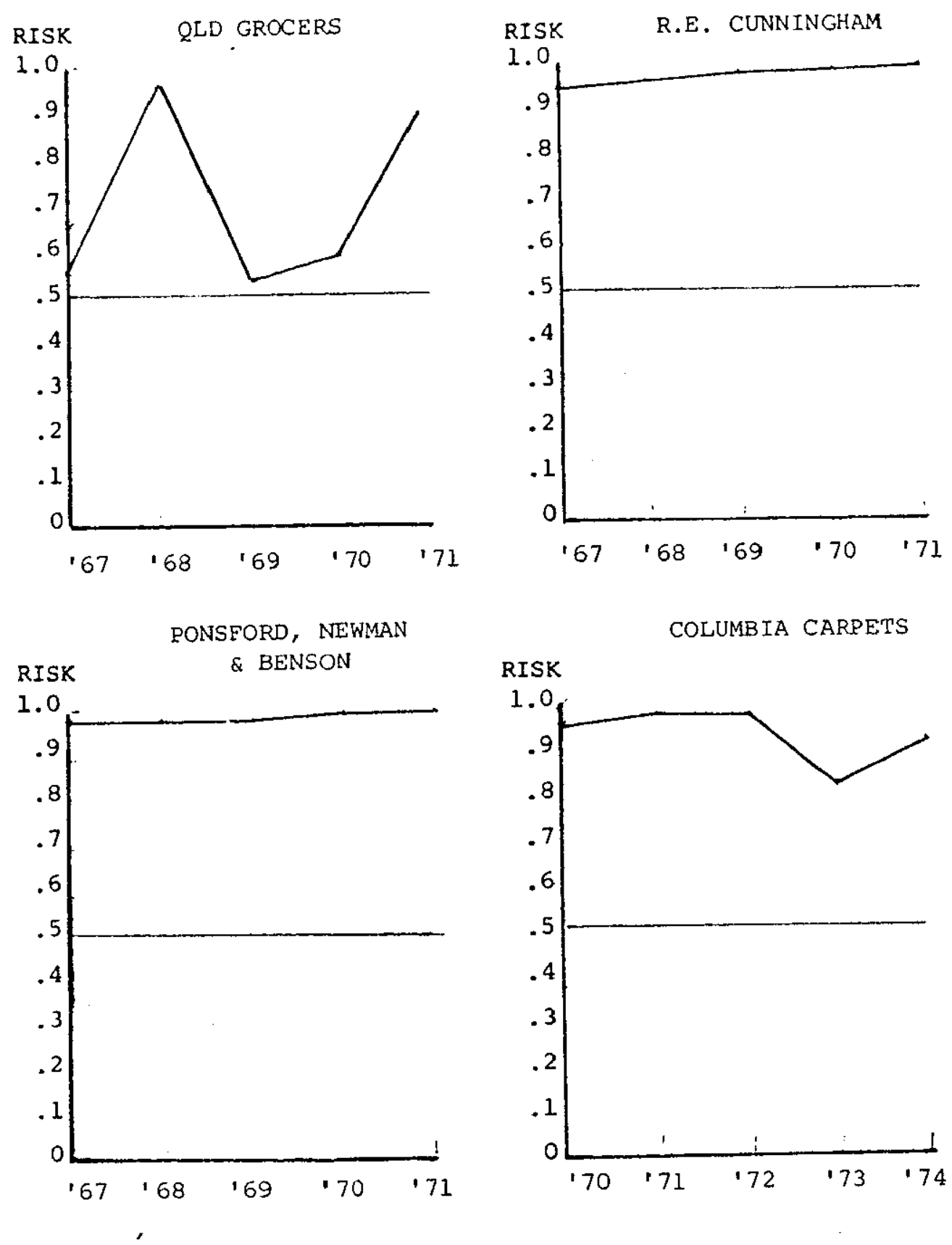
312
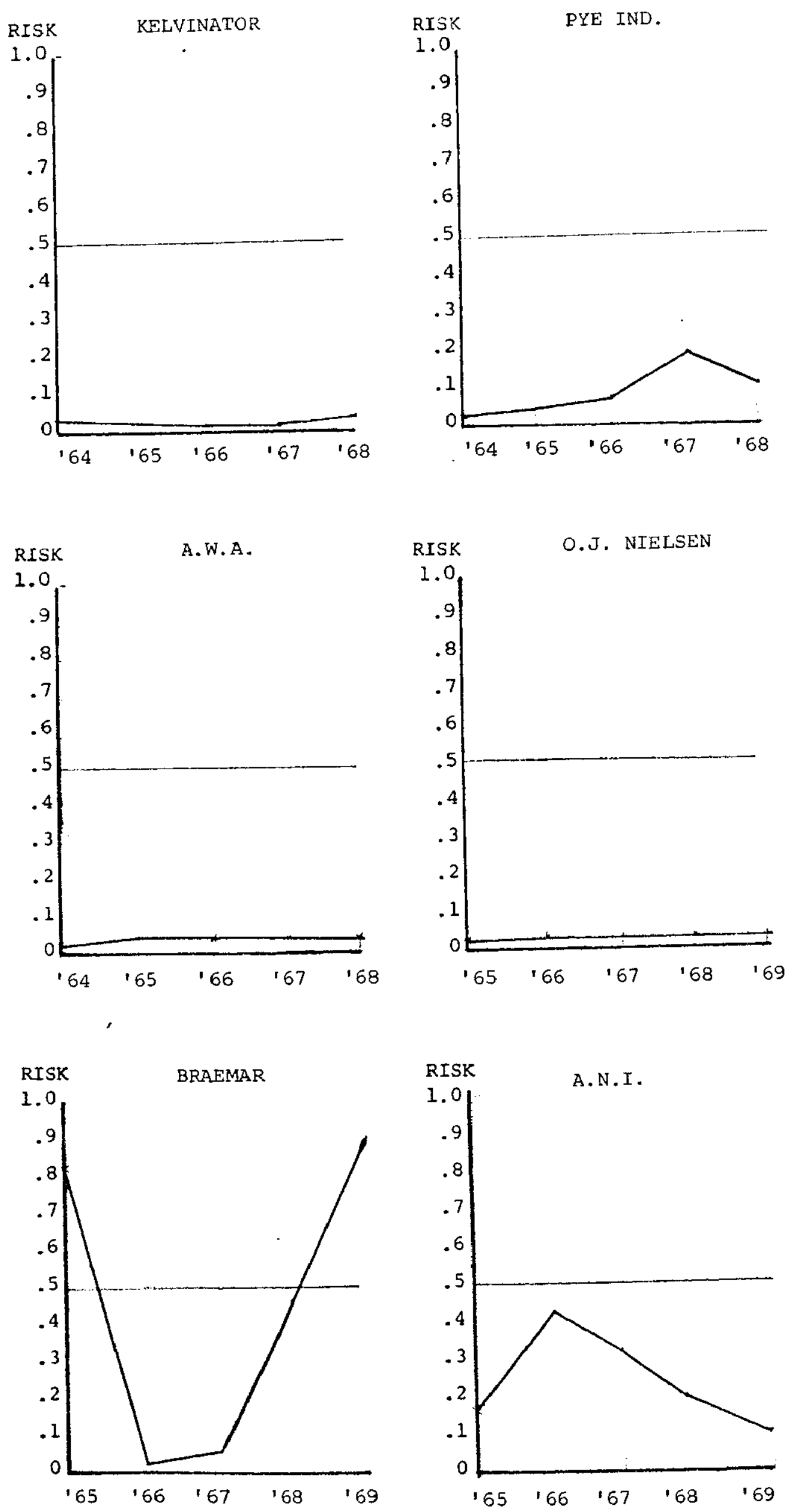

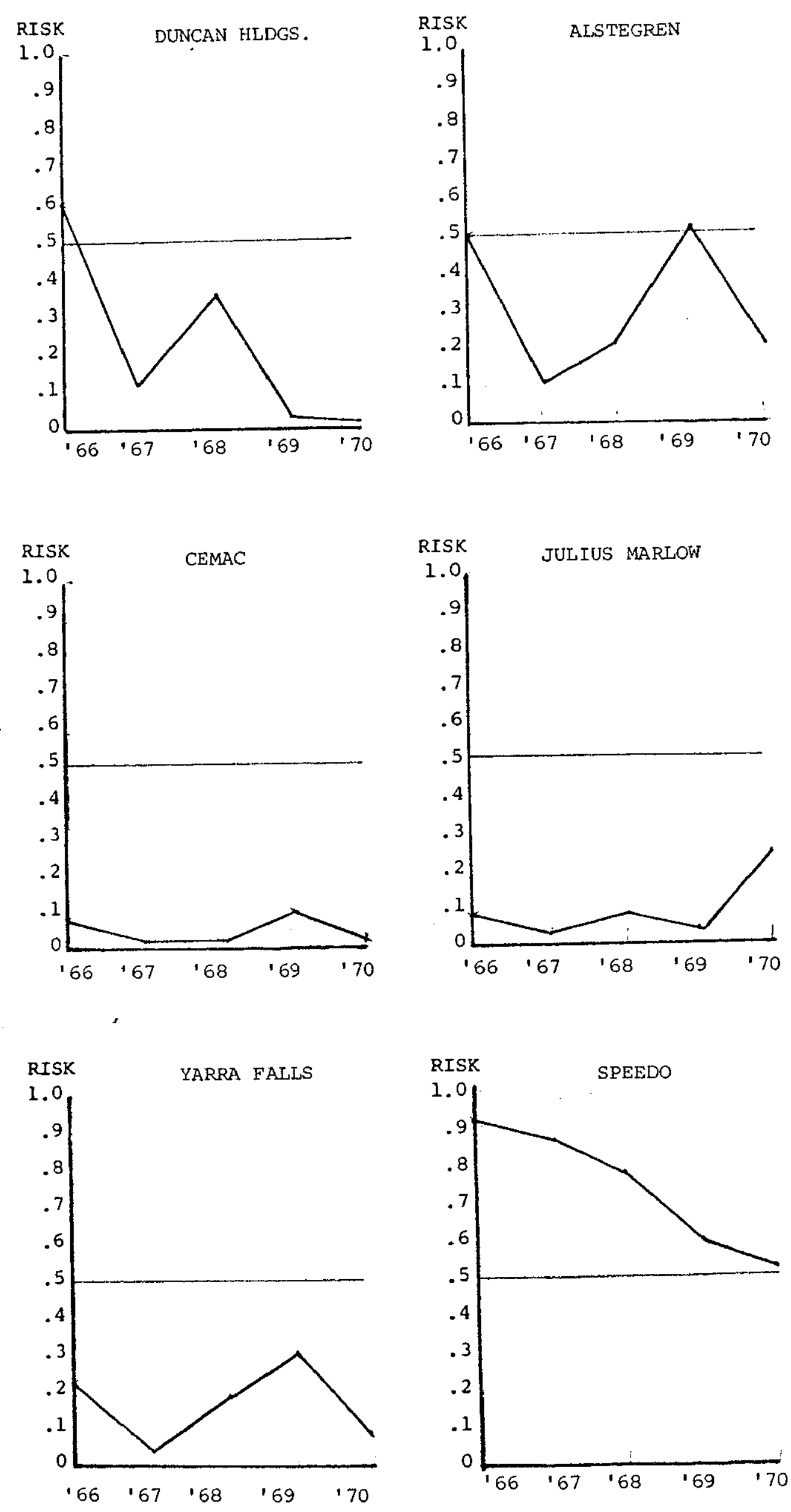

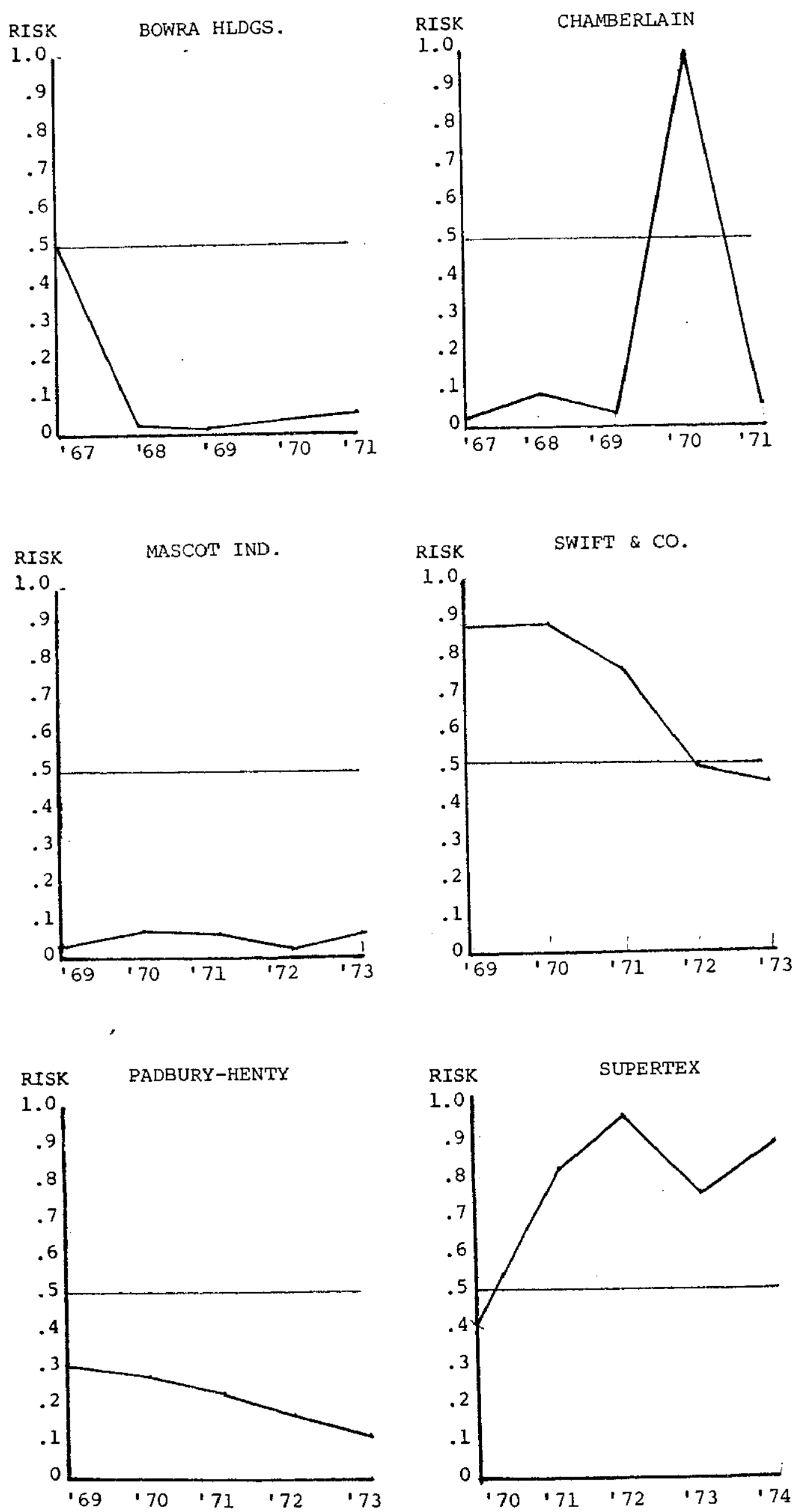
313
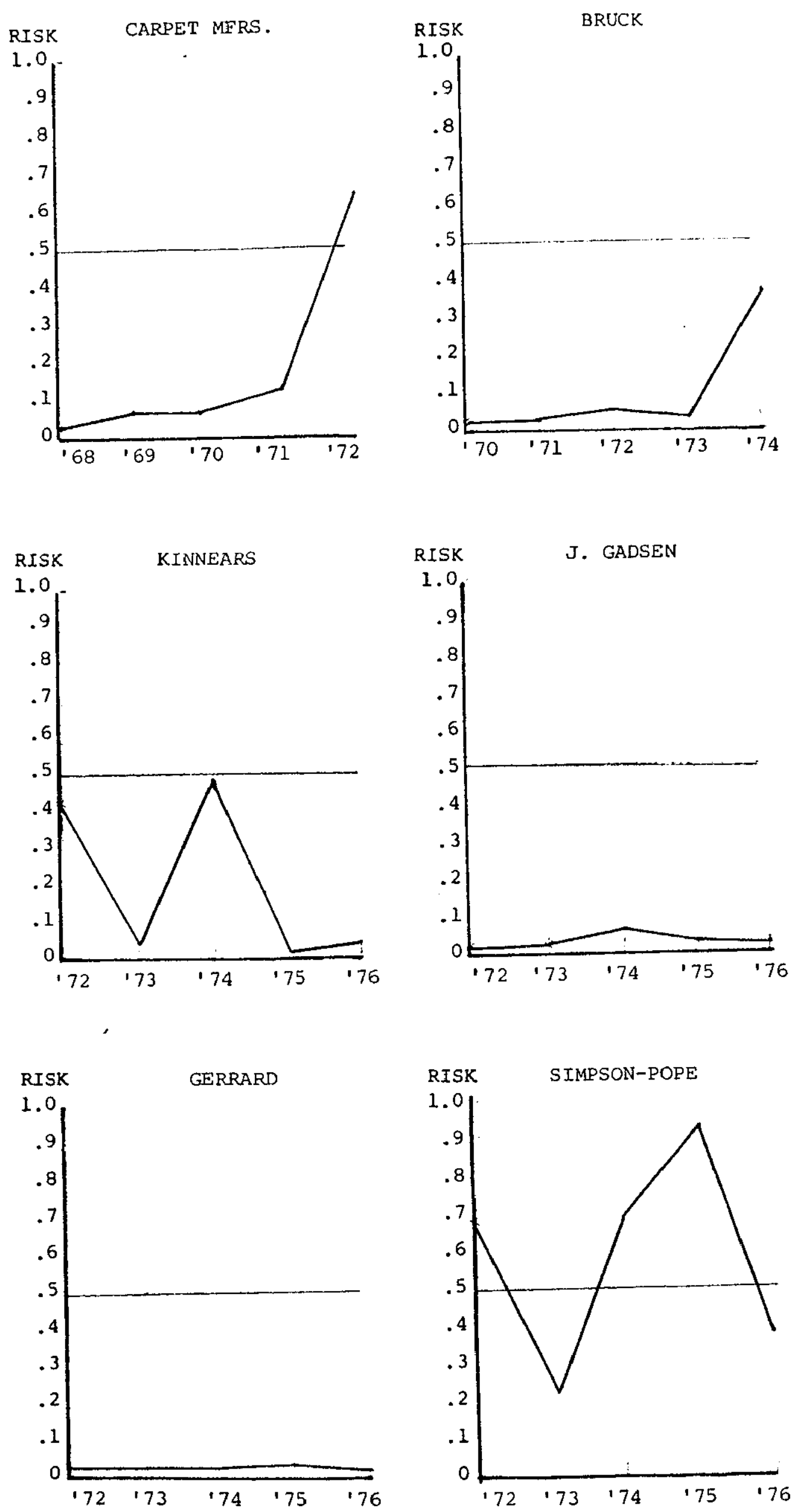

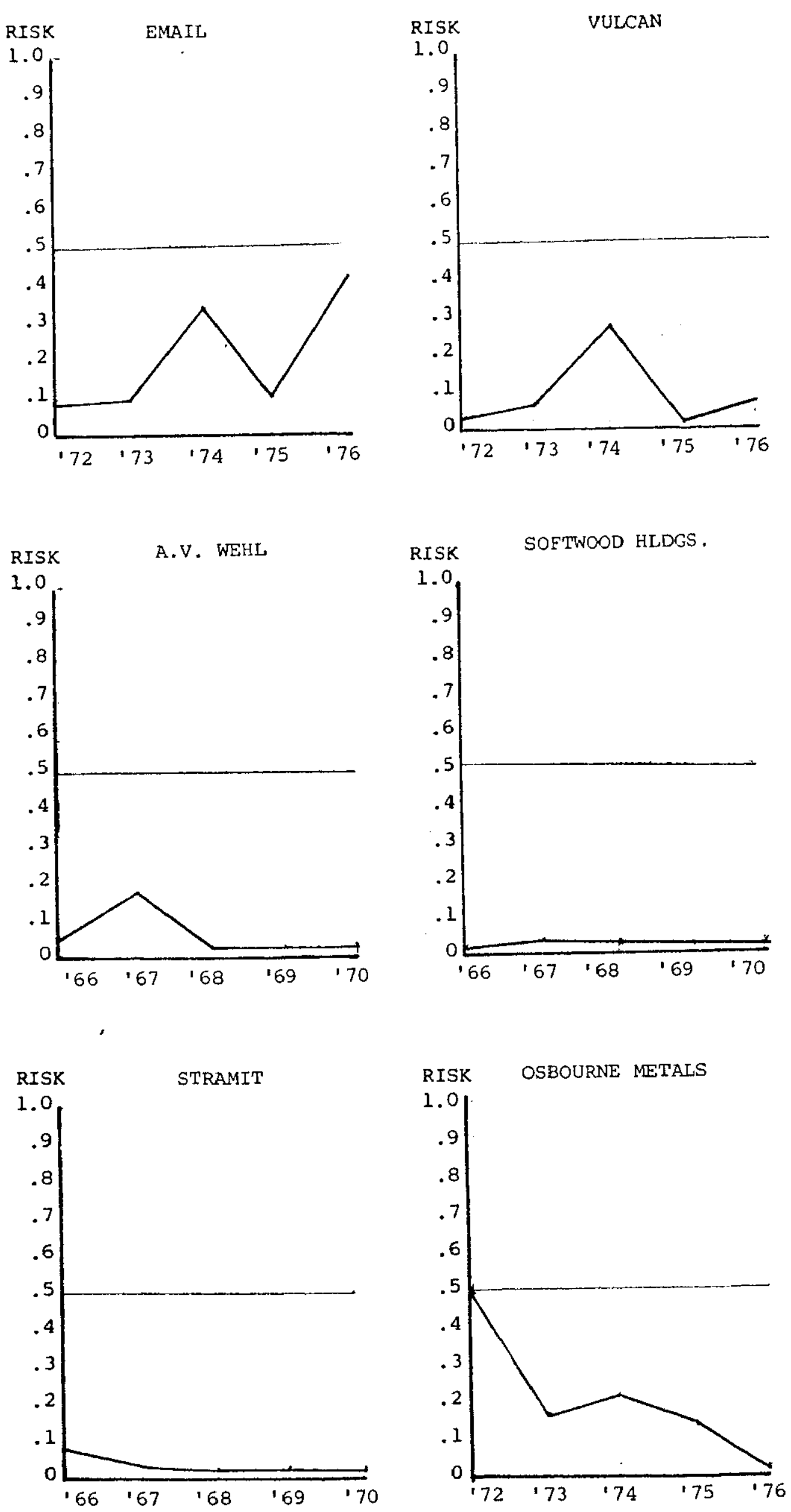
AURI BROS.

317
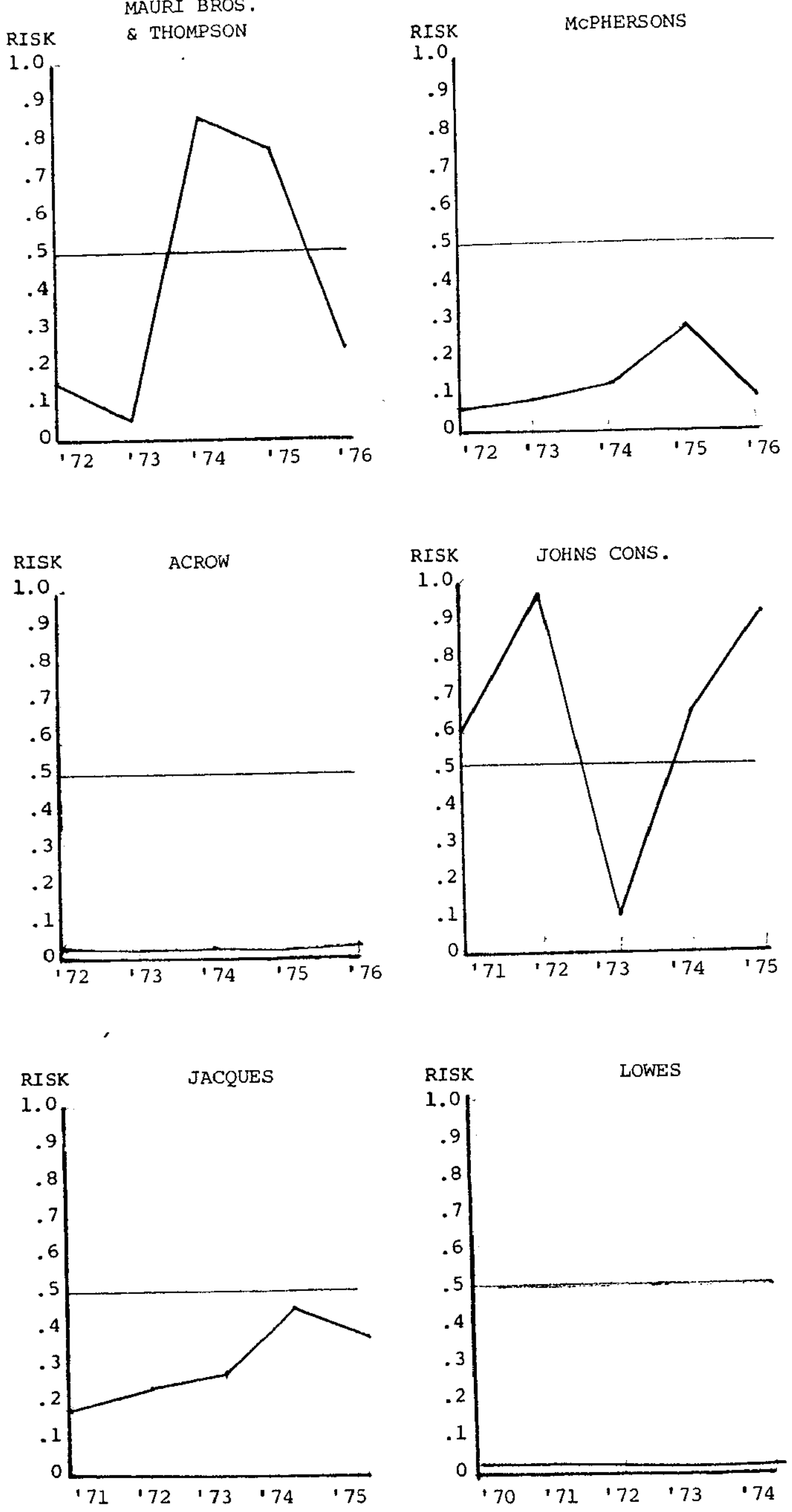

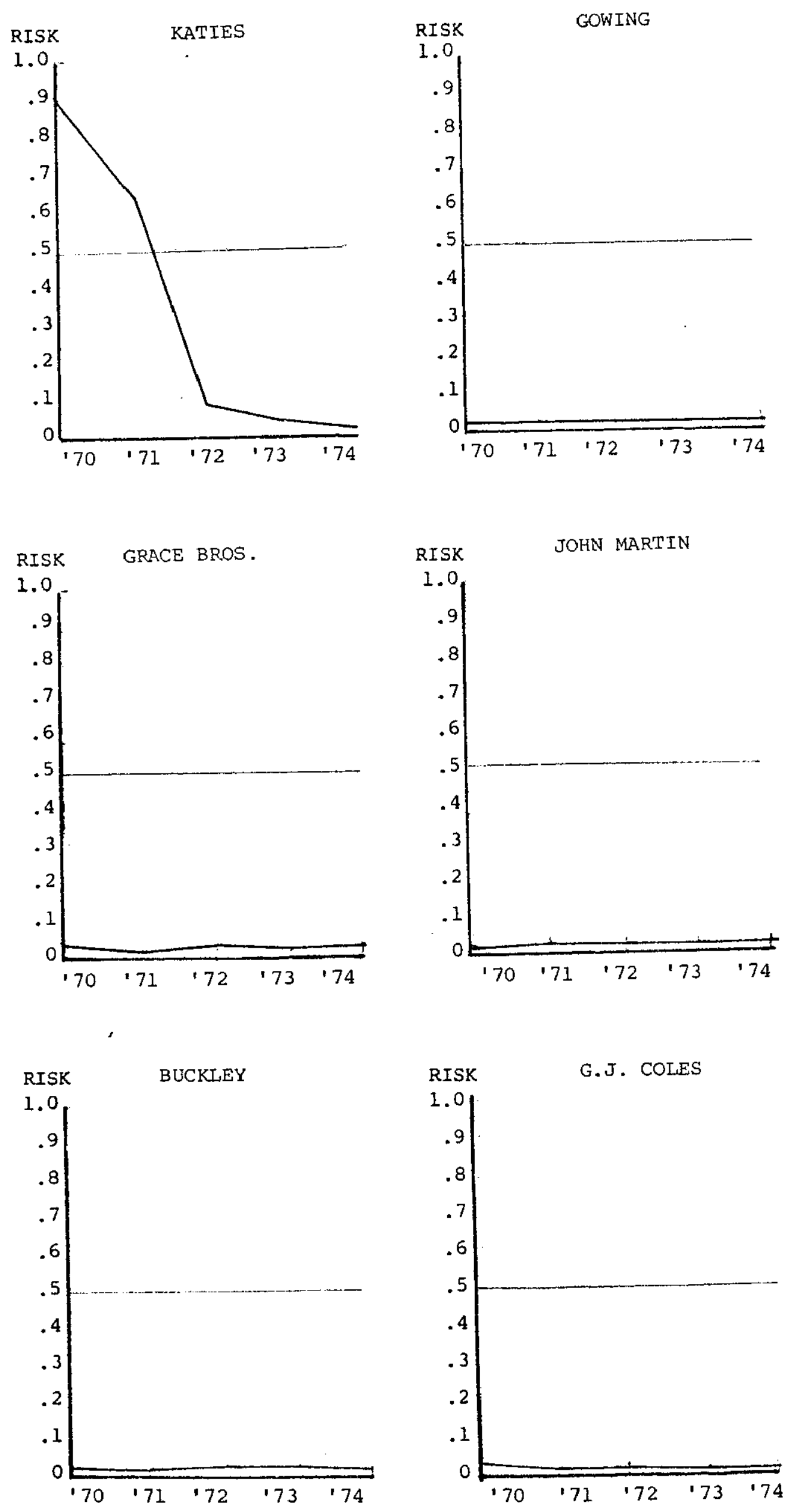

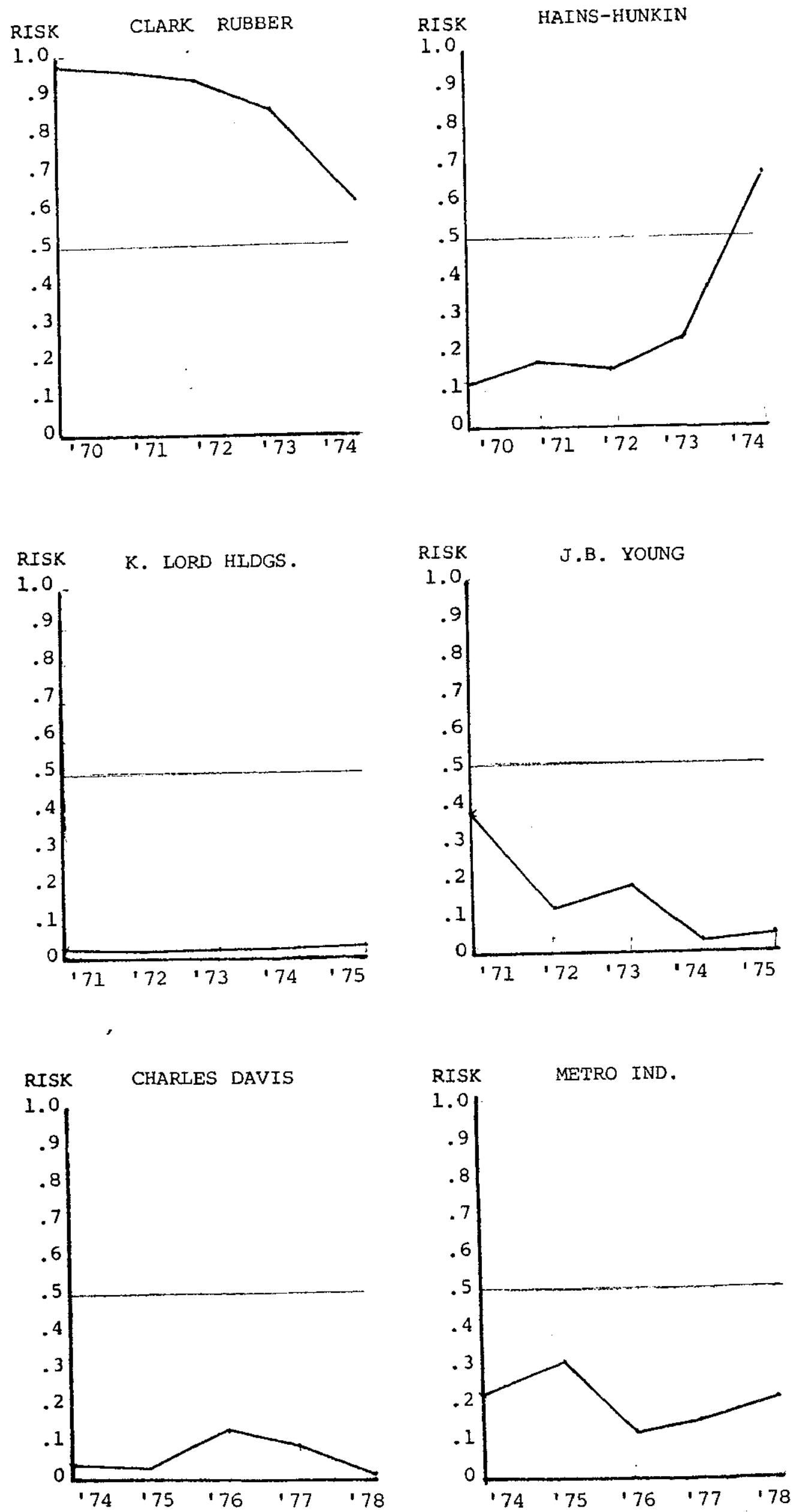

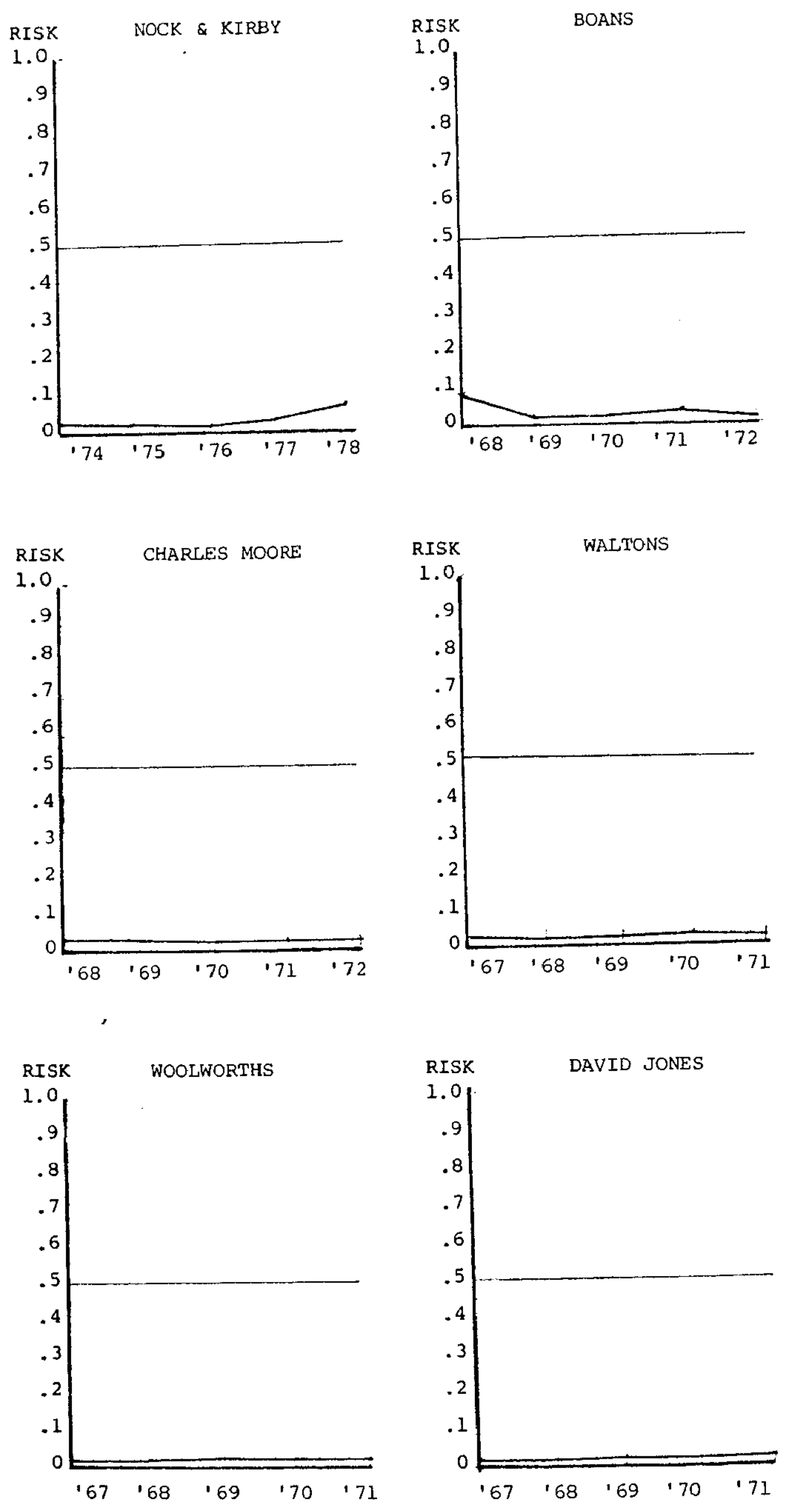
321
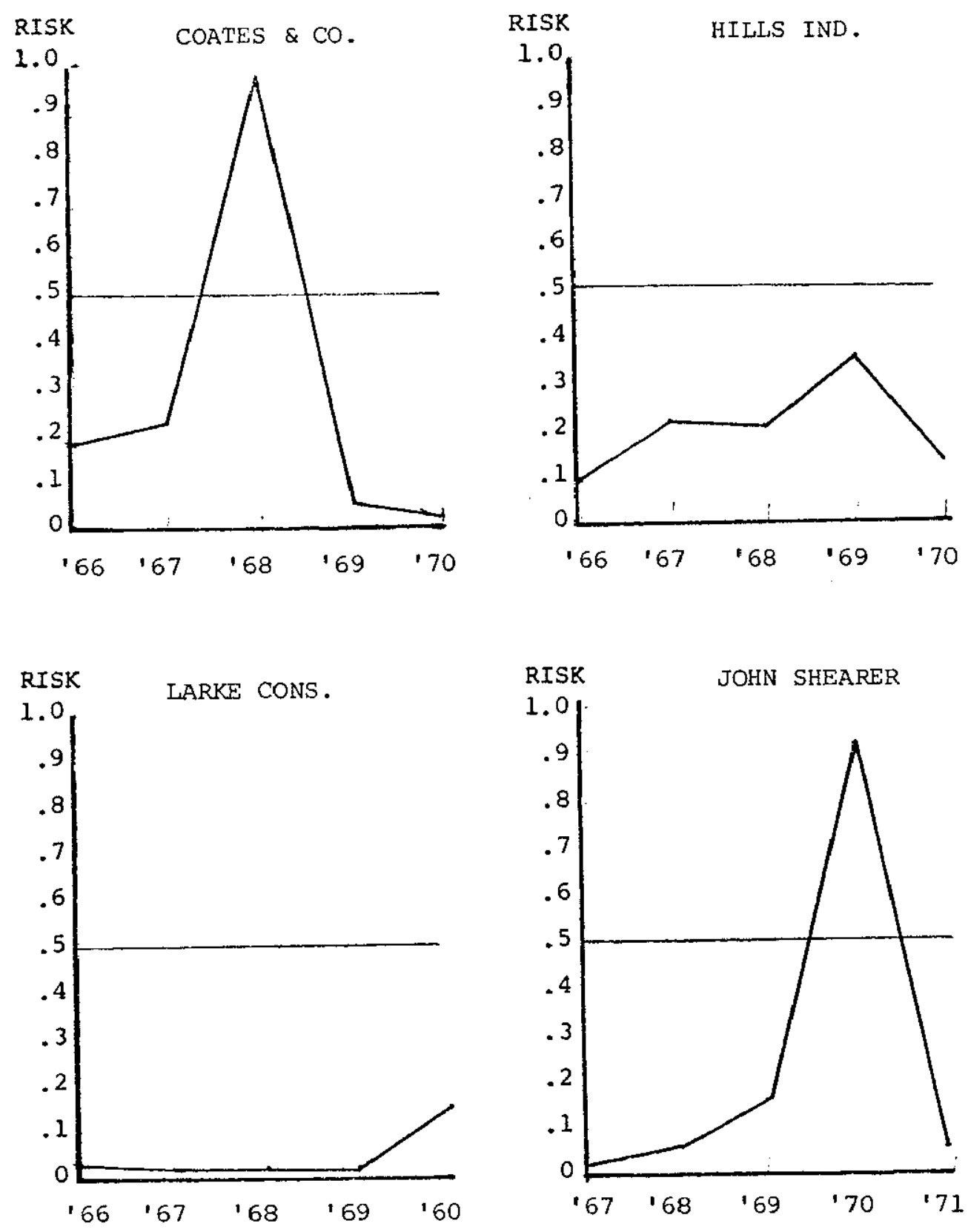

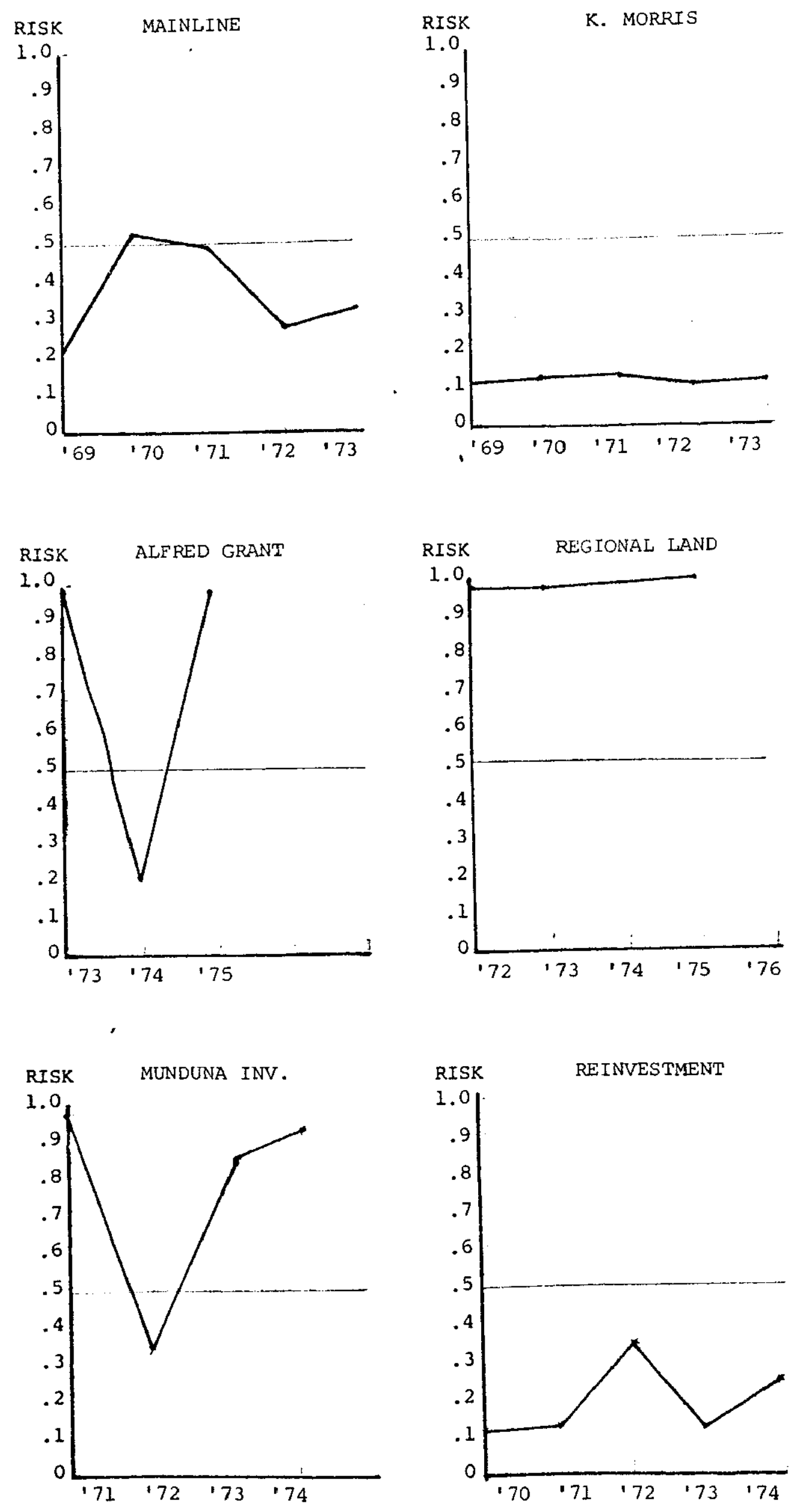

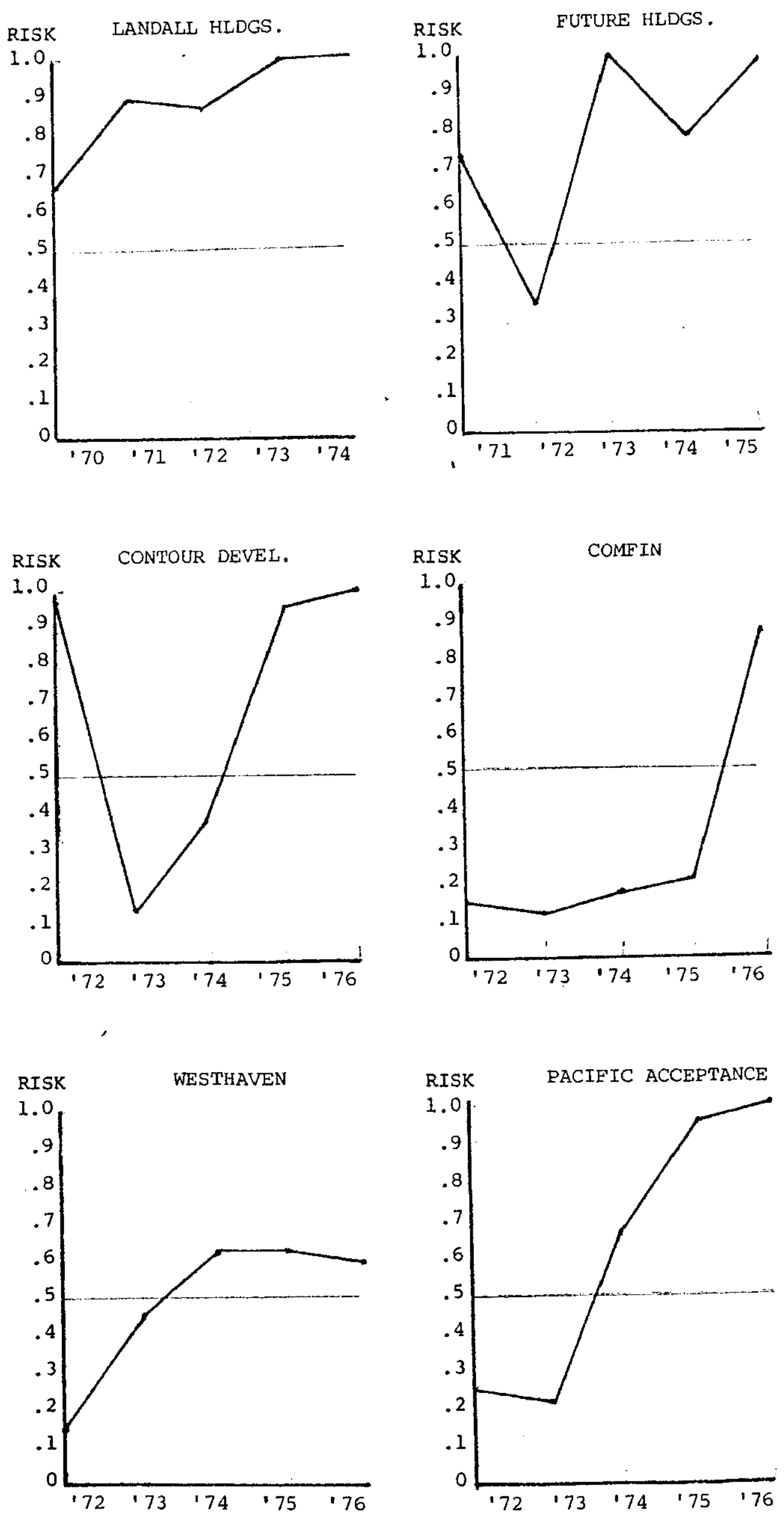

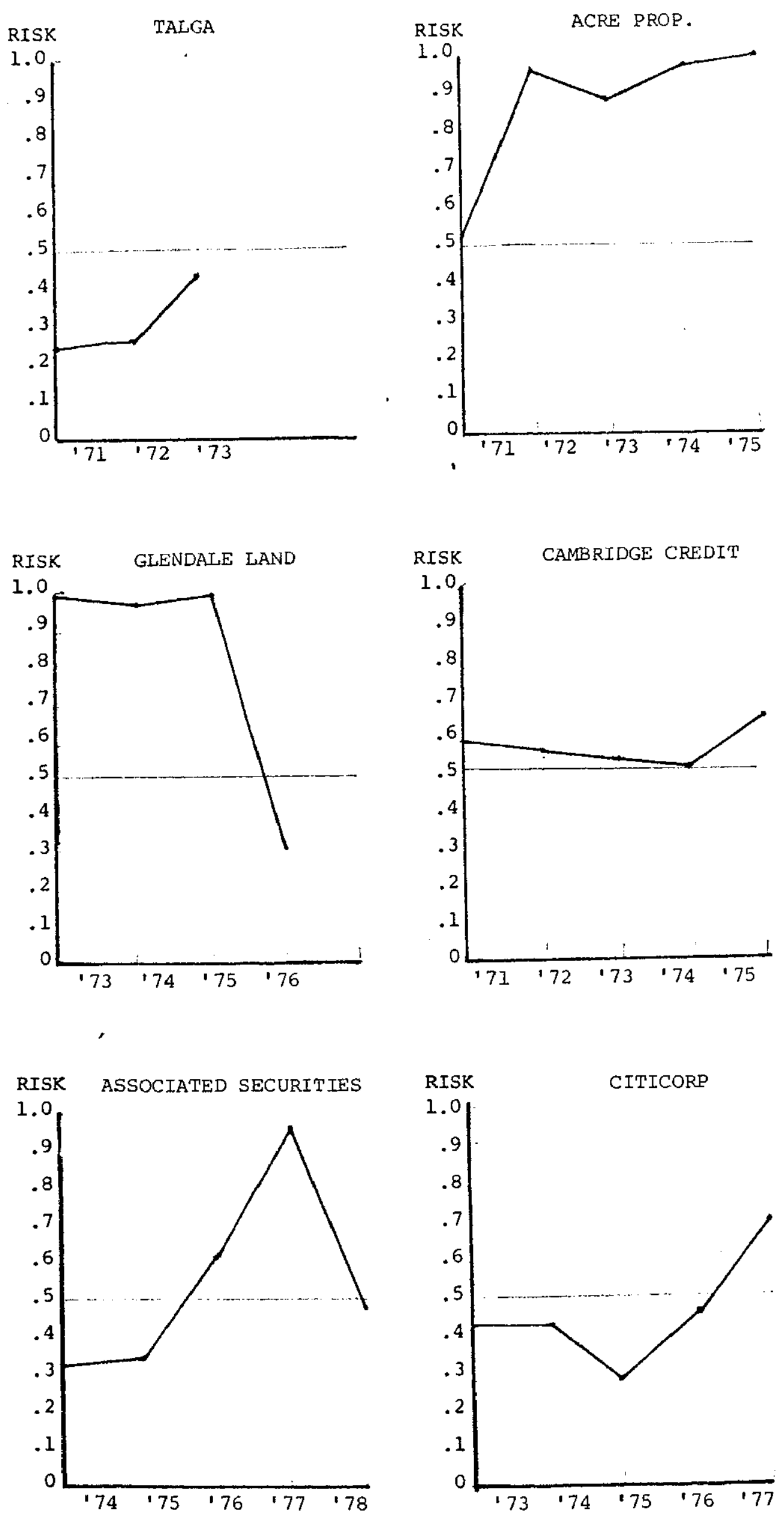


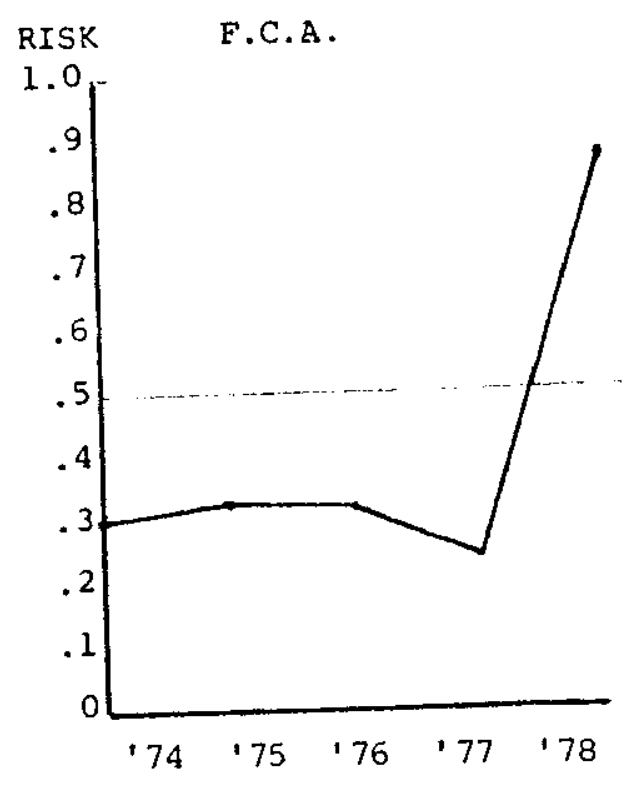



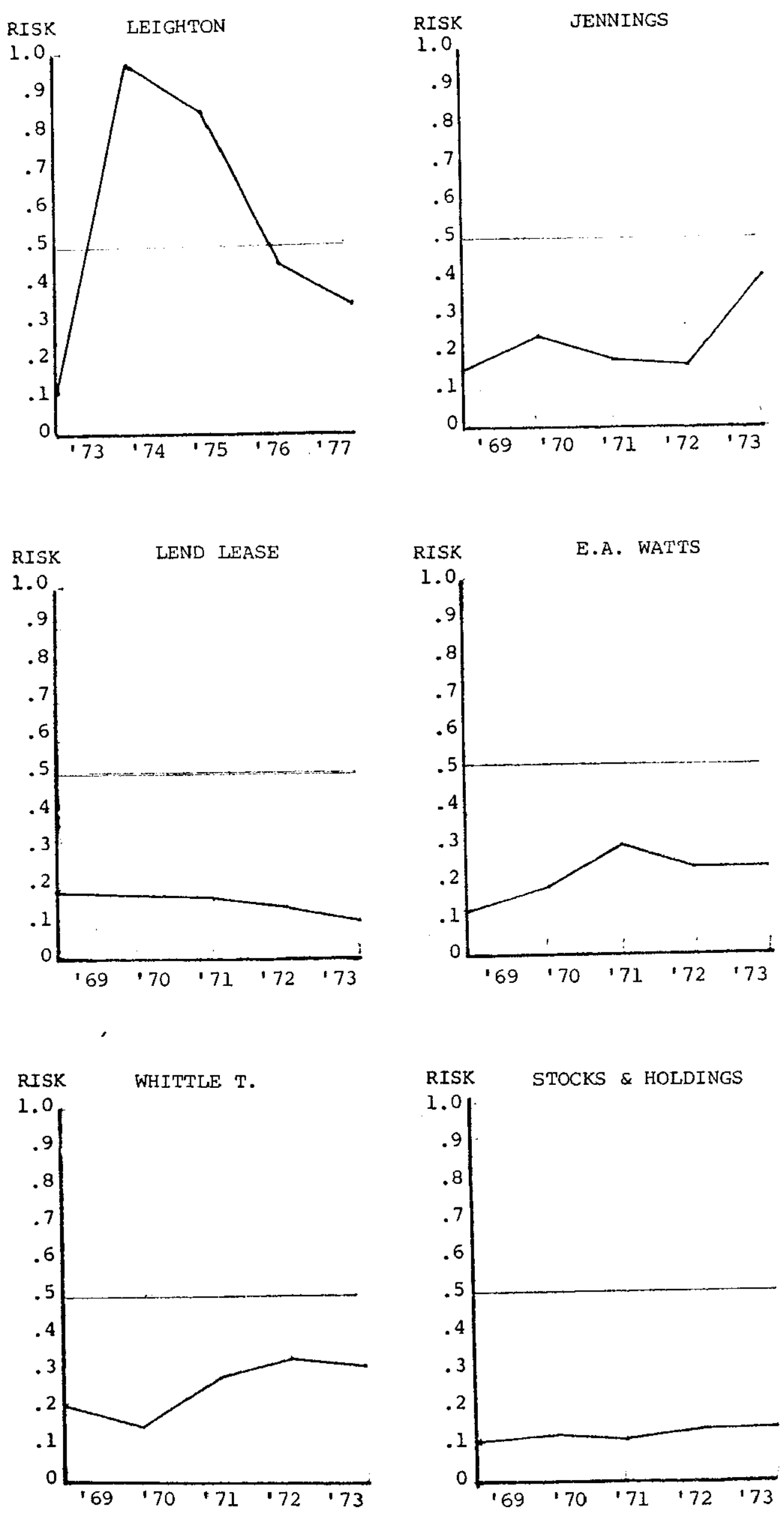

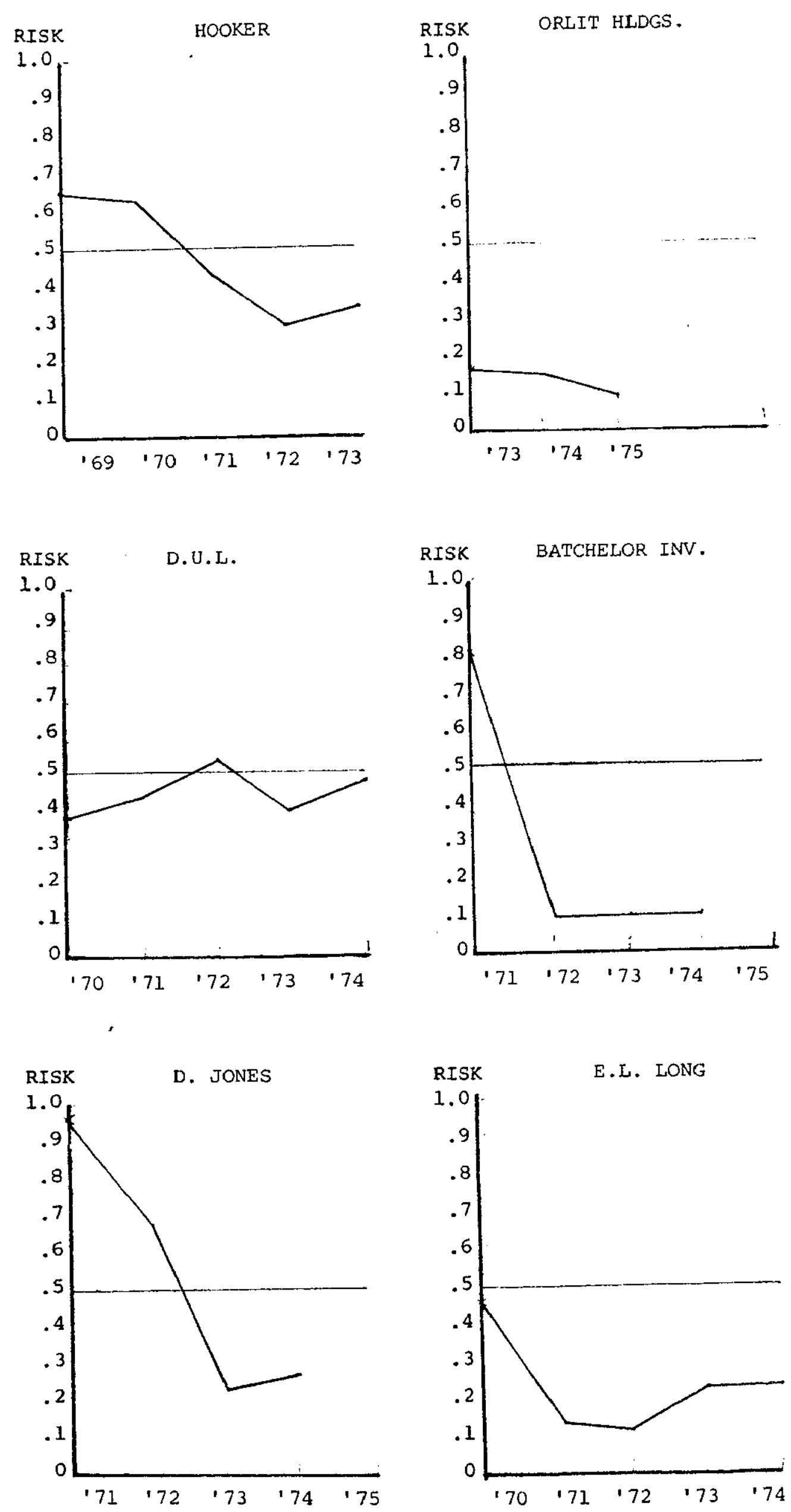

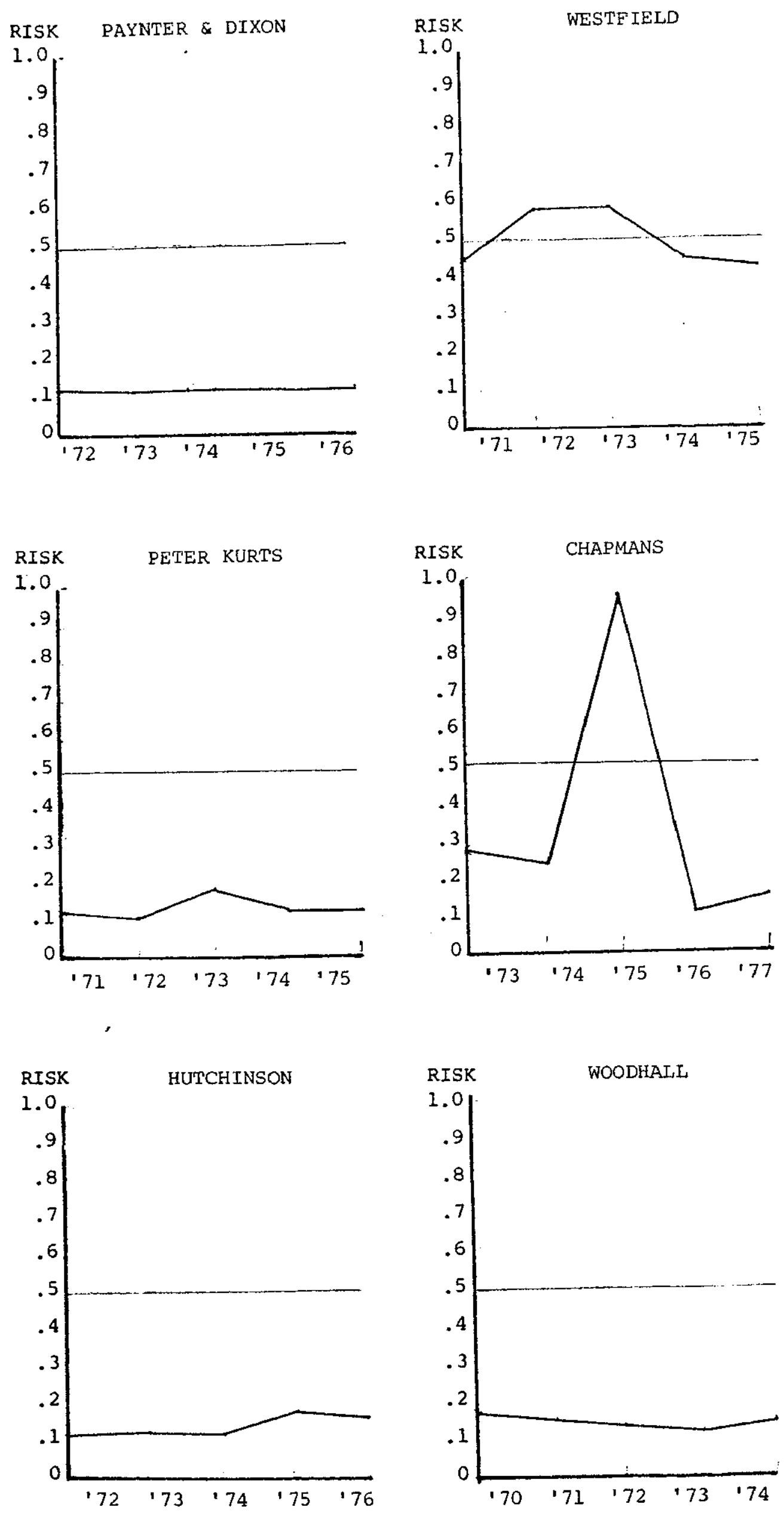

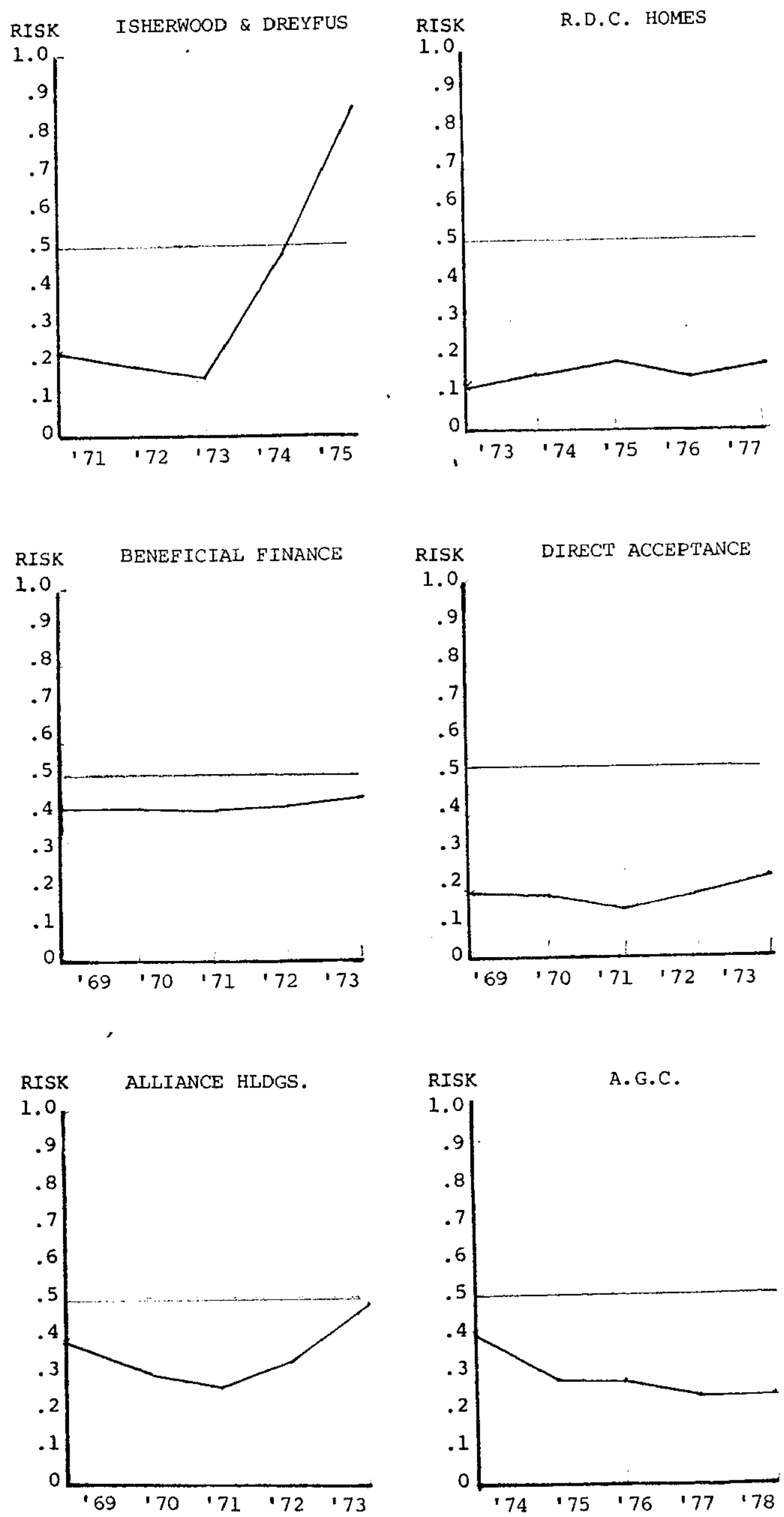

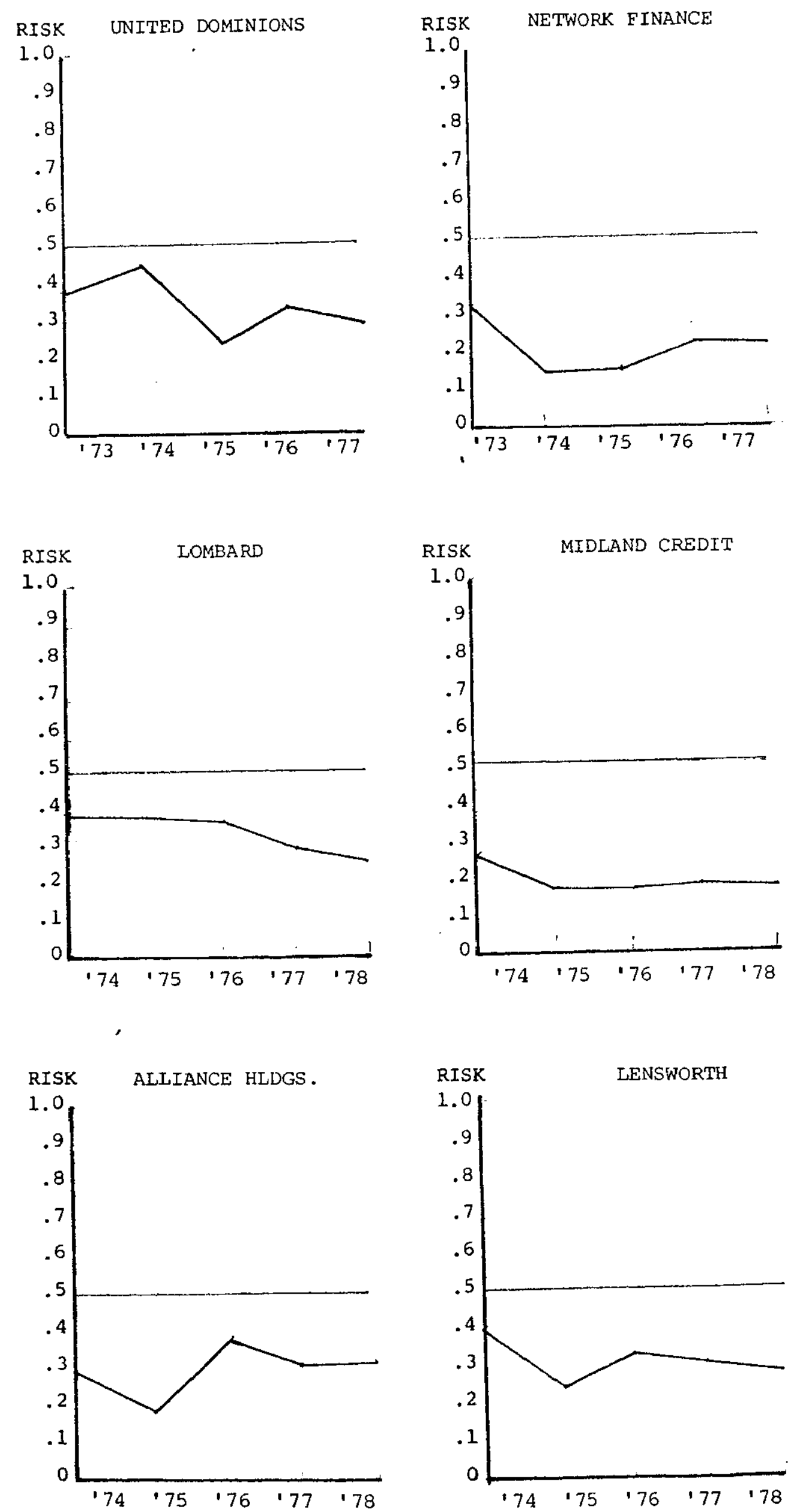

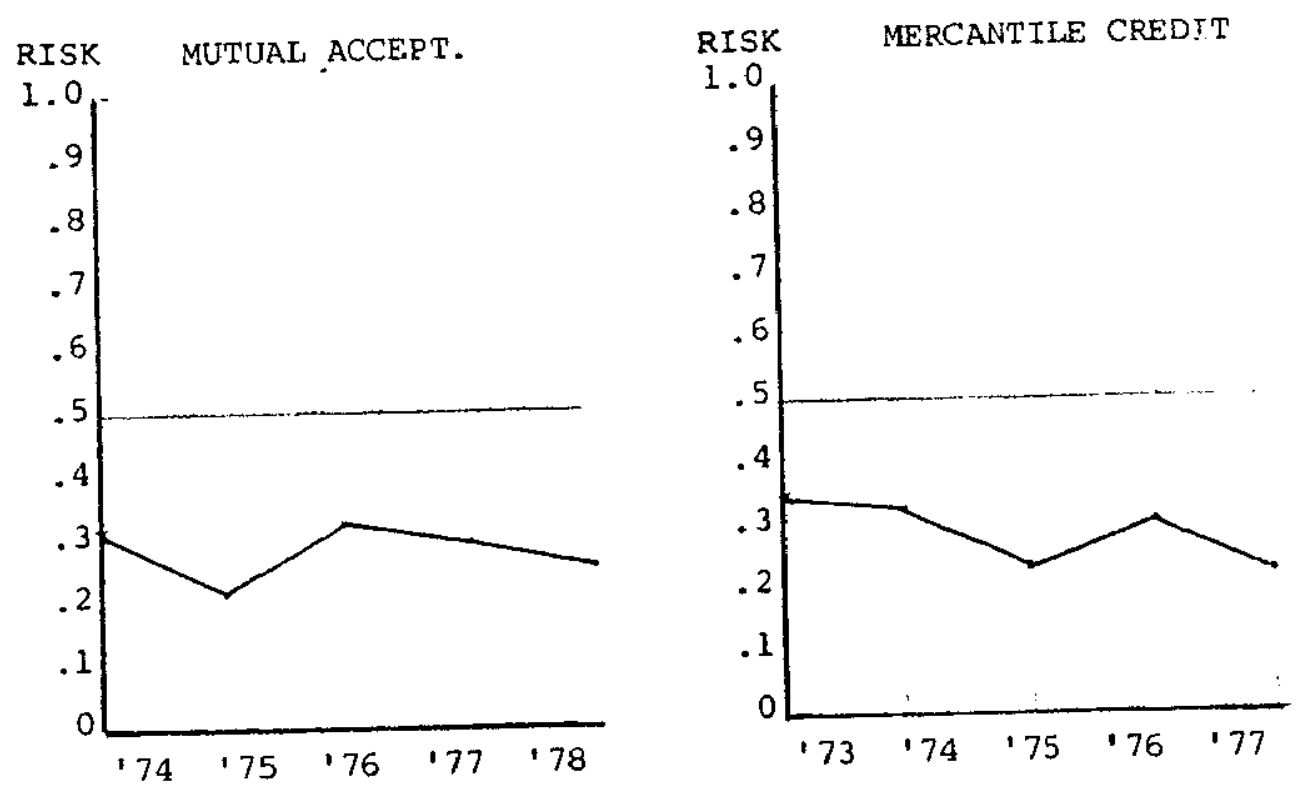


\section{APPENDIX S}

z-Scores, levels of insolvency risk, weighted and unweighted ratios, for selected failed and nonfailed firms 
A. G.C.

\begin{tabular}{|c|c|c|c|c|c|}
\hline & 1974 & 1975 & 1976 & 1977 & 1978 \\
\hline Z-Score & 0.0069 & 0.2518 & 0.2440 & 0.5104 & 0.5570 \\
\hline $\begin{array}{l}\text { Change in } \\
\mathrm{z} \text {-Score }{ }^{1}\end{array}$ & - & +0.2449 & -0.0078 & +0.2664 & +0.0466 \\
\hline Risk & 0.3937 & 0.2960 & 0.2987 & 0.2211 & 0.2103 \\
\hline \multicolumn{6}{|l|}{ Weighted Ratios } \\
\hline $\begin{array}{l}\text { PITTAI } \\
\text { TITAI }\end{array}$ & $\begin{array}{r}1.6696 \\
-2.1056\end{array}$ & $\begin{array}{r}1.9276 \\
-2.1185\end{array}$ & $\begin{array}{r}1.9239 \\
-2.1227\end{array}$ & $\begin{array}{r}2.1534 \\
-2.0858\end{array}$ & $\begin{array}{r}2.2124 \\
-2.0982\end{array}$ \\
\hline \multicolumn{6}{|l|}{$\begin{array}{l}\text { Change in } \\
\text { weighted Ratios }\end{array}$} \\
\hline $\begin{array}{l}\text { PITTAI } \\
\text { TLTAI }\end{array}$ & $\overline{-}$ & $\begin{array}{l}+0.2580 \\
-0.0129\end{array}$ & $\begin{array}{l}-0.0037 \\
-0.0142\end{array}$ & $\begin{array}{l}+0.2295 \\
+0.0369\end{array}$ & $\begin{array}{l}+0.0590 \\
-0.0124\end{array}$ \\
\hline \multicolumn{6}{|l|}{ Unweighted Ratios } \\
\hline $\begin{array}{l}\text { PITTAI } \\
\text { TLTAI }\end{array}$ & $\begin{array}{l}0.0882 \\
0.8770\end{array}$ & $\begin{array}{l}0.1018 \\
0.8825\end{array}$ & $\begin{array}{l}0.1017 \\
0.8842\end{array}$ & $\begin{array}{l}0.1138 \\
0.8688\end{array}$ & $\begin{array}{l}0.1169 \\
0.8740\end{array}$ \\
\hline
\end{tabular}

1. Minus is an increase in insolvency risk. plus is a decrease in insolvency risk. 
CAMBRIDGE CREDIT

\begin{tabular}{|c|c|c|c|c|c|}
\hline & 1969 & 1970 & 1971 & 1972 & 1973 \\
\hline Z-Score & -0.3635 & -0.2695 & -0.2679 & -0.2020 & -0.4265 \\
\hline $\begin{array}{l}\text { Change in } \\
Z \text {-Score }\end{array}$ & - & +0.0940 & +0.0016 & +0.0659 & -0.2245 \\
\hline Risk & 0.5846 & 0.5330 & 0.5321 & 0.5032 & 0.6194 \\
\hline Weighted Ratios & & ' & & & \\
\hline $\begin{array}{l}\text { PITTAI } \\
\text { TLTAI }\end{array}$ & $\begin{array}{r}1.2933 \\
-2.0996\end{array}$ & $\begin{array}{r}1.1756 \\
-1.8878\end{array}$ & $\begin{array}{r}1.4088 \\
-2.1195\end{array}$ & $\begin{array}{r}1.3853 \\
-2.0301\end{array}$ & $\begin{array}{r}1.3608 \\
-2.2301\end{array}$ \\
\hline $\begin{array}{l}\text { Change in } \\
\text { weighted Ratios }\end{array}$ & & & & & \\
\hline $\begin{array}{l}\text { PITTAI } \\
\text { TLTAI }\end{array}$ & $\begin{array}{l}- \\
-\end{array}$ & $\begin{array}{l}-0.1177 \\
+0.2118\end{array}$ & $\begin{array}{l}+0.2332 \\
-0.2317\end{array}$ & $\begin{array}{l}-0.0235 \\
+0.0894\end{array}$ & $\begin{array}{l}-0.0245 \\
-0.2000\end{array}$ \\
\hline Unweighted Ratios & & & & & \\
\hline $\begin{array}{l}\text { PITTAI } \\
\text { TLTAI }\end{array}$ & $\begin{array}{l}0.0683 \\
0.8746\end{array}$ & $\begin{array}{l}0.0621 \\
0.7864\end{array}$ & $\begin{array}{l}0.0744 \\
0.8829\end{array}$ & $\begin{array}{l}0.0732 \\
0.8456\end{array}$ & $\begin{array}{l}0.0719 \\
0.9289\end{array}$ \\
\hline
\end{tabular}

1. Minus is an increase in insolvency risk. plus is a decrease in insolvency risk. 
CHAMBERLAIN

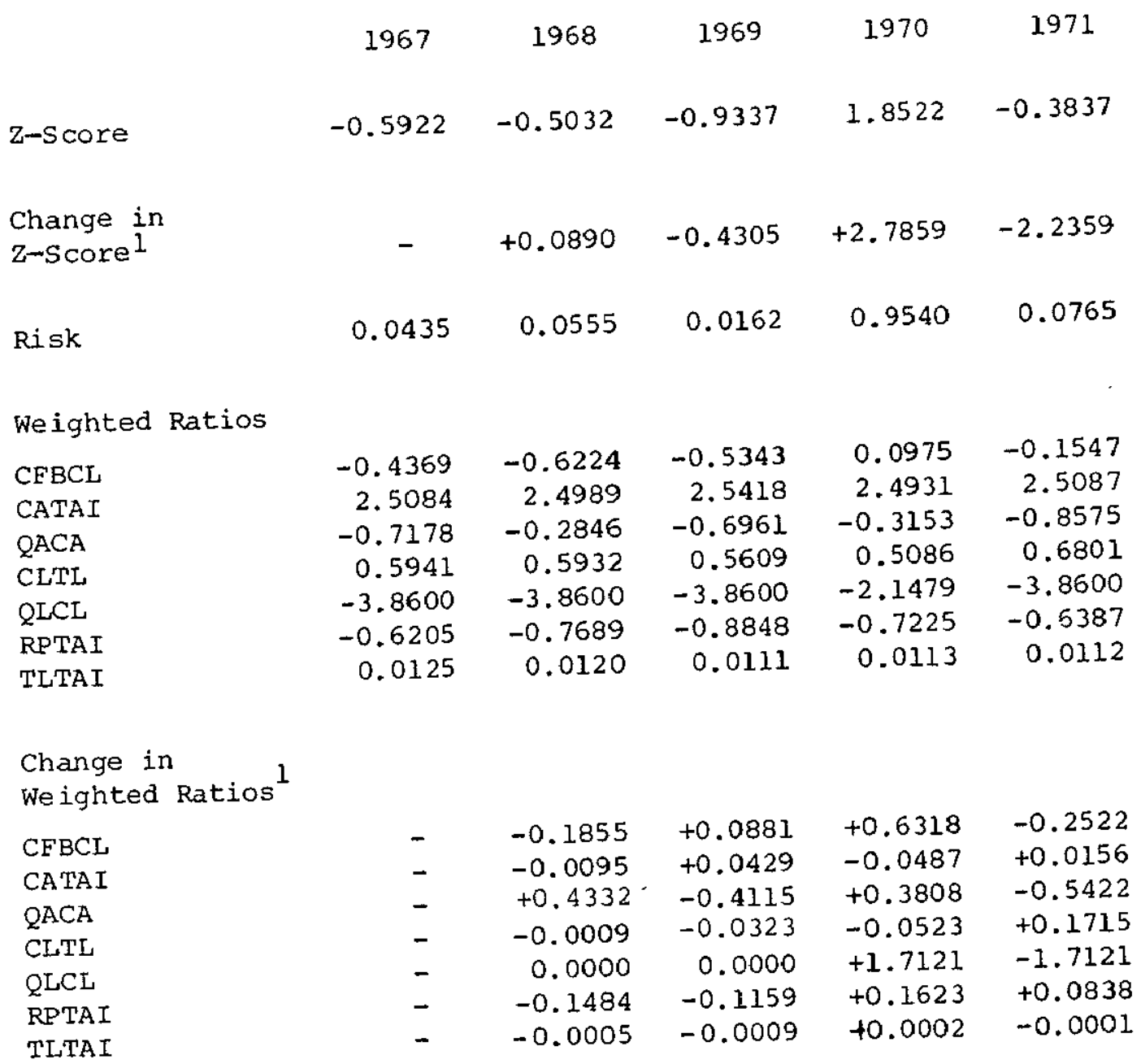

Unweighted Ratios

$\begin{array}{llllrr}\text { CFBCL } & 0.4965 & 0.7072 & 0.6072 & -0.1108 & 0.1758 \\ \text { CATAI } & 0.7229 & 0.7201 & 0.7325 & 0.7185 & 0.7230 \\ \text { QACA } & 0.2930 & 0.1162 & 0.2841 & 0.1287 & 0.3500 \\ \text { CLTL } & 0.4336 & 0.4330 & 0.4094 & 0.3712 & 0.4964 \\ \text { QLCL } & 1.0000 & 1.0000 & 1.0000 & 0.5564 & 1.0000 \\ \text { RPTAI } & 0.1495 & 0.1853 & 0.2132 & 0.1741 & 0.1539 \\ \text { TLTAI } & 0.6266 & 0.6018 & 0.5572 & 0.5648 & 0.5622\end{array}$

1. Minus is a decrease in insolvency risk. plus is an increase in insolvency risk. 
CLARK RUBBER

$\begin{array}{lrrrrr} & 1970 & 1971 & 1972 & 1973 & 1974 \\ & & & & & \\ \text { Z-Score } & 2.0875 & 2.0178 & 1.7277 & 1.1418 & 0.7162 \\ & & & & & \\ \text { Change in } & & & & & \\ \text { Z-Score } & & -0.0697 & -0.2901 & -0.5859 & -0.4256 \\ & & & & & \\ \text { Risk } & 0.9712 & 0.9669 & 0.9410 & 0.8112 & 0.6068 \\ & & & & & \\ \text { Weighted Ratios } & & & & & \\ \text { CFBCL } & -0.2486 & -0.2170 & -0.2586 & -0.3793 & -0.3726 \\ \text { CATAI } & 3.0215 & 3.1223 & 3.0361 & 2.9222 & 2.9340 \\ \text { QACA } & -0.2873 & -0.5205 & -0.3303 & -0.3692 & -0.4649 \\ \text { CLTL } & 1.3344 & 1.3240 & 1.3433 & 1.2109 & 1.1954 \\ \text { QLCL } & -3.0871 & -3.0104 & -3.1990 & -3.2727 & -3.6614 \\ \text { RPTAI } & -0.5849 & -0.6219 & -0.8030 & -0.9081 & -0.8557 \\ \text { TLTAI } & 0.0124 & 0.0143 & 0.0124 & 0.0111 & 0.0138\end{array}$

Change in

weighted Ratios ${ }^{1}$

CFBCL

CATAI

QACA

CLTL

QLCL

RPTAI

TLTAI

$\begin{array}{lllll}- & +0.0316 & -0.0416 & -0.1207 & +0.0067 \\ - & +0.1008 & -0.0862 & -0.1139 & +0.0118 \\ - & -0.2332 & +0.1902 & -0.0389 & -0.0957 \\ - & -0.0104 & +0.0193 & -0.1324 & -0.0155 \\ - & +0.0767 & -0.1886 & -0.0737 & -0.3887 \\ - & -0.0370 & -0.1811 & -0.1051 & +0.0524 \\ - & +0.0019 & -0.0019 & -0.0013 & +0.0027\end{array}$

Unweighted Ratios

$\begin{array}{llllll}\text { CFBCL } & 0.2825 & 0.2466 & 0.2939 & 0.4311 & 0.4234 \\ \text { CATAI } & 0.8707 & 0.8998 & 0.8750 & 0.8421 & 0.8455 \\ \text { QACA } & 0.1173 & 0.2125 & 0.1348 & 0.1507 & 0.1898 \\ \text { CLTL } & 0.9740 & 0.9664 & 0.9805 & 0.8838 & 0.8726 \\ \text { QLCL } & 0.7798 & 0.7799 & 0.8288 & 0.8478 & 0.9485 \\ \text { RPTAI } & 0.1409 & 0.1499 & 0.1935 & 0.2188 & 0.2062 \\ \text { TLTAI } & 0.6222 & 0.7128 & 0.6184 & 0.5555 & 0.6903\end{array}$

1. Minus is a decrease in insolvency risk. plus is an increase in insolvency risk. 
COATES AND CO.

$\begin{array}{lccccc} & 1966 & 1967 & 1968 & 1969 & 1970 \\ & & & & & \\ \text { z-Score } & -0.0336 & +0.1157 & +1.8057 & -0.5733 & -1.4089 \\ \begin{array}{l}\text { Change in } \\ \text { z-Score }\end{array} & - & +0.1493 & +1.6900 & -2.3790 & -0.8356 \\ \text { Risk } & 0.18 & 0.25 & 0.95 & 0.05 & 0.01\end{array}$

Weighted Ratios

$\begin{array}{lrrrrr} & & & & \\ \text { CFBCL } & -0.4829 & -0.3946 & -0.2683 & -0.3833 & -0.5872 \\ \text { CATAI } & 2.6899 & 2.6969 & 2.8331 & 1.4465 & 1.5935 \\ \text { QACA } & -1.0125 & -0.8457 & -0.8218 & -1.2413 & -1.1555 \\ \text { CLTL } & -1.3192 & 1.2096 & 1.3494 & 1.3478 & 0.9908 \\ \text { QLCL } & -3.8600 & -3.8600 & -2.6071 & -3.0454 & -3.5659 \\ \text { RPTAI } & -0.6172 & -0.6215 & -0.6115 & -0.6297 & -0.6198 \\ \text { TLTAI } & 0.0049 & 0.0056 & 0.0068 & 0.0073 & 0.0090\end{array}$

Change in
Weighted Ratios

$\begin{array}{llcccc}\text { CFBCL } & - & +0.0883 & +0.1263 & -0.1150 & -0.2039 \\ \text { CATAI } & - & +0.0070 & +0.1362 & -1.3866 & +0.1470 \\ \text { QACA } & - & +0.1668 & +0.0239 & -0.4195 & +0.0858 \\ \text { CLTL } & - & -0.1096 & +0.1398 & -0.0016 & -0.3570 \\ \text { QLCL } & - & 0 & +1.2529 & -0.4383 & -0.5205 \\ \text { RPTAI } & - & -0.0043 & +0.0100 & -0.0182 & +0.0099 \\ \text { TLTAI } & - & +0.0007 & +0.0012 & +0.0005 & +0.0017\end{array}$

Unweighted Ratios

$\begin{array}{llllll}\text { CFBCI } & 0.5486 & 0.4484 & 0.3049 & 0.4356 & 0.6673 \\ \text { CATAI } & 0.7752 & 0.7772 & 0.8165 & 0.4169 & 0.4592 \\ \text { QACA } & 0.4133 & 0.3452 & 0.3354 & 0.5066 & 0.4717 \\ \text { CLTL } & 0.9629 & 0.8829 & 0.9849 & 0.9838 & 0.7232 \\ \text { QLCL } & 1.0000 & 1.0000 & 0.6754 & 0.7890 & 0.9238 \\ \text { RPTAI } & 0.1487 & 0.1498 & 0.1473 & 0.1517 & 0.1494 \\ \text { TLTAI } & 0.2447 & 0.2808 & 0.3397 & 0.3629 & 0.4518\end{array}$

1. Minus is a decrease in insolvency risk. plus is an increase in insolvency risk. 
G.J . COLES

$\begin{array}{lrrrrr} & 1970 & 1971 & 1972 & 1973 & 1974 \\ & & & & & \\ \text { Z-Score } & -1.0678 & -1.2151 & -1.6619 & -1.5735 & -0.8879 \\ & & & & & \\ \text { Change in } & & & & & \\ \text { Z-Score1 } & - & -0.1473 & -0.4468 & +0.0884 & +0.6856 \\ & & & & & \\ \text { Risk } & 0.0108 & 0.0069 & 0.0017 & 0.0022 & 0.0186 \\ & & & & & \\ \text { Weighted Ratios } & & & & & \\ \text { CFBCL } & -0.3903 & -0.3849 & -0.4056 & -0.4915 & -0.3392 \\ \text { CATAI } & 0.7754 & 0.8348 & 0.9274 & 1.1847 & 1.2345 \\ \text { QACA } & -0.3144 & -0.6584 & -0.7090 & -0.8227 & -0.4081 \\ \text { CLTL } & 0.8701 & 0.8373 & 0.8858 & 0.9173 & 1.0450 \\ \text { QLCL } & -3.2424 & -3.2280 & -3.6873 & -3.7254 & -3.7155 \\ \text { RPTAI } & -0.7025 & -0.5521 & -0.6094 & -0.6445 & -0.6421 \\ \text { TLTAI } & 0.0092 & 0.0096 & 0.0095 & 0.0099 & 0.0106\end{array}$

Change in

Weighted Ratios ${ }^{1}$

CFBCL
CATAI
QACA
CLTL
QLCL
RPTAI

$\begin{array}{lll}- & +0.0054 & -0.0207 \\ - & +0.0594 & +0.0926 \\ - & -0.3440 & -0.0506 \\ - & -0.0328 & +0.0485 \\ - & +0.0144 & -0.4593 \\ - & +0.1504 & -0.0573 \\ - & +0.0004 & -0.0001\end{array}$

$-0.0859$

$+0.1523$

$+0.2573+0.0498$

$-0.1137+0.4146$

$+0.0315+0.1277$

$-0.0381+0.0099$

$-0.0351+0.0024$

TLTA I

Unweighted Ratios

$\begin{array}{llllll}\text { CFBCL } & 0.4435 & 0.4374 & 0.4609 & 0.4768 & 0.3855 \\ \text { CATAI } & 0.2235 & 0.2406 & 0.2673 & 0.3414 & 0.3558 \\ \text { QACA } & 0.1283 & 0.2687 & 0.2894 & 0.3358 & 0.1666 \\ \text { CLTL } & 0.6351 & 0.6111 & 0.6466 & 0.6695 & 0.7628 \\ \text { QLCL } & 0.8400 & 0.8363 & 0.9553 & 0.9651 & 0.9626 \\ \text { RPTAI } & 0.1693 & 0.1330 & 0.1468 & 0.1553 & 0.1547 \\ \text { TLTAI } & 0.4595 & 0.4776 & 0.4758 & 0.4965 & 0.5321\end{array}$

1. Minus is a decrease in insolvency risk.

plus is an increase in insolvency risk. 
DUNCAN HOLDINGS

$\begin{array}{lllll}1966 & 1967 & 1968 & 1969 & 1970\end{array}$

$\begin{array}{lccccc}\text { Z-Score } & 0.7366 & -0.1749 & 0.2931 & -1.3875 & -1.2554 \\ \text { Change in } & - & -0.9115 & +0.4680 & -1.6806 & +0.1321 \\ \text { Z-Score } & & & & & \\ \text { Risk } & 0.6188 & 0.1295 & 0.3444 & 0.0040 & 0.0061\end{array}$

Weighted Ratios

$\begin{array}{lrrrrr} & & & & \\ \text { CFBCL } & -0.2493 & -0.2835 & -0.2438 & -0.4341 & -0.2988 \\ \text { CATAI } & 2.3061 & 2.2573 & 2.3100 & 2.0142 & 1.9637 \\ \text { QACA } & -1.4506 & -1.4924 & -1.4708 & -1.4592 & -1.3992 \\ \text { CLTL } & 1.3584 & 1.1122 & 1.1648 & 0.8794 & 0.7910 \\ \text { QLCL } & -2.5233 & -3.0281 & -2.8247 & -3.7967 & -3.8600 \\ \text { RPTAI } & -0.6370 & -0.6722 & -0.5759 & -0.5246 & -0.3871 \\ \text { TLTAI } & 0.0078 & 0.0069 & 0.0084 & 0.0078 & 0.0090\end{array}$

Change in

Weighted Ratios ${ }^{1}$

$\begin{array}{llllll}\text { CFBCL } & - & -0.0342 & +0.0397 & -0.1903 & +0.1353 \\ \text { CATAI } & - & -0.0488 & +0.0527 & -0.2958 & -0.0505 \\ \text { QACA } & - & -0.0418 & +0.0216 & +0.0116 & +0.0600 \\ \text { CLTL } & - & -0.2462 & +0.0526 & -0.2854 & -0.0884 \\ \text { QLCL } & - & -0.5048 & +0.2034 & -0.9720 & -0.0633 \\ \text { RPTAI } & - & -0.0352 & +0.0963 & +0.0513 & +0.1375 \\ \text { TLTAI } & - & -0.0009 & +0.0015 & -0.0006 & +0.0012\end{array}$

Unweighted Ratios

$\begin{array}{llllll} & & & & \\ \text { CFBCL } & 0.2833 & 0.3221 & 0.2770 & 0.4932 & 0.3398 \\ \text { CATAI } & 0.6646 & 0.6505 & 0.6657 & 0.5805 & 0.5659 \\ \text { QACA } & 0.5921 & 0.6091 & 0.6003 & 0.5956 & 0.5711 \\ \text { CLTL } & 0.9915 & 0.8119 & 0.8502 & 0.6419 & 0.5774 \\ \text { QLCL } & 0.6537 & 0.7845 & 0.7318 & 0.9836 & 1.0000 \\ \text { RPTAI } & 0.1535 & 0.1620 & 0.1388 & 0.1264 & 0.0933 \\ \text { TLTAI } & 0.3878 & 0.3430 & 0.4212 & 0.3894 & 0.4490\end{array}$

1. Minus is a decrease in insolvency $r$ isk. plus is an increase in insolvency risk. 
GOLLIN HOLDINGS

$\begin{array}{lrrrrr} & 1971 & 1972 & 1973 & 1974 & 1975 \\ & & & & & \\ \text { Z-Score } & 0.8666 & 1.2237 & 1.5567 & 1.1781 & 1.4272 \\ & & & & & \\ \text { Change in } & & & & & \\ \text { Z-Score } & & +0.3571 & +0.3330 & -0.3786 & +0.2491 \\ & & & & & \\ \text { Risk } & 0.6905 & 0.8386 & 0.9167 & 0.8238 & 0.8919 \\ & & & & & \\ \text { Weighted Ratios } & & & & & \\ \text { CFBCL } & -0.0379 & 0.0075 & -0.0496 & -0.0752 & 0.0594 \\ \text { CATAI } & 2.4644 & 2.4268 & 2.5283 & 2.6576 & 2.4718 \\ \text { QACA } & -1.5007 & -1.3698 & -1.4547 & -1.1955 & -1.4616 \\ \text { CLTL } & 1.1679 & 1.1558 & 1.2768 & 1.1775 & 1.1054 \\ \text { QLCL } & -2.8566 & -2.7694 & -2.5752 & -3.1727 & -2.9697 \\ \text { RPTAI } & -0.3116 & -0.1682 & -0.1105 & -0.1573 & 0.2749 \\ \text { TLTAI } & 0.0148 & 0.0147 & 0.0154 & 0.0166 & 0.0197 \\ & & & & & \end{array}$

Change in

Weighted Ratios ${ }^{1}$

CFBCL

CATAI

QACA

CLTL

QLCL

RPTAI

TLTAI

$\begin{array}{lllll}- & +0.0454 & -0.0571 & -0.0256 & +0.1346 \\ - & -0.0376 & +0.1015 & +0.1293 & -0.1858 \\ - & +0.1309 & -0.0849 & +0.2592 & -0.2661 \\ - & -0.0121 & +0.1210 & -0.0993 & -0.0721 \\ - & +0.0872 & +0.1942 & -0.5975 & +0.2030 \\ - & +0.1434 & +0.0577 & -0.0468 & +0.4322 \\ - & -0.0001 & +0.0007 & +0.0012 & +0.0031\end{array}$

Unweighted Ratios

$\begin{array}{lrrrrr}\text { CFBCL } & 0.0431 & -0.0085 & 0.0564 & 0.0854 & -0.0675 \\ \text { CATAI } & 0.7102 & 0.6994 & 0.7268 & 0.7659 & 0.7123 \\ \text { QACA } & 0.6125 & 0.5591 & 0.5938 & 0.4880 & 0.5966 \\ \text { CLTL } & 0.8525 & 0.8436 & 0.9320 & 0.8595 & 0.8069 \\ \text { QLCL } & 0.7401 & 0.7175 & 0.6671 & 0.8219 & 0.7693 \\ \text { RPTAI } & 0.0751 & 0.0405 & 0.0266 & 0.0379 & -0.0662 \\ \text { TLTAI } & 0.7400 & 0.7360 & 0.7722 & 0.8314 & 0.9826\end{array}$

1. Minus is a decrease in insolvency risk.

Plus is an increase in insolvency risk. 
A.G. HEALING

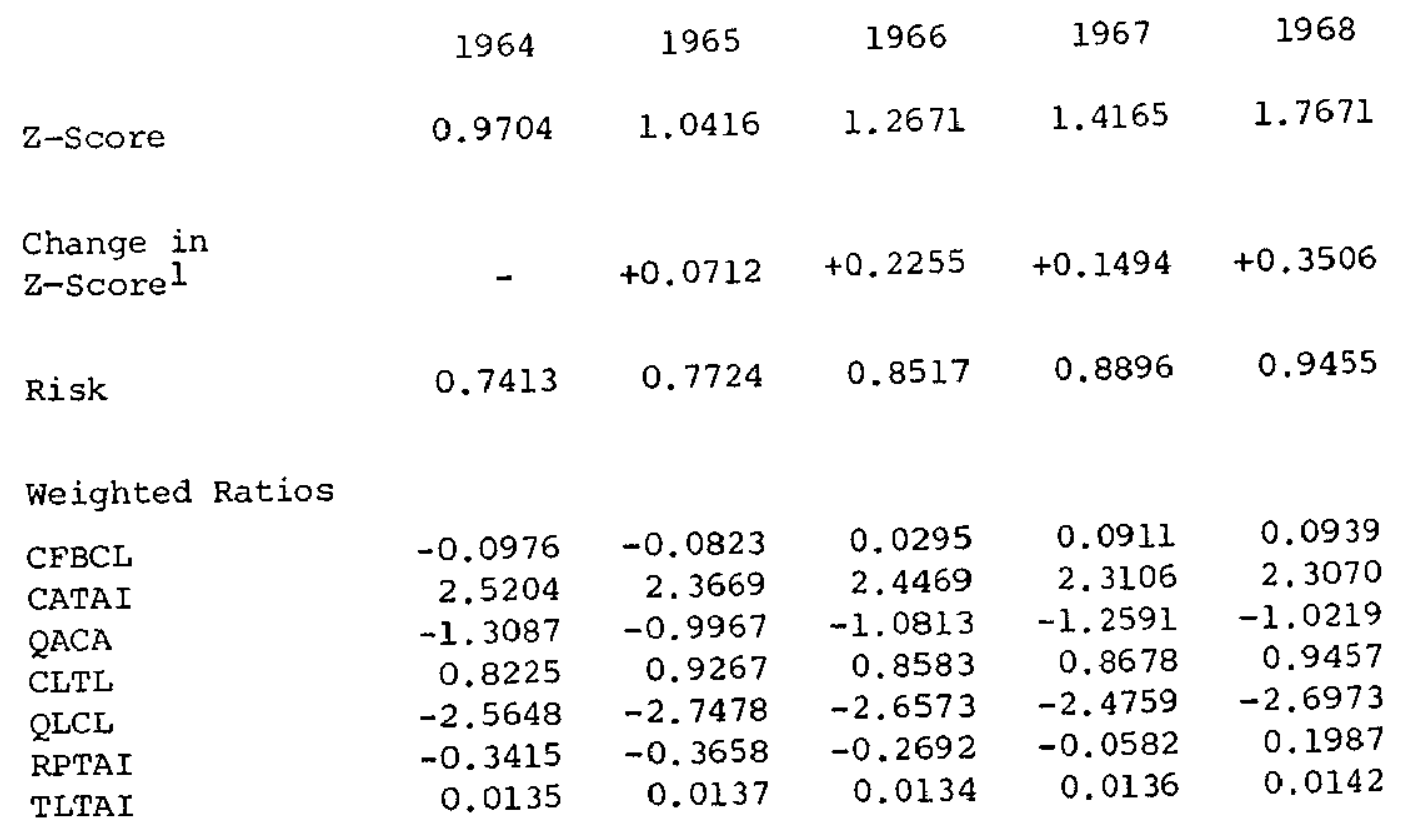

Change in
weighted Ratios

$\begin{array}{llllll}\text { CFBCL } & - & +0.0153 & +0.1118 & +0.0616 & +0.0028 \\ \text { CATAI } & - & -0.1535 & +0.0800 & -0.1363 & -0.0036 \\ \text { QACA } & - & +0.3120 & -0.0846 & -0.1778 & +0.2372 \\ \text { CLTL } & - & +0.1042 & -0.0684 & +0.0095 & +0.0779 \\ \text { QLCL } & - & -0.1830 & +0.0905 & +0.1814 & -0.2214 \\ \text { RPTAI } & - & -0.0243 & +0.0966 & +0.2110 & +0.2569 \\ \text { TLTAI } & - & +0.0002 & -0.0003 & +0.0002 & +0.0006\end{array}$

Unweighted Ratios

$\begin{array}{lrrrrr}\text { CFBCL } & 0.1110 & 0.0935 & -0.0355 & -0.1035 & -0.1067 \\ \text { CATAI } & 0.7263 & 0.6821 & 0.7051 & 0.6659 & 0.6648 \\ \text { QACA } & 0.5342 & 0.4068 & 0.4413 & 0.5139 & 0.4171 \\ \text { CLTL } & 0.6003 & 0.6764 & 0.6265 & 0.6335 & 0.6903 \\ \text { QLCL } & 0.6644 & 0.7119 & 0.6884 & 0.6414 & 0.6988 \\ \text { RPTAI } & 0.0823 & 0.0882 & 0.0649 & 0.0440 & -0.0479 \\ \text { TLTAI } & 0.6757 & 0.6831 & 0.6714 & 0.6820 & 0.7106\end{array}$

1. Minus is a decrease in insolvency risk. Plus is an increase in insolvency risk. 
HOOKER

\begin{tabular}{|c|c|c|c|c|c|}
\hline & 1969 & 1970 & 1971 & 1972 & 1973 \\
\hline Z-Score & -0.4642 & -0.4189 & -0.0969 & 0.3078 & 0.2103 \\
\hline $\begin{array}{l}\text { Change in } \\
\text { Z-Score }\end{array}$ & - & +0.0453 & +0.3220 & +0.4047 & -0.0975 \\
\hline Risk & 0.6402 & 0.6152 & 0.4430 & 0.2774 & 0.3106 \\
\hline \multicolumn{6}{|l|}{ Weighted Ratios } \\
\hline $\begin{array}{l}\text { PITTAI } \\
\text { TLTAI }\end{array}$ & $\begin{array}{r}0.8398 \\
-1.7468\end{array}$ & $\begin{array}{r}0.8753 \\
-1.7370\end{array}$ & $\begin{array}{r}1.1813 \\
-1.7209\end{array}$ & $\begin{array}{r}1.5161 \\
-1.6511\end{array}$ & $\begin{array}{r}1.4458 \\
-1.6782\end{array}$ \\
\hline \multicolumn{6}{|l|}{$\begin{array}{l}\text { Change in } \\
\text { Weighted Ratios }\end{array}$} \\
\hline $\begin{array}{l}\text { PITTAI } \\
\text { TLTAI }\end{array}$ & - & $\begin{array}{l}+0.0355 \\
+0.0098\end{array}$ & $\begin{array}{l}+0.3060 \\
+0.0161\end{array}$ & $\begin{array}{l}+0.3348 \\
+0.0698\end{array}$ & $\begin{array}{l}-0.0703 \\
-0.0271\end{array}$ \\
\hline \multicolumn{6}{|l|}{ Unweighted Ratios } \\
\hline $\begin{array}{l}\text { PITTAI } \\
\text { TLTAI }\end{array}$ & $\begin{array}{l}0.0444 \\
0.7276\end{array}$ & $\begin{array}{l}0.0463 \\
0.7235\end{array}$ & $\begin{array}{l}0.0624 \\
0.7168\end{array}$ & $\begin{array}{l}0.0801 \\
0.6878\end{array}$ & $\begin{array}{l}0.0764 \\
0.6991\end{array}$ \\
\hline
\end{tabular}

1. Plus is a decrease in insolvency risk.

Minus is án increase in insolvency risk. 
INTERNATIONAL FOOTWEAR

Change in

1.2968

1.1034

1.9460

1.0933

1.3808

Risk

0.8600

$-0.1934$

$+0.8426$

$-0.8527$

$+0.2875$

Weighted Ratios

CFBCL
CATAI
QACA
CLTL
QLCL
RPTAI
TLTAI

-0.0290
2.5213
-1.1734
0.9750
-3.1491
0.2101

-0.1890
2.6068
-0.9273
1.0341
-3.2722
-0.0899
0.0138

0.0693

$-0.0513$

0.0021

$-1.0105$

2.8411

2.9053

1.1126

$-1.3425$

$-1.2596$

$-3.0052$

1.1349

1.1970

0.0148

0.2002

$-3.5718$

$-3.6265$

0.1409

0.2189

TLTAI

0.0153

0.0153

0.0165

Change in

Weighted Ratios ${ }^{1}$

CFBCL
CATAI
QACA
CLTL
QLCL
RPTAI
TLTAI

$\begin{array}{ll}- & -0.1600 \\ - & +0.0855 \\ - & +0.2461 \\ - & +0.0591 \\ - & -0.1231 \\ - & -0.3000 \\ - & -0.0010\end{array}$

$+0.2583$

$+0.0307$

$-0.0832$

$+0.0785$

$+0.2670$

$+0.2901$

$-0.1206$

$+0.0534$

$+0.2036$

$-0.3320$

$+0.0642$

$+0.0223$

$+0.0829$

$-0.5666$

$+0.0621$

$-0.0593$

$-0.0447$

$+0.0015$

0.0000

$+0.0780$

$+0.0012$

Unweighted Ratios

$\begin{array}{lrrrrr} & & & & \\ \text { CFBCL } & 0.0329 & 0.2148 & -0.0787 & 0.0583 & -0.0024 \\ \text { CATAI } & 0.7266 & 0.7512 & 0.7601 & 0.8188 & 0.8373 \\ \text { QACA } & 0.4789 & 0.3785 & 0.4124 & 0.5479 & 0.5141 \\ \text { CLTL } & 0.7117 & 0.7548 & 0.8122 & 0.8284 & 0.8738 \\ \text { QLCL } & 0.8158 & 0.8477 & 0.7785 & 0.9253 & 0.9395 \\ \text { RPTAI } & -0.0506 & 0.0217 & -0.0482 & -0.0339 & -0.0527 \\ \text { TLTAI } & 0.7393 & 0.6890 & 0.7637 & 0.7636 & 0.8238\end{array}$

1. Minus is a decrease in insolvency risk. plus is an increase in insolvency risk. 
IANDALL HOLDINGS

\begin{tabular}{|c|c|c|c|c|c|}
\hline & 1970 & 1971 & 1972 & 1973 & 1974 \\
\hline Z-Score & -0.7236 & -1.0230 & -0.9341 & -2.2538 & -3.9321 \\
\hline $\begin{array}{l}\text { Change in } \\
\mathrm{z} \text {-Score }\end{array}$ & - & -0.2994 & +0.0889 & -1.3197 & -1.6783 \\
\hline Risk & 0.7733 & 0.9449 & 0.8589 & 0.9984 & 0.9999 \\
\hline \multicolumn{6}{|l|}{ Weighted Ratios } \\
\hline $\begin{array}{l}\text { PITTAI } \\
\text { TLTAI }\end{array}$ & $\begin{array}{r}0.8967 \\
-2.0631\end{array}$ & $\begin{array}{r}0.6400 \\
-2.1057\end{array}$ & $\begin{array}{r}0.7331 \\
-2.1080\end{array}$ & $\begin{array}{l}-0.4283 \\
-2.2683\end{array}$ & $\begin{array}{l}-1.9738 \\
-2.4011\end{array}$ \\
\hline \multicolumn{6}{|l|}{$\begin{array}{l}\text { Change in } \\
\text { Weighted Ratios } 1\end{array}$} \\
\hline $\begin{array}{l}\text { PITTAI } \\
\text { TLTAI }\end{array}$ & - & $\begin{array}{l}-0.2567 \\
-0.0426\end{array}$ & $\begin{array}{l}+0.0931 \\
-0.0023\end{array}$ & $\begin{array}{l}-1.1614 \\
-0.1603\end{array}$ & $\begin{array}{l}-1.5455 \\
-0.1328\end{array}$ \\
\hline \multicolumn{6}{|l|}{ Unweighted Ratios } \\
\hline $\begin{array}{l}\text { PITTAI } \\
\text { TLTAI }\end{array}$ & $\begin{array}{l}0.0474 \\
0.8594\end{array}$ & $\begin{array}{l}0.0338 \\
0.8771\end{array}$ & $\begin{array}{l}0.0386 \\
0.8781\end{array}$ & $\begin{array}{r}-0.0226 \\
0.9448\end{array}$ & $\begin{array}{c}-0.1043 \\
1.000\end{array}$ \\
\hline
\end{tabular}

1. Plus is a decrease in insolvency risk.

Minus is an increase in insolvency risk. 
LEND LEASE

$\begin{array}{lccccc} & 1969 & 1970 & 1971 & 1972 & 1973 \\ & & & & & \\ \text { Z-Score } & 0.6939 & 0.8683 & 0.9484 & 1.2415 & 1.4765 \\ \text { Change in } & & & & & \\ \text { Z-Score } & & +0.1744 & +0.0801 & +0.2931 & +0.2350 \\ & & & & & \\ \text { Risk } & 0.1829 & 0.1556 & 0.1456 & 0.1189 & 0.1066 \\ & & & & & \\ \text { Weighted Ratios } & & & & & \\ \text { PITTAI } & 1.9638 & 2.1217 & 2.2574 & 2.4174 & 2.6873 \\ \text { TLTAI } & -1.7127 & -1.6961 & -1.7518 & -1.7084 & -1.6536 \\ & & & & & \\ \text { Change in } & & & & & \\ \text { Weighted Ratios } & & & & & \\ \text { PITTAI } & - & +0.1579 & +0.1357 & +0.1600 & +0.2699 \\ \text { TLTAI } & - & +0.0166 & -0.0557 & +0.0434 & +0.0548 \\ & & & & & \\ \text { Unweighted Ratios } & & & & & \\ \text { PITTAI } & 0.1038 & 0.1121 & 0.1193 & 0.1277 & 0.1420 \\ \text { TLTAI } & 0.7134 & 0.7065 & 0.7297 & 0.7116 & 0.6889\end{array}$

1. Plus is a, decrease in insolvency risk.

Minus is an increase in insolvency risk. 
MAINLINE

$\begin{array}{lccccc} & 1969 & 1970 & 1971 & 1972 & 1973 \\ \text { Z-Score } & 0.4694 & -0.2307 & -0.1563 & 0.4744 & 0.0592 \\ & & & & & \\ \text { Change in } & & -0.7001 & +0.0744 & +0.6307 & -0.4152 \\ \text { Z-Score } & & & & & \\ \text { Risk } & 0.2312 & 0.5121 & 0.4730 & 0.2299 & 0.3706\end{array}$

Weighted Ratios

$\begin{array}{lrrrrr}\text { PITTAI } & 2.0060 & 1.2535 & 1.3870 & 1.9329 & 1.5997 \\ \text { TLTAI } & -1.9795 & -1.9270 & -1.9861 & -1.9013 & -1.9833 \\ & & & & & \\ \text { Change in } & & & & & \\ \text { Weighted Ratios }{ }^{1} & & & & & \\ \text { PITTAI } & - & -0.7525 & +0.1335 & +0.5459 & -0.3332 \\ \text { TLTAI } & - & +0.0525 & -0.0591 & +0.0848 & -0.0820\end{array}$

Unweighted Ratios

$\begin{array}{llllll} & & \\ \text { PITTAI } & 0.1060 & 0.0662 & 0.0733 & 0.1021 & 0.0845 \\ \text { TLTAI } & 0.8245 & 0.8027 & 0.8273 & 0.7920 & 0.8261\end{array}$

1. Plus is a decrease in insolvency risk.

Minus is an increase in insolvency risk. 
JULIUS MARLOW

$\begin{array}{lllll}1966 & 1967 & 1968 & 1969 & 1970\end{array}$

$\begin{array}{lccccc}\text { z-Score } & -0.3759 & -1.0306 & -0.3657 & -0.6154 & 0.0916 \\ \text { Change in } & - & -0.6547 & +0.6649 & -0.2497 & +0.7070 \\ \text { Z-Score } & & & & & \\ \text { Risk } & 0.0780 & 0.0121 & 0.0801 & 0.0407 & 0.2354\end{array}$

Weighted Ratios

$\begin{array}{lrrrrr} & & & & \\ \text { CFBCL } & -0.6002 & -0.5913 & -0.3886 & -0.4702 & -0.3643 \\ \text { CATAI } & 2.2469 & 2.0483 & 2.2072 & 2.2290 & 2.1375 \\ \text { QACA } & -0.8487 & -1.0042 & -0.9354 & -0.8939 & -0.7323 \\ \text { CLTL } & 0.9244 & 0.8471 & 1.1427 & 1.1850 & 1.0929 \\ \text { QLCL } & -3.1573 & -3.1991 & -3.2299 & -3.3601 & -2.8145 \\ \text { RPTAI } & -0.8773 & -1.0669 & -1.0972 & -1.2403 & -1.1645 \\ \text { TLTAI } & 0.0096 & 0.0090 & 0.0095 & 0.0091 & 0.0104\end{array}$

Change in
Weighted Ratios

$\begin{array}{llllll}\text { CFBCL } & - & +0.0089 & +0.2027 & -0.0816 & +0.1059 \\ \text { CATAI } & - & -0.1986 & +0.1589 & +0.0218 & -0.0915 \\ \text { QACA } & - & -0.1555 & +0.0688 & +0.0415 & +0.1616 \\ \text { CLTL } & - & -0.0773 & +0.2956 & +0.0423 & -0.0921 \\ \text { QLCL } & - & -0.0418 & -0.0308 & -0.1402 & +0.5456 \\ \text { RPTAI } & - & -0.1896 & -0.0303 & -0.1431 & +0.0758 \\ \text { TLTAI } & - & -0.0006 & +0.0005 & -0.0004 & +0.0013\end{array}$

Unweighted Ratios

$\begin{array}{llllll} & & & \\ \text { CFBCL } & 0.6821 & 0.6719 & 0.4416 & 0.5343 & 0.4140 \\ \text { CATAI } & 0.6475 & 0.5903 & 0.6361 & 0.6424 & 0.6160 \\ \text { QACA } & 0.3464 & 0.4099 & 0.3818 & 0.3649 & 0.2989 \\ \text { CLTL } & 0.6747 & 0.6183 & 0.8341 & 0.8650 & 0.7977 \\ \text { QLCL } & 0.8179 & 0.8288 & 0.8368 & 0.8705 & 0.7291 \\ \text { RPTAI } & 0.2114 & 0.2571 & 0.2644 & 0.2989 & 0.2806 \\ \text { TLTAI } & 0.4811 & 0.4480 & 0.4744 & 0.4527 & 0.5219\end{array}$

1. Minus is a decrease in insolvency risk. plus is an increase in insolvency risk. 
MCPHERSONS

Change in

Risk

Weighted Ratios

CFBCL
CATAI
OACA
CLTL
QLCL

RPTAI

TLTAI

$\begin{array}{rr}-0.2446 & -0.2813 \\ 2.0682 & 2.1222 \\ -0.9296 & -1.0257 \\ 0.7862 & 0.7786 \\ -3.2446 & -3.1749 \\ -0.7884 & -0.8238 \\ 0.0094 & 0.0093\end{array}$

-0.2735
2.3947
-1.1333
0.7938
-3.1774
-0.7514
0.0103

$\begin{array}{rr}-0.2189 & -0.2319 \\ 2.3472 & 2.0468 \\ -0.8057 & -0.8957 \\ 0.8298 & 0.7571 \\ -3.2137 & -3.2261 \\ -0.6902 & -0.8077 \\ 0.0105 & 0.0095\end{array}$

Change in

Weighted Ratios ${ }^{\text {I }}$

$\begin{array}{llllll}\text { CFBCL } & - & -0.0367 & +0.0078 & +0.0546 & -0.0130 \\ \text { CATAI } & - & +0.0540 & +0.2725 & -0.0475 & -0.3004 \\ \text { QACA } & - & -0.0961 & -0.1076 & +0.3276 & -0.0900 \\ \text { CLTL } & - & -0.0076 & +0.0152 & +0.0360 & -0.0727 \\ \text { QLCL } & - & +0.0697 & -0.0025 & -0.0363 & -0.0124 \\ \text { RPTAI } & - & -0.0354 & +0.0724 & +0.0612 & -0.1175 \\ \text { TLTAI } & - & -0.0001 & +0.0010 & +0.0002 & -0.0010\end{array}$

Unweighted Ratios

$\begin{array}{llllll}\text { CFBCL } & 0.2779 & 0.3197 & 0.3108 & 0.2488 & 0.2635 \\ \text { CATAI } & 0.5960 & 0.6116 & 0.6901 & 0.6764 & 0.5899 \\ \text { QACA } & 0.3794 & 0.4187 & 0.4626 & 0.3289 & 0.3656 \\ \text { CLTL } & 0.5739 & 0.5683 & 0.5794 & 0.6057 & 0.5527 \\ \text { QLCL } & 0.8406 & 0.8225 & 0.8232 & 0.8326 & 0.8358 \\ \text { RPTAI } & 0.1900 & 0.1985 & 0.1811 & 0.1663 & 0.1946 \\ \text { TLTAI } & 0.4705 & 0.4640 & 0.5125 & 0.5245 & 0.4756\end{array}$

1. Minus is a decrease in insolvency risk. plus is an increase in insolvency risk. 
KEITH MORRIS

$\begin{array}{lccccc} & 1969 & 1970 & 1971 & 1972 & 1973 \\ & & & & & \\ \text { Z-Score } & 1.0798 & 1.1724 & 0.9979 & 1.7249 & 1.3504 \\ & & & & & \\ \text { Change in } \\ \text { Z-Score }\end{array}$

1. Plus is a decrease in insolvency risk.

Minus is an increase in insolvency risk. 
DAVID SHEARER

$\begin{array}{lrrrrr} & 1967 & 1968 & 1969 & 1970 & 1971 \\ & & & & \\ \text { Z-Score } & 2.8647 & 2.0202 & 3.7671 & 4.6684 & 4.0535 \\ & & & & & \\ \text { Change in } & & & & & \\ \text { Z-Score } & & -0.8445 & +1.7469 & +0.9013 & -0.6149 \\ & & & & & \\ \text { Risk } & 0.9932 & 0.9671 & 0.9984 & 0.9995 & 0.9989 \\ & & & & & \\ \text { Weighted Ratios } & & & & & \\ & & & & & \\ \text { CFBCL } & & & & & \\ \text { CATAI } & -0.0797 & -0.2190 & 0.0568 & 0.2288 & 0.0410 \\ \text { QACA } & 2.5588 & 2.6182 & 2.7029 & 2.5693 & 2.6030 \\ \text { CLTL } & -0.6115 & -0.9037 & -0.6342 & -0.4881 & -0.7542 \\ \text { QLCL } & 1.3313 & 1.3323 & 1.3444 & 1.3523 & 1.3540 \\ \text { RPTAI } & -1.6225 & -2.0093 & -1.2926 & -1.4368 & -1.7900 \\ \text { TLTAI } & -0.6483 & -0.7344 & -0.3476 & 0.4930 & 0.6563 \\ & 0.0108 & 0.0105 & 0.0115 & 0.0152 & 0.0165\end{array}$

Change in
Weighted Ratios

$\begin{array}{llllll}\text { CFBCL } & - & -0.1393 & +0.2758 & +0.1720 & -0.1878 \\ \text { CATAI } & - & +0.0594 & +0.0847 & -0.1336 & +0.0337 \\ \text { QACA } & - & -0.2922 & +0.2695 & +0.1461 & -0.2661 \\ \text { CLTL } & - & +0.0010 & +0.0121 & +0.0079 & +0.0017 \\ \text { QLCL } & - & -0.3868 & -0.7167 & -0.1442 & -0.3532 \\ \text { RPTAI } & - & -0.0861 & +0.3868 & +0.8406 & +0.1633 \\ \text { TLTAI } & - & -0.0003 & +0.0010 & +0.0037 & +0.0013\end{array}$

Unweighted Ratios

$\begin{array}{lrrrrr} & & & & \\ \text { CFBCL } & 0.0906 & 0.2489 & -0.0646 & -0.2600 & -0.0466 \\ \text { CATAI } & 0.7374 & 0.7545 & 0.7789 & 0.7404 & 0.7501 \\ \text { QACA } & 0.2496 & 0.3689 & 0.2588 & 0.1992 & 0.3078 \\ \text { CLTL } & 0.9718 & 0.9724 & 0.9813 & 0.9871 & 0.9883 \\ \text { QLCL } & 0.4203 & 0.5206 & 0.3349 & 0.3722 & 0.4637 \\ \text { RPTAI } & 0.1562 & 0.1770 & 0.0837 & -0.1188 & -0.1582 \\ \text { TLTAI } & 0.5396 & 0.5241 & 0.5760 & 0.7624 & 0.8232\end{array}$

1. Minus is a decrease in insolvency risk. plus is an increase in insolvency risk. 
JOHN SHEARER

$\begin{array}{lrrrrr} & 1967 & 1968 & 1969 & 1970 & 1971 \\ & & & & & \\ \text { Z-Score } & -2.1744 & -0.6547 & -0.1419 & 1.4748 & -0.4322 \\ & & & & & \\ \text { Change in } & & & & & \\ \text { Z-Score1 } & - & +1.5197 & +0.5128 & +1.6167 & -1.9070 \\ & & & & & \\ \text { Risk } & 0.0003 & 0.0365 & 0.1402 & 0.9018 & 0.0672 \\ & & & & & \\ \text { Weighted Ratios } & & & & & \\ \text { CFBCL } & -0.8049 & -0.5465 & -0.5612 & 0.2364 & 0.4430 \\ \text { CATAI } & 2.3851 & 2.3798 & 2.3173 & 2.2945 & 2.4138 \\ \text { QACA } & -1.1051 & -0.6646 & -0.4942 & -0.4682 & -0.7139 \\ \text { CLTL } & 1.3700 & 1.3700 & 1.3700 & 1.3700 & 1.3700 \\ \text { QLCL } & -3.8600 & -3.0487 & -2.5287 & -1.8593 & -3.8600 \\ \text { RPTAI } & -2.0885 & -2.0740 & -2.1741 & -2.0271 & -2.0116 \\ \text { TLTAI } & 0.0042 & 0.0044 & 0.0040 & 0.0044 & 0.0028\end{array}$

Change in

Weighted Ratios ${ }^{1}$

CFBCL

CATAI

QACA

CLTL

QLCL

RPTAI

TLTAI

$\begin{array}{lrr}- & +0.2584 & -0.0147 \\ - & -0.0053 & -0.0625 \\ - & +0.4405 & +0.1704 \\ - & 0.0000 & 0.0000 \\ - & +0.8113 & +0.5200 \\ - & +0.0145 & -0.1001 \\ - & +0.0002 & -0.0004\end{array}$

$+0.7976$

$+0.2066$

$-0.0228$

$+0.1193$

$+0.0260$

$-0.2457$

0.0000

$+0.6694$

$+0.1470$

0.0000

$-2.0007$

$+0.0155$

$+0.0004-0.0016$

Unweighted Ratios

$\begin{array}{llllll}\text { CFBCL } & 0.9146 & 0.6210 & 0.6377 & -0.2686 & -0.5034 \\ \text { CATAI } & 0.6873 & 0.6858 & 0.6678 & 0.6612 & 0.6956 \\ \text { QACA } & 0.4510 & 0.2713 & 0.2017 & 0.1911 & 0.2914 \\ \text { CLTL } & 1.000 & 1.000 & 1.000 & 1.000 & 1.000 \\ \text { QLCL } & 1.000 & 0.7898 & 0.6551 & 0.4817 & 1.000 \\ \text { RPTAI } & 0.5032 & 0.4998 & 0.5239 & 0.4885 & 0.4847 \\ \text { TLTAI } & 0.1376 & 0.2190 & 0.1993 & 0.2199 & 0.2084\end{array}$

1. Minus is a decrease in insolvency risk. Plus is an increase in insolvency risk. 
SPEEDO HOLDINGS

$\begin{array}{lrrrrr} & 1966 & 1967 & 1968 & 1969 & 1970 \\ \text { Z-Score } & & & & & \\ & 1.7193 & 1.2885 & 1.0711 & 0.7206 & 0.6103 \\ \text { Change in } & & & & & \\ \text { Z-Score1 } & & & & & \\ & & -0.4308 & -0.2174 & -0.3505 & -0.1103 \\ \text { Risk } & & & & & \\ & 0.9400 & 0.8578 & 0.7845 & 0.6094 & 0.5423 \\ \text { Weighted Ratios } & & & & & \\ \text { CFBCL } & & & & & \\ \text { CATAI } & -0.1346 & -0.1485 & -0.2355 & -0.2435 & -0.3274 \\ \text { QACA } & 2.1700 & 2.2204 & 2.0523 & 2.1153 & 2.1068 \\ \text { CLTL } & -0.7648 & -0.7324 & -0.8836 & -0.9444 & -0.8866 \\ \text { QLCL } & 1.2517 & 1.0441 & 0.8287 & 0.9632 & 0.9380 \\ \text { RPTAI } & -2.0500 & -2.4035 & -1.9946 & -2.4416 & -2.4322 \\ \text { TLTAI } & -0.6888 & -0.6261 & -0.6315 & -0.6645 & -0.7226 \\ & 0.0101 & 0.0085 & 0.0091 & 0.0100 & 0.0083\end{array}$

Change in

Weighted Ratios ${ }^{1}$

$\begin{array}{llllll}\text { CFBCL } & - & -0.0139 & -0.0870 & -0.0080 & -0.0839 \\ \text { CATAI } & - & +0.0504 & -0.1681 & +0.0630 & -0.0085 \\ \text { QACA } & - & +0.0324 & -0.1512 & -0.0608 & +0.0578 \\ \text { CLTL } & - & -0.2076 & -0.2154 & +0.1345 & -0.0252 \\ \text { QLCL } & - & -0.3535 & +0.4089 & -0.4470 & +0.0094 \\ \text { RPTAI } & - & +0.0627 & -0.0054 & -0.0330 & -0.0581 \\ \text { TLTAI } & - & -0.0016 & +0.0006 & +0.0009 & -0.0017\end{array}$

Unweighted Ratios

$\begin{array}{llllll}\text { CFBCL } & 0.1529 & 0.1687 & 0.2676 & 0.2767 & 0.3720 \\ \text { CATAI } & 0.6254 & 0.6399 & 0.5914 & 0.6096 & 0.6072 \\ \text { QACA } & 0.3121 & 0.2989 & 0.3606 & 0.3854 & 0.3619 \\ \text { CLTL } & 0.9136 & 0.7621 & 0.6049 & 0.7031 & 0.6846 \\ \text { QLCL } & 0.5311 & 0.6227 & 0.5167 & 0.6325 & 0.6301 \\ \text { RPTAI } & 0.1660 & 0.1509 & 0.1522 & 0.1601 & 0.1741 \\ \text { TLTAI } & 0.5041 & 0.4254 & 0.4573 & 0.5977 & 0.4152\end{array}$

1. Minus is a decrease in insolvency risk. plus is an increase in insolvency risk. 
WESTFIELD

$\begin{array}{lccccc} & 1971 & 1972 & 1973 & 1974 & 1975 \\ & -0.0758 & -0.3356 & -0.3159 & -0.1234 & -0.0695 \\ \text { Z-Score } & - & -0.2598 & +0.0197 & +0.1925 & +0.0539 \\ \begin{array}{l}\text { Change in } \\ \text { Z-Score }\end{array} & 0.4326 & 0.5692 & 0.5584 & 0.4562 & 0.4296 \\ \text { Risk } & & & & & \end{array}$

Weighted Ratios

$\begin{array}{lrrrrr}\text { PITTAI } & 1.6405 & 1.4432 & 1.4035 & 1.5753 & 1.6437 \\ \text { TLTAI } & -2.1591 & -2.2216 & -2.1622 & -2.1415 & -2.1560\end{array}$

Change in

Weighted Ratios

PITTAI

TLTAI

$\begin{array}{lllll}- & -0.1973 & -0.0397 & +0.1718 & +0.0684 \\ - & -0.0625 & +0.0594 & +0.0207 & -0.0145\end{array}$

Unweighted Ratios

$\begin{array}{llllll}\text { PITTAI } & 0.0867 & 0.0763 & 0.0742 & 0.0832 & 0.0868 \\ \text { TLTAI } & 0.8994 & 0.9254 & 0.9007 & 0.8920 & 0.8981\end{array}$

1. Plus is a 'decrease in insolvency risk. Minus is an increase in insolvency risk. 
WOOLWORTHS

Change in

z-Score ${ }^{l}$

Risk

0.0180

0.0081

0.0047

0.0049

0.0142

Weighted Ratios

$\begin{array}{lrrrrr}\text { CFBCL } & -0.3291 & -0.3915 & -0.3014 & -0.3329 & -0.2916 \\ \text { CATAI } & 0.9144 & 0.9428 & 0.9777 & 1.0587 & 1.1089 \\ \text { QACA } & -0.3504 & -0.5236 & -0.4677 & -0.4531 & -0.2752 \\ \text { CLTL } & 0.7156 & 0.5976 & 0.7123 & 0.6828 & 0.7230 \\ \text { QLCL } & -3.4879 & -3.4086 & -3.8600 & -3.8600 & -3.8217 \\ \text { RPTAI } & -0.2988 & -0.3162 & -0.3361 & -0.3561 & -0.3613 \\ \text { TLTAI } & 0.0100 & 0.0108 & 0.0115 & 0.0114 & 0.0117\end{array}$

Change in

weighted Ratios

CFBCL
CATAI
CACA
QLCL
RPTAI
TLTAI

$\begin{array}{ll}- & -0.0624 \\ - & +0.0284 \\ - & -0.1732 \\ -\quad & -0.1180 \\ -\quad & +0.0793 \\ -\quad & -0.0174 \\ -\quad & +0.0008\end{array}$

$+0.0901$

$-0.0315$

$+0.0413$

$-0.0349$

$+0.0810$

$+0.0502$

$+0.0559+0.0146$

$+0.1779$

$+0.1147-0.0295$

$+0.0402$

$-0.4514$

0.0000

$+0.0383$

TLTAI

$-0.0199$

$-0.0200$

$-0.0052$

Unweighted Ratios

$\begin{array}{llllll}\text { CFBCI } & 0.3739 & 0.4449 & 0.3425 & 0.3783 & 0.3313 \\ \text { CATAI } & 0.2635 & 0.2717 & 0.2818 & 0.3051 & 0.3196 \\ \text { QACA } & 0.1430 & 0.2137 & 0.1909 & 0.1849 & 0.1123 \\ \text { CLTL } & 0.5223 & 0.4362 & 0.5199 & 0.4984 & 0.5277 \\ \text { QLCL } & 0.9036 & 0.8831 & 1.0000 & 1.0000 & 0.9901 \\ \text { RPTAI } & 0.0720 & 0.0762 & 0.0810 & 0.0858 & 0.0871 \\ \text { TLTAI } & 0.4997 & 0.5382 & 0.5758 & 0.5722 & 0.5850\end{array}$

1. Minus is a decrease in insolvency risk. plus is an increase in insolvency risk. 
APPENDIX T

\section{A Re-evaluation of the "Acid-Test Ratio" QAQL}

One ratio that is widely used by financial analysts is the so-called "acid-test ratio" QAQL. This ratio depicts the ability of a business to meet its most immediate debt commitments. It is expressed as quick assets (QA)/quick liabilities (QL); $Q A=$ current assets $(C A)$ - stock (STOCK), and $\mathrm{QL}=$ current liabilities (CL) - bank overdraft (BO'D). The ratio suggests that low $Q I$ indicates a strong liquidity situation. For example, if QAQI equals 1.00 , then immediate commitments are covered. By reducing $Q L, Q A Q L$ increases and there is an improvement in the safety margin of cash to immediate commitments: a low $\mathrm{QL}$, according to the theory that this is the acid-test ratio, indicates a healthy financial position. However, this study has suggested that a low QL, when it is caused by a high bank overdraft, is evidence of a high degree of insolvency risk, not of a low level of shortterm insolvency risk as a traditional analysis of the acid-test ratio would suggest. Therefore the value of this liquid-asset ratio is severely limited: in fact, interpretation of it in the past has been quite misleading. 
Foldout Glossary of Variables 


\section{Glossary of Variables}

\begin{tabular}{|c|c|}
\hline $\begin{array}{l}\text { CACL } \\
\text { CAQL }\end{array}$ & $\begin{array}{l}\text { Current assets to current liabilities } \\
\text { current assets to quick liabilities }\end{array}$ \\
\hline CATAI & $\begin{array}{l}\text { Current assets to quick liabilities } \\
\text { Current assets to total assets }\end{array}$ \\
\hline CATL & $\begin{array}{l}\text { Current assets to total assecs } \\
\text { current assets to total liabilities }\end{array}$ \\
\hline CEBCA & $\begin{array}{l}\text { Current assets to colal } \\
\text { Cash flow before tax to current assets }\end{array}$ \\
\hline $\begin{array}{l}\text { CFBCL } \\
\text { CFBOA }\end{array}$ & Cash flow before tax to current liabilities \\
\hline $\begin{array}{l}\text { CFBQA } \\
\text { CFBQL }\end{array}$ & \\
\hline CEBTAI & $\begin{array}{l}\text { Cash flow before tax to quick liabilities } \\
\text { Cash flow before tax to total assets }\end{array}$ \\
\hline CFBTL & $\begin{array}{l}\text { Cash flow before tax to total assets } \\
\text { Cash flow before tax to total liabilities }\end{array}$ \\
\hline CEBWC & $\begin{array}{l}\text { Cash flow before tax to total liablilties } \\
\text { Cash flow before tax to working capital }\end{array}$ \\
\hline $\begin{array}{l}\text { CLTL } \\
\text { CLTAI }\end{array}$ & $\begin{array}{l}\text { Cash flow before tax to work liabilities to total liabilities } \\
\text { Current liabilities to total assets } \\
\text { Current liabilitien }\end{array}$ \\
\hline LTAI & $\begin{array}{l}\text { Current liabilities to total assets } \\
\text { Logarithm of total assets }\end{array}$ \\
\hline NOPCA & $\begin{array}{l}\text { Logarithm of total assets } \\
\text { Net operating profit after tax to current assets }\end{array}$ \\
\hline $\begin{array}{l}\text { NOPCL } \\
\text { NOPQA }\end{array}$ & $\begin{array}{l}\text { Net operating profit after tax to current assets } \\
\text { Net operating profit after tax to current liabilities }\end{array}$ \\
\hline NOPQA & $\begin{array}{l}\text { Net operating profit after tax to curren } \\
\text { Net operating profit after tax to quick assets } \\
\text { Net operating profit after tax to quick liabilities }\end{array}$ \\
\hline NOPTAI & 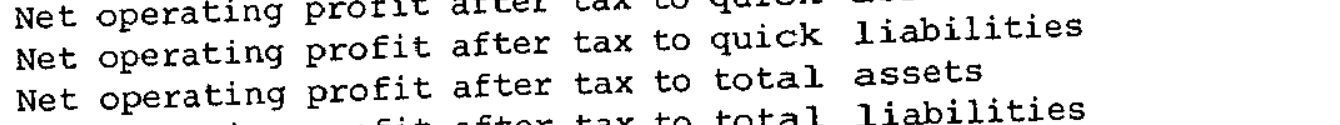 \\
\hline NOPTL & $\begin{array}{l}\text { Net operating profit after tax to total assets } \\
\text { Net operating profit after tax to total liabilities }\end{array}$ \\
\hline $\begin{array}{l}\text { NOPWC } \\
\text { PITCA }\end{array}$ & $\begin{array}{l}\text { Net operating profit after tax to total } \\
\text { Net operating profit after tax to working capital }\end{array}$ \\
\hline & $\begin{array}{l}\text { Net operating profit before interest and tax to current } \\
\text { assets }\end{array}$ \\
\hline PITCL & $\begin{array}{l}\text { assets } \\
\text { Net operating profit before interest and tax to current } \\
\text { liabilities }\end{array}$ \\
\hline $\begin{array}{l}\text { PITQA } \\
\text { PTTOL }\end{array}$ & $\begin{array}{l}\text { Net operating profit before interest and tax to quick assets } \\
\text { Net operating profit before interest and tax to quick }\end{array}$ \\
\hline & $\begin{array}{l}\text { Net operating profit before interest and tax to quick } \\
\text { liabilities } \\
\text { Net operating profit before interest and tax to total assets }\end{array}$ \\
\hline $\begin{array}{l}\text { PITTAI } \\
\text { PITTL }\end{array}$ & $\begin{array}{l}\text { Net operating profit before interest and tax to total assets } \\
\text { Net operating profit before interest and tax to total }\end{array}$ \\
\hline PITWC & $\begin{array}{l}\text { Net operating profit before interest and lax lo cocar } \\
\text { liabilities } \\
\text { Net operating profit before interest and tax to working capi }\end{array}$ \\
\hline $\begin{array}{l}\text { PS } \\
\text { QACA } \\
\text { QACL }\end{array}$ & $\begin{array}{l}\text { Net operating profit before interest and tax to working cap } \\
\text { Earnings stability }\end{array}$ \\
\hline $\begin{array}{l}\text { QACA } \\
\text { QACL } \\
\text { QAQL }\end{array}$ & $\begin{array}{l}\text { Earnings stability } \\
\text { Quick assets to current assets }\end{array}$ \\
\hline $\begin{array}{l}\text { QACL } \\
\text { QAQL } \\
\text { QATAI }\end{array}$ & $\begin{array}{l}\text { Quick assets to current assets } \\
\text { Quick assets to current liabilities } \\
\text { Ouick assets to quick liabilities }\end{array}$ \\
\hline $\begin{array}{l}\text { QAQL } \\
\text { QATAI }\end{array}$ & $\begin{array}{l}\text { Quick assets to curren } \\
\text { Quick assets to quick liabilities } \\
\text { Quick assets to total assets }\end{array}$ \\
\hline QATL & $\begin{array}{l}\text { Quick assets to total assets } \\
\text { Quick assets to total liabilities }\end{array}$ \\
\hline QLCL & $\begin{array}{l}\text { Quick assets to total liabilities } \\
\text { Quick liabilities to current liabilities }\end{array}$ \\
\hline QLTAI & $\begin{array}{l}\text { Quick liabilities to current llablllcles } \\
\text { Quick liabilities to total assets } \\
\text { Quick liabilities to total liabilities }\end{array}$ \\
\hline $\begin{array}{l}\text { QLTL } \\
\text { RPCA }\end{array}$ & $\begin{array}{l}\text { Quick liabillties to cotal asom } \\
\text { Quick liabilities to total liabilities } \\
\text { Retained profits to current assets }\end{array}$ \\
\hline RPCL, & $\begin{array}{l}\text { Retained profits to current assets } \\
\text { Retained profits to current liabilities }\end{array}$ \\
\hline $\mathrm{RPQA}$ & $\begin{array}{l}\text { Retained profits to current liabilities } \\
\text { Retained profits to quick assets }\end{array}$ \\
\hline RPQL & $\begin{array}{l}\text { Retained profits to quick assets } \\
\text { Retained profits to quick liabilities }\end{array}$ \\
\hline RPTAI & $\begin{array}{l}\text { Retained profits to quick liabilities } \\
\text { Retained profits to total assets }\end{array}$ \\
\hline RPTL & $\begin{array}{l}\text { Retained profits to total assets } \\
\text { Retained profits to total liabilities }\end{array}$ \\
\hline RPWC & $\begin{array}{l}\text { Retained profits to total liaplitures } \\
\text { Retained profits to working capital }\end{array}$ \\
\hline TLTAI & $\begin{array}{l}\text { Retained profits to working } \\
\text { Total liabilities to total assets }\end{array}$ \\
\hline WCCL & Working capital to current liabilities \\
\hline WCQL & Working capital to quick liabilities \\
\hline $\begin{array}{l}\text { WCTAI } \\
\text { WCTL }\end{array}$ & Working capital to total assets \\
\hline & Working capital to total liabilities \\
\hline
\end{tabular}




\section{University Library}

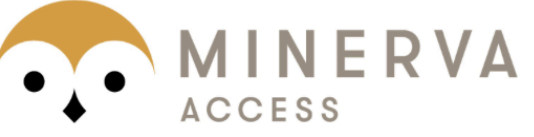

A gateway to Melbourne's research publications

Minerva Access is the Institutional Repository of The University of Melbourne

Author/s:

Lincoln, Mervyn George

Title:

An empirical study of the usefulness of accounting ratios to describe levels of insolvency risk

Date:

1982

\section{Citation:}

Lincoln, M. G. (1982). An empirical study of the usefulness of accounting ratios to describe levels of insolvency risk. PhD thesis, Graduate School of Business Administration, The University of Melbourne.

Publication Status:

Unpublished

Persistent Link:

http://hdl.handle.net/11343/38867

Terms and Conditions:

Terms and Conditions: Copyright in works deposited in Minerva Access is retained by the copyright owner. The work may not be altered without permission from the copyright owner. Readers may only download, print and save electronic copies of whole works for their own personal non-commercial use. Any use that exceeds these limits requires permission from the copyright owner. Attribution is essential when quoting or paraphrasing from these works. 